IUCN

Environmental

Law

Programme

\title{
Explanatory Guide to the International Treaty on Plant Genetic Resources for Food and Agriculture
}

Gerald Moore and Witold Tymowski

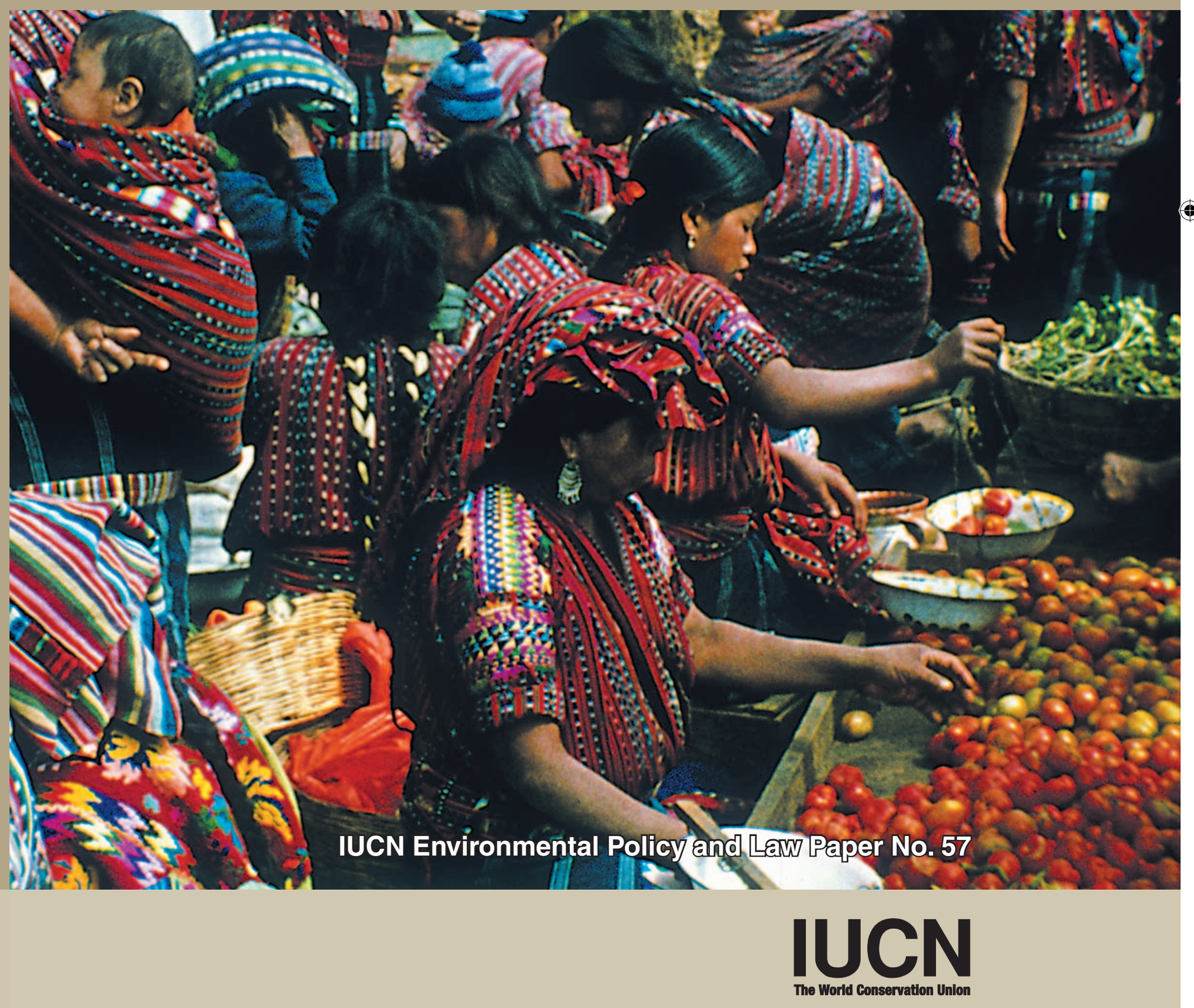




\section{Explanatory Guide to the International Treaty on Plant Genetic Resources for Food and Agriculture}





\section{Explanatory Guide to the International Treaty on Plant Genetic Resources for Food and Agriculture}

Gerald Moore and Witold Tymowski

IUCN Environmental Policy and Law Paper No. 57

IUCN - The World Conservation Union 
The designation of geographical entities in this book, and the presentation of the material, do not imply the expression of any opinion whatsoever on the part of IUCN concerning the legal status of any country, territory, or area, or of its authorities, or concerning the delimitation of its frontiers and boundaries.

The views expressed in this publication do not necessarily reflect those of IUCN or other sponsors of this project.

Published by: $\quad$ IUCN, Gland, Switzerland and Cambridge, UK in collaboration with IUCN Environmental Law Centre, Bonn, Germany

\section{IUCN \\ The World Conservation Union}

Copyright: $\quad$ C 2005 International Union for Conservation of Nature and Natural Resources

Reproduction of this publication for educational or other non-commercial purposes is authorized without prior permission from the copyright holder provided the source is fully acknowledged.

Reproduction of this publication for resale or other commercial purposes is prohibited without prior written permission of the copyright holder.

Citation: Gerald Moore and Witold Tymowski (2005). Explanatory Guide to the International Treaty on Plant Genetic Resources for Food and Agriculture. IUCN, Gland, Switzerland and Cambridge, UK. xii + $212 \mathrm{pp}$.

ISBN:

2-8317-0819-2

Cover design by: IUCN Environmental Law Centre

Front cover photo: José Esquinas-Alcázar, 2004

Back cover photo: The Hapsburg Emperor Rudolf II as Vertumnus, by Giuseppe Archimboldo, 1591. Reprinted by kind permission from Skokloster Castle, Sweden, for use in connection with the FAO International Treaty on Plant Genetic Resources for Food and Agriculture.

Layout by: $\quad$ Barbara Weiner

Produced by: $\quad$ IUCN Environmental Law Centre

Printed by: $\quad$ medienHaus Plump GmbH, Rheinbreitbach, Germany

Available from: $\quad$ IUCN Publications Services Unit

219c Huntingdon Road, Cambridge CB3 ODL, UK

www.iucn.org/bookstore

or

IUCN Environmental Law Centre

Godesberger Allee 108-112, D-53175 Bonn, Germany

www.iucn.org/themes/law

A catalogue of IUCN publications is also available

The text of this book is printed on paper made from low chlorine pulp. 


\section{Table of Contents}

Preface $\quad$ ix

$\begin{array}{ll}\text { Authors of this Guide } & \mathrm{x}\end{array}$

Acknowledgments $\quad$ xi

List of Acronyms $\quad$ xii

$\begin{array}{ll}\text { Introduction } & 1\end{array}$

$\begin{array}{ll}\text { Background } & 1\end{array}$

The special nature of PGRFA and their importance for agriculture and food security 2

The interdependence of countries on access to plant genetic resources 4

Box 1. Interdependency and food security 5

$\begin{array}{ll}\text { The origins of the Treaty } & 6\end{array}$

Box 2. The International Undertaking on Plant Genetic Resources

Why a special treaty on plant genetic resources for food and agriculture was

$\begin{array}{ll}\text { necessary } & 10\end{array}$

Relationship of the Treaty with the Convention on Biological Diversity 11

Objectives of the guide and its audience 11

$\begin{array}{ll}\text { Box 3. The Convention on Biological Diversity } & 12\end{array}$

Summary of the Main Components of the Treaty 14

General provisions on conservation and sustainable utilization of PGRFA 14

Farmers' Rights $\quad 14$

Multilateral System of Access and Benefit Sharing $\quad 15$

Supporting Components $\quad 16$

$\begin{array}{ll}\text { Financial provisions } & 17\end{array}$

$\begin{array}{ll}\text { Institutional provisions } & 17\end{array}$

$\begin{array}{ll}\text { Final Clauses } & 18\end{array}$

$\begin{array}{ll}\text { PREAMBLE } & 19\end{array}$

Box 4. Plant Breeding and the role of genetic resources 23

PART I - INTRODUCTION 29

$\begin{array}{lll}\text { Article } 1 \text { - Objectives } & 29\end{array}$

Article 2 - Use of Terms 33

$\begin{array}{lll}\text { Article } 3 \text { - Scope } & 37\end{array}$ 
PART II - GENERAL PROVISIONS

Article $4-$ General Obligations

Article 5 - Conservation, Exploration, Collection, Characterization, Evaluation and Documentation of Plant Genetic Resources for Food and Agriculture

Article 6 - Sustainable Use of Plant Genetic Resources

Box 5. Systems of Supply of Seed and Other Propagating Material, and the Sustainable Utilization of PGRFA

Box 6. Implementation of Farmers' Rights at the national level

Article 7 - National Commitments and International Cooperation

Box 7. The World Intellectual Property Organisation (WIPO) and Traditional Knowledge

Article 8 - Technical Assistance

Box 8. The FAO Global System on Plant Genetic Resources

PART III - FARMERS' RIGHTS $\quad 67$

Article 9 - Farmers' Rights $\quad 67$

Box 9. The International Union for the Protection of New Varieties of Plants

Box 10. The International Network of Ex Situ Collections under the Auspices of FAO

\section{PART IV - THE MULTILATERAL SYSTEM OF ACCESS AND BENEFIT-SHARING}

Article 10 - Multilateral System of Access and Benefit-sharing

Article 11 - Coverage of the Multilateral System

Article 12 - Facilitated access to plant genetic resources for food and agriculture within the Multilateral System

Box 11. Intellectual Property Rights over PGRFA

Box 12. International Code of Conduct for Plant Germplasm Collecting and Transfer

Box 13. Material Transfer Agreements (MTAs)

Box 14. National Sovereignty and Property Rights

\section{PART V - SUPPORTING COMPONENTS}

Box 15. The Report on the State of the World's Plant Genetic Resources and the Global Plan of Action for the Conservation and Sustainable Use of Plant Genetic Resources for Food and Agriculture 
Article 14 - Global Plan of Action

Box 16. Facilitating Mechanism for the Global Plan of Action

Article 15 - Ex Situ Collections of Plant Genetic Resources for Food and Agriculture held by the International Agricultural Research Centres of the Consultative Group on International Agricultural Research and other International Institutions

Box 17. The International Agricultural Research Centres of the CGIAR

Article 16 - International Plant Genetic Resources Networks

Box 18. International Networks for Plant Genetic Resources

Article 17 - The Global Information System on Plant Genetic Resources for Food and Agriculture

Box 19. World Information and Early Warning System (WIEWS)

PART VI - FINANCIAL RESOURCES

Article 18 - Financial Resources

Box 20. Global Crop Diversity Trust

PART VII - INSTITUTIONAL PROVISIONS

Article 19 - Governing Body

Article 20 - Secretary

Article 21 - Compliance

Article 22 - Settlement of Disputes

157

Article 23 - Amendments of the Treaty

Article 24 - Annexes

Article 25 - Signature 165

Article 26 - Ratification, Acceptance or Approval 167

Article 27 - Accession

Article 28 - Entry into Force

Article 29 - Member Organizations of FAO

Article 30 - Reservations

Article 31 - Non-Parties

Article 32 - Withdrawals

Article 33 - Termination

Article 34 - Depositary

Article 35 - Authentic Texts

185

Box 21. National legislation and policy options for implementation

186 
ANNEX II

APPENDIX 1

195

Text of the Convention

197 


\section{Preface}

The entry into force of the International Treaty on Plant Genetic Resources for Food and Agriculture marks a very important milestone in international management and governance of biological diversity. It represents the commitment of the world community to a new kind of international synergy - a freestanding convention directed at addressing, in combination, global needs for food security, and internationally agreed objectives regarding the concepts of 'access and benefit-sharing' found in the Convention on Biological Diversity. As such, this Treaty contributes to improving human livelihoods, preventing hunger and conserving biological diversity.

This Guide is the sixth in a series of Guides to the implementation of particular international instruments and concepts. Its objective is to promote greater understanding of the Treaty's text and possible implications - to explain the text and some of the scientific, technical and legal issues upon which it is founded. Unlike previous Guides, due to unexpected loss of critical funding, this Guide was not able to utilise expert workshops as a mechanism to ensure its impartiality, but has been fortunate to have received significant direct contributions and comments from a large group of international experts.

IUCN's Environmental Law Centre and the International Plant Genetic Resources Institute (IPGRI) are proud to have sponsored the creation, publication, and circulation of this Guide and hope that it will be useful to those involved with implementing the Treaty.

We are very grateful to the German Federal Ministry for Economic Co-operation and Development (BMZ) and to the UN Food and Agriculture Organisation (FAO), for financial contributions which, in combination with other funds from IUCN, have made the publication of this Guide possible.

Alejandro Iza

Director, IUCN Environmental Law Centre

Emile Frison

Director General, International Plant Genetic Resources Institute 


\section{Authors of this Guide}

Gerald Moore was the Legal Counsel of FAO from 1988 to 2000. He is now an Honorary Fellow with the International Plant Genetic Resources Institute (IPGRI) in Rome, Italy.

Witold Tymowski, B.C.L \& LL.B (McGill), B.A. (McGill) is a Legal Counsel at the Supreme Court of Canada, and a Legal Research Fellow at the Centre for International Sustainable Development Law (CISDL). Mr. Tymowski has practised in the field of international trade and intellectual property law with the law firm Stikeman Elliott LLP. He has previously worked for the Environmental Law and Policy Center (ELPC) in Chicago, Illinois, the Center for International Environmental Law (CIEL) in Geneva, Switzerland, and IUCN - The World Conservation Union's Environmental Law Centre in Bonn, Germany.

The IUCN-ELP Guide series seeks to address a critical need within international law of conservation and sustainable development - to provide neutral expert analysis of the text of critical international documents. It focuses primarily on new international instruments, providing an explanation of their contents and relationship with other key instruments, policy documents and action plans. The Guides are intended as reference documents for anyone desiring more information on these key instruments and possible steps for their implementation.

As the multilateral environmental agreements mature, it is expected that some future Guides will focus on implementation of existing instruments, providing information on national and international implementing policy, legislation, institutions and activities. 


\section{Acknowledgments}

Various drafts of this Guide were circulated three different times to a broad selection of interested parties covering a range of agricultural or biodiversity issues and positions, including at least 28 from national governments, 21 from intergovernmental bodies, and 24 from non-governmental organizations. The authors would like to acknowledge the contributions of the following people who provided (verbal or written) comments and other information relevant to the preparation of this Guide:

Regine Andersen; Larry Christy; David Cooper; Kate Davis; Jade Donavanik; Jan Engels; José Esquinas-Alcázar; Brad Fraleigh; George Greene; Michael Halewood; Robert Lettington; Leslie Lipper; Christian Lopez-Silva; Daniele Manzella; Ali Mekouar; Haruko Okusu; Alfred OtengYeboah; Elpidio Peria; Francois Pythoud; Clive Stannard; Martin Eric Smith; Nuria Urquia; Morten Walløe Tvedt; and Tomme Young. 


\section{List of Acronyms}

\begin{tabular}{|c|c|}
\hline ARD & - Agricultural Research for Development \\
\hline CBD & - Convention on Biological Diversity \\
\hline CGIAR & - Consultative Group on International Agricultural Research \\
\hline CGRFA & - Commission on Genetic Resources for Food and Agriculture \\
\hline CIMMYT & - International Maize and Wheat Improvement Center \\
\hline COGENT & - International Coconut Genetic Resources Network \\
\hline $\mathrm{EC}$ & - European Community \\
\hline EDV & - essentially derived varieties \\
\hline FAO & - Food and Agriculture Organization of the United Nations \\
\hline GEF & - Global Environment Facility \\
\hline GFAR & - Global Forum on Agricultural Research \\
\hline GPA & $\begin{array}{l}\text { - Global Plan of Action for the Conservaion and Sustainable Use of Plant } \\
\text { Genetic Resources for Food and Agriculture }\end{array}$ \\
\hline IARCs & - International Agricultural Research Centres \\
\hline IBPGR & - International Board for Plant Genetic Resources \\
\hline ICJ & - International Court of Justice \\
\hline IP & - Intellectual property \\
\hline IPGRI & - International Plant Genetic Resources Institute \\
\hline IPR & - Intellectual Property Right \\
\hline MTA & - Material Transfer Agreement \\
\hline PGR & - Plant Genetic Resources \\
\hline PGRFA & - Plant Genetic Resources for Food and Agriculture \\
\hline TK & - Traditional Knowledge \\
\hline TRIPS Agreement & - Agreement on Trade-Related Aspects of Intellectual Property Rights \\
\hline UN & - United Nations \\
\hline UNCED & - United Nations Conference on Environment and Development \\
\hline UNDP & - United Nations Development Programme \\
\hline UNEP & - United Nations Environment Programme \\
\hline UNESCO & - United Nations Educational, Scientific and Cultural Organization \\
\hline UPOV & - International Union for the Protection of New Varieties of Plants \\
\hline WIEWS & $\begin{array}{l}\text { - FAO World Information and Early Warning System on Plant Genetic } \\
\text { Resources }\end{array}$ \\
\hline WIPO & - World Intellectual Property Organization \\
\hline WTO & - World Trade Organization \\
\hline
\end{tabular}




\section{Introduction}

\section{BACKGROUND}

The International Treaty on Plant Genetic Resources for Food and Agriculture (the "Treaty") was adopted by the Thirty-first session of the FAO Conference on 3 November 2001. The Treaty was approved under Article XIV ${ }^{1}$ of the FAO Constitution by a vote of 116 Members in favour with two abstentions. ${ }^{2}$ The Treaty has since been signed by 78 countries and entered into force on 29 June 2004, ninety days after the deposit of the fortieth instrument of ratification, acceptance, approval or accession. ${ }^{3}$ The adoption of the Treaty brought to an end more than seven years of difficult negotiations, launched by Resolution 7/93 of the Twenty-seventh Session of the FAO Conference in 1993: the Resolution called for negotiations, through the FAO Commission on Genetic Resources for Food and Agriculture (CGRFA), to revise the International Undertaking on Plant Genetic Resources, in harmony with the Convention on Biological Diversity ${ }^{4}$ (CBD).

The Treaty, in harmony with the CBD, provides for the conservation and sustainable use of plant genetic resources for food and agriculture (hereafter referred to as "PGRFA"), as the basis for sustainable agriculture and food security. Most importantly, it provides for the special needs associated with plant genetic resources for food and agriculture. For a multitude of generations, farmers have drawn on many thousands of different plant genetic resources in order to breed the major crops that today feed the world. The further development of agriculture, and the world's food security, will depend on farmers and breeders continuing to have easy, low-cost access to the plant ge- netic resources necessary to face new environmental and agricultural challenges, including access to the information, technical and financial resources and capacity necessary to utilize those resources fully. This flow of plant genetic resources for food and agriculture had been endangered by developments that have in practice forced breeders and farmers to seek access to PGRFA on a bilateral basis and by practical difficulties of negotiating terms for access and benefit sharing for such a large number of individual transactions.

The Treaty ensures this continued flow so essential to agriculture and food security by setting up a multilateral system of facilitated access and benefit sharing for those plant genetic resources that are most important for food security and on which countries are most interdependent. These plant genetic resources are listed in Annex I to the Treaty.

For these resources, the Contracting Parties to the Treaty have, in the exercise of their sovereign rights over their plant genetic resources, agreed to facilitate access on a multilateral basis. Moreover, they have agreed on standard terms and conditions for access and benefit sharing, thereby avoiding the need to resort to bilateral negotiations over each transaction. These standard terms and conditions include the sharing of benefits derived from the commercial use of PGRFA. In addition, Contracting Parties have agreed on a range of other benefits to be shared, including information, capacity building and access to and transfer of technology. These benefits are targeted at de-

1 Article XIV of the FAO Constitution provides that " $[\mathrm{t}]$ he Conference may, by a two-thirds majority of the votes cast and in conformity with rules adopted by the Conference, approve and submit to Member Nations conventions and agreements concerning questions relating to food and agriculture".

2 Under the terms of Article XIV, the Conference is required to proceed to a vote on the adoption of conventions. The outcome of the vote is equivalent to an adoption by consensus, in that no Member voted against the adoption of the Treaty.

3 Article 28.

4 Convention on Biological Diversity, 5 June 1992, 31 I.L.M. 818 (1992). 
veloping countries to enable them to conserve and utilise their own PGRFA and any they may obtain from the Multilateral System. While the Multilateral System covers only certain listed plant genetic resources, the Treaty sets a framework for the conservation and sustainable use of all PGRFA and establishes the institutional ma- chinery to oversee the implementation of its provisions.

Before dealing in more detail with the origins of the Treaty, it may be appropriate to clarify the special nature of PGRFA and their importance for agriculture and food security.

\section{The SPECIAL Nature of PGRFA AND their IMPORTANCE FOR AGRICULTURE AND FOOD SECURITY}

The special nature of PGRFA and the need to seek special solutions for PGRFA as separate from other genetic resources have been recognized by Resolution 3 of the Nairobi Conference that adopted the CBD in 1982, by the Conference of Parties to the CBD itself, ${ }^{5}$ and in the Preamble to the Treaty. ${ }^{6}$ What then is the special nature of PGRFA that differentiates them from other genetic resources and why are they so important for agriculture and food security? ${ }^{7}$

As used in the Treaty, ${ }^{8}$ PGRFA (and "plant genetic resources") are the genetic resources or material of actual or potential value for food and agriculture that are contained in plants. ${ }^{9}$ As such they are to be differentiated from the crops themselves as commodities, i.e. the biological resources. PGRFA are important as tools or "building blocks" for breeders, including traditional farmers, in improving crops and introducing new traits into those crops, such as drought or pest resistance.

PGRFA, or at least those of cultivated crops, are essentially a man-made form of biodiversity. Cultivated crops, on which man de- pends for his food and survival, have been created by man, and, for the most part, cannot exist without his continued intervention. Over the millennia, farmers have domesticated wild plants and, through a process of selection and breeding, made them suitable for modern agriculture. This they have done by breeding out the natural traits, such as shattering of seed-heads prior to maturity or seed dormancy, that allow those plants to survive in the wild. They have also done it by breeding in new traits such as higher yields, and drought or disease resistance. Any individual landrace is thus the product of the breeding work of thousands of farmers over many generations. PGRFA also depend on continued and active human management. Without that human care and selection, PGRFA will revert to the wild and may be of little further value to food and agriculture. Maintaining intra-specific genetic diversity, i.e. genetic diversity within individual species, is essential for maintaining yield stability and the ability of crops to adapt to new diseases and other environmental challenges.

Farmers and breeders depend on PGRFA as building blocks for the improvement of their

5 Decision II/15 of the second Meeting of the Conference of Parties starts with the words "Recognizing the special nature of agricultural biodiversity, its distinctive features and problems needing distinctive solutions".

The first paragraph of the Preamble to the Treaty provides that the Contracting Parties are "convinced of the special nature of PGRFA, their distinctive features and problems needing distinctive solutions".

7 See generally, Carlos Correa, Implications of National Access Legislation for Germplasm Flows, Proceedings of the GFAR conference 21-23 May 2003, Dresden, Germany, GFAR/IPGRI, 2003, p. 37.

As distinct from its usage in the Convention on Biological Diversity, as discussed below.

9 Article 2 of the Treaty defines plant genetic resources for food and agriculture as "any genetic material of plant origin of actual or potential value for food and agriculture". "Genetic material", in turn, is defined as "any material of plant origin, including reproductive and vegetative propagating material, containing functional units of heredity." 
crops. The world is continually faced with the need to increase crop productivity, and to develop new varieties more adapted to face environmental and biological challenges or to meet the needs of local communities. To meet these needs and challenges, farmers and plant breeders must have access to a wide range of PGRFA and to the essential information about those PGRFA that will allow good use to be made of them.

PGRFA are important in two ways.

First, they are important as an immediate resource, i.e. for the particular characteristics they may provide, in terms of pest resistance, drought tolerance, plant architecture, taste or colour. ${ }^{10}$ Much of the increase in food production over the last half century can be attributed to innovations achieved through plant breeding, drawing on existing genetic resources. However, the large increases in yield that have been achieved in areas of high agricultural potential have not been replicated in more marginal areas. There is also a problem of genetic erosion caused by the replacement of diverse genetic material on farms by modern varieties. Further large increases in food production will be required to feed the dramatically expanding population of the world. New plant breeding strategies will have to aim at improving economic and environmental sustainability by developing cultivars that produce ever higher yields with less use of expensive and potentially harmful chemical inputs. The new varieties will also need to be more adapted to the needs of local farmers in more marginal areas or economies, and incorporate increased genetic diversity. All of this will place increased demands on the availability of a wide range of PGRFA. While many countries may have large genebanks re- lating to their major crops, there will always be a need for access to a wider range of diversity from the centres of origin of the crop species, for example to find resistances to new diseases.

The nature of the plant breeding process calls for a broad range of plant genetic resources as inputs into any one successful product. Indeed a new plant variety can often be the product of generations of breeding by farmers and breeders, which may stretch across many countries. Even at the stage of developing an individual new commercial variety, scientists may have to screen literally thousands of samples in search of a particular agronomic characteristic. Depending on the crop, breeders commonly work with up to 60 or so different landraces originating from 20 to 30 different countries. This wealth of parentage, particularly when seen in the context of the selection and breeding work of generations of farmers, means that it is difficult to track the original parentage of the products of plant breeding or of their several distinctive properties, as well as to calculate the extent to which any particular genetic input has been instrumental in producing the special characteristics of a new commercial variety. ${ }^{11}$

But PGRFA are not only important for dedicated plant breeders: they are also particularly important for traditional small-scale farmers in maintaining the quality and yield of their crops. Farmers have traditionally engaged in crop improvement, selecting seeds for various desirable traits, and replanting only those that displayed the best characteristics. Part of this tradition of crop improvement has been the practice of exchanging seeds among farmers in order to maintain levels of intra-specific genetic diversity that can protect their crops against yield fluctuation and diseases and other environmental challenges. However, as

10 See generally, Cooper D., Engels, J. and Frison, E. 1994. A multilateral system for plant genetic resources : imperatives, achievements and challenges. Issues in Genetic Resources No. 2, May 1994. International Plant Genetic Resources Institutes, Rome, Italy.

In this sense, the distinctive nature of PGRFA raises questions as to the extent to which the definition of country of origin established in the Convention on Biological Diversity can be easily applied to agricultural crops, which are noted for their intra-species diversity. The definition seems to have been more appropriate for the regulation of access to medicinal species found in rain forests. See Cary Fowler, Implementing access and benefit-sharing procedures under the Convention on Biological Diversity: the Dilemma of crop genetic resources and their origins, in Strengthening partnerships in agricultural research for development in the context of globalization, Proceedings of the GFAR conference 21-23 May 2003, Dresden, Germany, GFAR/IPGRI, 2003, p. 110. 
farmers have become more reliant on modern, commercial agriculture, new varieties of crops havereplaced the traditional, highly variablefarmer varieties, leading to an overall loss of diversity, including intra-species diversity, at the farm level.

Second, PGRFA are important as an insurance against unknown future needs. Modern varieties that tend to be more uniform are replacing a large number of traditional genetically more heterogeneous varieties, thus increasing crop vulnerability. Disasters such as the Irish potato famine in the 1840 s and the destruction of the Sri Lankan coffee industry by rust are in themselves evidence of the need for increased genetic diversity in crops. Meeting such new and unexpected challenges will require continuing and increased exchange of PGRFA.

The fundamental importance of PGRFA for agriculture and food security was recognized by the World Food Summit - a landmark event in the fight against food insecurity held in
Rome in 1966. The Rome Declaration on World Food Security and the World Food Summit Plan of Action, adopted at the close of the Summit, provide a framework for ongoing efforts to eradicate hunger. Objective 3 of the Plan of Action contains an express commitment on the part of governments to "promote the conservation and sustainable use of biological diversity and its components in terrestrial and marine ecosystems, with a view to enhancing food security". "In Objective 3.2 (e), the governments further commit themselves to promoting "an integrated approach to conservation and sustainable utilisation of PGRFA, through inter alia appropriate in situ and ex situ approaches, systematic surveying and inventorying, approaches to plant breeding which broaden the genetic base of crops, and fair an equitable sharing of the benefits arising from the use of such resources." Conversely, the linkage between PGRFA and food security is also underlined in the specific reference to the World Food Summit's Declaration and Plan of Action in the Preamble to the Treaty.

\section{THE INTERDEPENDENCE OF COUNTRIES ON ACCESS TO PLANT GENETIC RESOURCES}

PGRFA have, for centuries, been freely and widely exchanged, not only among farmers in a particular locality, but also more widely across the world's continents and regions. Potatoes originated in the Andes mountains of Latin America and are now staple crops in Europe and elsewhere in the world; barley and wheat were first domesticated in the Near East; rice originated in South-East Asia. Very often crops fared better in their new environments than in the original centres of origin, given that the new environments were often free from the natural diseases and pests prevalent in those centres of origin. But once such diseases and pests do find their way into those new environments, breeders and farmers may have to go back to the centres of origin and biodiversity of crops in order to find natural resistances. The Irish potato famine of the 1840s is one example, where natural resistances to the phytophthera infestans potato blight had to be sought in the centres of origin of the potato in South America, in order to save Europe's potato harvests. A more recent example has been the Taro Leaf Blight, which threatened to wipe out the taro crop of at least one South Pacific country, a crop that was essential to the food security of that country. The country had to look to other countries, both within the Pacific Region and outside in order to find new taro stock that is resistant to the disease. Other countries in the region will be forced to broaden the genetic base of their taro crops if

12 World Food Summit Plan of action. Objective 3.1(a), in Report of the World Food Summit, 1996 FAO Doc. WFS 96/REP Part One. The term "food security" has been defined in the World Food Summit Plan of Action. The introduction to the Plan of Action states that it has to be considered "at the individual, household, national, regional and global levels. Food security exists when all people, at all times, have physical and economic access to sufficient, safe and nutritious food to meet their dietary needs and food preferences for an active and healthy life". More specifically, Objective 2.3 states that food supplies should be "safe, ... appropriate and adequate to meet the energy and nutrient needs of the population". 


\section{Box 1. Interdependency and food security}

All regions and countries are dependent, to a greater or lesser degree on PGRFA from other regions or countries, i.e. countries are interdependent in so far as PGRFA are concerned. Plant genetic resources are also the foundation for modern agriculture and thus essential for achieving food security. The list of crops set out in Annex 1 to the Treaty, which are included in the Multilateral System of access and benefit-sharing, has been established in accordance with the criteria of food security and interdependence.

A recent study ${ }^{13}$ presented to the FAO CGRFA concluded that for the major food crops, all regions were dependent on PGRFA from other regions to a high degree: the degree of dependence for most regions being over $50 \%$. Interdependence in Central Africa ranges from $67 \%$ to $94 \%$. Interdependence in the Indian Ocean countries ranges from $85 \%$ to $100 \%$. No country in the study was ranked as completely self-sufficient. Ethiopia were listed as being $28 \%$ to $56 \%$ interdependent. The figures for Bangladesh range from $14 \%$ minimum to $21 \%$ maximum. In view of this high degree of interdependence, continued access by countries to a wide range of plant genetic resources in other regions is essential for crop improvement and thus critical to modern agriculture.

World food security depends to a large extent on the continued improvement of plant crops. A study ${ }^{14}$ undertaken by FAO and submitted to the FAO Commission on Plant Genetic Resources for Food and Agriculture during the course of the negotiations for the revision of the International Undertaking concluded that plant products contribute the vast proportion of the world's energy food supply, ${ }^{15}$ particularly for developing countries in Africa, Asia and the Pacific. Thus in Africa, plants provide 93\% of energy food supplies, in Asia and the Pacific the figure is 87\%, in the Near East 88\%, in Europe $72.5 \%$, in Latin America and the Caribbean $81 \%$ and in North America $73 \% .65 \%$ of more of the total energy food supply is provided by four crops and their derivatives - rice, wheat, sugar (sugar cane and sugar beet), and maize. The crops listed in Annex I to the Treaty together contribute some $80 \%$ of the world's total energy food supply. As income increases, the proportional contribution from plants decreases and that from animal products increases.

they are to avoid similar crises. Broadening the genetic base of staple crops in the Pacific region was specifically recognized by the Ministers of
Agriculture in the Pacific Region as being crucial to food security in the region. ${ }^{16}$

13 Ximena Flores Palacios, Contribution to the Estimation of countries' interdependence in the area of plant genetic resources, Background Study Paper No. 7, Rev.1.

Nutritional value of some of the crops under discussion in the development of a multilateral system, Background Study Paper No. 11, April 2001, prepared by the Nutrition Division of FAO.

I.e. the supply of energy available from foods. For each nutrient, a Nutrition Conversion Factor (NCF) specific to each FAO commodity was selected in the study and used to calculate the energy or nutrient availability from that commodity.

16 In Point 17 of their Communiqué adopted in September 2004, the Ministers of Agriculture of the Pacific Region "Acknowledged that access to genetic resources (crop, tree and animal) is necessary to ensure food security in the long-term. Broadening the genetic base of crops, trees and livestock, genetic improvement and diversification are crucial in coping with rapid change. Regional initiatives such as NARI's PARCIP should be supported. Access to and utilization of genetic resources will be enhanced through active participation in PGR networks, both at the regional level (PAPGREN) and at the international level (COGENT and BAPNET). To ensure continued access to genetic resources the countries of the region should consider endorsing the RGC MTA, ratifying the International Treaty, signing the Establishment Agreement for the Global Crop Diversity Trust." 
The exchange of PGRFA has continued over the ages, and almost all countries in the world are now heavily interdependent on PGRFA from other parts of the world for their agricultural development. Moreover, the flow of PGRFA is two-way. No country or region of the world is entirely self-sufficient in terms of the plant genetic resources needed to sustain and improve its major crops. ${ }^{17}$

\section{THE ORIGINS OF THE TREATY}

The origins of the Treaty date back to the International Undertaking on Plant Genetic Resources (the "International Undertaking"), which was adopted by the FAO Conference in November 1983 under Resolution 8/83 (see Box 2). It was the first international instrument dealing with the conservation and sustainable use of PGRFA. The International Undertaking ${ }^{18}$ was a voluntary (non legally-binding) agreement which sought "to ensure that plant genetic resources of economic and/or social interest, particularly for agriculture, will be explored, preserved, evaluated and made available for plant breeding and scientific purposes". 19 The International Undertaking was based on the principle, then universally accepted, that plant genetic resources were "a heritage of mankind and consequently should be available without restriction". 20 In line with that principle, adhering governments and institutions having plant genetic resources under their control subscribed to the policy of allowing access to samples of such resources and to permit their export where the resources have
Without access to genetic diversity from sources outside the country or region, crop improvement in those countries or regions cannot be properly undertaken. Conserving PGRFA is not just a question of preserving diversity of consumer choice for tomatoes or potatoes: it is a matter of ensuring that tomatoes and potatoes, and any other crops for that matter, can continue to be available to feed the world!

been requested for the purposes of scientific research, plant breeding or genetic resource conservation.

While the International Undertaking attracted wide support, ${ }^{22}$ a number of countries either indicated that they could not support it $^{23}$ or adhered to it only subject to reservations, ${ }^{24}$ in part concerning the concept of free availability and its compatibility with Plant Breeders' Rights. At the same time, there was a growing feeling of the inequality of a system that rewarded the contributions of some innovators to the development of plant genetic resources through plant variety protection and patents, but failed to recognize the important contribution over time of farmers' innovations in selecting and breeding, as well as conserving, plant genetic resources. There was also growing concern that any system addressing PGRFA must reflect more fully the sovereign rights that countries have, and always have had over those resources. To meet these growing concerns, the FAOCon-

17 See Cary Fowler: Rights and Responsibilities: Linking Conservation, Utilization, and Sharing of Benefits of Plant Genetic Resources, in Intellectual Property Rights III Global Genetic Resources: Access and Property Rights, Eds S. Eberhart, H. Shands, W. Collins \& R. Lower, Crop Science Society of America, Madison, Wisconsin, USA 1998, p. 34-35.

For the full text of the International Undertaking see http://www.fao.org/ag/cgrfa/IU.htm.

International Undertaking, Article 1.

International Undertaking, Article 1.

International Undertaking, Article 5.

113 countries adhered to the International Undertaking.

E.g. Australia, Canada, and United States of America.

24 E.g. Argentina, Belgium, Bulgaria, Colombia, Cuba, Denmark, Egypt, France, Germany, Hungary, Iceland, Ireland, Israel, Jamaica, Mexico, Netherlands, New Zealand, Oman, Switzerland, United Kingdom, and Zimbabwe. 


\section{Box 2. The International Undertaking on Plant Genetic Resources}

The International Undertaking on Plant Genetic Resources was adopted by the FAO Conference in November 1983 by Resolution 8/83. It was the first international instrument dealing with the conservation and sustainable use of PGRFA. The International Undertaking was a voluntary (nonlegally binding) instrument, which was "adhered to" by 113 countries. Canada, France, Germany, Japan, New Zealand, Switzerland, UK and USA expressed their official reservations to the International Undertaking, at least at that time.

The objective of the International Undertaking as described in Article 1, was "to ensure that plant genetic resources of economic and/or social interest, particularly for agriculture, will be explored, preserved, evaluated and made available for plant breeding and scientific purposes. This Undertaking is based on the universally accepted principle that plant genetic resources are a heritage of mankind and consequently should be made available without restriction." Plant genetic resources in the Undertaking were defined as being "the reproductive or vegetative propagating material of the following categories of plants: $i$. Cultivated varieties (cultivars) in current use and newly developed varieties; ii. Obsolete cultivars; iii. Primitive cultivars (landraces); $i v$. Wild and weed species, near relatives of cultivated varieties; $v$. special genetic stocks (including elite and current breeders' line and mutants)".

Under Article 3 of the Undertaking, the adhering governments undertook to organize exploration missions to identify potentially valuable plant genetic resources in danger of extinction as well as other plant genetic resources that might be useful for development but whose existence or essential characteristics were then unknown. Appropriate legislative and other measures were to be maintained and where necessary developed and adopted to protect and preserve the plant genetic resources of plants growing in areas of their natural habitats in the major centres of diversity. Where important plant genetic resources were in danger of extinction, measures were to be taken to ensure scientific collection and safeguarding of material. Material held in genebanks was to be conserved and maintained to preserve their valuable characteristics for use in scientific research and plant breeding, and was to be evaluated and fully documented (Article 4).

Perhaps the most important provision of the International Undertaking was that on availability of plant genetic resources. Article 5 provided that it would be the policy of adhering Governments and institutions to allow access to plant genetic resources under their control and to permit their export, where the resources have been requested for the purposes of scientific research, plant breeding or genetic resource conservation. Samples were to be made available "free of charge, on the basis of mutual exchange or on mutually agreed terms".

The International Undertaking provided in general terms for international cooperation, including in establishing and strengthening the capabilities of developing countries in the area of plant genetic resources, and intensifying international activities in preservation, evaluation, documentation, exchange of plant genetic resources, plant breeding, germplasm maintenance and seed multiplication. International cooperation could also be directed to the financing of activities relating to plant genetic resources (Article 6).

The International Undertaking called for the development of the international arrangements then being carried out by FAO and International Board for Plant Genetic Resources (IBPGR; the predecessor of IPGRI) in order to develop a global system for plant genetic resources. This should include an internationally coordinated network of national, regional and international centres, "including an international network of base collections in genebanks, under the auspices or the jurisdiction of FAO, that have assumed the responsibility to hold, for the benefit of the international community and on the principle of unrestricted exchange, base or active collections of the plant genetic resources of particular plant species" (Article 7). Adhering Governments or institutions could voluntarily place their collections in the international network under the auspices or jurisdiction of FAO. Sufficient

continued next page 
funding and facilities should be provided to enable the centres to carry out their tasks. Article 7 also provided for a global information system and early warning system, as part of the global system.

Under the International Undertaking, adhering Governments and financing agencies "will consider" adopting measures that would place activities on a firmer financial basis and "will explore" the possibility of establishing mechanisms to guarantee the availability of funds for centres faced with emergencies (Article 8). FAO was tasked with keeping the international situation with respect to plant genetic resource under continuous review, and with establishing an intergovernmental body (the FAO Commission on Plant Genetic Resources, which was later to become the FAOCGRFA) to monitor the operation of the international arrangements referred to in Article 7.

A series of Agreed Interpretations were adopted by the FAO Conference in 1989 and 1991. The First Agreed Interpretation, introduced under Conference Resolution 4/89, recognized that Plant Breeders Rights, as provided for under the UPOV Convention, were not incompatible with the International Undertaking, and recognized also the enormous contribution that farmers of all regions have made to the conservation and development of plant genetic resources, which form the basis for the concept of Farmers' Rights. Farmers' Rights can best be implemented through ensuring the conservation, management and use of plant genetic resources for the benefit of present and future generations of farmers.

The Second Agreed Interpretation (Conference Resolution 5/89) specifically endorsed the concept of Farmers' Rights. These were defined as rights arising from the past, present and future contributions of farmers in conserving, improving, and making available plant genetic resources, particularly those in the centres of origin/diversity. These rights were vested in the international community, as trustees for present and future generations of farmers, for the purpose of ensuring full benefits to farmers and supporting the continuation of their contributions.

The Third Agreed Interpretation (Conference Resolution 3/91) recognized that nations have sovereign rights over their plant genetic resources, and provided that breeders' lines and farmers' breeding material should be available only at the discretion of their developers during the period of their development. It also provided that Farmers' Rights should be implemented, in particular, through an International Fund for Plant Genetic Resources.

ference in 1989 adopted a series of Agreed Interpretations of the International Undertaking. ${ }^{25}$ The Agreed Interpretations recognized that Plant Breeders' Rights, as provided for by the International Union for the Protection of New Varieties of Plants (UPOV) (see Box 9), were not incompatible with the International Undertaking. At the same time, they recognized Farmers' Rights arising from the past, present and future contributions of farmers in conserving, improving, and making available plant ge- netic resources, particularly those in the centres of origin/diversity. ${ }^{26}$ A further Conference Resolution in 1991 reiterated the sovereign rights of States over their plant genetic resources, clarified that breeders' lines and farmers' breeding materials should only be available at the discretion of their developers during the period of their development, and that Farmers' Rights should be implemented through an international fund on plant genetic resources. ${ }^{27}$
25

26

Resolutions 4/89 and 5/89.

The Resolution provides that these rights are vested in the International Community, as trustee for present and future generations of farmers, for the purpose of ensuring full benefits to farmers, and supporting the continuation of their contributions, as well as the attainment of the overall purposes of the International Undertaking. 
Meanwhile negotiations on access to genetic resources, and the fair and equitable sharing of benefits arising from their use, formally adopted in May 1992, at a Conference ${ }^{28}$ convened by United Nations Environment Programme (UNEP) in Nairobi (the Nairobi Conference). The Convention was heralded and opened for signature almost immediately thereafter at the United Nations Conference on Environment and Development (UNCED) of 1992. It entered into force in December 1993. The CBD provided a comprehensive framework for the conservation and sustainable use of biological resources, and a series of commitments regarding sharing genetic resources and their benefits, with emphasis on decision-making at the national level. It recognizes the sovereignty of States over their natural resources, and laid down the principle that the authority to determine access to genetic resources rests with the national government concerned, implemented through national legislation. However, each Contracting Party is to endeavour to create conditions to facilitate access to genetic resources for environmentally sound uses, and agrees not to impose restrictions that run counter to the objectives of the Convention. Access, where granted, is to be on mutually agreed terms and is subject to prior informed consent of the Contracting Party providing such resources unless otherwise determined by that Party. ${ }^{29}$ The countries in which the resources are to be used are also bound by specific requirements regarding measures taken with the aim of sharing benefits arising from the commercial and other utilization of genetic resources and other matters. These are similarly to be on terms mutually agreed with the Contracting Party providing the resources.
For the purpose of access and benefit sharing, "genetic resources provided by a Contracting Party are only those that are provided by Contracting Parties that are countries of origin of such resources or by the Parties that acquired the genetic resources in accordance with the Convention." 30 Some commentators (including the authors) interpret this provision to be a specific exclusion, eliminating ex situ material collected before the entry into force of the Convention, including gene bank collections of the International Agriculture Research Centres of the Consultative Group on International Agricultural Research (CGIAR) as well as many national collections. ${ }^{31}$ The Nairobi Conference recognized the need to seek solutions to these and other outstanding matters concerning plant genetic resources within the Global System for the Conservation and Sustainable Use of Plant Genetic Resources for Food and Agriculture established by FAO (see Box 8$).{ }^{32}$ It called in particular for solutions to be found to the question of access to ex situ collections not acquired in accordance with the Convention and to the question of farmers' rights. ${ }^{33}$ This call was reinforced in Agenda 21, ${ }^{34}$ adopted by UNCED, which called for the strengthening of the FAO Global System on Plant Genetic Resources, and its adjustment in line with the outcome of the negotiations on the CBD, as well as for the realization of Farmers' Rights.

The invitation extended by the Nairobi and UNCED was taken up in November 1993 by the FAO Conference, which adopted Resolution 7/ 93 requesting the Director-General of FAO to provide a forum for negotiations among governments for the adaptation of the International

28 Conference for the Adoption of the Agreed Text of the Convention on Biological Diversity.

29 The Convention does not prescribe how that determination should be made by individual Contracting Parties: in the absence of any such prescription, it could include both determinations at the national level and determinations within the context of a multilateral arrangement.

Convention on Biological Diversity, Article 15.3.

31 See Glowka, et al., A Guide to the Convention on Biological Diversity (IUCN Environmental Policy and Law Paper No. 30) (IUCN, 1994).

32 See Final Act of the Conference for the Adoption of the Agreed Text of the Convention on Biological Diversity, 22 May 1992.

Resolution 3, operative paragraph 4.

Agenda 21, UN Doc. A/CONF.151/4 (1992). 
Undertaking on Plant Genetic Resources, in harmony with the CBD, the consideration of the issue of access on mutually agreed terms to plant genetic resources, including ex situ collections not addressed by the Convention, and the issue of the realization of Farmers' Rights.

As mentioned above, the negotiations, which culminated in the adoption of the Treaty were long and difficult. They took place within the framework of the FAO CGRFA, initially in the Commission itself, and later in a Contact
Group of some 40 delegations established by the Commission. At one stage the Chairman convened an informal meeting of experts in Montreux, Switzerland, to help give direction to the negotiations. The Chairman's elements derived from that meeting were indeed instrumental in that respect. The main difficulties arose out of the need to balance access with real benefit sharing, the need to take into account intellectual property issues, and the inherent complexity of the subject matter.

\section{WHY A SPECIAL TREATY ON PLANT GENETIC RESOURCES FOR FOOD AND AGRICULTURE WAS NECESSARY}

The CBD (see Box 3) and the Bonn Guidelines adopted under it have taken great steps in protecting the world's genetic resources and biodiversity, and ensuring equitable regimes of access and benefit sharing. But the CBD is not an implementation mechanism, and does not address the role of existing international systems, or directly address the special needs associated with PGRFA. In particular, where it is thought necessary to negotiate access to genetic resources on a case-by-case bilateral basis, the consequent high transaction costs involved, coupled with increased prevalence of intellectual property rights over genetic resources, has threatened to stifle the continued exchange of PGRFA on which modern agriculture depends. ${ }^{35}$ Accessing PGRFA on a bilateral basis is problematic for farmers and breeders in all countries. It is in fact particularly difficult for those developing countries that are both economically poor and relatively poor in genetic resources. They have fewer prospects of accessing genetic resources through bilateral exchanges, given that they do not have the funds, technologies or sources of original genetic diversity to negotiate such exchanges. ${ }^{36}$
The Treaty addresses germplasm availability, directly. Countries have decided, in the exercise of their sovereign rights over their genetic resources and in harmony with the CBD, to establish a multilateral system for access and benefit sharing for a negotiated list of important crops - selected on the basis of their importance for food security and the extent of countries interdependence on access to those resources. For these resources, the Contracting Parties to the Treaty have agreed to forgo their individual rights to negotiate separate access and benefit sharing terms and to insist on giving their prior informed consent on a bilateral basis. For these resources, they have agreed to apply standard terms that have been mutually agreed by all parties on a multilateral basis, in order to ensure the continued flow of those plant genetic resources and to lower the transaction costs involved.

The CBD also left unsettled the issue of the ex situ collections, such as those held by the International Agricultural Research Centres (IARCs) of the Consultative Group on International Agricultural Research (CGIAR), acquired

While the CBD called on Contracting Parties to endeavour to create conditions to facilitate access to genetic resources, the Convention requires that access be subject to prior informed consent and on mutually agreed terms. Since the CBD operates through legislative, policy and other measures adopted at the national level, these requirements have necessarily been implemented on a bilateral, even a caseby-case basis, thus slowing down the exchange of PGRFA, to such an extent as to endanger plant breeding activities particularly in the developing world and with small scale enterprises.

See Cooper D., Engels, J. and Frison, E. 1994, p. 4. 
prior to the entry into force of the Convention. Resolving the status of these collections was one of the main objectives of the negotiations, and is an important achievement, of the new Treaty.
Both FAO and the Conference of Parties to the CBD have welcomed the Treaty as providing a special solution for plant genetic resources for food and agriculture that is responsive to the needs of farmers, breeders and sustainable agriculture in general.

\section{Relationship of the Treaty with the Convention on Biological Diversity}

The original mandate for the negotiation of the Treaty, as given by the FAO Conference in 1993, stressed that the revision of the International Undertaking should be in harmony with the CBD and should deal with the issues of access on mutually agreed terms to PGRFA, including ex situ collections, and the realization of Farmers' Rights. This indeed sums up the essence of the relationship between the Treaty and the CBD. The Convention deals with biological diversity as a whole and sets the framework for its conservation and sustainable use. It creates a series of specific commitments relating to genetic resources, specifically, access and benefit sharing. While addressing economic and social concerns, its objectives are basically environment oriented. The Treaty, on the other hand, deals with the specific issues raised by the conservation and sustainable use of PGRFA, and its objectives are more related to food and agriculture. For the PGRFA that have been deemed especially important for food security and on which countries are most interdependent, as listed in Annex I to the Treaty, the Parties to the Treaty have agreed on a special multilateral system of access and benefit sharing. This is not inconsistent with the Convention, but is an area in which the Parties to the Treaty have agreed that, as between themselves, the terms under which these genetic resources are accessed should be mutually agreed on a multilateral rather than on a bilateral basis, and they are the terms set out in the Treaty itself.

During the final stages of the negotiations of the Treaty, questions arose as to its legal status, and its connection with the CBD. At one stage, it was suggested that the Treaty might become a Protocol to the Convention. In the end, this approach was rejected, and the Treaty was adopted as an independent international agreement under Article XIV of the FAO Constitution. One of the main reasons for this approach was the idea that the Treaty was essentially an agricultural rather than an environmental treaty and as such should be responsive to the needs of the agriculture sector: the agricultural flavour of the Treaty, and the necessary technical support, would best be maintained by locating its Governing Body and Secretariat within FAO. The Treaty, however, expressly recognizes the importance of maintaining close links between the Treaty and both FAO and the Convention. ${ }^{37}$

\section{Objectives of the guide ANd its Audience}

The objective of this Guide is to help countries, institutions and individuals to understand the provisions of the Treaty, and to assist them in considering options for its implementation. It does not attempt to provide an authoritative interpretation of the Treaty or to resolve any of the many ambiguities in the text of the Treaty. This is a function for the Contracting Parties themselves, acting in their own countries or in the Governing Body of the Treaty. In keeping with this objective, the Guide is aimed at governments, international institutions, public institutions, civil society organizations, and private entities and individuals who have an interest in the provisions of the new Treaty.

37 Article 1.2 states that the Treaty's objectives "will be attained by closely linking this Treaty to the Food and Agriculture Organization of the United Nations and to the Convention on Biological Diversity." 


\section{Box 3. The Convention on Biological Diversity}

The CBD was one of two major treaties opened for signature at the United Nations Conference on Environment and Development (UNCED) in 1992. Having secured its 30th ratification in September 1993, the CBD entered into force on 29 December 1993. As of this writing, 188 countries are Contracting Parties to this Convention.

The CBD is a landmark in the environment and development field, as it takes for the first time a comprehensive rather than a sectoral approach to conservation of the earth's biodiversity and sustainable use of biological resources. It recognizes the vital point made in the World Conservation Strategy (1980), Caring for the Earth (1991), the Global Biodiversity Strategy (1992) and many other international documents that both biodiversity and biological resources should be conserved for reasons of ethics, economic benefit and indeed human survival, as well as the biological reasons commonly underlying nature conservation. It implicitly accepts the telling point that the environmental impact which future generations may most regret about our time is the loss of biodiversity, which is irreversible.

The CBD is oriented around three principles (conservation of biodiversity, sustainable use of its components, and equitable sharing of the benefits from the utilisation of genetic resources), thereby extending its mandate far beyond the conventional view of conservation and sustainable use, to encompass access to genetic resources, the use of genetic material and access to technology, including biotechnology.The CBD is a framework agreement. It leaves it up to individual parties to determine how most of its provisions are to be implemented. Indeed, its provisions are mostly expressed as shared goals and policies, rather than as hard and precise obligations, of the type found in, for example, the Convention on International Trade in Endangered Species of Wilde Fauna and Flora ${ }^{38}$ (CITES). It does not create lists of species or ecosystems, or set targets (as does, for example, the European Council Directive on the Conservation of Natural Habitats and of Wild Fauna and Flora, ${ }^{39}$ which lists hundreds of species that should be brought back to "satisfactory levels".) Instead, it places the main decisionmaking at the national level, and establishes an operating framework within which its Conference of Parties provides guidance, guidelines, suggestions and other tools to enable national action. The CBD affirms that conservation of biological diversity (usually shortened to "biodiversity") ${ }^{40}$ is a common concern of humankind and reaffirms that nations have sovereign rights over their own biological resources. Implementation depends principally on action by Parties at the national level, with the Convention providing general guidance on best practices. The CBD covers both terrestrial and marine biota, and Parties are explicitly required to implement the CBD consistent with the rights and obligations of States under the law of the sea.

The major commitments made by Parties to the CBD include to:

- develop national strategies, plans or programmes for the conservation and sustainable use of biodiversity; and to integrate, as far as possible and appropriate, the conservation and sustainable use of biological diversity into relevant sectoral or cross-sectoral plans (Article 6);

- identify and monitor the components of biodiversity, as well as activities which have or might have significant adverse impacts (Article 7);

38 Convention on International Trade in Endangered Species of Wild Fauna and Flora, 3 March 1973, 993 U.N.T.S. 243 (1976) (entered into force 1 July 1975).

39

Council Directive 92/43/EEC of 21 May 1992 on the Conservation of Natural Habitats and of Wild Fauna and Flora, 1992 O.J. (L 206) 7.

40

The treaty defines biological diversity as "the variability among living organisms from all sources including, inter alia, terrestrial, marine and other aquatic ecosystems and the ecological complexes of which they are part; this includes diversity within species, between species and of ecosystems." 
- adopt measures for in situ conservation and take steps to implement them, including establishing protected areas or areas where special measures are needed; regulating or managing biological resources important to biodiversity; promoting protection of ecosystems and natural habitats; promoting environmentally sound and sustainable development in areas adjacent to protected areas; preventing introduction of species from outside a country that could threaten native ecosystems or species; developing or maintaining necessary legislation and other regulatory provisions for protection of threatened species and populations; preserving and maintaining knowledge of indigenous and local communities embodying traditional lifestyles that are compatible with conservation or sustainable use requirements, and establishing means to regulate, manage or control risks associated with use and release of living modified organisms from biotechnology with likely adverse environmental effects (Article 8);

- adopt measures for ex situ conservation of components of biological diversity (Article 9);

- integrate consideration of the conservation and sustainable use of biodiversity resources into national decision-making; adopt measures relating to the use of biological resources to avoid or minimize adverse impacts on biological diversity; protect and encourage customary uses of biological resources in accordance with traditional practices; support remedial action in degraded areas; and encourage cooperation between the government and private sector to develop methods for sustainable use (Article 10);

- adopt economically and socially sound measures that act as incentives for the conservation and sustainable use of components of biological diversity (Article 11);

- establish programs for scientific and technical education and training in identification, conservation, sustainable use of biodiversity and promote research that contributes to biodiversity (Article 12);

- promote programs for public education and awareness (Article 13);

- require environmental impact assessments that address impacts on biodiversity and minimize such impacts. (Article 14);

- create conditions that facilitate access to genetic resources on mutually agreed terms and subject to prior informed consent, recognizing sovereign rights of States over their natural resources; and that share in a fair and equitable way the benefits (including the results of research and development) arising from the commercial utilization of genetic resources with Contracting Parties providing such resources (Article 15);

- encourage access to, and transfer of, technology relevant to the conservation and sustainable use of biological diversity or that makes use of genetic resources and does not cause significant damage to the environment, and where possible to promote joint development of such technologies (Article 16);

- facilitate the exchange of information and scientific and technical cooperation in the field of the conservation and sustainable use of biological diversity (Articles 17 and 18); and

- encourage biotechnology research, especially in developing countries; ensure the fair and equitable sharing of benefits from biotechnology; and address safety concerns related to the transfer, handling and use of living modified organisms (Article 19). (It was in partial fulfillment of this Article that the Cartagena Protocol on Biosafety ${ }^{41}$ was negotiated. The Protocol entered into force on 11 September 2004).

Developed country Parties are required to provide "new and additional financial resources" to assist developing country parties to meet the incremental costs of implementing measures that fulfill the obligations of the CBD. These resources are provided through the Global Environment Facility (GEF) (Articles 20 and 21).

In the spring of 2002, the Sixth COP of the CBD approved the Bonn Guidelines on Access to Genetic Resources and Fair and Equitable Sharing of the Benefits Arising out of their Utilization (see Decision continued next page

41 Cartagena Protocol on Biosafety to the Convention on Biological Diversity, 29 January 2000, 39 I.L.M. 1027 (2000). 
VI/24). The Bonn Guidelines address certain questions relating to national measures on access to genetic resources in several sections dealing with prior informed consent and benefit sharing.

The Bonn Guidelines are an evolving document. They are entirely voluntary, and are intended to provide possible approaches that may assist parties, governments and other stakeholders in developing overall access and benefit-sharing strategies, in establishing legislative, administrative or policy measures on access and benefit-sharing and/or in negotiating contractual arrangements for access and benefit-sharing.

The Bonn Guidelines identify the steps in the access and benefit-sharing process, and emphasize the obligation for users to seek the prior informed consent of providers. They identify the basic requirements for mutually agreed terms, define the main roles and responsibilities of users and providers and stress the importance of the involvement of all stakeholders. They also cover other elements such as incentives, accountability, means for verification and dispute settlement. Finally, they enumerate suggested elements for inclusion in MTAs and provide an indicative list of both monetary and non-monetary benefits.

\section{Summary of the Main Components of the Treaty}

The main components of the Treaty are the general provisions relating to conservation and sustainable use of plant genetic resource for food and agriculture, the provisions on Farmers' Rights, the Multilateral System of Access and Benefit Sharing, Supporting Components and Financial Provisions. The other provisions of the Treaty deal with institutional matters and final clauses.

\section{General PROVISIONS ON CONSERVATION AND SUSTAINABLE UTILIZATION OF PGRFA}

The general provisions on the conservation and sustainable utilization of PGRFA apply to all PGRFA, and not just those listed in Annex I to the Treaty. Drawing on the Global Plan of Action for the Conservation and Sustainable Use of PGRFA (GPA) (see Box 15), and developing themes already set out in the CBD, the general provisions of the Treaty set a modern framework for the conservation and sustainable utilization of PGRFA. Article 5 sets out the main tasks that Contracting Parties are to carry out with respect to the conservation, exploration, collection, characterization, evaluation and documentation of PGRFA. As with comparable $\mathrm{CBD}$ provisions relating to identification, con-

\section{FARMERS' RIGHTS}

Article 9 of the Treaty deals with Farmers' Rights, in response to the requests of both the servation, sustainable use and monitoring of biological diversity, these responsibilities are placed on each Contracting Party, acting individually or where appropriate in cooperation with other Contracting Parties, and call for the promotion of an integrated approach to the exploration, conservation and sustainable use of PGRFA. Article 6 requires the Contracting Parties to develop and maintain appropriate policy and legal measures that promote the sustainable use of PGRFA and gives a nonexhaustive list of the types of measure that may be included. Articles 7 and 8 deal with national commitments, international cooperation and technical assistance.

Nairobi Conference for the adoption of the CBD, ${ }^{42}$ and the 1993 FAO Conference. Article 
9 recognizes the contribution of local and indigenous communities and farmers to the conservation and development of plant genetic resources as a basis for food and agriculture production, and places the responsibility for realizing those rights on national governments. The measures that individual Contracting Parties should take include the protection and promotion of: (i) traditional knowledge relevant to PGRFA (Article 9.2(a)); (ii) rights of farmers to participate equitably in the sharing of benefits arising from the utilization of PGRFA (Article 9.2(b)); and (iii) the right to participate in mak- ing decisions at the national level with respect to the conservation and sustainable use of PGRFA. The provisions of Article 9 are neutral with respect to the issue of the right of farmers to save, use, exchange and sell farm-saved seed, the so-called "farmers' privilege", an issue that was hotly contested during the negotiations. The compromise wording of the Treaty recognizes implicitly that farmers may have such rights under national law; if they do have such rights, they are not in any way to be seen as limited by the provisions of Article 9 .

\section{Multilateral System of Access and Benefit Sharing}

A key focus of the Treaty is the Multilateral System of Access and Benefit-sharing established by the Contracting Parties under Part IV. The Multilateral System was established both to facilitate access to genetic resources of major food crops and forage species and to share, in a fair and equitable way, the benefits arising from the utilization of these resources, in accordance with multilaterally agreed terms and conditions.

Many countries wished to see as wide a coverage as possible of crops to be included in the Multilateral System. Others wished to see the Multilateral System starting off with a strictly limited list of the most important crops. In the end, the negotiators agreed on a list of crops, chosen ostensibly according to the criteria of their importance for food security and their interdependence.

In practice the list, set out in Annex I to the Treaty, was negotiated at least in part on the basis of the perceived interests of individual negotiating parties, with some crops important to food security being excluded. ${ }^{43}$ Nevertheless the list as finally negotiated does include most of the major food crops, including cereals such as rice, wheat, maize, sorghum and millets; grain legumes such as beans, peas, lentils, chick- peas and cowpeas; roots and tubers such as potatoes, sweet potatoes, cassava and yams; oil crops such as coconut, sunflower and the Brassica complex; and fruits such as Citrus, apple and banana/plantain. Missing from the list are a number of crops that might appear to be covered by the criteria of food security and interdependence, such as soybeans, groundnuts, sugar cane, the wild relatives of cassava included in the genus Manihot, several fruits, and tomato. ${ }^{44}$ In some cases, some species of crops, such as species of maize and Brassicas, have been specifically excluded. In addition to food crops, the list set out in Annex I also includes 29 genera of forages, mainly of temperate origin.

Not all crops on the list, however, are automatically included in the Multilateral System. Only those crops for which some PGRFA are under the management and control of the Contracting Parties, and are in the public domain, are included within the Multilateral System (see Article 11.2). The Multilateral System also includes PGRFA listed in Annex I and held by the IARCs of the CGIAR, or by other entities that have voluntarily included them in the Multilateral System (Article 11.5). The Contracting Parties are required to take appropriate measures to encourage natural and legal per-

Each country in the negotiations had the opportunity to exclude any crop from the list. In some cases, had countries agreed to include particular crops, this might well have sparked reciprocal concessions from other countries on other crops.

44 See H. David Cooper, The International Treaty on Plant Genetic Resources for Food and Agriculture, in Reciel, Vol. 11 No. 1, 2002. 
sons in their jurisdictions to include their holdings of Annex I PGRFA in the Multilateral System. The Governing Body is to review progress in this regard within a period of two years of the entry into force of the Treaty.

Under Article 12 of the Treaty, the Contracting Parties agree to take the necessary legal or other appropriate measures to provide facilitated access through the Multilateral System to other Contracting Parties and to legal and natural persons under their jurisdiction. The Article also sets out the terms and conditions that will be applicable for such facilitated access. These include the important condition that access will be provided solely for the purpose of utilization and conservation for research, breeding and training for food and agriculture. Access for other purposes may be subject to future regimes, including those developed by the CBD, as between Parties to that Convention. Recipients of material through the Multilateral System are required not to claim intellectual property or other rights that limit facilitated access to PGRFA, or their genetic parts or components, in the form received from the Multilateral System. As in Article 15.5 of the CBD, access is subject to prior informed consent of the Contracting Party providing such resources, unless otherwise determined by that Party. Facilitated access is to be accorded through a standard Material Transfer Agreement (MTA) to be adopted by the Governing Body of the Treaty.

Article 13 of the Treaty sets out the agreed terms for benefit sharing within the Multilateral System. First of all, the Contracting Parties recognize that facilitated access to PGRFA itself constitutes a major benefit of the Multilateral System (Article 13.1). Other mechanisms for benefit sharing include the exchange of

\section{Supporting Components}

Part V of the Treaty deals with supporting components for the Treaty. In general these are activities that lie outside the institutional structure of the Treaty itself, but which provide essential support for the proper implementation of the Treaty and its objectives. These include promoting the effective implementation of the rolling GPA, the encouragement of international plant genetic resources networks, and the development and strengthening of a Global information, access to and transfer of technology, capacity building, and the sharing of benefits arising from commercialisation (Article 13.2). Commercial benefit sharing is to be achieved through the involvement of the private and public sectors in activities identified in Article 13, through partnerships and collaboration. The most striking innovation in the area of benefit sharing, however, is the agreement that the standard MTA is to include a requirement that recipients that commercialize products that are PGRFA and incorporate materials accessed from the Multilateral System pay to an international fund or other mechanism established by the Governing Body an equitable share of the benefits arising from the commercialisation of the product (Article 13.2(d)). The payment is to be mandatory where restrictions are placed on the availability of the product for further research and breeding, as for example is the case with the taking out of patents in some jurisdictions. Where no such restrictions are placed on further availability for research and breeding, the recipient is not under any obligation to make such a payment, but is encouraged to do so. The level, form and manner of payment, in line with commercial practice, are to be determined by the Governing Body at its first meeting. The Governing Body is empowered, though not obliged, to review the levels of payment, and may also assess, within a period of five years from the entry into force of the Treaty, whether to extend the mandatory payments to cases where no restrictions are placed on availability. The benefits arising from the use of PGRFA are to flow directly or indirectly to farmers in all countries who conserve and utilize PGRFA, especially those in developing countries and countries with economies in transition (Article 13.3).

Information System on PGRFA, including a periodic assessment of the state of the world's PGRFA.

Of particular importance are the provisions of Article 15 dealing with ex situ collections held by the IARCs of the CGIAR and other international institutions. As noted above, the negotiators were anxious to include the collections of Annex I materials held by the IARCs in 
the Multilateral System, but the Treaty itself could not deal directly with those collections, because the IARCs have their own international legal personality, and thus cannot be bound without their consent. Since they are not States, they are not entitled to become parties to the Treaty in their own right. A different legal mechanism had to be found to ensure that the IARCs and their collections would be covered. Accordingly, the Treaty now includes a provision calling on the IARCs to sign agreements with the Governing Body to bring their collections within the purview of the Treaty.

PGRFA listed in Annex I that are held by the IARCs are to be made available as part of the Multilateral System. Material held by the IARCs, and collected before the entry into force of the Treaty, that are not listed in Annex I are to be made available in accordance with the MTA currently being used by the IARCs under their in trust agreements with FAO. These MTAs are to be amended by the Governing Body no later

\section{FINANCIAL PROVISIONS}

Part VI of the Treaty addresses one of the most important aspects of the Treaty, namely, the financial resources. Article 18 provides that parties that Parties are to implement a funding strategy that will assist in the implementation of the Treaty's activities. The objectives of the strategy are to enhance the availability, transparency, efficiency and effectiveness of the provision of financial resources for the Treaty. The funding strategy will include the financial benefits arising from the commercialisation of plant genetic resources under the Multilateral System, but also includes funds made available

\section{INSTITUTIONAL PROVISIONS}

The Treaty establishes a Governing Body composed of all Contracting Parties. The Governing Body will act as the supreme body for the Treaty and provide policy direction and guidance for the implementation of the Treaty and in particular the Multilateral System. All decisions of the Governing Body are to be taken by consensus, although the Governing Body is empowered to agree by consensus on another method of deci- than its second session, to bring them into line with the Treaty, including in particular its provisions on facilitated access and benefit sharing under the Multilateral System. Non-Annex I material received by the IARCs after the coming into force of the Treaty are to be made available for access on terms consistent with those agreed between the IARCs and the country of origin of the resources, or the country that acquired them in accordance with the CBD. The Contracting Parties agree to provide IARCs that have signed agreements with the Governing Body with facilitated access to PGRFA covered by the Multilateral System. Parties are also encouraged to provide those IARCs with access, on mutually agreed terms, to non-Annex I material that are important to the programmes and activities of the IARCs.

The Governing Body will also seek to establish similar agreements with other relevant international institutions.

through other international mechanisms, funds and bodies. In this connection, the Contracting Parties commit themselves to taking the necessary and appropriate measures to ensure that due priority is given to the effective allocation of predictable and agreed resources for the implementation of plans and programmes under the Treaty. The Governing Body may establish targets for funding for priority activities, plans and programmes. Voluntary contributions may be provided by Contracting Parties and other sources, but this Part does envisage mandatory payments by Contracting Parties.

sion making for all matters other than amendments to the Treaty and to its Annexes. The Treaty also provides for the appointment of a Secretary of the Governing Body. Since the Treaty is adopted under Article XIV of the FAO Constitution, the Secretary is to be appointed by the Director General of FAO, although he is required to seek the approval of the Governing Body for that appointment. 


\section{Final Clauses}

The Treaty was open for signature between 4 November 2001 and 3 November 2002 and is subject to ratification, acceptance or approval. It remains open for accession by all Members of FAO, including Member Organizations such as the European Community, and by other States that are members of the United Nations (UN) or any of its specialized agencies or the International Atomic Energy Agency (IAEA). It entered into force 90 days after the deposit of the fortieth instrument of ratification, acceptance, approval or accession, i.e. on 29 June 2004. 


\section{PREAMBLE}

As in other international treaties, the preamble forms part of the treaty, but does not establish binding legal obligations. Rather, it serves to explain the motives of the negotiating States, and the basic assumptions on which the treaty is based. It also serves to express additional concerns of the negotiating States and organiza- tions, not all of which may be fully taken up in the substantive provisions of the treaty.

A short commentary is provided with respect to the paragraphs of the preamble. Many of the themes presented below will be examined in greater detail in the commentary on substantive articles of the Treaty.

\section{The Contracting Parties,}

\section{Convinced of the special nature of plant genetic resources for food and agriculture, their distinctive features and problems needing distinctive solutions;}

There are several distinctive features of PGRFA that are not reflected in other components of biodiversity:

- PGRFA is actively managed by farmers;

- Many components of PGRFA would not survive without human activity; local and indigenous knowledge and culture are integral parts of agricultural biodiversity;

- PGRFA has, historically, spread to outside regions of origin, and large collections of this material exist outside these regions;

- Many economically important farming systems are based on crop species introduced from elsewhere. This creates a high degree of interdependence between countries for the genetic resources on which our food systems are based;

- As regards crop improvement and use, genetic diversity within species is at least as important as diversity between species, in particular for crop improvement purposes;

- Maintaining the flow of plant genetic materials and the genetic diversity within them is essential to the work of crop improvement that will allow agriculture to respond to new environmental and economic challenges and help to ensure world food security;

- The nature of the plant breeding process calls for a broad range of genetic diversity as inputs to any one successful product, implying difficulties in tracking original parentage and in calculating the extent to which any par- ticular genetic input has been instrumental in producing the special characteristics of a new commercial variety;

- Because of the degree of human management of agricultural biodiversity, its conservation in production systems is inherently linked to sustainable use preservation through protected areas is of less relevance to cultivated genetic resources and more to the wild relatives of these crops;

- While in situ (or on-farm) conservation of PGRFA remains of primary importance, much of the crop diversity is now being held ex situ in genebanks or breeders' materials, rather than on-farm.

This paragraph acknowledges that PGRFA have distinctive features and characteristics as compared with other genetic resources, and raise distinctive issues that are not satisfactorily dealt with by existing genetic resources regimes.

The wording of the paragraph follows quite closely that of Decision II/ 15 of the second meeting of the Conference of Parties to the CBD, which starts with the words "Recognizing the special nature of agricultural biodiversity, its distinctive features and problems needing distinctive solution". The Nairobi Conference that adopted the CBD in adopting Resolution 3 on The Interrelationship between the CBD and the Promotion of Sustainable Agriculture "recognize[d] the need to seek solutions to outstanding matters concerning plant genetic resources within the Global System for the Conservation and Sustainable Use of Plant Genetic Resources for Food and Sustainable Agri- 
culture, in particular (a) Access to ex situ collections not acquired in accordance with th[e] Convention; and (b) The question of farmers' rights".
The paragraph thus sets out the need for special treatment of PGRFA, and in particular the justification for the establishment of a multilateral system for access and benefit sharing.

\section{Alarmed by the continuing erosion of these resources;}

This paragraph recognizes that PGRFA have been, and continue to be, eroded, and implies that this will have negative consequences. For example, a reduction in plant genetic resources will limit the evolutionary adjustment of agricultural systems to changing environmental and economic conditions. Moreover, farmers would not be able to spread the risk of crop failure or experiment with and refine crop varieties to suit their tastes and changing needs, including the needs of consumers. tions:

PGRFA are essential for two main func-

- Sustainable production of food and other agricultural products, including providing the building blocks for the evolution or deliberate breeding of useful new crop varieties; and

- Meeting new and unforeseen needs and conditions. The transformation of agriculture, including the rapid spread of high-yielding, widely adapted varieties, has raised concern that the diversity of traditional varieties and farmers' landraces is being lost. This concern is especially relevant in areas where diversity is concentrated and where farmers maintain not only local seed of ancestral crop populations, but also the human knowledge and behavioural practices that have shaped this diversity for generations.
The Report on the State of the World's Plant Genetic Resources for Food and Agriculture found specific examples of ongoing replacement of farmer varieties and loss of wild relatives of cultivated crops:

- The Republic of South Korea referred to a study which showed that 74 percent of varieties of 14 crops being grown on particular farms in 1985 had been replaced by 1993.

- China reported that nearly 10,000 wheat varieties were in use in 1949. Only 1,000 were still in use by the 1970s. China also notes losses of wild groundnut, wild rice, and an ancestor of cultivated barley.

- Malaysia, Philippines and Thailand reported that local rice, maize, and fruit varieties are being replaced.

- Ethiopia noted that native barley was suffering serious genetic erosion and that durum wheat is being lost.

- Large-scale erosion of local varieties of native crops and crop wild relatives was noted by Andean countries. Argentina points to losses of Amaranthus and quinoa.

- Uruguay stated that many landraces of vegetables and wheathad been replaced. And Costa Rica reported replacement of native varieties of maize and Phaseolus vulgaris.

- Chile commented on losses of local potato varieties, as well as oats, barley, lentils, watermelon, tomato and wheat.

\section{Cognizant that plant genetic resources for food and agriculture are a common concern of all countries, in that all countries depend very largely on plant genetic resources for food and agriculture that originated elsewhere;}

Building on the CBD, this paragraph makes reference to plant genetic resources for food and agriculture as a "common concern of all countries." Common concern implies the paramount importance of PGRFA to the international community. The change in wording from the Inter- national Undertaking on Plant Genetic Resources should be noted. The International Undertaking described plant genetic resources as "a heritage of mankind". This was later clarified in the third agreed interpretation annexed to the International Undertaking as being subject to 
the sovereignty of the states over their plant genetic resources.

The paragraph emphasizes that all countries depend very largely on PGRFA that originated elsewhere. Indeed, there is much greater interdependence among countries for PGRFA than for any other kind of biodiversity. Continued agricultural progress implies the need for continued access to the global stock of PGRFA. No region can afford to be isolated, or to isolate itself, from the germplasm of other parts of the world. (On the interdependency of countries on one another's PGRFA see Box 1).

The concept of common concern is normally to be found together with the principle of national sovereignty in modern treaties. The relationship between these two principles will be examined in further detail below (see, for example, Article 5.1 and Box 14).

\section{Acknowledging that the conservation, exploration, collection, characterization, evalu- ation and documentation of plant genetic resources for food and agriculture are essential in meeting the goals of the Rome Declaration on World Food Security and the World Food Summit Plan of Action and for sustainable agricultural development for this and future generations, and that the capacity of developing countries and countries with economies in transition to undertake such tasks needs urgently to be reinforced;}

This paragraph emphasizes the importance of plant genetic resources, including their conservation, exploration, collection, characterization, evaluation and documentation, for world food security. The Rome Declaration on World Food Security, adopted at the World Food Summit in 1996, committed the world's leaders to an ongoing effort to eradicate hunger in all countries, with an immediate view to reducing the number of undernourished people to half their present level no later than 2015. At that time, the number of people that did not have enough food to meet their basic nutritional needs stood at over 800 million. The Rome Declaration also recognized the need for urgent action to combat the erosion of biological diversity. Paragraph (f) of Objective 2.1 of the World Food Summit Plan of Action states that governments, in partnership with all actors of civil society, and with the support of international institutions will, as appropriate, "promote access, by farmers and farming communities, to genetic resources for food and agriculture." Paragraph (e) of Objective 3.2 provides that they will also "promote an integrated approach to conservation and sustainable utilization of PGRFA, through inter alia appropriate in situ and ex situ approaches, systematic surveying and inventorying, ap- proaches to plant breeding which broaden the genetic base of crops, and fair and equitable sharing of benefits arising from the use of such resources".

The paragraph also introduces elements of intergenerational equity - the relationship between past, present, and future generations with respect to the use of the common patrimony of the world's natural and cultural resources. ${ }^{45}$ The starting proposition is that each generation is simultaneously custodian and beneficiary of this common patrimony. As custodian, each generation owes certain moral obligations to future generations. These moral obligations can be transformed into legally enforceable norms, and include the duty to conserve resources, to avoid adverse impacts, and to compensate for environmental harm. As beneficiary, each generation has certain rights to this common patrimony. These rights are the obverse of the moral obligations each generation owes, as the custodian of the common patrimony, to future generations. The theory of intergenerational equity is based on three principles:

- The principle of conservation of options requires each generation to con(1990); Edith Brown Weiss, The Planetary Trust: Conservation and Intergenerational Equity, 11 Ecology L. Q. 495 (1984). See also Gary P. Supanich, The Legal Basis of Intergenerational Responsibility: An Alternative View-The Sense of Generational Identity, 3 Y.B. Int'1 Envtl. L. 94 (1992). 
serve the diversity of the natural and cultural resource base so that it does not unduly restrict the options available to future generations in solving their problems and satisfying their own values.

- The principle of conservation of quality requires each generation to maintain the quality of the planet so that it is passed on in no worse condition than the present generation received it.

- The principle of maintained access requires each generation to provide its members with equitable rights of access to the legacy from past generations and should conserve this access for future generations.
Third, this paragraph specifies that developing countries and economies in transition require specific attention. These countries often do not possess the financial resources and knowledge to properly conserve, explore, collect, characterize, evaluate, and document PGRFA. The needs of developing countries and countries with economies in transition are addressed in Article 7 (international cooperation), 8 (technical assistance), 13 (benefit sharing and capacity building) and 18 (financial resources).

The obligations of Contracting Parties with respect to the conservation, exploration, collection, characterization, evaluation and documentation of PGRFA are set out in Article 5.

\section{Noting that the Global Plan of Action for the Conservation and Sustainable Use of Plant Genetic Resources for Food and Agriculture is an internationally agreed framework for such activities;}

The GPA, which was adopted by the Fourth International Conference on Plant Genetic Resources in 1996 sets a scientific and technical framework for the conservation and sustainable utilization of all PGRFA and identifies agreed priority activity areas (see Box 15). Articles 5 and 6 of the Treaty, which set out the basic obligations of Contracting Parties with respect to the conservation and sustainable use of PGRFA draw heavily on this scientific and technical framework. The importance of the GPA for the Treaty - it is listed as one of the Treaty's supporting components - is specifically recognized in Article 14 of the Treaty, and all Contracting Parties should promote its effective implementation.

\section{Acknowledging further that plant genetic resources for food and agriculture are the raw material indispensable for crop genetic improvement, whether by means of farmers' selection, classical plant breeding or modern biotechnologies, and are essential in adapting to unpredictable environmental changes and future human needs;}

PGRFA are essential "building blocks" for plant breeding programmes. They include germplasm from primary, secondary and tertiary genepools. Primary genepools include the genetic variation in the breeding population of a species and closely related species that commonly interbreed with, or can be routinely crossed with, the species. Secondary genepools include the genetic variation in the breeding populations of related species that can be crossed with the species using less usual methods, such as mentor pollen, or embryo rescue. Tertiary genepools refer to all the genetic variation in other organisms that cannot be crossed with the species. With the development of genetic engineering, it is theoretically possible to transfer genes isolated from any organism (plant, animals, virus, or bacterium) into a plant. This makes the line between the secondary and tertiary gene pools somewhat fuzzy (see Maynard, C. 1996. Forest Genetics Glossary).

The paragraph acknowledges that crop genetic improvement can be achieved by many different means: farmers' selection, classical plant breeding, or modern biotechnologies. In view of its historical importance, farmers' selection is listed first.

The paragraph re-emphasizes the element of intergenerational equity by making reference to future human needs, and stresses the importance of plant genetic resources as a raw material that can be used to adapt crops to unpredictable environmental changes. Since one cannot predict the full extent of those changes, there is a corresponding need to conserve as broad an array of biodiversity as possible (on the role of PGRFA in plant breeding, see Box 4). 


\section{Box 4. Plant Breeding and the role of genetic resources}

Farmers have practiced seed selection and plant breeding since the first beginnings of agriculture some 10,000 years ago.

The Russian scientist N.I. Vavilov, writing in the 1930s and building on the work of Alphonse de Candolle $^{46}$ in the previous century, first put forward the idea that the roots of modern agriculture are to be found in eight geographical centres of genetic diversity. These were concentrated centres of natural plant diversity important to agriculture, in which farmers originally domesticated and developed, through selection and breeding, the major crops that are the foundation of modern agriculture and food security. The eight centres were listed as follows: China; India, with a related centre in Indo-Malaya; Central Asia; the Near East; the Mediterranean; Abyssinia (Ethiopia); southern Mexico and Central America; and South America (Peru, Ecuador, and Bolivia), with two lessercentres: the island of Chiloe off the coast of southern Chile, and an eastern secondary centre in Brazil and Paraguay. Vavilov thought that the centres of diversity were the natural centres of origin of those crops. It is the local and indigenous communities and farmers in these and similar areas that the Treaty identifies as having made a special contribution to the improvement of agricultural crops. Vavilov believed that the centres of origin of crops were to be found in the areas where the greatest natural diversity of those crops was to be found (the "centres of diversity"). Later it was discovered that this was not necessarily so and that many crops had secondary centres of diversity that exhibited as much or more genetic diversity. While some of Vavilov's theories regarding the conflation of centres of natural diversity and centres of origin have since been shown to be incomplete, his ideas are still the foundation of the modern science of plant genetic resources.

Farmers developed the precursors of modern agricultural crops by selecting the most productive and disease-resistant naturally-occurring genotypes, and then breeding them with other varieties of the same species in order to produce new and improved varieties. The natural diversity of plant genetic resources was, and still is, an essential requisite for such plant breeding. For example, all species of cereals have varieties with husks, and varieties without husks, and all have varieties with stable and with brittle ears. In nature, traits such as the tendency of seed heads to shatter and scatter their seed, and the capacity of seeds of wild plants to lie dormant and thus survive periods of drought, are important to securing natural regeneration. Such traits, however, make such plants less useful for cultivation. The task of farmers was thus to select and breed naturally occurring plants to breed out unwanted traits and to breed in desired characteristics, including resistance to diseases. The work of farmers in improving crops to meet local ecological conditions continues to this day. Traditional farmers also seek to maximize natural diversity in their traditional crops (the so-called "landraces" or "farmers" varieties") in order to increase yield stability and adaptability to new environments, and to decrease vulnerability to disease. Traditional farmers are thus continually seeking new influxes of genetic diversity, through exchange of seed with neighbouring farmers and from outside the immediate farming area or region.

Scientific plant breeding uses a number of techniques, some older and others newer, in order to induce variation, select desired traits and propagate and multiply new varieties.

Older techniques involve crossing parents with complementary characteristics to generate a population of genetically recombined plants, a small proportion of which, it is hoped, will provide the particular

continued next page

De Candolle was one of the foremost botanists of the nineteenth century. His book, Origin of Cultivated Plants, (reprinted in 1959) tried to locate the region of origin of cultivated plants using such techniques as the distribution of wild relatives, linguistic derivatives, variation patterns etc. 
assemblage of genes required. In a modern variety, genes from a very large number of parents, from many different countries or regions, may be combined. The VEERY spring bread wheat variety, developed by the International Maize and Wheat Improvement Center (CIMMYT), which was the leading cultivar among varieties during the 1980s, was the product of 3170 different crosses involving some 51 parent varieties from at least 26 countries.

Modern plant breeding depends on the breeder having access to a wide range of plant varieties. In the early stages of breeding, scientists may screen thousands of germplasm samples in search of useful new traits. In general plant breeders normally work with existing cultivars or advanced (elite) materials, which are materials that have already been improved by other plant breeders. Sometimes, however, they may need to turn to landraces, which are varieties developed by farmers on their fields, or crop wild relatives, which are the weeds and/or wild species related to the cultivated crops. This is particularly the case where resistance traits are being sought.

Using this material, crosses are made giving rise to thousands of different combinations. These are narrowed down by testing and selection, generally of individual plants or lines, over several generations. The overwhelming majority of combinations are discarded during this process. In the later stages, crops are normally cultivated and evaluated in a variety of locations (multilocation evaluation) to determine the degree of adaptation of the remaining lines to the target environments. At the end of the process, the breeder normally submits a small number of highly selected lines for independent evaluation before they are released to the farmer. Sometimes crosses are made that are not intended to deliver a variety directly, but rather to produce improved parents for further crossing ('pre-breeding'). Much of the use of PGRFA takes this form. The development of new varieties depends on the use of genetic resources over a long period: the whole process of breeding and releasing a new grain variety can take at least 10 years and often takes longer. The rice variety IR36, for example, has 15 landraces and one wild species in its heritage and was the result of some 20 years of breeding work.

Molecular biology is providing new tools for plant breeding. Genes can now be transferred across species barriers or even from the animal or microbial kingdoms into plants. Although to date, relatively few varieties have been commercialized through such gene transfers, the number of successes will undoubtedly increase in the future. The potential contribution of the new techniques is enormous; it is also a potential threat to existing genetic diversity.

All plant breeding depends on continued access to a diverse range of plant materials. While the products of plant breeding that fulfill certain criteria can be protected by intellectual property rights in the form of Plant Breeders' Rights or patents (see Box 11), no such protection is available for other innovations that do not meet these criteria, including massal selection, ${ }^{47}$ an ongoing process of selection and propagation practiced by generations of farmers.

47 The term "massal selection" refers to the traditional method of selecting suitable reproductive material from the best plants in a particular farm or other holding. 
Affirming that the past, present and future contributions of farmers in all regions of the world, particularly those in centres of origin and diversity, in conserving, improving and making available these resources, is the basis of Farmers' Rights;

This paragraph acknowledges the importance of the past, present and future contributions of farmers in conserving, improving and making available PGRFA, and introduces the concept of "Farmers' Rights". The concept first entered international law via the first two agreed interpretations of the International Undertaking on Plant Genetic Resources of the Food and Agriculture Organization. Annex II to the International Undertaking, adopted by Resolution 5/89 of the FAO Conference, defined Farmers' Rights as:

"Rights arising from the past, present and future contributions of farmers in conserving, improving and making available plant genetic resources, particularly those in centres of origin/diversity."

As formulated in the agreed interpretations, the recognition of Farmers' Rights was linked with the recognition of Plant Breeders' Rights, and, in the view of many, balanced those more formal rights. Innovations achieved through the process of traditional farmer selection ongoing over many generations, had not hitherto been recognized or rewarded.

The paragraph presages the substantive article on Farmers' Rights in Part III (Article 9) of the Treaty.

The paragraph also acknowledges that the contributions of farmers are not evenly distributed across the planet but are instead concentrated in "centres of origin and diversity" of cultivated plants and their wild relatives, which are largely located in the tropical and subtropical regions of Africa, Asia and South America.

On the meaning of the terms "centres of origin" and "centres of diversity", see Box 4.

\begin{abstract}
Affirming also that the rights recognized in this Treaty to save, use, exchange and sell farm-saved seed and other propagating material, and to participate in decisionmaking regarding, and in the fair and equitable sharing of the benefits arising from, the use of plant genetic resources for food and agriculture, are fundamental to the realization of Farmers' Rights, as well as the promotion of Farmers' Rights at national and international levels;
\end{abstract}

The substantive provisions on Farmers' Rights are set out in Article 9 of the Treaty. This paragraph would suggest that Farmers' Rights will be realized and promoted at national and international levels by implementation of these substantive provisions.

There are, however, some differences between the substantive provisions and those set out in this paragraph.

First, the list of rights "recognized in this Treaty" differs somewhat from the list of Farmers' Rights that the Contracting Parties agree to protect and promote in Article 9. Most impor- tant, the right to save, use, exchange and sell farm-saved seed is listed on an equal footing with the other rights as being fundamental to the realization of Farmers' Rights. In Article 9, the equivalent provision on farm-saved seed is separate from the treatment of other manifestations of Farmers' Rights and is largely neutral in its effect. While Contracting Parties should take measures to protect traditional knowledge, to protect and promote the right to share equitably in benefits, and to enable participation in making decisions, Article 9 places no obligations on Contracting Parties with respect to farm-saved seeds: the treatment of the so-called farmers' privilege $^{48}$ is left entirely to national decision- 
makers. Article 9 thus limits itself to clarifying that the provisions of the substantive Article do not limit any rights that may be granted under national law. The preambular paragraph seems to go further than the substantive provision, and follows more closely some of the wording of the Chairman's Elements derived from the Montreux meeting of experts (see Introduction). On the other hand, the list of examples of the components of Farmers' Rights is more extensive in Article 9, which, unlike the preambular paragraph, mentions the protection of traditional knowledge.

Second, the explicit reference in the preambular paragraph to the promotion of Farmers' Rights at the international level should be viewed in the context of the substantive provisions of Article 9, which carefully refrain from any reference to Farmers' Rights at the international level. This was intended, in conformity with the wording of the Chairman's Elements derived from the Montreux meeting of experts.

Some developing countries may be considering the inclusion of a national mechanism for Farmers' Rights on their own or as part of national sui generis Plant Breeders' Rights legislation, following the Agreement on TradeRelated Aspects of Intellectual Property Rights 49 (TRIPS Agreement) of the Uruguay Round of multilateral trade negotiations. Such provisions find support in this explicit reference in the preambular paragraph to the promotion of Farmers' Rights at the international as well as the national level. Farmers' Rights have already been recognized at the international level, albeit in non-legally binding instruments adopted before the adoption of the Treaty (Agenda 21 and Resolution 3 of the Nairobi Final Act).

To a certain extent, the multilateral system of benefit sharing set up under Article 13 of the Treaty, including the payments to be made under Article 13.2(d)(ii), the benefits of which are to flow primarily to farmers in all countries, can also be seen as a practical implementation of Farmers' Rights at the international level. This ties in with FAO Conference Resolution $4 / 89$, in which the adhering states to the International Undertaking considered that "the best way to implement the concept of Farmers' Rights is to ensure the conservation, management and use of plant genetic resources, for the benefit of present and future generations offarmers. This could be achieved through appropriate means, monitored by the Commission on Plant Genetic Resources, including in particular the International Fund for Plant Genetic Resources". This point was endorsed by FAO Conference Resolution 3/91 in the following words: "... Farmers' Rights will be implemented through an international fund on plant genetic resources which will support plant genetic conservation and utilization programmes, particularly, but not exclusively, in the developing countries".

Recognizing that this Treaty and other international agreements relevant to this Treaty should be mutually supportive with a view to sustainable agriculture and food security;

\section{Affirming that nothing in this Treaty shall be interpreted as implying in any way a change in the rights and obligations of the Contracting Parties under other interna- tional agreements;}

\section{Understanding that the above recital is not intended to create a hierarchy between this Treaty and other international agreements;}

These three paragraphs should be viewed together. They constitute a compromise wording designed to address the question of the relationship between the Treaty and other relevant international agreements, including in particular the CBD and various World Trade Organization (WTO) trade agreements. Under the Vienna Convention on the Law of Treaties, ${ }^{50}$ later 
treaties between the same parties dealing with the same subject matter supersede the provisions of earlier treaties, unless wording to the contrary is included in the later treaty. The negotiators were eager to avoid this effect, while at the same time avoiding any notion of hierarchy among the various international agreements. To this end, the first of the three paragraphs specifically states that all relevant treaties should be interpreted in a mutually supportive manner that achieves the goals of the Treaty, namely, sustainable agriculture and food secu- rity. This evokes a similar provision in the preamble to the CBD dealing with the complementarity of existing international arrangements. In the Convention, however, the substance of the second paragraph is dealt with in a separate article in the main body of the Convention, Article $22 .{ }^{51}$ The Treaty paragraph does not include the exception contained in the Convention covering the situation where the exercise of the rights and obligations under existing agreements would cause serious damage or threat to biological diversity.

\section{Aware that questions regarding the management of plant genetic resources for food and agriculture are at the meeting point between agriculture, the environment and commerce, and convinced that there should be synergy among these sectors;}

This paragraph recognizes the complex relationship between PGRFA, the environment and commerce, including trade related intellectual property rights. All sectors must work together in order to be effective, both at the national and at the international level. In a sense, the paragraph highlights the essential nature of the Treaty. The Treaty is essentially an agricultural treaty, dealing with plant genetic resources and their importance for food and agriculture and eventually food security. On the other hand, the Treaty was intended to be in harmony with the $\mathrm{CBD}$ and the environmental framework it set up for the conservation and sustainable use of all biodiversity. The need for the Treaty to look both towards the needs of agriculture and the concerns of the environment is also reflected in particular in the wording of Article 2.1, which provides that the objectives of the Treaty will be attained by closely linking the Treaty to FAO and to the CBD.

At the national level, this paragraph also implies that close cooperation between the relevant ministries will be required in implementing the Treaty.

\section{Aware of their responsibility to past and future generations to conserve the World's diversity of plant genetic resources for food and agriculture;}

This paragraph draws on a similar provision in the preamble to the CBD. In the case of the Treaty paragraph, however, more stress in laid on the past contributions of farmers in conserv- ing and developing PGRFA, which themselves create a responsibility on the present generation to conserve that diversity for future generations.

50 Vienna Convention on the Law of Treaties, 23 May 1969, 8 I.L.M. 679.

51 Article 22 states:

1. The provisions of this Convention shall not affect the rights and obligations of any Contracting Party deriving from any existing international agreement, except where the exercise of those rights and obligations would cause serious damage or threat to biological diversity.

2. Contracting Parties shall implement this Convention with respect to the marine environment consistently with the rights and obligations of States under the law of the sea. 
Recognizing that, in the exercise of their sovereign rights over their plant genetic resources for food and agriculture, states may mutually benefit from the creation of an effective multilateral system for facilitated access to a negotiated selection of these resources and for the fair and equitable sharing of the benefits arising from their use; and

First, this paragraph reaffirms the concept that Contracting Parties have sovereign rights over their PGRFA. This reflects similar wording in the preamble to the CBD and indeed in the Third Agreed Interpretation of the International Undertaking. As noted above, the notion of "sovereign rights" is normally linked to the concept of "common concern" expressed in the third preambular paragraph.Second, this paragraph introduces the concept of the multilateral system. The paragraph recognizes that all countries may benefit from the creation of a multilateral approach for plant genetic resources that are important for food security and on which all countries are interdependent. The paragraph further makes the point that this multilateral approach is not inconsistent with the CBD and the concept that States have sovereign rights over their PGRFA. Indeed, the paragraph points out that it is "in the exercise of their sovereign rights" that the Contracting Parties to the Treaty have agreed to establish a multilateral system for those plant genetic resources. By agreeing to the terms of the Treaty, countries are effectively agreeing that for access to a defined sub-category of PGRFA, as between Contracting Par- ties, prior informed consent will not be required for each transaction, and the terms of access and benefit sharing will not need to be negotiated bilaterally. Rather, a multilaterally determined set of mutually agreed terms will apply. By recognizing the mutual benefits Contracting Parties may derive from the multilateral system, this paragraph implicitly acknowledges that a purely bilateral approach to access and benefit sharing is not well suited for PGRFA. This is so for several reasons:

- Due to movements of people and resources over the past millennia as well as to modern collecting efforts, the genetic resources of major crops are widely distributed ex situ both in genebanks and in production areas;

- Agriculture in all countries depends largely on PGRFA that originated elsewhere; and

- Future advances in crop improvements, which are needed for sustainable agriculture and food security, require continued access to a wide genetic base without major restrictions.

\section{Desiring to conclude an international agreement within the framework of the Food and Agriculture Organization of the United Nations, hereinafter referred to as FAO, under Article XIV of the FAO Constitution;}

Article XIV of the FAO Constitution empowers the FAO Conference to "... approve and submit to Member Nations conventions or agreements concerning questions relating to food and agriculture". International agreements adopted under this procedure are international agreements in their own right, and once they come into force, are fully binding on their Contracting Parties. They are however adopted under the constitutional aegis of FAO and thus have constitutionally prescribed links with FAO. These include the power of the Director-General to appoint the Secretary of the Governing Body (Article 20), albeit only with the approval of the Governing Body. Article XIV agreements also historically benefit from a certain level of financial and technical support from FAO. This constitutional linkage of the Treaty with FAO acknowledges the essentially agricultural flavour of the interests addressed by the Treaty and the competence of FAO in this area. However, the Treaty stresses in Article 1 that the Treaty must also be closely linked to the CBD if it is to attain its objectives. 52 


\section{PART I - INTRODUCTION}

\section{Article 1 - Objectives}

This article sets out the overall objectives and direction of the Treaty and outlines the framework within which implementing actions have to be taken. It sets the stage for the subsequent articles which establish more specific obligations. Defining the objectives of the Treaty in precise terms also allows for ongoing evaluation of the extent to which the objectives are being attained by providing a point of reference or benchmark for monitoring implementation.

By providing an overall sense of direction, this article helps to:

- Ensure that balanced decisions are taken. Where one activity under the Treaty may conflict with another, the article may provide some safeguard that all interests are considered. It would not, for example, be in conformity with this article to pursue policies of access to PGRFA without considering the fair and equitable sharing of the benefits derived from their use.
- Resolve cases of divergent interpretation, possible conflicts between different provisions, and assist in settling disputes.

For all these reasons, Article 1 is important for all those involved with the Treaty, including in particular the Treaty's Governing Body (see Article 19), and Contracting Parties' national policy-makers charged with ensuring the implementation of the Treaty within their jurisdictions.

The Article also has important legal consequences for states signatory to the Treaty that have not yet ratified it, and for states that have ratified it but for whom the Treaty has not yet entered into force. Under Article 18 of the Vienna Convention on the Law of Treaties, once a state has signed a treaty or expressed its consent to be bound by a treaty, it is bound to refrain from acts that would defeat the object and purpose of the treaty, pending the entry into force for it of the Treaty.

Commission for the Mediterranean (1949) [Amended text approved by FAO Council at its 113th Session], the International Plant Protection Convention (1951) [Revised text approved by FAO Conference at its 29th Session (November 1997)], the Constitution of the European Commission for the Control of Foot-and-Mouth Disease (1953), the Plant Protection Agreement for the Asia and Pacific Region (1955), the Convention Placing the International Poplar Commission within the framework of FAO (1959), the Agreement for the Establishment of an FAO Commission for Controlling the Desert Locust in South-West Asia (1963), the Agreement for the Establishment of a Commission for Controlling the Desert Locust in the Central Region (1965), Agreement for the Establishment of a Commission for Controlling the Desert Locust in North-West Africa (1970), the Agreement for the Establishment of a Regional Animal Production and Health Commission for Asia and the Pacific (1973), the Agreement to Promote Compliance with International Conservation and Management Measures by Fishing Vessels on the High Seas (1993), the Agreement for the Establishment of the Indian Ocean Tuna Commission (1993), the Agreement for the Establishment of the Regional Commission for Fisheries (RECOFI) (1999), and the Agreement for the Establishment of a Commission for Controlling the Desert Locust in the Western Region (2000). 


\subsection{The objectives of this Treaty are the conservation and sustainable use of plant genetic resources for food and agriculture and the fair and equitable sharing of the benefits arising out of their use, in harmony with the Convention on Biological Diversity, for sustainable agriculture and food security.}

This first paragraph of this article states the objectives of the Treaty:

- The conservation (see in particular Article 5) and sustainable use (see in particular Article 6) of PGRFA;

- The equitable sharing of the benefits arising out of their use (see in particular Articles 9 and 13); and

- With the ultimate goal of achieving sustainable agriculture and food security.

These objectives establish, first, the fundamental balance of the Treaty between conservation and sustainable use and second, the balance between both of these and benefit sharing. Third, they emphasize the ultimate, essentially agricultural, scope and aim of the Treaty. In this connection it is to be noted that the subject matter of the Treaty is PGRFA as defined in Article 2: plant genetic material of actual or potential value for food and agriculture. The Treaty provides for its conservation, use and benefit sharing for the purpose of achieving sustainable agriculture and food security.

The paragraph makes the explicit statement that the objectives of the Treaty are to be attained "in harmony with the Convention on Biological Diversity." It was the original request of both Agenda 21, adopted at UNCED in 1992, and the FAO Conference in 1993 that the adaptation of the International Undertaking should be in harmony with the CBD. The Treaty provides a more detailed regime applicable to PGRFA within the overall regime applicable to biodiversity in general. For the PGRFA included in the Multilateral System, the Treaty provides for mutually agreed terms of access and benefit sharing that have been pre-agreed by the Parties on a multilateral basis.

Biodiversity is defined very broadly in the $\mathrm{CBD}$ as "the variability among living organisms from all sources including, inter alia, terrestrial, marine and other aquatic ecosystems and the ecological complexes of which they are part; this includes diversity within species, between species and of ecosystems." The CBD therefore encompasses all the variability among the building blocks of life (i.e., genetic diversity), different life forms (species diversity) and the interrelationships of life (ecosystem diversity). In other words, the CBD is the legally binding umbrella for all levels and forms of diversity. The Treaty, in contrast, focuses on one specific area of biological diversity, namely, the diversity of plants used for one particular purpose, namely food and agriculture. It is nevertheless apparent that the objectives of the CBD and the Treaty are complementary, and as such, need to operate in harmony.

Unlike the International Undertaking, which specifically referred to the concept of 'availability' in its objectives, the Treaty does not mention access as one of its objectives. However the notion of availability is implicit in the notion of sustainable use.

\subsection{These objectives will be attained by closely linking this Treaty to the Food and Agriculture Organization of the United Nations and to the Convention on Biological Diversity.}

Having defined the objectives in the first paragraph, the second paragraph proceeds to state one important aspect of the means by which the objectives are to be attained. The negotiators of the Treaty recognized that PGRFA are an im- portant component of biodiversity in general, as well as an essential basis for agriculture and food security. Some negotiators, and at one time the Conference of the Parties to the CBD, ${ }^{51}$ had thought that the Treaty might be adopted as a 
protocol to the CBD, which would naturally emphasize the environmental dimension of the Treaty. However, the agricultural dimension of the new Treaty and the importance of PGRFA for world food security and the need for specialized agricultural expertise in the implementation of the Treaty warranted its adoption as a separate agreement within the constitutional framework of FAO. The second paragraph recognizes this twofold dimension of the Treaty and requires that close links be established both with the FAO, representing the agricultural interest and expertise, and the CBD, representing the interests and expertise of general biodiversity and the environment.

i) FAO - The FAO has a long-standing involvement with PGRFA which goes back to the 1960s. ${ }^{54}$ The International Undertaking on Plant Genetic Resources was adopted by the FAO Conference in 1983 and was, as stated earlier, the first international instrument that addressed the conservation and sustainable use of PGRFA. In 1989, the FAO Conference adopted a series of Agreed Interpretations of the International Undertaking. The FAO is also the focal point in the UN system for world food security and was the host of the World Food Summit in 1996. The link to FAO is therefore a logical one, as is the decision to place the Treaty's Governing Body and Secretariat within FAO. A potential consequence, at the national level, would be to expect the responsible ministry of agriculture to be the "lead agency". In any case, given the agricultural flavour of the Treaty, the ministry responsible for agriculture should be closely involved in its implementation.

ii) CBD - In a broader context, as specified in the Preamble, the issue of PGRFA is also closely linked to the CBD. Adopted as part of the UNCED in 1992, the CBD provided a comprehensive framework for the conservation and sustainable use of biological diversity, and a framework for access to genetic resources and sharing the benefits of their utilization. Its emphasis is on decision-making at the national level, in recognition of the sovereign rights that states have over their natural resources (including biodiversity). (For a description of the CBD, see Box 3.)

54 While some activities took place in the 1950s, the 1961 Technical Meeting on Plant Exploration and Introduction was the first initiative on a wide multilateral basis. For a history of FAO's involvement in plant genetic resources, see Robin Pistorius, "Scientists, plants and politics: A History of the Plant Genetic Resources Movement” (Rome: International Plant Genetic Resources Institute, 1997). 
Explanatory Guide to the International Treaty on Plant Genetic Resources for Food and Agriculture 


\section{Article 2 - Use of Terms}

\section{For the purpose of this Treaty, the following terms shall have the meanings
hereunder assigned to them. These definitions are not intended to cover trade in \\ For the purpose of this Treaty, the following terms shall have the meanings
hereunder assigned to them. These definitions are not intended to cover trade in commodities:}

\begin{abstract}
The purpose of definitions in legal instruments is to provide agreed specific meaning to certain terms used in the Treaty. In interpreting a Treaty, terms are normally given their ordinary meaning according to everyday usage. However, some terms may need to be given specific meanings that may differ from normal usage. The way in which such terms are defined can and will affect the nature and scope of the obligations assumed and rights accorded under the Treaty. The definitions found in this section are thus fundamental in determining the scope of the Treaty. Since the definitions section forms part of the binding terms of the Treaty, the definitions found in this section prevail in the event of any inconsistency with their usual meaning.
\end{abstract}

The definitions given in Article 2 are of course limited in their application to the Treaty itself. In particular, the negotiators have been careful to indicate that these definitions, including in particular the definition of PGRFA, do not cover trade in commodities. This was introduced to prevent misinterpreting the term "products" in Article 13.2(d)(ii) as referring to commodities. ${ }^{55}$ Indeed it is important to recall that the Treaty refers to plant genetic resources and not to plants or crops as commodities.

Eight terms are defined in this Article. As will be seen in more detail below, most of the definitions are based, more or less closely, on those found in the CBD.

\section{"In situ conservation" means the conservation of ecosystems and natural habitats and the maintenance and recovery of viable populations of species in their natural surroundings and, in the case of domesticated or cultivated plant species, in the surroundings where they have developed their distinctive properties.}

The Treaty's definition of "in situ conservation" is identical to that in the CBD, with the exception of the limiting reference to plant species. It acknowledges that genetic resources exist both in natural ecosystems and human created agro-eco-systems. Thus, the definition of this term extends to both wild and domesticated genetic resources for food and agriculture. Wild genetic resources occur in situ where they exist in natural surroundings such as ecosystems and habitats. Domesticated or cultivated species occur in situ where they exist in "the surroundings where they have developed their distinctive properties."

In addition to addressing the "maintenance and recovery of viable populations of species", the Treaty's definition of "in situ conservation" with respect to wild species extends to the conservation of the actual ecosystems, as well as the natural habitats that populations of spe- cies depend on. This definition therefore implicitly recognizes that in situ species conservation of wild species cannot be successful without conserving the environment in which the populations of those species exist.

With respect to the in situ conservation of domesticated or cultivated plant species, the phrase "in the surroundings where they have developed their distinctive properties" refers to the development of identifiable plant varieties, such as landraces, within man-made agricultural systems. This applies whether or not those plants are reproductively isolated from the wild populations from which they originated. The term would also refer to a research centre, if that is where the distinctive properties of a given variety were developed.

The term "in situ conservation" is only used once in the Treaty, namely, in Article

55 It should be noted that the common usage of "commodities" would exclude PGRFA. See: www.investorwords.com/cgi-bin/getword.cgi. 
5.1(d), which states that each Contracting Party will "promote in situ conservation of wild crop relatives and wild plants for food production".

Unlike the CBD, no separate definition is given of the term "in situ conditions". However the meaning is clear from the terms used in the definition of "in situ conservation", which is in line with the definition used in the CBD. The definition in Article 2 of the CBD reads: "In situ conditions means conditions where genetic resources exist within ecosystems and natural habitats, and, in the case of domesticated or cultivated species, in the surroundings where they have developed their distinctive properties."

\section{"Ex situ conservation" means the conservation of plant genetic resources for food and agriculture outside their natural habitat.}

With the exception of the use of the more specific "plant genetic resources for food and agriculture" instead of "components of biological diversity", the definition used in the Treaty is identical to that found in the CBD.

The term includes conservation of PGRFA in genebanks in the form of seed, tissue or pollen; in plantations; or in botanic gardens or other live collections, such as ex situ conservation stands. The definition also includes biological resources cultivated in areas other than those where they had developed their distinctive properties and maintained on farms that have not contributed to the development of those properties (for example, fruit trees kept in a field genebank or orchard).
Ex situ conservation is an important tool for the conservation of plant biodiversity, as well as to allow for the recovery of PGRFA following natural and humanitarian emergencies, and to provide continuous access to plant genetic resources to plant breeders, other researchers, farmers and indigenous and local communities. In such cases, the role of good and accessible documentation is very important.

The only reference to this term in the Treaty can be found at Article 5.1(e), which states that each Contracting Party will, inter alia, "cooperate to promote the development of an efficient and sustainable system of ex situ conservation".

\section{"Plant genetic resources for food and agriculture" means any genetic material of plant origin of actual or potential value for food and agriculture.}

\section{“Genetic material” means any material of plant origin, including reproductive and vegetative propagating material, containing functional units of heredity.}

As two of the most important terms found in the Treaty, there was considerable debate over these definitions, which lasted right up to the actual adoption of the Treaty. The main issue was whether or not to expand the definition of PGRFA to include not only genetic material of plant origin, but also its genetic parts and components. The issue is linked closely with the provisions of Articles 12 and 13 on access to PGRFA and benefit sharing in the Multilateral System. The final compromise was to refrain from including the reference to genetic parts and components in the definition of PGRFA, but to include it in Article 12.3(d) in connection with the ban on the claiming of intellectual property rights over material received from the Multilateral System in the form received. Some ambiguities remain in the wording of Article 12.3(d), which will be commented on in connection with that provision. Under Article 13.2(d)(ii), the right of recipients to take out intellectual property rights over derivatives of material accessed from the Multilateral System is implicitly recognized. Article 13.2(d)(ii) provides for recipients of material to make mandatory or voluntary payments where plant genetic resources products that incorporate material accessed from the Multilateral System are commercialized.

Under the definitions as they now stand, PGRFA are defined as meaning any genetic material of plant origin of actual or potential value for food and agriculture, and in its turn, genetic material is defined as any material of plant origin, including reproductive and vegeta- 
tive propagating material, containing functional units of heredity. These definitions parallel similar definitions in the CBD.

The following three comments can be made on the content of these definitions:

- PGRFA are subject to the provisions of the Treaty only insofar as they have value for food and agriculture. The requirement that genetic material must have actual or potential value if it is to be classed as PGRFA is drawn from the parallel definition in the CBD. In this connection, it is to be noted that almost all plant genetic resources may be of potential value: indeed that value may only be realized when future needs arise, as for example in the case of pest or disease resistant traits. Of particular importance however is the restriction that the value must be for food and agriculture. Indeed the Treaty covers only plant genetic resources in so far as they are used, or can be used, for food and agriculture, and does not cover their use for any other purpose.

- PGRFA are defined as genetic material, and "genetic material" is defined as containing functional units of heredity. It can be argued, therefore, that functional units of heredity (i.e. genetic parts and components such as individual genes or gene sequences) are not in themselves PGRFA, although they are part, or components, of PGRFA. The definition, however, remains ambiguous in this respect, and may need to be clarified by the Governing Body.

- The term "functional unit of heredity" is not defined, but would appear to include at least all genetic elements containing DNA (deoxyribonucleic acid) i.e. genes.

\section{"Variety" means a plant grouping, within a single botanical taxon of the lowest known rank, defined by the reproducible expression of its distinguishing and other genetic characteristics.}

The plant kingdom has been classified into a ranking system containing many divisions and sub-divisions. The most commonly used ranks of classification in the plant kingdom are, in descending order, Division, Class, Order, Family, Genus and Species. These ranks are called taxonomic groups, or "taxa" for short. While the above are the main taxa, most taxonomists would continue the classification to the level of sub-species, and even botanical races.

The rank of species denotes a group of individuals that share a long number of heritable characteristics, but which are mainly reproductively isolated, that is, the individuals of a species cannot usually interbreed by natural means with individuals of another species.
Although the rank of species is an important botanical classification, it is clear that the plants within a species can be very different. Farmers and growers need plants that are adapted to the environment in which they are grown and which are suited to the cultivation practices employed. Therefore, farmers and growers use a more narrowly defined group of plants, selected from within a species, called a plant "variety", (not necessarily, in the precise sense used in the UPOV Convention).

The definition found in the Treaty, which is similar in many respects to that found in the UPOV Convention, ${ }^{56}$ states that it is "a plant grouping within a single botanical taxon of the lowest known rank" (i.e. sub-species or botanical race).

56 The UPOV Convention defines "plant variety" in Article 1(vi) as:

"a plant grouping within a single botanical taxon of the lowest known rank, which grouping, irrespective of whether the conditions for the grant of a breeder's right are fully met, can be

- defined by the expression of the characteristics resulting from a given genotype or combination of genotypes,

- distinguished from any other plant grouping by the expression of at least one of the said characteristics and

- considered as a unit with regard to its suitability for being propagated unchanged;". 
Moreover, this definition clarifies that a variety's distinguishing and other genetic characteristics must remain unchanged through the process of propagation. In essence this reflects the 'distinctness', and 'stability' criteria set out in the UPOV Convention. If a plant variety grouping does not meet these criteria, it is not considered to be a "variety" for the purpose of the Treaty.

The term "variety" appears in the Treaty in two places in Article 6. Article 6.2(b) states that the sustainable use of PGRFA may include measures such as "strengthening research which enhances and conserves biological diversity by maximizing intra- and inter-specific variation for the benefit of farmers, especially those who generate and use their own varieties". Article 6.2(g) addresses "reviewing, and, as appropriate, adjusting breeding strategies and regulations concerning variety release".

It is interesting to note that the use of the term in Article 6(b) refers to farmers' varieties. These may, in fact, not always meet the criteria of stability referred to above. There may indeed be a lack of consistency between the definition of "variety" and the actual use of the term in the Treaty.

\section{"Ex situ collection" means a collection of plant genetic resources for food and agriculture maintained outside their natural habitat.}

Similar to the term "ex situ conservation", this term focuses on the physical collection of plant genetic resources held outside the environment where the plants developed their distinctive properties.

Most of the ex situ collections are held in national seed banks. The IARCs of the CGIAR hold about $12 \%$ of the world's ex situ collections of PGRFA ${ }^{57}$ and also have major crop improvement programmes, organized in collaboration with national programmes. They hold most of their ex situ collections 'in trust' for the benefit of the international community under agreements with FAO (see Box 10).

The term "ex situ collections" is used in Article 11, which addresses the coverage of the Multilateral System. Article 11.5 states that the Multilateral System shall include the plant and genetic resources for food and agriculture held in the ex situ collections of the IARCs of the CGIAR. Further reference to this issue is made in Article 15.1

\section{"Centre of origin" means a geographical area where a plant species, either domes- ticated or wild, first developed its distinctive properties.}

\section{"Centre of crop diversity" means a geographic area containing a high level of genetic diversity for crop species in in situ conditions.}

The terms "centre of origin" and "centre of diversity" or "centre of crop diversity" are used in the Treaty on two occasions. First, the Preamble acknowledges the past, present and future contributions of farmers, "particularly those in centres of origin and diversity". Second, Article 9.1 states that "the Contracting Parties recognize the enormous contribution that the local and indigenous communities and farmers of all regions of the world, particularly those in the centres of origin and crop diversity, have made and will continue to make".
As in the definition of "in situ" conservation, the definition makes reference to both wild and domesticated plant species. However, the emphasis in the definition is on the process of domestication and cultivation carried out by farmers and indigenous communities in the centres of origin and crop diversity, given the use of the phrase "first developed its distinctive properties". Nevertheless, it can still be difficult to determine in any particular case where a plant species first developed its distinctive properties.

More information about the centres of origin and centres of diversity can be found in Box 4. 


\section{Article 3 - Scope}

This Treaty relates to plant genetic resources for food and agriculture.

The scope of the Treaty is all PGRFA, as defined in Article 2. The Multilateral System of access and benefit-sharing established by the Treaty covers only those crops listed in Annex I that are under the management and control of the Contracting Parties, and in the public do- main. But the Treaty as a whole, including the substantive articles on conservation and sustainable use, international cooperation, the GPA, networks, the Global Information System, and the funding strategy, covers all PGRFA, and not just the crops listed in Annex 1. 
Explanatory Guide to the International Treaty on Plant Genetic Resources for Food and Agriculture 


\section{PART II - GENERAL PROVISIONS}

\section{Article 4 - General Obligations}

Each Contracting Party shall ensure the conformity of its laws, regulations and procedures with its obligations as provided in this Treaty.

This provision is of particular importance: while the rights and obligations under the Treaty are at the level of the Contracting Parties to the Treaty, the Multilateral System of access and benefitsharing will, in part, operate in practice at the level of individuals and within the sphere of private contract law and administrative procedures. Article 12.5, for example, provides that Contracting Parties shall ensure that an opportunity to seek recourse is available under their legal systems in case of contractual disputes arising under MTAs entered into within the framework of the Multilateral System. The obligation assumed by Contracting Parties under this Article is concrete and unqualified. However, the provision does not require each Contracting Party to adopt new laws and regulations, if it is satisfied that the obligations assumed under the Treaty can be implemented effectively under existing laws and regulations. 
Explanatory Guide to the International Treaty on Plant Genetic Resources for Food and Agriculture 


\section{Article 5 - Conservation, Exploration, Collection, Characterization, Evaluation and Documentation of Plant Genetic Resources for Food and Agriculture}

The provisions of Article 5 and 6 were basically non-contentious in the Treaty negotiations. They nevertheless are central to the Treaty and provide a modern framework for action on the conservation and sustainable use of PGRFA. ${ }^{58}$ The provisions expand and modernize the earlier provisions of the International Undertaking (Articles 3 and 4 in particular), develop a PGRFA application of themes that are set out in the CBD, and draw heavily on the areas identified in the GPA adopted by the International Technical Conference on Plant Genetic Resources in Leipzig in 1996 (see Box 15), especially those identified as priorities in decision III/11 of the CBD.

\subsection{Each Contracting Party shall, subject to national legislation, and in cooperation with other Contracting Parties where appropriate, promote an integrated approach to the exploration, conservation and sustainable use of plant genetic resources for food and agriculture and shall in particular, as appropriate:}

The chapeau of Article 5.1 calls for promoting an integrated approach to the exploration, conservation and sustainable use of PGRFA and, in this sense, draws together the provisions of Articles 5 and 6. None of the provisions of these two articles can stand alone: all of the actions required must form part of an integrated approach if they are to be effective. Survey and inventory activities, for example, would be of little use if subsequent action is not taken to collect, conserve and use the PGRFA.

This Article, like the Preamble, recognizes the principle of national sovereignty. It specifically states that while Contracting Parties shall promote the exploration, conservation and sustainable use of PGRFA, this nevertheless remains "subject to national legislation".

Normally any subjection of a Contracting Party's obligations under an international treaty to its national legislation is somewhat suspect. In this particular case, the insertion serves to indicate that, even where the actions are taken in cooperation with other Contracting Parties, the final decisions regarding the promotion of an integrated approach to the exploration, conservation and sustainable use of PGRFA lie with the state in which the plant genetic resources are to found.
This chapeau also acknowledges that in some cases cooperative action with other Contracting Parties may well be called for in order to achieve this goal.

It is important to note that this article only imposes a commitment to promote an integrated approach to the exploration, conservation and sustainable use of PGRFA. This obligation does not include the duty to regulate, although regulation would be one method by which countries could meet their obligation to "promote an integrated approach". The Treaty does not specify any particular action, so much as a general direction to be taken toward the goal to be attained. The manner in which this is to be attained is left largely to the discretion of the Contracting Parties. In this respect, paragraphs (a) to (f) serve as important elements required to achieve the goals established in this Article. These paragraphs focus on three fundamental conservation methods: on-farm conservation (paragraph (c)), in situ conservation (paragraph (d)), and ex situ conservation (paragraph (e)). They also address other steps involved in the conservation of PGRFA: surveying and inventorying (paragraph (a)), collection (paragraph (b)), and monitoring (paragraph (f)). The provisions concerning monitoring relate to all three methods of conservation. The steps and meas-

58 See generally, H. David Cooper, The International Treaty on Plant Genetic Resources for Food and Agriculture, in Reciel, Vol. 11, No. 1, 2002. 
ures set out these paragraphs are not intended to be exhaustive.

Finally, while the various paragraphs of Article 5.1 list a number of areas in which concrete action should be taken, the use of the words "as appropriate" indicates that each Contracting Party has a good deal of discretion in choosing the most appropriate ways for it to fulfill its general obligation.

(a) Survey and inventory plant genetic resources for food and agriculture, taking into account the status and degree of variation in existing populations, including those that are of potential use and, as feasible, assess any threats to them;

As is made clear in the first priority activity area under the GPA, rational conservation, both in situ and ex situ, begins with the surveying and inventorying of existing PGRFA. Contracting Parties need to know what resources exist in their countries before they are able to develop and elaborate policies and strategies for the conservation and utilization of PGRFA.

Countries that have ratified the CBD, pursuant to Article 7, have accepted responsibility to identify and monitor components of biological diversity important for its conservation and sustainable use. However, FAO Country Reports prepared in 1995 in connection with the formulation of the GPA indicated that little systematic work had been done in this regard for many crops and their wild relatives. The same principle applies to threats to PGRFA.

Surveys help identify areas with high natural plant genetic diversity and areas where plant genetic diversity is at risk, as well as the state of ex situ and national collections. These are the necessary factual bases that must be determined before Contracting Parties can proceed to minimize and eliminate threats to PGRFA, as provided for in Article 5.2. Surveying and inventorying will provide database information on the identification, characterization, evaluation and utilization of the existing germplasm pool of the country's wild array of flora. Such inventories are needed in order to develop appropriate conservation strategies and to ensure complementarity between in situ and ex situ conservation.

Paragraph (a) calls on Contracting Parties to pay attention in their surveys and inventories to both (i) the status of existing populations and (ii) the degree of variation within those populations. In this connection, it is uncertain whether the term "of potential use" qualifies the term "populations" or "PGRFA". If it were taken as qualifying the term "PGRFA", it would appear to be unnecessary and duplicative, given that PGRFA are defined in Article 2 as meaning genetic material of actual or potential value for food and agriculture. For this reason it could be argued that the term "of potential use" should be taken as qualifying the term "populations". Regardless of which interpretation is adopted, it remains difficult to ascertain which PGRFA, or which populations, may be of potential use, given that new ecological conditions and challenges may throw up the need for different characteristics that may not hitherto have proved to be of actual commercial value. The reference to "potential use" evidences the precautionary approach adopted by the Treaty.

The emphasis on the degree of variation in existing populations reflects the importance of intra-species as well as inter-species diversity of PGRFA for plant breeding programmes.

Much of the inventory/survey work recently performed has been undertaken in environments selected for their high diversity. Work in areas where modern cultivars have substantially replaced traditional cultivars has been limited. For the most part, the scale of many projects has been small and often only 3-6 crops have been selected for study, over several villages in 3 to 4 agroecological zones. The "Flora of Ethiopia and Eritrea" project, however, provides one example of an attempt to work at a wider scale. The project, which was initiated in 1980, aims to survey and inventory all the flora of Ethiopia and Eritrea. When completed, the Flora of Ethiopia and Eritrea will be a medium-sized to large African flora manual, covering approximately 7,000 species of vascular plants, of both indigenous and important cultivated species. ${ }^{59}$ The project has developed capacity on plant taxonomy and includes intra- 
specific crop diversity studies to help assess the amount and distribution of crop diversity. In general, however, PGRFA inventories and surveys have tended to provide a "snapshot" of plant genetic diversity rather than a good overall estimation that could be used for future monitoring.
It is important to note that Contracting Parties are also to assess any threats to PGRFA. This provides the rational for identifying the PGRFA to be collected under Article 5.1(b).

\section{(b) Promote the collection of plant genetic resources for food and agriculture and relevant associated information on those plant genetic resources that are under threat or are of potential use;}

Contracting Parties are expected to collect PGRFA that are under threat or are of potential use. PGRFA that are under active use or are not threatened need not be collected, although in practice they may well be included in ex situ collections so that samples can be made available for further research and breeding. Collection of plant genetic material began very early in history (see Harlan, Crops and Man), but in modern times peaked in the early 1970s. This was partly due to the need to enhance the contribution of PGRFA to new agricultural development. It was also in part sparked by the newly felt need to preserve genetic variability, threatened by the replacement of traditional varieties of the major crops by higher yielding cultivars. For the most part, collections are held in genebanks. Supporting planned and targeted collecting of PGRFA is a priority activity area of the GPA.

This paragraph addresses not only the PGRFA per se, but also "relevant associated information". Ex situ collections of PGRFA are more useful for plant breeding if the breeders have full information on the samples collected and clues as to the possible traits they may exhibit. The term "relevant associated information" is not defined, but Article 12(c), in connection with the Multilateral System, refers to "all available passport data and, subject to applicable law, any other associated available non-confidential descriptive information". Elements that could constitute "relevant associated information" are also discussed under Article 5.1(e).

It is unclear from a textual reading of this paragraph whether the qualifying clause "that are under threat or are of potential use" refers to PGRFA that are to be collected in general, or to those PGRFA on which relevant associated information is to be collected. However, the sense of the paragraph would sustain the former interpretation rather than the latter, despite the lack of commas surrounding the words "and relevant associated information on those plant genetic resources".

(c) Promote or support, as appropriate, farmers and local communities' efforts to manage and conserve on-farm their plant genetic resources for food and agriculture;

This paragraph and the subsequent paragraph, separate in situ conservation into the distinct activities of on-farm conservation and in situ conservation of wild PGRFA (see Paragraph (d)). This is an example of greater specificity in the Treaty as compared to the CBD, and reflects the treatment of in situ conservation in the GPA. This is the first time that the specific role of farmers and local communities in conserving genetic resources has been recognized in a legally binding international treaty.

Paragraph (c) calls for promotion or support of farmers and local communities efforts to manage and conserve their PGRFA on-farm. Where such efforts are lacking, then the Con- tracting Parties should strive to promote them. Where they do exist, the Contracting Parties should support those efforts, presumably through technical and financial support. The extent to which this support is provided, and the means by which it is provided, is left to the individual Contracting Parties to determine.

Various projects serve as examples of the kind of support that can be provided:

- In Ethiopia, the United Nations Development Programme(UNDP)/GEF supported a project to promote "A Dynamic Farmer-based Approach to the Conservation of Plant Genetic Re- 
sources". ${ }^{60}$ After constructing 12 community genebanks, the project is now working to link these to locally used seed storage systems in order to strengthen the seed supply and enhance its viability. This helps to preserve the traditional storage system and link it to national research stations, universities and ministries.

- The Biodiversity Use and Conservation in Asia Program (BUCAP) is an initiative that addresses the problems of narrowing genetic diversity in rice in Asia and inadequate farmers participation in agricultural development. It is currently being implemented in Bhutan, Laos and Vietnam.

Active measures must be taken to promote or support on-farm conservation of PGRFA. Modern plant breeding has been remarkably successful in helping raise yields, and in improving resistance to pests and diseases and quality of food products, especially in favourable environments. Farmers choose crops and cultivars for planting based on their unique set of production and consumption conditions. Their choices also determine their level of on-farm conservation. Farmers' planting decisions are driven by agro-ecological factors, market and socio-economic factors and availability of planting materials. For some farmers, particularly those in highly heterogeneous production areas, or where market development is very limited, maintaining a diverse set of plant genetic resources is the most efficient means of managing their farming system. For others however, the adoption of a more narrow set of plant genetic resources may best serve their interests, leading to a lower level of crop diversity. In the first instance there is a high degree of compatibility between the private interest of the farmer, and the public interest in conserving genetic resources and evolutionary processes for possible future use. In the second case, however, public and private interests diverge, and some sort of intervention may be necessary to provide farmers with the necessary incentive to conserve plant genetic resources on-farm.

On-farm conservation is important because, in addition to genetic diversity, it preserves evolutionary interactions necessary for the continuous adaptation to shifting environmental conditions, such as changes in pest populations or climate. It is the best way to uphold the knowledge of the farming systems in which the crops have evolved. Finally, on-farm conservation provides a continuing source of germplasm for ex situ collections.

\section{(d) Promote in situ conservation of wild crop relatives and wild plants for food produc- tion, including in protected areas, by supporting, inter alia, the efforts of indigenous and local communities;}

Natural ecosystems hold important PGRFA, including endemic and threatened wild crop relatives and wild plants that produce food. This genetic diversity, because of interactions that generate new biodiversity, is potentially an economically important component of natural ecosystems and cannot easily be maintained ex situ. Where natural ecosystems are not managed sustainably, erosion of PGRFA will inevitably result.

The focus of this paragraph is the "in situ conservation of wild crop relatives and wild plants for food production". The wild relatives of crop plants, which include the progenitors of crops, as well as species more or less closely related to them, constitute an increasingly important resource for improving agricultural production and for maintaining sustainable agroecosystems. While most farmers and plant breeders normally prefer to work with existing cultivars or advanced breeding materials, as they are more productive and relatively easier to interbreed, they sometimes need to search further afield to find specific traits when faced with new or evolved pests and diseases or other ecological challenges. www.gefweb.org/COUNCIL/GEF_C15/GEF_C15_Inf.21.doc. 
Using conventional methods, wild relatives of crops are generally more difficult to work with, in that undesirable traits already present may be difficult to separate from the desirable trait. But where they are used, they can have quite dramatic results. Historically, they have contributed many useful genes to crop plants, and modern varieties of most crops now contain genes from their wild relatives. In modern varieties of potatoes, wheat, barley, rice, maize and oat, among other crops, traits from wild relatives have improved productivity as well as tolerance to pests, disease and difficult growing conditions.

Germplasm collection of wild crop relatives serves a multitude of purposes. They are gene repositories, preserving alleles of potential agronomic utility that have not been captured in the gene pool of elite cultivars, and provide reference material for which a body of information may be accumulated through study by different researchers. The wise conservation and use of crop wild relatives are essential elements for increasing food security, eliminating poverty, and maintaining the environment.

With the increased use of modern (or laboratory) biotechnology, it is becoming increasingly common to use genes from wild crop relatives and transfer them to cultivated varieties. This therefore increases the value of such wild species to PGRFA.

In addition to domesticated crops, wild biodiversity provides a diverse range of edible plant and species that have been and continue to be used as wild sources of food. About 7000 species of plants have been used for human food at one time or another. Wild sources of food in general remain particularly important for the poor and landless, and are especially important during times of famine, insecurity or conflict, where normal food supply mechanisms are disrupted and local or displaced populations have limited access other forms of nutrition. Even at normal times wild foods are often important in complementing staple foods to provide a balanced diet.
As stated previously, in situ conservation aims to include not only the conservation of the genetic resources, but also elements of the environment in which they have developed.

The reference to "protected areas" is also important. Efforts need to be made to ensure the management of wild crop relatives and other useful species for food and agriculture within protected areas. There may, of course, be issues to resolve concerning the complementary management of specific species of value to food and agriculture and other forms of wildlife.

The paragraph specifically acknowledges the efforts of indigenous and local communities. At the same time, there is a clear statement that supporting the efforts of local communities is only one of many ways in which in situ conservation can be promoted.

The United Nations Educational, Scientific and Cultural Organization's (UNESCO) work in the Man and the Biosphere programme is an example of supporting a number of activities that are of particular importance for the conservation of genetically important wild crop relatives situated in forest habitats (for example, the Mazatlan Biosphere Reserve in Mexico for wild perennial teosinte/maize).

Other examples include:

- The International Network for the Improvement of Banana and Plantain (INIBAP) supported projects on in situ conservation of banana and plantains in the Great Lakes area in Uganda and Tanzania. $^{61}$

- A multi-partner project on conservation and improvement of crop production supported by the McKnight Foundation supports work by University of Guadalajara and by the Instituto Manantlan de Ecología y Conservación de la Biodiversidad (IMECBIO). ${ }^{62}$

- The Mexico Country component of the International Plant Genetic Resources Institute(IPGRI) global project "Streng-

61 See www.inibap.org/presentation/onfarm-conservation_eng.htm.

62 Conservation of Genetic Diversity and Improvement of Crop Production in Mexico: A Farmer-Based Approach. The project entails (1) a description and analysis of the relationships between farmer knowledge, socio-economic factors, and genetic diversity in the Mexican milpa agroecosystem; (2) a 
thening the Scientific Basis of In Situ Conservation of Agricultural Biodiversity On-Farm" in the Yucatan, a project on shade coffee plantations and their associated biodiversity. ${ }^{63}$

(e) Cooperate to promote the development of an efficient and sustainable system of $e x$ situ conservation, giving due attention to the need for adequate documentation, characterization, regeneration and evaluation, and promote the development and transfer of appropriate technologies for this purpose with a view to improving the sustainable use of plant genetic resources for food and agriculture;

A large amount of PGRFA vital to world food security is stored ex situ. Most of this PGRFA is stored in national genebanks. ${ }^{64}$ Important collections are also held by the IARCs of the CGIAR. There is value, and a degree of security, in the diversity of the collections, but many of the samples held are duplicates of samples held within the same genebank and many collections are short of funds and in a perilous condition. This paragraph calls for the development of a system of ex situ conservation that is efficient and sustainable. The development of such a system requires international cooperation: an efficient and sustainable system of $e x$ situ conservation cannot be achieved by focussing exclusively on individual national collections. The GPA notes the need for a more rational system of genebanks that avoids, in particular, unnecessary and unintended duplication. Indeed the GPA emphasizes that rationalizing the present system and making it more efficient could reduce costs and release money for expanding ex situ conservation activities. The GPA states the aim as being the development of an efficient goal-oriented, economically efficient and sustainable system of ex situ conservation. The principle of cooperation is also explicitly mentioned in Article 16 of the Treaty, which encourages cooperation in international PGRFA networks. The wording of Article 5(e) picks up this theme indicating that it is not enough for Parties to act separately to promote ex situ conservation.
In an effort to raise the quality of ex situ collections, the FAO CGRFA has adopted, and will keep under review, a series of Technical Standards for Genebanks, covering wild, forest and crop species. The standards are designed in particular to minimize the loss of genetic integrity in seed accessions during storage and regeneration. The standards were endorsed by the FAO Commission in order that they might acquire universal value and be more easily adopted by countries. In this sense the standards, while not binding, will be an essential guide for national collections and the implementation of this paragraph of the Treaty. Under the in-trust Agreements between the CGIAR Centres and FAO placing collections of plant germplasm under the auspices of FAO, signed in 1994, the Centres undertake to manage and administer the in-trust germplasm in accordance with internationally accepted standards, including, with respect to the storage, exchange and distribution of seeds, the International Genebank Standards endorsed by the FAO Commission. ${ }^{65}$ Article $15.1(\mathrm{~d})$ of the Treaty requires that a similar provision be included in the new agreements to be entered into between the Governing Body and the CGIAR Centres.

Ensuring "adequate documentation, characterization, regeneration and evaluation" is fundamental to an efficient system of ex situ conservation, if it is to achieve its objective of "improving the sustainable use of plant genetic

characterization of the structure of crop biodiversity and the magnitude of gene flow from wild or cultivated relatives to maize, bean, and squash crops; and (3) the development and evaluation of on-farm breeding methods to improve the productivity of local landrace germplasm through mass selection of introgression from improved germplasm (maize) or wild or cultivated relatives (bean and squash). See http://www.grcp.ucdavis.edu/projects/projdet.htm.

See web.idrc.ca/en/ev-4937-201-1-DO_TOPIC.html.

According to the first Report on the State of the World's Plant Genetic Resources for Food and Agriculture, some $88 \%$ of global PGRFA held ex situ is maintained in national collections.

For a more detailed description of the in-trust agreements, see Box 11. 
resources for food and agriculture". "Documentation" refers to the totality of the documentation that should be available for genebank accessions, including that related to the characterization, regeneration, and evaluation of the individual accessions. "Characterization" refers to the categorization of data on highly heritable characteristics of genebank accessions, such as colour of flowers, that are constant in any environment, and would include information on the nature and extent of genetic diversity obtained using various technologies, including molecular techniques. "Regeneration" refers to the need to grow out stored seeds periodically to ensure that they remain viable and to ensure that there is sufficient seed for conservation and redistribution. "Evaluation", on the other hand, relates to the assessment of the agronomic characteristics of the material, including disease or drought resistance, including by molecular technologies. To a large extent, the accessibility of germplasm, and its usefulness for farmers and plant breeders, will depend on the adequacy of the documentation, characterization, regeneration and evaluation of that germplasm. A recently published guide on effective germplasm collection management by IPGRI, FAO and others ${ }^{66}$ provides information on how best to conduct information management, characterization, regeneration and evaluation activities.

The paragraph also emphasizes that the development of an effective system of ex situ conservation requires the development and transfer of appropriate technologies. This is one of the objectives of Priority Activity Area 8 of the GPA, which emphasizes the needs of developing countries in this regard, and calls for strengthening field genebanks and enhancing the conservation activities of botanic gardens. The GPA also puts emphasis on the need to develop improved conservation methods including appropriate in vitro and cryopreservation and in particular low cost techniques appropriate to local operating conditions. There are many nonorthodox species for which there are not yet appropriate and effective conservation technologies. Contracting Parties should therefore promote the development of such technologies in their own countries, in particular because technologies transferred from temperature climates may not always be appropriate for condi- tions in tropical countries. The final phrase of the paragraph states the objective of improving the sustainable use of PGRFA. It is unclear whether this refers only to the development and transfer of technology or to the entire contents of the paragraph.

Promoting the development of ex situ conservation requires financial as well as technological support. In this context, an initiative is underway to establish a fund (the Global Crop Diversity Trust) to provide financial support for the development of an efficient and sustainable system of ex situ conservation, including upgrading the capacities of institutions, including genebanks, to meet international standards for the various activities carried out for ex situ conservation (see Box 20). The Global Crop Diversity Trust would operate at the international level as an essential element of the Treaty's funding strategy (see Article 18).

Other support mechanisms already exist at the national level. For example, Cuba's National Diversity Strategy and Action Plan promotes the establishment of mechanisms to allow validation, use and dissemination of genetic material included in ex situ collections of plants of economic importance. In addition, there is an on-going project to understand (1) whether home gardens retain varietal and species diversity that is undergoing genetic erosion in other production systems, (2) how commercialisation and crop introduction or improvement affect species and varietal diversity in home gardens and, (3) what targeted development interventions enhance home garden biodiversity and improve family nutrition and income.

To the extent that such mechanisms do not already exist at the international or national levels, the paragraph would require the Contracting Parties to cooperate to establish them.

Together, the forgoing paragraphs (c), (d) and (e) can contribute to achieve target IX of the CBD's Global Strategy for Plant Conservation: "70 per cent of the genetic diversity of crops and other major socio-economically valuable plant species conserved, and associated indigenous and local knowledge maintained". 
(f) Monitor the maintenance of the viability, degree of variation, and the genetic integrity of collections of plant genetic resources for food and agriculture.

The need to develop an efficient and sustainable system of ex situ collections of PGRFA was addressed in the preceding paragraph. The current paragraph seeks to ensure that Contracting Parties continue to monitor the viability and genetic variation and integrity of collections of PGRFA. Such monitoring might include activities such as measuring seed moisture content and the germinability of genebank accessions at regular intervals, characterization during regeneration process to verify if progenies are true-to type, conducting baseline studies to determine the extent of variation in genebank accessions, assessment of genetic variation and maintenance integrity using molecular markers at each regeneration, and monitoring of germplasm management procedures in genebanks to determine whether materials are properly conserved. Ultimately, the purpose of this paragraph is to ensure that the diversity of any given accession is conserved, either as seed, tissue or plants. To assist in this purpose, IPGRI produces and provides freely many publications to help genebanks in these important conservation and management activities. ${ }^{67}$
Technologies that can be used to study the degree of variation of collections and monitor genetic integrity include morphological characterization as well as molecular DNA techniques such as RFLP, RAPD, AFLP, PCR-based techniques and micro-arrays. Analysis of isoenzyme and other protein variations are not as widely used at present as they used to be.

The above paragraph is aimed mainly at $e x$ situ collections. However, it is also important to implement appropriate monitoring for in situ material, e.g. relating to the effects of the introduction of new alien material, the effects of introduction of new genetic material by farmers as well as of gene flow and subsequent introgression from cultivated as well as wild related taxa, including that of genetically modified elements. Guidelines and other technical publications are being developed by IPGRI and other research institutes.

\subsection{The Contracting Parties shall, as appropriate, take steps to minimize or, if possible, eliminate threats to plant genetic resources for food and agriculture.}

While Article 5.1 focuses on the action that Contracting Parties must take to survey, inventory, collect and conserve PGRFA, particularly those under threat, and to identify threats, Article 5.2 places a positive obligation on the Contracting Parties to minimize or, if possible, eliminate those threats. Major causes of loss of diversity of PGRFA include changing agricultural practices and loss of agricultural land. The use of genetically modified organisms in centres of diversity may also be regarded as a possible threat to plant genetic resources. Possible ways of mitigating the threats include collecting resources for ex situ maintenance, the development of in situ conservation actions, adoption of agricultural practices which enhance the use of a diverse mix of varieties and the maintenance of genetic diversity in crop varieties by broadening the genetic base of materials in production. The GPA describes and promotes many of these activities. A technical manual on germplasm collecting provides in-

67 Examples include: "Procedures for Handling Seeds in Genebanks", Practical Manuals for Genebanks: No. 1, (1985) IPGRI, Rome, Italy; "Handbook of Seed Technology for Genebanks", in Handbooks for Genebanks No. 2 and No. 3, (1985) IBPGR, Rome, Italy; and several Technical Bulletins and handbooks published by IPGRI, e.g. "A protocol to determine seed storage behaviour", Technical Bulletin No. 1, (1996) IPGRI, Rome, Italy; “Accession management. Combining or splitting accessions as a tool to improve germplasm management efficiency”, Technical Bulletin No. 5, (2002) IPGRI, Rome, Italy; and "A guide to effective management of germplasm collections", IPGRI Handbook for Genebanks No. 6 (2003). 
formation on collecting procedures to promote expansion of ex situ collections, while ensuring that wild collection does not threaten the conservation status of wild varieties. ${ }^{68}$ Also the earlier cited "A guide to effective management of germplasm collections" IPGRI Handbook for Genebanks No. 6 (2003) provides useful approaches and management suggestions on how to minimize and/or eliminate threats to PGRFA in genebanks.

In order to implement this provision the Contracting Parties will need to develop proce- dures for identifying and quantifying threats to plant genetic resources and systems of monitoring changes in the conservation status of PGRFA. This will allow for the timely development of procedures to minimize the effect of threats and, possibly, take remedial action to eliminate them. Some work on indicators has been undertaken $^{69}$ and work is continuing by FAO and IPGRI within the framework of the CBD Strategy (e.g. Resolution COP7/30) and the CBD Programme of Work on Agricultural Biodiversity. 
Explanatory Guide to the International Treaty on Plant Genetic Resources for Food and Agriculture 


\title{
Article 6 - Sustainable Use of Plant Genetic Resources
}

\author{
6.1 The Contracting Parties shall develop and maintain appropriate policy and legal \\ measures that promote the sustainable use of plant genetic resources for food and \\ agriculture.
}

\subsection{The sustainable use of plant genetic resources for food and agriculture may include such measures as:}

This Article requires parties to develop and maintain appropriate policy and legal measures that promote the sustainable use of PGRFA. The obligation in Article 6.1 is absolute and does not contain any elements that qualify it, such as the reference to national legislation in Article 5.1. On the other hand, the list of measures given in Article 6.2 is illustrative only, providing examples to the Contracting Parties of possible measures that they can use to achieve their obligations under paragraph 6.1 (as underscored by the qualification "as appropriate"). As with Article 5, this Article draws heavily on the priority activity areas set out in the GPA, in particular: broadening the genetic base of major crops; increasing the range of genetic diversity available to farmers; strengthening capacity to develop new crops and varieties that are specifically adapted to local environments; exploration and promotion of the use of underutilized crops, and deployment of genetic diversity to reduce crop vulnerability.

In this sense, Article 6 and Article 5.2 provide a good basis for a policy that stimulates agriculture that is both environmentally friendly and has a broad genetic basis.

The Article is much more specific than the corresponding Articles in the CBD. Article 6 of the CBD, appropriately entitled "general measures", requires each Contracting Party to develop or adapt "national strategies, plans or programmes" to reflect the measures set out in the Convention for the conservation of biodiversity and the sustainable use of its components.
"Strategies, plans or programmes" are not defined in the text of the CBD, but have been refined by the Contracting Parties, though COP decisions and national implementation. As currently understood, CBD Article 6 refers to "National Biodiversity Strategies and Action Plans" (NBSAPs), which have been adopted by most Contracting Parties. NBSAPs are intended to promote inter-sectoral cooperation, toward the goal of "sustainable use", as set out in Article 10 of the CBD.

For purposes of applying the NBSAP concept within the Treaty, those terms are often seen as sequential:

- Strategies set out specific recommendations or steps for national actions to conserve biodiversity and sustainable use of its components;

- Plans explain how a strategy's specific recommendations will be achieved; and

- Programmesimplement strategies and plans.

Sustainable use of PGRFA is crucial to both short-term and long-term food security. PGRFA support the livelihood of every person on Earth. They are the plant breeder's most important raw material and the farmer's most essential input. Properly managed, these resources need never be depleted, for there is no inherent incompatibility between conservation (Article 5) and utilization (Article 6).

(a) pursuing fair agricultural policies that promote, as appropriate, the development and maintenance of diverse farming systems that enhance the sustainable use of agricultural biological diversity and other natural resources;

The focus of this paragraph is on promoting diverse farming systems that enhance agricultural biodiversity. Farming systems relate to the whole farm rather than its individual elements; they are driven as much by the overall welfare of farming households as by goals of yield and profitability. Farming systems are closely linked to livelihoods because agriculture remains the 
single most important component of most rural people's lives as well as playing an important role in the lives of many people in peri-urban areas. Thus, in this paragraph, the Treaty reaches beyond its scope of PGRFA to address broader issues of agricultural biodiversity, including at the farming system level.

Farming systems involve a complex combination of inputs, managed by farming families but influenced by environmental, political, economic, institutional and social factors. Research and extension institutions are increasingly aware that a holistic approach, drawing on both local and external knowledge, is necessary to address poverty and sustainability effectively.

The paragraph calls for policies that promote diversity in farming systems. It also calls for the promotion of farming systems that enhance the sustainable use of agricultural diversity.

The addition of the reference to "fair" agricultural policies is a reference to the need to ensure that agricultural policies do not have distorting effects on trade through the granting of subsidies disguised as measures to promote traditional farming and sustainable agriculture.

\section{(b) strengthening research which enhances and conserves biological diversity by maxi- mizing intra- and inter-specific variation for the benefit of farmers, especially those who generate and use their own varieties and apply ecological principles in maintain- ing soil fertility and in combating diseases, weeds and pests;}

This paragraph draws on Priority Activity Area 11 of the GPA: "Promoting Sustainable Agriculture through Diversification of Crop Production and Broader Diversity in Crops". The paragraph draws particular attention to the need to ensure the highest degree of intra-specific variation or diversity (Priority Area 11), as well as maximizing variation between species (Priority Area 12: "Promoting Development and Commercialization of Under-utilized Crops and Species"). Traditional farming practices and farmers management of their landraces sometimes increase intra-specific variation as a means of ensuring more stable yields and greater resistance to diseases and pests as well as greater adaptability to new environmental stresses. It is important to strengthen research to determine which elements of these practices are robust enough to persist through changes in farming practices.

Diversity in cropping systems is often of particular importance from the standpoint of pest control. Short rotations of crops with a uniform genetic base are particularly vulnerable to pest pressures. The two prime examples of this vulnerability are the tragic potato blight
(Phytophthora infestans) epidemic in Ireland in the 19th century, and more recently, the corn leaf blight (Helminthosporum maydis) epidemic of the 1970s in the United States. This paragraph therefore demonstrates the importance of maintaining a diverse genetic base as a resource for farmers and plant breeders to develop crop varieties resistant to various pest organisms. More diverse farming systems may be less vulnerable to pests and diseases and may offer greater food security. Traditional farming systems tend to be more agriculturally diverse. Recent studies have revealed the extent to which traditional farmers seek to conserve and enhance the genetic diversity of their landraces as a means of ensuring yield stability and resistance to disease and changing environmental conditions. Seed is often brought in from outside the immediate farming area as a means of enhancing the diversity of local crops; in some societies such seed exchanges are sanctioned by religious or other rituals. ${ }^{90}$ Priority Activity Area 11 stresses the need to

"support efforts to identify those activities used in plant breeding, plant research and farming systems that foster on-farm diver- 


\section{Box 5. Systems of Supply of Seed and Other Propagating Material, and the Sustainable Utilization of PGRFA}

Seed systems that supply seed and other propagating material such as clones, are critical in determining farmers' choice of planting material, and thus utilization patterns of crop genetic resources. Such systems are formed by the interaction between farmers' demand for crop varieties and the traits they embody, and the available supply of such varieties. Seed and propagating material systems impact on the degree of choice farmers have in selecting varieties - which in turn affects the degree to which the public good of diversity conservation is provided and ultimately the sustainability of the system of utilization. Better understanding of how such systems impact farmers' choices is important in designing efforts to promote sustainable utilization.

On the supply side, it is important to understand the way in which seeds and other propagating material are produced, including both genetic content (e.g. breeding) and physical quality (seed and clonal production), as well as the way in which they are distributed or made available (markets, extension packages, social exchange networks), and the costs at which they are made available. The demand side of the system is comprised of the individual and overall portfolio of characteristics or services which farmers desire from seeds, clones and the genetic resources they embody, as well as the physical attributes of the delivery mechanism, e.g. seed and clonal quality, and the farmers' ultimate willingness to pay for such goods either in cash or kind.

Farmers, particularly small farmers, make use of multiple channels for sourcing their seed. In recent literature, these channels been considered as belonging to one of two broad seed systems: the "formal" seed system, and the "informal" system. The latter is variously described as the "local", "traditional" or "farmer" seed system. 71

The formal seed system is straightforward to characterize, as it is deliberately constructed and involves a chain of activities leading to clear products: certified seed of verified varieties. The chain usually starts with plant breeding, resulting in different types of varieties and hybrids, and promotes materials towards formal variety release and maintenance. Formal regulations or protocols aim to maintain varietal identify and purity, as well as to guarantee physical, physiological and sanitary quality. Seed marketing takes place through officially recognized seed outlets, either commercially, or via national agricultural research systems. The central premise of the formal system is that there is a clear distinction between what is "seed" and what is "grain".

The informal seed system is basically what the formal system is not. Activities tend to be integrated and locally organized, and the informal system embraces most of the other ways in which farmers themselves produce, disseminate and access seed: directly from their own harvest; through barter among friends, neighbours and relatives, and through local grain markets or traders. What characterizes the local system most is its flexibility. The same general steps take place in the informal system as in the formal, but they take place as integral parts of farmers' grain production rather than as discrete activities. The steps also do not flow in a linear sequence, and are not monitored or controlled by government regulations. Rather, they are guided by local technical knowledge and standards and by local social structures and norms, including market forces. Varieties may be landraces or mixed races.

India, inferred from gene flow data. Abstract from the XVIth EUCARPIA Congress, Plant Breeding: Sustaining the Future, Edinburgh, Scotland, 10-14 September 2001.

Each of these terms has a particular nuance, and each is problematic. "Informal" systems are not purely "farmer" systems in that markets are important. Neither are they purely "local" since both markets, and exchange through social networks connect various localities. Finally, they are not "traditional" in the strict sense, because they are constantly evolving. "Formal" and "informal" systems should not be equated with formal and informal sectors. 
sity. Such research might include a review of non-homogenous farming systems such as those based on intercropping, polycropping, integrated pestmanagement, and integrated nutrient management, for their possible wider applicability, as well as research to develop appropriate plant breeding methodologies.... Support should be encouraged for developing improved tools and methodologies for assessing genetic vulnerability and identifying, if possible, the ideal equilibria in crops between genetic uniformity and diversity consistent with practical, technical andeconomic considerations that sustain ecosystems." (GPA, paragraphs 174, 185 and 186)

(c) promoting, as appropriate, plant breeding efforts which, with the participation of farmers, particularly in developing countries, strengthen the capacity to develop varieties particularly adapted to social, economic and ecological conditions, including in marginal areas;

This paragraph calls for participatory plant breeding that develops varieties particularly adapted to local social, economic and ecological conditions. It expands on Priority Area 2 of the GPA.
The reference to the participation of farmers links up with the right to participate in decision-making set out in Article 9.2(c). The paragraph focuses in particular on farmers in developing countries.

\section{(d) broadening the genetic base of crops and increasing the range of genetic diversity available to farmers;}

This paragraph reflects the concerns of Priority Activity Area 10 of the GPA ("Increasing genetic enhancement and base-broadening efforts"). ${ }^{72}$ Farmers over time have developed landraces that are particularly adapted to local conditions, including social, economic and ecological conditions, and incorporate a large degree of intra-specific genetic diversity. Intraspecific diversity (i.e. the diversity within each species as opposed to the diversity between species) is particularly important in allowing crops to resist disease or pests, or to respond to local conditions of drought, excessive humidity or other current or future ecological challenges. This is particularly important for crops on marginal lands.

As noted above, the introduction of new and improved plant varieties may increase genetic uniformity and, as local farmers turn to new varieties for greater productivity, reduce the diversity of their crops. There is thus a need to broaden the genetic base of crops, including by incorporating some of the genetic traits present in the landraces hitherto used in those localities, to the extent they allow those landraces to respond better to particular local conditions.
Farmers using traditional methods will tend to undertake such base-broadening activities through interbreeding new improved varieties with their own local crops. However, from the perspective of any individual farmer, breeder, company or institute, the costs of incorporating diverse germplasm into varieties that have already been improved may be excessive and may well outweigh the benefits they can realize. Such benefits will accrue, not only to the individual farmer, but also to the local community and to society in general.

Public support is necessary to promote these plant breeding efforts where the private sector cannot accomplish this on its own. However, due to their local knowledge and access to locally adapted landraces, the participation of local farmers is particularly useful. Approaches identified in the GPA include introgression of useful agronomic traits identified through characterization or evaluation into locally adapted or elite material for further use in breeding programmes, and base-broadening of breeders' material through incorporation of wider genetic diversity in general and locally adapted traits in particular.

72 See also D. Cooper et al. 2001. Broadening the genetic base of crop production. CABI, FAO and IPGRI. 
These activities are closely related to the promotion of the expanded use of local and locally adapted crops and underutilized species which are the subject of Paragraph (e) below, as the incentive for producing such crops is much greater if markets can be found for them.

Increasing the diversity of materials available to farmers is one of the underlying objectives of the Treaty. Ultimately it is the farmers themselves that will need to make use of this diversity to improve their crops and protect them against yield fluctuations and diseases. While no mechanism is expressly specified for increasing the range of such material available to farmers, it is clear that the other components of the Treaty (including international cooperation, technical assistance, the ex situ collections of PGRFA held by the IARCs, and, of course, the Multilateral System) can be instrumental. Modalities may include, for example, facilitating farmers' access to ex situ collections and creating market conditions that favour such availability.

\section{Box 6. Implementation of Farmers' Rights at the national level}

At the national level, some proposals for national legislation have reaffirmed support for the concept of Farmers' Rights. An example of the possible implementation of such rights at the national level is offered by the Protection of Plant Varieties and Farmer's Rights Act 2001 (the "Act"), approved in India in August 2001. Farmers' Rights are not specifically defined. However, Section 31 of the draft states that:

Nothing contained in this Act shall affect the right of a farmer to save, use, exchange, share or sell his farm produce of a variety produced under this Act ... provided that a farmer shall not be entitled for such right in case where the sale is for the purpose of reproduction under commercial marketing arrangements.

Another feature is the Act's efforts to put Farmers' Rights at a par with Plant Breeders' Rights. The Act gives farmers the entitlement, like industrial breeders, to apply for registration of a plant variety. Section 16 (d) includes "any farmer or group of farmers or community of farmers ..." in the list of applicants for registration. Farmers are entitled not only to apply for registration of a new variety but also of a farmer's variety (Section 39(1)(i)). Under the definition of farmer's variety the Act includes "(i) a variety which has been traditionally cultivated and evolved by the farmers in their fields; or (ii) a wild relative or landrace of a variety about which the farmers possess the common knowledge" (Section 2(k)). The Act gives protection not only to newly-developed varieties but also to existing varieties ('extant variety' in the wording of the Act - Section 2(j)). According to Section 39(1)(i), the registration is subject to the same UPOV-derived criteria that apply to commercial breeders. However, at time of publication, the governing body of UPOV had not yet stated whether the provisions of this Act were compatible with the UPOV Convention.

In the same Act a fundamental component of Farmers' Rights is the benefit-sharing mechanism. The Act sets out two channels for providing benefits to traditional farmers. The first is inserted in the process of registration of a variety. The Protection of Plant Varieties and Farmers' Rights Authority publishes the contents of the certificate of registration and invites claims on benefit-sharing to the variety. Any person or group of persons or non-governmental organisation is entitled to claim such benefit-sharing. A procedure is established in order to grant the breeder the right to opposition to such claim. The final decision on the amount of benefit-sharing is reserved to the Authority, that shall take into consideration both the extent and nature of the use of the genetic material of the claimant in the development of the variety and the commercial utility and demand in the market of the variety. The sum shall be deposited by the breeder of the variety in the National Gene Fund (Section 26, sub-sections 1 to 6). The second benefit-sharing channel is set out in the provisions included in the Farmers' Rights section. Section 39(1)(iii) reads as follows:

"[a farmer] who is engaged in the conservation of genetic resources of land races and wild relatives of economic plants and their improvement through selection and preservation shall be entitled ...

continued next page 
for recognition and reward from the National Gene Fund ... provided that material so selected and preserved has been used as donors of genes in varieties registrable under this Act."

Entitled to file claims for recognition and reward of contributions are any person, group of persons or any governmental or non-governmental organisation on behalf of any village or local community. The claims are to be filed in any centre notified with the previous approval of the central Authority. The centre is responsible for verifying ' ... if it is satisfied that such village or local community has contributed significantly to the evolution of the variety which has been registered ...'. Once the central Authority has received the report from the centre and the breeder has been given the opportunity to file objections, an order may be issued to grant a sum of compensation to the claimant. The breeder of the variety shall deposit the prescribed sum in the National Gene Fund (section 41, sub-sections 1 to 4).

Another interesting example of possible implementation is the "African Model Legislation for the Recognition and Protection of the Rights of Local Communities, Farmers and Breeders, and for the Regulation of Access of Genetic Resources", developed by the Organization of African Unity (OAU) in 2000, but which however has not been implemented by any African country. Part V of the draft defines the concept and the scope of Farmers' Rights:

24(1) Farmers' Rights are recognized as stemming from the enormous contributions that local farming communities, especially their women members, of all regions of the world, particularly those in the centres of origin or diversity of crops and other agrobiodiversity, have made in the conservation, development and sustainable use of plant and animal genetic resources that constitute the basis of breeding for food and agriculture production; and

(2) For farmers to continue making these achievements, therefore, Farmers' Rights have to be recognized and protected.

Article 26 defines the scope of the Farmers' Rights:

26(1) Farmers' Rights shall, with due regard for gender equity, include the right to:

a) the protection of their traditional knowledge relevant to plant and animal genetic resources;

b) obtain an equitable share of benefits arising from the use of plant and animal genetic resources;

c) participate in making decisions, including at the national level, on matters related to the conservation and sustainable use of plant and animal genetic resources;

d) save, use, exchange and sell farm-saved seed/propagating material of farmers' varieties;

e) use a new breeders' variety protected under this law to develop farmers' varieties, including material obtained from genebanks or plant genetic resource centres; and

f) collectively save, use, multiply and process farm-saved seed of protected varieties.

(2) Notwithstanding sub-paragraphs c) and d), the farmer shall not sell farm-saved seed/ propagating material of a breeder's protected variety in the seed industry on a commercial scale.

(3) Breeders' Rights on a new variety shall be subject to restriction with the objective of protecting food security, health, biological diversity and any other requirements of the farming community for propagation material of a particular variety.

Among other examples, in 2002, the Republic of Philippines enacted a new Plant Variety Protection Act. ${ }^{73}$ The Act provides for the protection of plant varieties in the Philippines, along the lines of UPOV 
1991 (see Box 9). It is designed to protect and secure the exclusive rights of plant breeders with respect to new plant varieties they have bred, discovered or developed that meet the criteria of being new, distinct, uniform and stable. Certificates of Plant Variety Protection may be issued providing protection for 25 years, for trees and vines, and 20 years for other types of plant. Section 43 of the Act provides for exceptions to plant variety protection. These include the "traditional right of small farmers to save, use, exchange, share or sell their farm produce of a variety protected under the Act, except when a sale is for the purpose of reproduction under a commercial marketing agreement." The National Plant Variety Protection Board is to determine the condition under which this exception is to apply, taking into consideration the nature of the plant cultivated, grown or sown. The provision is also to extend to the exchange and sale of seeds among and between small farmers, provided that the small farmers may exchange or sell seeds for reproduction and replanting in their own land.

Section 72 allows for the establishment of inventories to protect locally-bred varieties from misappropriation and unfair monopolization. Thus, in an effort to protect the rights of farmers against possible encroachment by plant breeders, the Campagao Farmers' Production and Research Association (CFPRA) of Campagao village has decided to establish a community registry of local rice varieties that they have developed, to ensure that they are not subsumed under the new Act, and are thus protected from misappropriation and unfair monopolization, and to assert the community's rights over its genetic resources. "After a series of group meetings and discussions, the group formulated a community affidavit declaring that all rice varieties maintained in their community shall be protected from the $P V P$ Act, and that seeds of these varieties shall remain freely accessible to farmers for purposes of using, selling, saving and exchanging with other farmers. The affidavit also includes a list of names and kinds of rice varieties that the community has been using and continually developing since they started their efforts in participatory plant breeding. The registry also includes basic characterization of the varieties." 74 The entries will be updated every cropping season.

Other proposals for the recognition of the rights of local, indigenous and farmer's communities at the national level include the following:

- The Zambian Government has drafted a plant variety protection law that seeks to protect the innovations of local communities and indigenous peoples, in keeping with its obligations under the CBD.

- In Thailand, a draft Plant Variety Protection Bill would combine recognition for the rights of plant breeders to their newly developed varieties with the protection of native varieties that have been conserved and developed by farmers and local communities.

- Costa Rica's "Biodiversity Law" (1998) recognizes and expressly protects the practices and innovations of indigenous peoples and local communities related to the use of biodiversity components, and their associated knowledge. The law obliges the competent authority to reject any request for recognition of intellectual or industrial rights for biodiversity components or knowledge that is already recognized by community rights.

- Bhutan's "Biodiversity Act" (2003) fights against illegal access to traditional resources, protects the rights of the farmers and of the selectors, establishes rights of ownership to the farmers on the plant varieties, and facilitates access to the foreign sources of varieties of plants improved in favour of Bhutan's farmers.

74 Alywin Darlen M. Arnejo, The Community Registry as an Expression of Farmers' Rights: Experiences in Collective Action Against the Plant Variety Protection Act of the Philippines, Paper presented to the CAPRI-IPGRI International Workshop on Property Rights, Collective Action and Local Conservation of Genetic Resources, Rome, 29 September - 2 October 2003. 
(e) promoting, as appropriate, the expanded use of local and locally adapted crops, varieties and underutilized species;

This paragraph reflects the GPA's Priority Activity Areas 2 ("Supporting on-farm management and improvement of plant genetic resources for food and agriculture"), 11 ("Promoting Sustainable Agriculture through Diversification of Crop Production and Broader Diversity in Crops"), 12 ("Promoting Development and Commercialization of Underutilized Crops and Species") and especially 14 ("Developing new markets for local varieties and "diversity rich" products").

For many developing countries, underutilized crops are essential for food security, but a large proportion of the resources available to plant breeders are invested in very few crops. Not all underutilized crops are "minor". Millet and cassava (both included in the Treaty's Multilateral System) are grown over enormous areas, but generally for subsistence needs and local markets. Other crops, such as teff (Erogrostis tef Zucc.), have enormous region-specific importance, but are not produced over large areas.

In order to fulfill the obligations of this paragraph, Contracting Parties will have to address the increasing uniformity in the agricultural market place, usually the result of the promotion of new and improved varieties that are widely adapted, concentration on productivity, the rise of global consumer markets, and changes in traditional cultures and consumer preferences. Better market opportunities and supportive policies for local and locally adapted and underutilized crops and species increase the incentive for farmers to continue to use these crops and species and thus to conserve biodiversity. They also help to maintain local knowledge concerning the management and uses of these crops and species. Many local and underutilized plants have potential for more widespread use, and their promotion could contribute not only to local income generation, but also to food security and agricultural diversification, particularly in areas where the cultivation of major crops is economically marginal. The Treaty encourages current programmes for conservation, research and development to promote these crops and species.

Promoting the expanded use of such crops will require capacity-building for farmers, local communities, scientists and extension specialists in identifying underutilized crops with potential for increased sustainable use, the development of sustainable management practices, developing post-harvest processing methods and developing marketing methods.

Finally, the Treaty recognizes that it may not always be appropriate to expand the use of local and locally adapted crops, varieties and underutilized species, for example when the most productive or sustainable variety is a widely adapted introduction, or when local staple food needs are such that only major crops can be cultivated.

- The Global Facilitation Unit for Underutilized Species is a multi-stakeholder initiative established in June 2002 under the umbrella of the Global Forum on Agricultural Research (GFAR) and currently hosted by IPGRI. The Unit supports and facilitates work on different aspects of underutilized species at different levels by networks, organizations, agencies and others around the world. The initiative aims at strengthening these stakeholders and encouraging new commitments for the development of underutilized species.

Initially the Unit is concentrating on stakeholders working with plant species. The main activities of the GFU include:

- providing improved access to information (making use of traditional and modern media);

- creating a platform for discussion of concepts, strategies and instruments to promote and facilitate the sustainable use of underutilized species; and

- facilitating stakeholders' access to financial resources. 
(f) supporting, as appropriate, the wider use of diversity of varieties and species in onfarm management, conservation and sustainable use of crops and creating strong links to plant breeding and agricultural development in order to reduce crop vulnerability and genetic erosion, and promote increased world food production compatible with sustainable development; and

This paragraph reflects Priority Activity Areas 10,11 and 13 of the GPA, and is closely linked with the preceding paragraphs.

The paragraph focuses on on-farm management and conservation and the need to expand the diversity of varieties and species to be used. Research needs to be undertaken, plant breeding efforts promoted and the genetic base of crops expanded in order to make a broader range of genetic diversity available for farmers to use. This paragraph focuses on their actual use on farm.

The paragraph also stresses the need to strengthen links between on-farm management, conservation and use on the one hand, and plant breeding and agricultural development. A wide diversity of varieties adapted to local conditions needs to be bred and the seed distributed. In this context, farmers benefit in many ways from having a wide range of seed varieties and other planting materials, including:

- farming in a variety of environments;

- coping with production risks;

- managing pests and pathogens;

- avoiding or minimizing labour bottlenecks;

(g) reviewing, and, as appropriate, adjusting breeding strategies and regulations concerning variety release and seed distribution.
Seed regulatory frameworks aim to promote varietal and seed quality, and thereby to protect farmers from planting sub-standard seed. Seed laws commonly regulate variety testing and release, seed certification, and seed quality control, and they establish the institutional framework of national seed councils and certification agencies. Variety release systems aim at making only varieties of proven value available to farmers. Seed certification aims at controlling the varietal identity and purity throughout the seed chain. Seed quality control checks on seed quality such as viability, purity and health. Seed quality control also protects bona fide seed producers from competition by less scrupulous colleagues. Seed laws are not usually intended
- fitting different budget constraints;

- providing variety to monotonous diets;

- providing special consumption items; and

- fulfilling rituals, generating prestige and forging social ties.

However, availability of a wider diversity of varieties can be constrained by poor harvests, inadequate on-farm storage facilities, insufficient means to multiply quality seed, and poor seed distribution systems. These problems can apply to seed of both local and commerciallybred varieties. Parastatal and commercial seed companies sometimes have difficulty supplying seed of varieties specifically adapted to unique and local conditions. Often they cannot offer the range of varieties, or seed of so-called "minor" crops, on which many farmers rely, because of high transaction costs and the low purchasing power of farmers. There is thus a need to strengthen local capacity among farmers and local communities to produce and distribute seed of many crop varieties, including some landraces/farmers' varieties, that are useful for diverse and evolving farming systems. to influence the direction of plant breeding. However, there are significant indirect effects of the variety release systems and of seed certification requirements on plant breeding methodologies and the resulting varieties. Breeders tend to target favourable farming conditions, wide adaptation and varietal uniformity as a result.

There are a number of options for regulatory reform. In plant breeding, more emphasis could be placed on decentralising variety testing, breeding for particular niches, and making site selection, trial management and analysis more representative of farmers' conditions. In variety regulation, simpler registration proce- 
dures may have advantages. Further, variety regulation might be adjusted to ensure that it does not bias or limit the development and use of public and farmer varieties. Variety performance testing for release could be made more flexible. In seed quality control, standards might be re-examined for their relevance to particular farming conditions, and much of the responsi- bility for monitoring seed quality could be passed to seed producers and merchants, accompanied by well-defined public oversight and enforcement mechanisms.

As situations may differ from country to country, this paragraph notes that such adjustments should be carried out as appropriate. 


\title{
Article 7 - National Commitments and International Cooperation
}

\author{
7.1 Each Contracting Party shall, as appropriate, integrate into its agriculture and rural \\ development policies and programmes, activities referred to in Articles 5 and 6, and \\ cooperate with other Contracting Parties, directly or through FAO and other \\ relevant international organizations, in the conservation and sustainable use of plant \\ genetic resources for food and agriculture.
}

Article 7.1 sets out the basic obligations of the Contracting Parties, which are expressed at two levels:

1. The obligation to integrate activities highlighted in Articles 5 and 6 into national agriculture and rural development policies and programmes; and

2. The obligation for Contracting Parties to cooperate at the international level in the conservation and sustainable use of PGRFA.

The first element mirrors the provisions of Articles 6(b) and 10(a) of the CBD, which call for the integration of the conservation and sustainable use of biological diversity into relevant sectoral or cross-sectoral plans, programmes and policies and into national decision-making. In this Article of the Treaty, the obligations are more specific in that they refer to specific programme activities and policies with respect to PGRFA that have already been described in Article 5 and 6 . The wording of the Article, as with other Articles, is binding, but allows a degree of flexibility by including the qualification "as appropriate".

The Article recognizes that while the activities specified in Article 5 and 6 are fundamental to the conservation and sustainable use of PGRFA, they can only be fully effective if they are integrated into broader agriculture and rural development policies and programmes. Since PGRFA activities involve public and private institutions and companies, non-govern- mental organizations, communities and individuals from the agriculture, environment and development sectors, the integration of existing PGRFA activities in the framework of a unified national programme provides the opportunity to enhance such diverse efforts within a country.

With respect to the second element, Contracting Parties are required to cooperate with each other in the conservation and sustainable use of PGRFA. Cooperation can either be direct, as through bilateral or regional programmes or networks, or through FAO, as for example through FAO-sponsored programmes or activities including those sponsored by the CGRFA. Cooperation can also be through other relevant international organizations, such as IPGRI or other IARCs of the CGIAR, or through the new Global Crop Diversity Trust in respect of ex situ collections.

The two levels of obligation cannot, however, be viewed in isolation. National policies and programmes can promote international cooperation on access to plant genetic resources and the fair and equitable sharing of the benefits arising from their use. In turn international cooperation is essential to provide support to national implementation activities, particularly in developing countries and countries with economies in transition. Effective national programmes provide a link between in-country activities and those at the regional and global levels.

\subsection{International cooperation shall, in particular, be directed to:}

Article 7.2 highlights some aspects of international cooperation that should be especially targeted, and must be read in conjunction with the basic obligation set out in Article 7.1. The enumeration of priority activities to which international cooperation should be directed, and indeed the whole wording of Article 7.2, is drawn essentially from Article 6 of the International Undertaking. International cooperation in the context of Article 7.2 would include regional cooperation. 
(a) establishing or strengthening the capabilities of developing countries and countries with economies in transition with respect to conservation and sustainable use of plant genetic resources for food and agriculture;

Paragraph (a) deals with the need to establish and strengthen the capabilities of developing countries and countries with economies in transition through international cooperation. In this connection, it is to be noted that, unlike the
$\mathrm{CBD}$, countries with economies in transition are given special consideration in the same way as developing countries throughout the Treaty. Establishing and strengthening national capabilities is an essential objective of the GPA.

(b) enhancing international activities to promote conservation, evaluation, documentation, genetic enhancement, plant breeding, seed multiplication; and sharing, providing access to, and exchanging, in conformity with Part IV, plant genetic resources for food and agriculture and appropriate information and technology;

Paragraph (b) deals with international cooperation to enhance international activities relating to various aspects of the conservation, use and exchange of PGRFA. Specific reference is made to the sharing of PGRFA and appropriate information and technology through the Multilateral System established under Part IV of the Treaty.

It is impossible to give an exhaustive list of all international cooperation programmes and activities currently operative, but it may be appropriate to draw attention to some of them. One group would be the activities sponsored by FAO and its CGRFA. A second would be activities currently being operated by the CGIAR Centres. A third category, which will to some extent overlap with the previous two, would be the various networks relating to specific plant genetic resources. Another would be bilateral and regional programmes operated by indi- vidual countries or groups of countries. All of these activities will draw on and operate under the umbrella of the rolling GPA. A fifth group would be the Global Crop Diversity Trust set up to provide financial support to $e x$ situ collections. Sixth, the GFAR is mobilizing the scientific community and all stakeholders in Agricultural Research for Development (ARD) to work together to face the new challenges and take advantage of the new opportunities presented by the deep changes that are influencing agricultural research. GFAR is also supporting the development of a multi- stakeholder Global Shared Vision in ARD to focus research at the global level through the activities of the SubRegional and Regional Forums, by promoting multi-stakeholder involvement in ARD, innovative research partnerships, and facilitating information and knowledge exchange among ARD stakeholders.

(c) maintaining and strengthening the institutional arrangements provided for in Part $\mathrm{V}$; and

Part V of the Treaty deals with the supporting components to the conservation and sustainable use of PGRFA, and covers:

The GPA (Article 14);

Ex situ collections of PGRFA held in trust by the IARCs of the CGIAR (Article 15);

International PGRFA networks (Article $16)$; and
The Global Information System on PGRFA (Article 17).

Paragraph (c) recognizes that the goals of the Treaty cannot be achieved without the Contracting Parties' support of the institutional arrangements mentioned in Part V, which, while recognized in the Treaty, exist independently of it. 


\section{Box 7. The World Intellectual Property Organisation (WIPO) and Traditional Knowledge}

Working in co-operation with other international organizations, WIPO provides a forum for international policy debate concerning the interplay between intellectual property (IP) and traditional knowledge, genetic resources, traditional cultural expressions (folklore), and is in the process of attempting to develop a range of practical tools aimed at enhancing the IP interests of the holders of such knowledge, resources and expressions.

In recent years, significant questions have been raised regarding the relationship of the intellectual property system to:

- Agricultural genetic resources, in the context of the CBD concept of "access to genetic resources and benefit-sharing";

- Traditional knowledge (TK), whether or not associated with those resources; and

- Traditional cultural expressions (Folklore).

For example, concerns have been raised relating to the misappropriation of TK by third parties, such as the unauthorized use of traditional designs, songs and dances by the entertainment and fashion industries to create works which are then protected by intellectual property.

Furthermore, holders of TK have expressed a need to be better informed of the IP implications of making their TK available to a wider audience; for instance, of using certain distinctive elements of their TK as intellectual property assets that may lead to economic growth.

As the specialized United Nations agency responsible for the promotion of IP worldwide, WIPO has worked in the field of traditional cultural expressions (folklore) for over thirty years, often in collaboration with UNESCO, and has, more recently, considered specific intellectual property issues related to traditional knowledge (TK) and genetic resources.

In particular, in 1998-1999 WIPO consulted with a wide range of stakeholders such as indigenous and local communities, civil society organizations, governmental representatives, academics, researchers and private sector representatives to determine the intellectual property needs and expectations of holders of TK.

In 2000, the WIPO General Assembly agreed to establish a unique intergovernmental body to discuss intellectual property issues related to traditional knowledge, genetic resources, and traditional cultural expressions (folklore). The Intergovernmental Committee on Intellectual Property and Genetic Resources, Traditional Knowledge and Folklore (IGC), has since met, in Geneva, several times. The primary themes that it would address in the course of its work, beginning with a meeting in April 2001, could include the intellectual property questions raised by:

- access to genetic resources and benefit-sharing;

- protection of traditional knowledge, whether or not associated with those resources;

- protection of expressions of folklore.

WIPO's work in this area involves close co-operation with other international organizations. It also involves the organization of a wide range of traditional knowledge-related capacity-building activities, such as the publication of case-studies, and the co-ordination of local, national and regional seminars, workshops and consultations. 


\section{(d) implement the funding strategy of Article 18.}

Article 18 provides for a funding strategy, the objectives of which are "to enhance the availability, transparency, efficiency and effectiveness of the provision of financial resources to implement activities under the Treaty." Further analysis of the funding strategy will be found in the commentary to Article 18. The wording of the obligation stated in Paragraph (d) reiterates in a more general context the wording of Article 18.1. Under Article 18.1, the Contracting Parties undertake, jointly and severally, to implement a funding strategy for the implementation of the Treaty in accordance with the provisions of Article 18. The present Article stresses the need for international cooperation in implementing the funding strategy. 


\section{Article 8 - Technical Assistance}

The Contracting Parties agree to promote the provision of technical assistance to Contracting Parties, especially those that are developing countries or countries with economies in transition, either bilaterally or through the appropriate international organizations, with the objective of facilitating the implementation of this Treaty.

A cornerstone of recent environmental and development treaties has been the inclusion of provisions for funding and technical assistance to address capacity needs and to support implementation by developing countries. Technical assistance, or technical cooperation, aims to transfer skills, technology, or ways of doing things, to individuals and organisations in developing countries. This is done in various ways, including by sending people with relevant skills to those countries, by training those countries' students in donor countries, and by providing access to technologies. Technical assistance can have other objectives besides capacity development. Its immediate objectives can include the facilitation, monitoring and supervision of resource flows. Its ultimate objective is to increase output and incomes in the developing country. Within this context, capacity development is an intermediate objective of technical assistance.

Technical assistance is a vital element in development assistance. It helps developing countries in:

- identifying, formulating, and implementing projects;

\section{Box 8. The FAO Global System on Plant Genetic Resources}

Resolution 3 adopted by the Diplomatic Conference for the Adoption of the Agreed Text of the CBD (the Nairobi Conference) recognized the need to seek solutions to outstanding matters concerning plant genetic resources within the Global System for the Conservation and Sustainable Use of Plant Genetic Resources for Food and Agriculture, thus providing more momentum for the renegotiation of the International Undertaking on plant genetic resources for food and agriculture. What exactly is the Global System, and of what does it consist?

The Global System consists of the following:

- A series of international agreements and other instruments, including the International Undertaking on Plant Genetic Resources and now the International Treaty on Plant Genetic Resources for Food and Agriculture, the Global Plan of Action for the Conservation and Sustainable Use of Plant Genetic Resources for Food and Agriculture and related Report on the State of the World's Plant Genetic Resources, and a series of Codes of Conduct on various aspects of PGRFA, including the Code of Conduct for Plant Germplasm Collecting and Transfer, Genebank Standards and Guidelines, and a Draft Preliminary Code of Conduct on Biotechnology.

- A series of global mechanisms, including Crop and Thematic Networks, the International Network of Ex situ Collections, and the World Information and Early Warning System (WIEWS).

- A global intergovernmental mechanism for monitoring and coordinating the development of the Global System, originally the FAO Commission on Plant Genetic Resources, and now the FAO Commission on Genetic Resources for Food and Agriculture, and its Intergovernmental Technical Working Group on Plant Genetic Resources for Food and Agriculture.

The objectives of the Global System are to ensure the safe conservation, and promote the availability and sustainable use of plant genetic resources by providing a flexible framework for sharing the benefits and burdens. 
- improving the institutional capabilities of governments and executing agencies;

- formulating development strategies;

- promoting and engaging in the transfer of technology; and

- fostering regional and sub-regional cooperation.

Within the context of the Treaty, this Article, in conjunction with Article 7.2(a), recognizes that the contributions of developed and developing states towards genetic resource problems are different, and that their economic and technical capacity to tackle these problems also varies widely. Therefore, Contracting Parties are urged to provide financial, technological, and other technical assistance in particular to developing countries and countries with economies in transition to help the implementation of the Treaty. The wording of the Article does not amount to an actual obligation to provide tech- nical assistance. The obligation is to promote the provision of technical assistance. Technical assistance can be provided either bilaterally or through the appropriate international organizations, such as FAO, the GEF or the CGIAR Centres.

An example is the Global Programme of Action for the Protection of the Marine Environment from Land-based Activities ClearingHouse mechanism, which provides a one-stop method that promotes the advertising, discovery, access, dissemination and use of related information and data held by numerous organizations using the decentralized capabilities of the Internet.

As with the previous Article, countries with economies in transition are treated on a par with developing countries. 


\section{PART III - FARMERS' RIGHTS}

\section{Article 9 - Farmers' Rights}

The concept of Farmers' Rights was first introduced into the FAO International Undertaking on Plant Genetic Resources as an Agreed Interpretation by FAO Conference Resolution 4/ $89,{ }^{75}$ and was further defined by FAO Conference Resolution 5/89. The concept resulted from debates in FAO that started in 1979 concerning what some countries saw as asymmetric benefits accruing to farmers whose efforts over the centuries in breeding and selecting farmers' varieties have made an immense contribution to modern agriculture, and the producers of commercial varieties that take these farmers' varieties as a starting point and reap the benefits from what were characterized as relatively small improvements. Farmers' Rights were seen as a means to reward farmers and their communities for their contributions in the past, to encourage them to continue in their efforts to conserve and improve PGRFA, and to allow them to participate in the benefits derived, at present and in the future, from the improved use of plant genetic resources, through plant breeding and other scientific methods.

Conference Resolution 5/89 defined the concept of Farmers' Rights in terms of the substantive grounds for the concept, the entities in which the rights were vested and the objectives for which they should be recognized. Thus the definition in the operative paragraph of Resolution 5/89 read as follows: "Farmers' Rights mean rights arising from the past, present and future contributions of farmers in conserving, improving, and making available plant genetic resources, particularly those in the centres of origin/diversity. These rights are vested in the International Community, as trustee for present and future generations of farmers, for the purpose of ensuring full benefits to all farmers, and supporting the continuation of their contributions, as well as the attainment of the overall purposes of the International Undertaking." By declaring that Farmers' Rights were vested in the International Community, the Resolution sought to differentiate them from the rights of individual farmers to compensation for individual innovations. This aspect was reinforced by FAO Conference Resolution 3/91, which indicated that 'Farmers' Rights will be implemented through an international fund on plant genetic resources which will support plant genetic conservation and utilization programmes, particularly, but not exclusively, in the developing countries".

The need to provide for the realization of Farmers' Rights was one of the principal objectives of the renegotiation of the International Undertaking, as indicated in FAO Conference Resolution 7/93, which initiated the negotiations for the Treaty. The need to realize Farmers' Rights was reaffirmed in various other contexts, including:

- Chapter 14.60(a) of Agenda 21 (approved at the UNCED, held in Rio de Janeiro in 1992), stated that the appropriate United Nations agencies and regional organizations should "strengthen the Global System on the Conservation and Sustainable Use of Plant Genetic Resources for Food and Agriculture (PGRFA) by [...] taking further steps to realize Farmers' Rights".

- Resolution 3 of the Nairobi Conference for the Adoption of an Agreed Text of the CBD identified the realization of Farmers' Rights as one of the "outstanding issues" for further negotiation. The CBD itself did not explicitly mention Farmers' Rights.

- The GPA included the realization of Farmers' Rights at the national, regional and international level, as one of the long-term objectives of the Plan, in the context of in situ conservation (para. 32).

75 While the Resolution was approved unanimously by more than 160 countries, it is to be noted that this fact did not necessarily mean that all countries were in total agreement with the concept of Farmers' Rights or the rationale for Farmers' Rights set out in the Agreed Interpretation, given that a number of countries had refrained from adhering to the International Undertaking in the first place. 
- A June 1999 study on the Right to Food, submitted to the Commission on Human Rights, urged that Farmers' Rights be promoted as part of the "Right to Food", especially since "our future food supply and its sustainability may depend on such rights being established on a firm footing" (Commission on Human Rights, 1999). ${ }^{76}$

During the course of the negotiations of the Treaty, the issue of the realization of Farmers' Rights caused considerable difficulties. One of the problems was that while the rationale for the concept was widely accepted, the actual definition of the content of those rights and the respective obligations remained somewhat vague and inchoate. Historically, Farmers' Rights had come to mean different things to different people. To some it was associated with a desire for a form of intellectual property rights for farmer-developed materials; to others as an approach to limit the encroachment of intellectual property rights on PGRFA; to others it was more of a political motivation for the promotion of PGRFA-re- lated activities of benefit to small, traditional farmers. Yet others were concerned that the "vesting of the rights in the international community" in the wording of Conference Resolution $5 / 89$ implied that the rights were too far removed from the farmers themselves.

The subject occupied considerable negotiating time during the negotiation of the Treaty, with the discussions focussing on "a bundle of rights" that were more directly related to the farmers themselves. Article 9 of the Treaty reiterates the broad rationale for Farmers' Rights in Article 9.1 and then identifies those rights in Paragraphs (a) to (c) of Article 9.2. In the final text of Article 9.2, the concept of Farmers' Rights has undergone a sea change from that originally envisaged in the Agreed Interpretations of the International Undertaking and has become more focussed on rights that may be enjoyed by farmers under national law. The identification of the various components of the "bundle of rights" also brings the concept of Farmers' Rights more in line with the provisions of Article 8(j) of the CBD.

\subsection{The Contracting Parties recognize the enormous contribution that the local and indigenous communities and farmers of all regions of the world, particularly those in the centres of origin and crop diversity, have made and will continue to make for the conservation and development of plant genetic resources which constitute the basis of food and agriculture production throughout the world.}

In Article 9.1, Contracting Parties acknowledge the enormous past, present and future contributions of farmers in conserving and developing plant genetic resources, particularly in centres of origin and crop diversity, and their fundamental importance to modern food and agriculture production. These contributions are not explicitly linked to Farmers' Rights in Article 9.1, although they are of course implicitly linked by their inclusion in an Article entitled Farmers' Rights. Similar wording in the Preamble is more explicitly linked to Farmers' Rights.

The text in Article 9.1 follows point 3 of the Agreed Interpretation in FAO Resolution 4/89. Note that while only "farmers" were mentioned in the Annexes to the International Undertak- ing, this Article refers to "the local and indigenous communities and farmers". This is a clear indicator of the growing recognition of the role played by indigenous communities in the creation and preservation of knowledge of value for the society as a whole. This distinction also has the effect of giving states the option of treating local and indigenous communities as a distinct class from that of farmers though in many cases indigenous people and farmers may be one and the same.

It should also be noted that this paragraph is just a statement of recognition, and does not create any type of legal obligation. Nevertheless, it does provide an important rationale for the substantive provisions that follow.

The right to adequate food and to be free from hunger: Updated study on the right to food, submitted by Mr. Asbjorn Eide in accordance with Sub-Commission decision 1998/106. UN doc. E/CN.4/Sub.2/ 1999/12 para. 121. 


\section{Box 9. The International Union for the Protection of New Varieties of Plants}

The International Union for the Protection of New Varieties of Plants (UPOV) is an intergovernmental organization with headquarters in Geneva, Switzerland, whose mission is to provide and promote an effective system of plant variety protection, with the aim of encouraging the development of new varieties of plants, for the benefit of society. UPOV was established by the International Convention for the Protection of New Varieties of Plants. ${ }^{77}$ The Convention was adopted in Paris in 1961 and it was revised in 1972, 1978 and 1991. The objective of the Convention is the protection of new varieties of plants by an intellectual property right.

\section{UPOV 1961}

(i) Forms of protection - Each member state could recognise the right of the breeder by the grant of a special title or of a patent. However, where national law allowed protection under both, only one form was allowed for the same botanical genera or species.

(ii) Coverage of varieties - Upon joining, each Member was expected to apply the provisions of the Convention to at least five of the genera mentioned in the Annex. Subsequently, Members had to add at least two further genera within three years, and at least four within 6 years. Within 8 years, Members had to apply the Convention to all the genera listed in the Annex.

(iii) Scope of protection - Prior authorization from breeders had to be sought for production, commercial marketing, offering for sale, and marketing of the reproductive or vegetative material of the new variety. However, the use of the varieties for research purposes was allowed.

(iv) Duration of protection - The Convention provided for a minimum of 18 years protection for vines, fruit trees and their root-stocks, and 15 years for all other plants.

(v) Conditions for protection - The Convention allowed protection of varieties that were (a) new, (b) distinct, (c) homogenous and (d) stable.

\section{UPOV 1978}

(i) Number of genera/species to be protected - Initially, the provisions had to apply to at least five genera or species, to at least 10 within 3 years, to at least 10 within three years, to at least 18 within six years, and at least 24 within 8 years. Exemptions from these obligations were if members suffered from "special economic and ecological conditions".

(ii) Conditions for protection - UPOV 1978 allowed protection of plant varieties that were: (a) new, (b) distinct from any other variety that was in common knowledge (c) sufficiently homogenous and (d) stable in their essential character (Article 6). Any plant variety that met these criteria could qualify for protection, irrespective of the origin, artificial or natural, of the initial variety from which it had resulted. This implies that unlike patents, which are normally not granted to discoveries, plant varieties could be protected even when they were "discovered".

(iii) Nature of protection - An exception was added to Article 2(1) allowing a state that already provided dual protection to continue to do so provided "it notifies the Secretary General (of the UPOV) of that fact". Furthermore, countries using the patent laws to protect plant varieties were allowed to use the patentability criteria and the period of protection that their patent law provided.

(iv) Scope of Plant Breeders' Rights - The rights provided, as spelt out in Article 5(1), are control over the production for the purposes of commercial marketing, the offering for sale, and the

continued next page

77 International Convention for the Protection of New Varieties of Plants, 2 December 1961, 33 U.S.T. 2703, 815 U.N.T.S. 89, as Revised at Geneva on 10 November 1972, on 23 October 1978, and on 19 March 1991. 
marketing of reproductive or vegetative propagating material. However, under Article 5(3), the authorization of the breeder was not required "either for the utilization of the variety as an initial source of variations for the purpose of creating other varieties or for the marketing of such varieties". However, authorization of the breeder was required when "repeated use of the variety was necessary for the commercial production of another variety". While there is no explicit wording in the Convention itself, the limitation of Plant Breeders' Rights to production for the purposes of commercial marketing etc, has been interpreted in practice as allowing farmers to replant and exchange farm-saved seed.

(v) Safeguarding public interests - Article 9 allows the exclusive rights of breeders to be restricted in the public interest. The Model Law of UPOV 1978 provided three possible interpretations: through the grant of a voluntary licence by the right holder for the exploitation of the variety; licences of right; and, compulsory licences.

\section{UPOV 1991}

(i) Coverage of varieties - Member states that have been members of the Convention have a fiveyear transition period to provide comprehensive coverage of plant varieties. New members, however, are required to protect 15 genera or species on accession and include all genera and species within 10 years.

(ii) Nature of rights enjoyed by the breeder - UPOV 1991 marks a major departure from UPOV 1978 in the nature of rights provided to the breeder. Article 14 defines these in four areas: (a) the propagating material, (b) the harvested material, (c) certain other products, which are discussed below, and (d) essentially derived varieties (EDVs). Breeder's rights on propagating material include: (a) production or reproduction (multiplication), (b) conditioning for the purposes of propagation, (c) offering for sale, (d) selling or other marketing, (e) exporting, (f) importing, and (g) stocking for any of the purposes referred to above. Propagating material, as understood in UPOV 1991, included "parts of the plant intended for the production of new plants, for example seeds", and certain parts of plants that may be used either for "consumption or sowing". Of particular importance was "conditioning for the purposes of propagation", which was intended to strengthen Plant Breeders' Rights by monitoring on-farm production and the use of harvested material. Plant Breeders' Rights were further strengthening by extending them to harvested material and products of harvested material that use protected varieties of plants.

(iii) Essentially derived varieties - The inclusion of EDVs in UPOV 1991 is generally regarded as the single most important change to UPOV.

(iv) Exceptions - Two sets of limited exceptions to Plant Breeders' Rights are included in Article 15 of UPOV 1991. The first (Article 15.1), designated as compulsory exceptions, include: (a) acts done privately and for non-commercial purposes, (b) acts done for experimental purposes and (c) acts done for the purpose of breeding other varieties, provided that such breeding activities did not result in the production of EDVs. Included in this set of exceptions is a more restricted version of "research exemption" available under UPOV 1978. The second set of optional exceptions (Article 15.2) includes those that are related to "farm saved seed" or the "farmers' privilege". Under Article 15.2, each Contracting Party may, within reasonable limits and subject to safeguarding the legitimate interests of the breeder, restrict the breeder's right in relation to any variety in order to permit farmers to use for propagating purposes, on their own holdings, seed from protected varieties they themselves have harvested.

(v) Contractual licences and the public interest - UPOV 1991 allows restrictions on the exercise of Plant Breeders' Rights to safeguard public interest (Article 17). However, unlike the interpretation of UPOV 1978, which had provided three options for contractual licences, the Model Law of UPOV 1991 provides only two options: voluntary licences or compulsory licences. 


\begin{tabular}{|c|c|c|c|}
\hline \multicolumn{4}{|c|}{ Members of UPOV (as of 30 June 2004) and Latest Act of the Convention to which State is party ${ }^{78}$} \\
\hline Argentina & 1978 Act & Lithuania & 1991 Act \\
\hline Australia & 1991 Act & Mexico & 1978 Act \\
\hline Austria & 1991 Act & Netherlands & $1991 \operatorname{Act}^{83}$ \\
\hline Belarus & 1991 Act & New Zealand & 1978 Act \\
\hline Belgium $^{79}$ & 1961/1972 Act & Nicaragua & 1978 Act \\
\hline Bolivia & 1978 Act & Norway & 1978 Act \\
\hline Brazil & 1978 Act & Panama & 1978 Act \\
\hline Bulgaria & 1991 Act & Paraguay & 1978 Act \\
\hline Canada & 1978 Act & Poland & 1991 Act \\
\hline Chile & 1978 Act & Portugal & 1978 Act \\
\hline China & 1978 Act $9^{80}$ & Republic of Korea & 1991 Act \\
\hline Colombia & 1978 Act & Republic of Moldova & 1991 Act \\
\hline Croatia & 1991 Act & Romania & $1991 \mathrm{Act}$ \\
\hline Czech Republic & 1991 Act & Russian Federation & 1991 Act \\
\hline Denmark $^{81}$ & 1991 Act & Singapore & 1991 Act \\
\hline Ecuador & 1978 Act & Slovakia & 1978 Act \\
\hline Estonia & 1991 Act & Slovenia & 1991 Act \\
\hline Finland & 1991 Act & South Africa & 1978 Act \\
\hline France $^{82}$ & 1978 Act & Spain $^{84}$ & 1961/1972 Act \\
\hline Germany & 1991 Act & Sweden & 1991 Act \\
\hline Hungary & 1991 Act & Switzerland & 1978 Act \\
\hline Ireland & 1978 Act & Trinidad and Tobago & 1978 Act \\
\hline Israel & 1991 Act & Tunisia & 1991 Act \\
\hline Italy & 1978 Act & Ukraine & 1978 Act \\
\hline Japan & 1991 Act & United Kingdom & 1991 Act $_{\mathrm{oF}}$ \\
\hline Kenya & 1978 Act & United States of America & $1991 \mathrm{Act}^{85}$ \\
\hline Kyrgyzstan & 1991Act & Uruguay & 1978 Act \\
\hline Latvia & $1991 \mathrm{Act}$ & & \\
\hline
\end{tabular}

78 Azerbaijan, Costa Rica, Egypt, Georgia, Honduras, Iceland, India, Jordan, Kazakhstan, Morocco, Serbia and Montenegro, Tajikistan, the Former Yugoslav Republic of Macedonia, Uzbekistan, Venezuela, Viet Nam and Zimbabwe, as well as the European Community and the African Intellectual Property Organization, have initiated with the Council of UPOV the procedure for becoming members of the Union. Many other non-member States currently have laws to protect plant varieties, or proposals for laws before their legislatures.

79 With a notification under Article 34(2) of the 1978 Act.

80 With a declaration that the 1978 Act is not applicable to the Hong Kong Special Administrative Region.

81 With a declaration that the Convention of 1961, the Additional Act of 1972, the 1978 Act and the 1991 Act are not applicable to Greenland and the Faroe Islands.

82 With a declaration that the 1978 Act applies to the territory of the French Republic, including the Overseas Departments and Territories.

83 Ratification for the Kingdom in Europe.

84 With a declaration that the Convention of 1961 and the Additional Act of 1972 apply to the entire territory of Spain.

85 With a reservation pursuant to Article 35(2) of the 1991 Act. 


\subsection{The Contracting Parties agree that the responsibility for realizing Farmers' Rights, as they relate to plant genetic resources for food and agriculture, rests with national governments. In accordance with their needs and priorities, each Contracting Party should, as appropriate, and subject to its national legislation, take measures to protect and promote Farmers' Rights, including:}

Article 9.2 makes it clear that under the Treaty the realization of Farmers' Rights is a matter for national governments. As noted above, this reflects a major change from the text of the Agreed Interpretation, which had emphasized the global nature of Farmers' Rights and the primary role of the international community in realizing Farmers' Rights. FAO Resolutions 4/ 89 and 3/91 had established, in this regard, that Farmers' Rights would be implemented through an International Fund. In the Treaty, this global element of Farmers' Rights finds its reflection more in the provisions of Article 13 on Benefitsharing in the Multilateral System and Article 18 on Financial Resources than in the provisions of Article 9.

Under Article 9.2, each Contracting Party is encouraged, "in accordance with their needs and priorities... as appropriate, and subject to its national legislation", to take measures to protect and promote Farmers' Rights. The various limiting epithets are central to the meaning of the provision. Decisions regarding the measures, if any, to be taken to protect and promote Farmers' Rights are decisions that each govern- ment is to take as appropriate in the context of its own needs and priorities and in accordance with its own national legislation. Governments are not required to take such measures, but through the word "should", are encouraged to do so, as and where appropriate. Implementation of the measures indicated in Paragraphs (a) to (c) will thus be largely dependent upon each government's judgement on what is appropriate in the light of its own priorities and its own national law. The nature and scope of the measures to protect and promote Farmers' Rights is, therefore, likely to differ significantly among countries.

The "core" content of Farmers' Rights at the national level is identified in Paragraphs (a) to (c) as the protection of traditional knowledge, the right to participate in benefit sharing, and the right to participate in making decisions at the national level regarding PGRFA. It is important to note, however, that Paragraphs (a) to (c) are only illustrative of the various components of Farmers' Rights, and do not exhaust the modalities by which Farmers' Rights may be realized.

(a) protection of traditional knowledge relevant to plant genetic resources for food and agriculture;

Paragraph (a) encourages measures for the protection of "traditional knowledge". Given the scope and objectives of the Treaty, the type of traditional knowledge to be protected is limited to that which is "relevant to plant genetic resources for food and agriculture". In this sense, the provision is narrower in scope than Article 8(j) of the CBD which addresses a broader range of biological resources. In another sense, however, the scope of the provision may be broader than that of the CBD in that it is not limited to traditional knowledge "of indigenous and local communities embodying traditional lifestyles" as in Article 8(j) of the CBD. In the Treaty, traditional knowledge would appear to refer more to the traditional knowledge of farmers, a group that may well overlap with indigenous and local communities, but is not necessarily coterminous with them. Under the Treaty, the issue of protection of traditional knowledge refers mainly to the knowledge used to develop, and is thus incorporated in, farmers' varieties ("landraces") and certain associated knowledge (e.g. specific cultivation practices).

The choice of the means by which any individual Contracting Party may protect traditional knowledge relevant to PGRFA is left to the Contracting Party concerned. The development of a sui generis regime for the protection of farmers' varieties is one of the possible ways of implementing this component of Farmers' Rights. ${ }^{86}$ The issue has received considerable attention in the literature, but little progress has been made in terms of actually implementing this kind of protection. The establishment of a sui generis regime poses, in fact, complex conceptual and practical issues. ${ }^{87}$ On the concep- 
tual level, it is not clear whether the protection of farmers' varieties under an intellectual property rights (IPRs) system would have any positive impact on their conservation or stimulate breeding activity. Indeed it may be that any system of protection might endanger the very traditional practices that promote genetic diversity in landraces. It is also unclear whether protection would serve the purpose of strengthening the rights of communities and traditional farmers over their resources. There may be more appropriate non-IPRs methods of protecting such varieties. One example could be through some form of "misappropriation regime" that would not grant farmers IPRs in the sense of a right to exclude use by third parties, but rather focus on any misuse or misappropriation of the knowledge. What would constitute misuse or misappropriation would of course need to be defined by the terms of the regime. ${ }^{88}$ In this context, the World Intellectual Property Organization (WIPO) and its Intergovernmental Committee on Intellectual Property and Genetic Resources, Traditional Knowledge and Folklore, have been reviewing state practice with respect to the protection of traditional knowledge through traditional intellectual property mechanism and the elements that would need to be included in any sui generis system for the protection of traditional knowledge. ${ }^{89}$

\section{(b) the right to equitably participate in sharing benefits arising from the utilization of plant genetic resources for food and agriculture; and}

FAO Resolution 5/89 introduced the concept of the participation of farmers in "benefit-sharing" as one of the objectives of Farmers' Rights. ${ }^{90}$ Under Part IV of the Treaty, the Contracting Parties agree that benefits arising from the use of PGRFA shared under the Multilateral System should flow primarily to farmers who conserve and sustainably utilize PGRFA, with priority accorded to those in developing countries, or countries with economies in transition. ${ }^{91}$ How those benefits will be shared will be a matter to be determined by the Governing Body of the Treaty, although Article 13.2 speci- fies a number of mechanisms ${ }^{92}$ and indicates that the sharing of benefits must take into account the priority activity areas in the GPA.

Paragraph (b), however, must be seen in its context of actions that national governments may take at the national level in exercise of their responsibility for realizing Farmers' Rights. Certainly national governments will have a role in the distribution of benefits arising under the Multilateral System in theirown countries, whetherthrough projects to develop the capabilities of farmers to conserve and use PGRFA, or other means referred

On this issue, see also Carlos M. Correa, Options for the Implementation of Farmers' Rights at the National Level, South Centre, 2000, Working Paper \#8.

See Seeding Solutions, Volume 2, Options for National Laws Governing Access to and Control Over Genetic Resources, The Crucible Group, IDRC, 2002.

On this suggestion, see Carlos Correa: Traditional Knowledge and Intellectual Property: Issues and options surrounding the protection of traditional knowledge, A Discussion Paper commissioned by the Quaker United Nations Office Geneva, with financial assistance from the Rockefeller Foundation, Geneva, November 2001.

See, e.g. Report on the Review of Existing Intellectual Property Protection of Traditional Knowledge, WIPO/GRTKF/4/7, November 2002, and Elements of a Sui Generis System for the Protection of Traditional Knowledge, WIPO/GRTKF/IC/4/8, September 2002.

90 “(c) allow farmers, their communities, and countries in all regions, to participate fully in the benefits derived, at present and in the future, from the improved use of plant genetic resources, through plant breeding and other scientific methods."

91 Article 13.3.

92 The exchange of information; access to and transfer of technology; capacity-building, and the sharing of benefits arising from commercialization. 
to in Article 13. But what other measures should national governments be taking to ensure that farmers get their fair share of benefits arising from the use of PGRFA?

In so far as material already in the Multilateral System is concerned (i.e. plant genetic resources listed in Annex I, under the management and control of the Contracting Parties and in the public domain), it would appear that the benefit-sharing mechanisms set up in Article 13 may be intended to be exclusive. In other words, countries receiving a request for PGRFA under the Multilateral System would not be entitled to impose a bilateral requirement for compensation for farmers under Article 9 in addition to the Multilateral System conditions provided for in articles 12 to 13 . However, for the most part, where PGRFA are found in in situ conditions, apart from that found in national parks or other publicly owned land, they may be found, under some countries' laws, to be the property of, or at least subject to additional property rights of, the owners of that land. In such cases, the material will not be completely within the management and control of the Contracting Parties. ${ }^{93}$ It will therefore be in the Multilateral System only if so included by the owner concerned. If this is to be desired, then the question is what incentives can the national governments offer farmers to include their plant genetic resources in the Multilateral System. Again, various options may be open to national governments, including participation in capacity building projects, participatory plant breeding, or other means discussed below.

\section{(c) the right to participate in making decisions, at the national level, on matters related to the conservation and sustainable use of plant genetic resources for food and agriculture.}

Poorer farmers, and most notably, women farmers, are often excluded from decision-making processes at different levels, including in particular at the national level. Their substantial efforts and innovations in plant genetic resources conservation and management may not be recognized and their specific needs and priorities may not therefore be adequately provided for in national policy. In recent years, Participatory Rural Appraisal and other similar participatory tools and techniques have been developed and adapted for use in different regions and sectors. Additional efforts are still required to ensure a gender sensitivity of such approaches in plant genetic resource conservation and utilization.

One of the components of Farmers' Rights, according to Paragraph (c), is "the right to participate in making decisions" at the national level "on matters related to the conservation and sustainable use" of PGRFA. This right, which implies a right to have a say in national policy making as well as administrative decisions relating to PGRFA, should be recognized, according to the chapeau of Article 9.2, "as appropriate" and subject to "national legislation". As stated above, this means that national governments have considerable scope to determine the extent of such right. The importance of ensuring the participation of local, indigenous and farming communities in decision-making concerning PGRFA has been stressed in various forums. 94

Some national laws have begun to incorporate these principles. In the Philippines, the Indigenous Peoples Rights Act contains a broad recognition of community rights. Access legis-

93 Whether or not the material owned is considered "genetic resources" as opposed to "biological resources" for these purposes will depend on the applicable national legislation, as well as the outcome of currently ongoing negotiations under the CBD. In this context, it is interesting to note the possible effects of recent legislation in Latin America that declares genetic resources as being part of the "patrimony" of the State. Depending on the interpretation of the concept of "patrimony" (i.e. whether it is closer to the concept of state property or to the concept of sovereignty) the effect of this may well be to place all PGRFA into the Multilateral System, even where they are to be found on farmers' land.

See e.g. the Draft UN Declaration on the Rights of Indigenous Peoples developed by the Working Group on Indigenous Populations. 
lation adopted in some countries also provides for some form of participation in relation to the collecting of genetic materials. Under Philippines Executive Order No. 247, ${ }^{95}$ for instance, the rights of indigenous and local communities must be taken into account with regard to informed consent procedures.

Other mechanisms, not necessarily set out in national legislation, may be found for ensuring the practical participation of farmers in decision making at the national level. Examples would be the inclusion of farmers or producers organizations on critical policy bodies such as national plant genetic resources committees, or on other bodies that take decisions relevant to plant genetic resources, in- cluding committees dealing with the registration of new varieties. ${ }^{96}$

The realization of Farmers' Rights in relation to farmers' participation in decision-making will be dependent upon the nature of the relations between local, indigenous and farming communities, on the one hand, and national governments, on the other hand. A wide range of scenarios can be considered in this regard. In any case, the formal recognition of Farmers' Rights in the Treaty certainly constitutes an important step towards the reaffirmation of farmers' and communities' rights to participate in the taking of decisions that essentially concern the kind of farming system that they wish to keep as an integral part of their culture and lifestyles.

\subsection{Nothing in this Article shall be interpreted to limit any rights that farmers have to save, use, exchange and sell farm-saved seed/propagating material, subject to national law and as appropriate.}

Farmers' rights with regard to saving, selling and exchanging seed are a controversial issue. One view is that farmers should be free from any restriction with regard to the use and disposition of seeds, including those protected under IPRs. This view is not shared, however, by those who believe that the unrestricted use of IPR protected materials by farmers would erode incentives to commercial breeding and create a threat to future world food security. The two viewpoints are reflected in the 1978 UPOV Convention, which implicitly recognized the rights of farmers to reuse farm-saved seed and the 1991 UPOV Convention, which extended the scope of breeders' rights, but provided that individual Contracting Parties may, in their national legislation, allow the reuse by farmers of farm-saved seed that is protected by Plant Breeders' Rights on their own holdings. ${ }^{97}$

Article 9.3 was therefore offered as a compromise solution between those who sought a positive recognition under the revised International Undertaking of certain rights of farmers in relation to saving, using and exchanging seeds, and those who feared that the Treaty could limit breeders' rights in a way that would be inconsistent with UPOV 1991.

The agreed text is neutral in that respect. While Article 9.3 would not be a sufficient legal basis for claiming rights in relation to saving, using and exchanging seeds, at the same time, it does not restrict the options that may be adopted by national governments in that regard. Clearly,

95 Executive Order No. 247, "Prescribing a Regulatory Framework for the Prospecting of Biological and Genetic Resources, their By-Products and Derivatives, for Scientific and Commercial Purposes, and for Other Purposes", signed in May 1995. Recently, the government adopted Republic Act 9147 or the Wildlife Act, which contains provisions superseding those of EO 247 with regard to regulating access to the country's biological and genetic resources.

In Canada, for example, producers' organizations are represented on the national Canadian Agricultural Research Council (CARC), the national Expert Committee on Plant and Microbial Genetic Resources and various variety registration committees.

See below in this section under Protected Varieties. 


\section{Box 10. The International Network of Ex Situ Collections under the Auspices of FAO}

Article 7 of the International Undertaking on Plant Genetic Resources provided for the development of an international network of national, regional and international centres, including an international network of base collections in genebanks under the auspices or the jurisdiction of FAO, that have assumed the responsibility to hold, for the benefit of the international community and on the principle of unrestricted exchange, base or active collections of the plant genetic resources of particular plant species.

In 1989, the FAO CGRFA called for the development of the International Network of Ex Situ Collections under the auspices or jurisdiction of FAO, because of lack of clarity regarding the legal situation of some national and international ex situ collections.

The CGRFA also decided to incorporate into the "international network" the network of base and active ex situ collections that had been developed by agreement between IBPGR and national authorities.

Twelve centres of the CGIAR signed agreements with FAO in 1994, placing most of their collections (some 500,000 accessions) in the International Network. Through these agreements, the Centres recognised the "intergovernmental authority of FAO and its Commission in setting policies for the International Network". They also agreed to hold the designated germplasm "in trust for the benefit of the international community", and "not to claim ownership, or seek intellectual property rights, over the designated germplasm and related information". The Regional Collection of the International Coconut Genetic Resources Network (COGENT), held by the governments of India, Indonesia and Cote d' Ivoire, was brought into the Network by a further agreement signed in October 1998. The agreements were entered into for a period of 4 years, automatically renewable unless decided otherwise by either Party. The agreements have been automatically renewed in 1998 and again in 2002.

The CGRFA monitors the implementation of the agreements and the Centres of CGIAR are invited to report to its biennial sessions. The CGRFA stated that the agreements provided an interim solution, until the revision of the International Undertaking was completed. The Commission has also noted that "the final form of the Agreements would depend on the outcome of the negotiations for the revision of the International Undertaking, and that the Agreements might need to be revised in the light of that outcome".

Under Article 15 of the Treaty, the Contracting Parties recognize the importance to the Treaty of the ex situ collections held in trust by the CGIAR Centres and call on those Centres to sign agreements with the Governing Body placing those collections within the purview of the Treaty. Article 15 lists the terms and conditions that are to be included in such agreements. Once the new agreements are signed, they will replace the interim "in-trust" agreements.

the agreed text does not exclude the possibility that national laws (including Plant Breeders' Rights and seed legislation) may recognize farmers' rights in relation to saving, using and exchanging seeds/propagating materials. Nor indeed does it prevent national laws from limiting or excluding such rights where the seed/propagating material is protected by Plant Breeders' Rights or where otherwise required by seed trade management considerations.
In light of the existing debate, a clear distinction must be made according to the types of materials involved.

- Farmers' varieties: There is no doubt that farmers can use, exchange, sell or otherwise dispose of the varieties that they have developed and which are not subject to third parties' IPRs. In fact, most farmers' varieties ("landraces") 
are today outside the IPRs system, except in rare cases. Hence, the farmer that has developed such varieties cannot be prevented from any action relating to them. At the same time, he/she has no legal power to prevent others from using or reproducing such varieties; this is precisely one of the problems that some proposals for sui generis protection aim to address.

- Farmers' own produce: Farmers are free to sell, exchange or share their own produce, whether it has been obtained from their own varieties or with varieties protected by IPRs (unless this right is curtailed by contractual obligations agreed with seed distributors). In this sense, the recognition of the right to dispose of the "farm produce" as proposed, for instance, in the Indian draft law on Plant Breeders' Rights, does not mean any significant concession to farmers, since they legally already enjoy the right to sell it.

- Protected varieties: The situation may be substantially different, however, in relation to the sale or other forms of distribution of seeds for propagating purposes, when such seeds are protected by IPRs held by third parties. Historically, national legislation for the protection of Plant Breeders' Rights has tended to allow farmers to reuse protected seeds they have saved on their own farms ("farmers' privilege" ${ }^{98}$ ), though it has normally prevented acts that may lead to further propagation without the consent of the Plant Breeders' Rights titleholder.

The scope of the "farmers' privilege" has varied in different national laws. UPOV 1978 was silent on the matter. Nevertheless Article 5(1) of the 1978 Act has been interpreted as implicitly allowing farmers to replant and exchange protected seeds in that it provided the breeder with exclusivity only in production for purposes of commercial marketing, offering for sale and marketing of seeds.

The 1991 revision of UPOV broadened the scope of Plant Breeders' Rights to preclude unauthorized production or reproduction of all protected seed. At the same time, it explicitly allowed for an optional exception to the Breeder's right to be established under national legislation. Under Article 15(2) of UPOV 1991, each Contracting Party may, within reasonable limits and subject to safeguarding the legitimate interests of the breeder, restrict the breeder's right in relation to any variety in order to permit farmers to use for propagating purposes, on their own holdings, seed from protected varieties they themselves have harvested.

Since UPOV 1991, national laws have tended to restrict the scope of the farmers privilege to different degrees, both in developed and in developing countries. Thus, the European Community Plant Variety Rights (Council Regulation EC No. 2100/94) limits the "farmers' exception" to certain species and requires the payment of an "equitable remuneration" to the breeder for planting-back protected seeds, except in the case of "small farmers". In Brazil, law No. 9456 (1997) has established that such exception does not apply in relation to sugar cane. It only benefits small farmers, who can provide or exchange seeds on a non-commercial basis with other small farmers.

In sum, Plant Breeders' Rights provide some room for the farmers' practice of saving seed, but the recent legislative trend has been to restrict the room available for following such practice.

Some options that would reconcile IPRs with the farmers' right to save, sell and exchange IPR protected materials may be consid- 
ered, such as the following, all of which present significant difficulties with regard to practical application:

- Distinguishing different groupings of farmers with regard to the plantingback of protected material, on the basis of volume of output, size of landholdings, species concerned, etc. although such determination is difficult on a practical basis. Thus, a broad farmers' exception may be granted to "primarily-subsistence farmers", or to "small" farmers who customarily reuse seed because they lack access to or financial resources for new seed every growing season. Large farmers in the commercial sector may be subject instead to other, more stringent, rules.

- Exempting exchanges of seed that take place within the same community or with neighbours, and between farming communities.

- Allowing certain sales of seeds as propagating materials, for instance, those that take place within the farmers' customary market area. 


\section{PART IV - THE MULTILATERAL SYSTEM OF ACCESS AND BENEFIT-SHARING}

\section{Article 10 - Multilateral System of Access and Benefit- sharing}

As stated earlier, given the peculiar characteristics of PGRFA, negotiators to the Treaty focussed on the creation of a multilateral system for PGRFA, in harmony with the CBD. This multilateral system obviates the need for determining countries of origin or negotiating terms of access on a case-by-case basis. Instead, facilitated access to genetic materials of an agreed list of crops (set out in Annex I) is to be given, and benefits are to be shared, by Contracting Parties to the Treaty, on the basis of multilaterally agreed terms.

The underlying reasons why a multilateral system for PGRFA was required are numerous. As noted earlier, the maintenance of a high level of intra-specific genetic diversity in crops is essential to preserve yield stability and the ability of crops to resist diseases and adapt to other environmental challenges. Plant breeders, including traditional farmers, need to have easy access to a wide range of genetic diversity in order to develop improved varieties that can meet these challenges. It is particularly important to have access to genetic diversity from the centres of origin and diversity of those crops. Crops often do better outside their centres of origin, where they may be free from their natu- ral pathogens and parasites. But where those or similar diseases and pests strike, it is essential to be able to go back to the centres of origin in order to find resistance to them. When, for example, the famous Irish potato famine struck in the 1830 s, it was necessary to turn to the centres of origin in South America to seek traits of resistance to Phytophthora downy mildew.

The needs are not just one way: all countries and regions are to a large extent interdependent on other countries and regions for plant genetic diversity if they are to maintain food security. Countries, particularly poor, developing countries, cannot rely on purely bilateral arrangements for securing access to the plant genetic diversity they need. Such arrangements cannot respond to the continuous needs of the agricultural sector. To set up purely bilateral arrangements is also too costly. Since all countries face the same needs, the only practical solution is to provide for a system of access and benefit sharing on a multilateral basis.

It is to meet these needs that Article 10 establishes the Multilateral System of access and benefit sharing for PGRFA (of a defined list of crops) and associated information.

10.1 In their relationships with other States, the Contracting Parties recognize the sovereign rights of States over their own plant genetic resources for food and agriculture, including that the authority to determine access to those resources rests with national governments and is subject to national legislation.

10.2 In the exercise of their sovereign rights, the Contracting Parties agree to establish a multilateral system, which is efficient, effective, and transparent, both to facilitate access to plant genetic resources for food and agriculture, and to share, in a fair and equitable way, the benefits arising from the utilization of these resources, on a complementary and mutually reinforcing basis.

In Articles 10.1 and 10.2, as well as in the Preamble to the Treaty, the Contracting Parties specifically assert that they have sovereign rights over their PGRFA, and that they are exercising these sovereign rights in establishing the multilateral system. Sovereign rights over PGRFA and the authority of national governments to determine access to those resources are central concepts in the CBD. This article links with the CBD, and makes it clear that the Multilateral System established by the Treaty is fully in harmony with the Convention. Indeed the rules set out in Article 15 of the Treaty governing access and benefit-sharing for the Multilateral 
System are intended to apply, inter alia, Article 15.2 of the CBD to PGRFA:

"[Parties] shall endeavour to create conditions to facilitate access to genetic resources for environmentally sound uses by other Contracting Parties and not to impose restrictions that run counter to the objectives of this Convention”

as well as Article 15.4:

"Access, where granted, shall be on mutually agreed terms and subject to the provisions of this Article"

and Article 15.5:

"Access to genetic resources shall be subject to prior informed consent of the Contracting Party providing such resources, unless otherwise determined by that Party."

By becoming party to the Treaty, Contracting Parties have mutually agreed, at the multilateral level, on the terms of access and benefit sharing for PGRFA covered by the Multilateral System to be used in transactions among themselves, and have given their prior informed consent on a multilateral basis, as a means of facilitating access to those PGRFA.
In addition to asserting the Parties' sovereign rights, Article 10.2 establishes the scope of the multilateral system. First, it serves a dual purpose, that is:

- To facilitate access to PGRFA; and

- To share the benefits arising from the utilization of PGRFA fairly and equitably.

These two purposes must operate on a "complementary and mutually reinforcing basis". As such, it would be inconsistent with the Treaty for Contracting Parties to promote a multilateral system that provides access without benefit-sharing, or benefit-sharing without access. Moreover, the processes of facilitating access, and sharing benefits should ideally strengthen each other.

Finally, Article 10.2 provides that the purposes of the multilateral system must be achieved in a manner that is "efficient, effective, and transparent". This provision refers, at least in part, to the institutional structure of the multilateral system, and is similar to some previous proposals, including those put forward as early as June 1991 by the participants at the Keystone International Dialogue Series on Plant Genetic Resources at their third plenary session in Oslo as part of their "Global Initiative for the Security and Sustainable Development of Plant Genetic Resources". 


\section{Article 11 - Coverage of the Multilateral System}

The Multilateral System having been established in Article 10, Article 11 establishes its scope. After much debate, it was agreed that while the scope of the Treaty in general would be "PGRFA" (as defined in Article 3), the multilateral system would only apply to PGRFA of a specified list of crops, chosen because countries' interdependence on them and their importance for food security. This is partly because some countries wanted to see how benefits would flow under a limited multilateral system before committing themselves to a wider coverage. It was also because some countries wanted to limit the application of the multilateral system so as to allow for bilateral arrangements for access and benefit sharing of other PGRFA.

\subsection{In furtherance of the objectives of conservation and sustainable use of plant genetic resources for food and agriculture and the fair and equitable sharing of benefits arising out of their use, as stated in Article 1, the Multilateral System shall cover the plant genetic resources for food and agriculture listed in Annex I, established according to criteria of food security and interdependence.}

Article 11.1 states that the multilateral system will cover the PGRFA listed in Annex I.

It also states that the list in Annex I is "established according to criteria of food security and interdependence." This reflects a historical statement referring to the way in which the list was put together. A first draft list was indeed proposed on the basis of the importance of the crops to food security and interdependence, although it was negotiated by States on the basis of other factors too. But as a historical statement, the phrase is of limited legal importance. The list has been established, and it is the list that governs whether a crop is within the Multilateral System or not. The statement of the basis on which the list is elaborated will however have legal import in the interpretation of the list and more particularly in considering future amendments to the list. These, under Article 23 and 24, must be adopted by consensus of the Governing Body. But the phrase "established according to criteria of food security and interdependence" gives criteria as to the crops that can, or should be included into the list in the future. Similarly, the introductory phrase to Article 11.1 ("In furtherance of the objectives of conservation and sustainable use of PGRFA and the fair and equitable sharing of benefits arising out of their use, as stated in Article 1") provides not only an explanation of how the list was put together and a tool for interpretation, but also a yard stick for future amendments, and good grounds on which new additions to the list may be put forward.

One of the criteria for the establishment of the list is "food security". The term "food secu- rity" has been defined in the World Food Summit Plan of Action. The introduction to the GPA states that it has to be considered "at the individual, household, national, regional and global levels. Food security exists when all people, at all times, have physical and economic access to sufficient, safe and nutritious food to meet their dietary needs and food preferences for an active and healthy life". More specifically, Objective 2.3 states that food supplies should be "safe, ... appropriate and adequate to meet the energy and nutrient needs of the population".

According to this agreed definition, food security has to be considered not only at a global level, but also at a regional and local level. Many minor crops, for example, are staple crops for populations regionally or locally. Importantly in this respect, Annex I to the Treaty includes taro, coconut, yam and grass-pea, staple crops of importance only for specific regions. In light of the criterion of "food security", Annex I should take into account a qualitative component. Some crops may bring rare aminoacids, rare lipids, vitamins, minerals, or any nutritional factor facilitating digestion or maintaining health by having bactericidal or vermifuge properties. Such a qualitative approach would suggest the inclusion of most fruits and nuts, as well as herbs and spices. Nevertheless, it is widely recognized that food security depends on a wider range of plant species that can be accommodated on any manageable list.

Annex I was the subject of substantial scientific input from experts through forums such as technical workshops and groups of experts. Nevertheless, the initial negotiating 
position of regions had some wanting as few as 6 crops for the multilateral system, while another pushed for more than 400. As the list was to be agreed "by consensus," negotiations began with the list of 6 crops and expanded largely as a result of countries' becoming convinced of the need to include more crops, including many of interest to the CGIAR within the Multilateral System. Ultimately, the Contracting Parties agreed that Annex I would include some 40 or so crops ${ }^{99}$ and 29 forage species (see Annex I). Nevertheless, soybean, groundnut, oil palm, flax, sugarcane, tomato and most tropical forages are excluded from the system. Moreover, certain species that are part of the genepool used by breeders of cassava, maize, potato and common beans are also excluded. The list does not include industrial crops such as tea and coffee, which thus fall totally outside the Multilateral System.

In addition to the problem of which crops to include, negotiators faced the related problem of how to define each crop in operational terms such that Contracting Parties and other actors might know, with certain precision, what fell within the scope of Annex I. There was never any doubt that wheat would be included in the multilateral system. But, what, precisely, does "wheat" really mean? Panels of experts provided scientific information on these and other questions (such as which forage species are most important to food security). In the end, negotiators listed crops, often as much on the basis of political as scientific criteria, including indicative genus/genera, noting whenever a particular genus or species was excluded.

In some cases, negotiators decided to exclude specific species associated with a crop, and in some cases the excluded species are ones typically considered part of the genepool that a breeder might use or want access to. Two examples would be Phaseolus polyanthus and Solanum phureja. The definition of cassava includes Manihot esculenta only, thus wild relatives now being used to increase protein content and improve disease resistance, are excluded from the
Multilateral System. Finally, some definitions are simply ambiguous. For example, "Wheat" is included in Annex I, but defined as "Triticum, et al.". The meaning of "et al." is left unclear. Additions and exclusions to Annex I can be made by consensus by the Governing Body. The extent to which the list is changed in the future will depend on the experience of countries in the initial running of the Multilateral System, including in particular the extent to which real benefits are perceived to flow under the System.

Importantly, in defining the coverage of the multilateral system, Article 11 makes no distinction between pre-existing material held and material acquired after entry into force of the Treaty. Material collected before, and after, entry into force of the CBD are also treated equally. In this way, only for PGRFA crops included in Annex I, Article 11 of the Treaty was intended to resolve the status of those $e x$ situ collections that were not "acquired in accordance with the CBD", as requested in the Nairobi Final Act. Other aspects are clarified in Article 15.

Aside from its substantive content, the text of Annex I is less than clear in certain regards, reflecting the state of biological science and changes in knowledge over time. For example, the Treaty acknowledges only implicitly the fact that taxonomists and breeders disagree about what is included within a particular crop gene pool. Knowledge of such groupings changes over time. It is questionable whether the materials under the Multilateral System will expand and contract as taxonomic understandings of what constitutes a particular genus evolve. Assuming that the Governing Body will not want to undertake the cumbersome and costly task of constituting its own taxonomic authority, on what basis will Contracting Parties and centres decide whether questionable categories/materials are included or excluded? Practically speaking, how would the Treaty handle cases where materials considered today to be part of Annex I, fall off the list by virtue of changes in taxonomic practices?

It is difficult to be specific on the number of crops included. The list of crops in Annex I has 35 entries. But some of these entries, such as "Brassica complex" include a number of distinct crops. In other cases, individual crops are excluded from the general entry, as for example, in connection with the listing of "maize". 
11.2 The Multilateral System, as identified in Article 11.1, shall include all plant genetic resources for food and agriculture listed in Annex I that are under the management and control of the Contracting Parties and in the public domain. With a view to achieving the fullest possible coverage of the Multilateral System, the Contracting Parties invite all other holders of the plant genetic resources for food and agriculture listed in Annex I to include these plant genetic resources for food and agriculture in the Multilateral System.

11.3 Contracting Parties also agree to take appropriate measures to encourage natural and legal persons within their jurisdiction who hold plant genetic resources for food and agriculture listed in Annex I to include such plant genetic resources for food and agriculture in the Multilateral System.

11.4 Within two years of the entry into force of the Treaty, the Governing Body shall assess the progress in including the plant genetic resources for food and agriculture referred to in paragraph 11.3 in the Multilateral System. Following this assessment, the Governing Body shall decide whether access shall continue to be facilitated to those natural and legal persons referred to in paragraph 11.3 that have not included these plant genetic resources for food and agriculture in the Multilateral System, or take such other measures as it deems appropriate.

Originally it was the intention of many of the negotiators to include all listed PGRFA in the Multilateral System and not just those under public management and control and in the public domain. It was thought by these negotiators that this would be simpler and would eliminate the need for contractual MTAs to accompany accessions obtained from the Multilateral System thus reducing transaction costs. The obligations under the Multilateral System would then need to be enforced through national policy or legislation. A number of countries, however, believed that it would be necessary to limit the obligations of Contracting Parties to material under their control and for which they were responsible as well as to materials placed voluntarily in the Multilateral System, and that the obligations attached to the accessions obtained from the Multilateral System would need to be passed on through some form of contractual instrument. In the end, and rather late in the negotiations, it was the latter view that prevailed. Once a contractual approach was agreed for Article 13.2(d)(ii), the limitation of the Multilateral System to materials under public management and control and in the public domain became inevitable. Indeed many governments felt that legally they could only commit to contractual conditions concerning PGRFA under their management and control and in the public domain, or PGRFA voluntarily placed in the Multilateral System by their holders: to purport to deal with all material subject to the property rights of individual natural or legal persons within their jurisdiction would, in their view, be to deprive those persons of some elements of those rights.

Article 11.2 thus states that the multilateral system includes "all PGRFA listed in Annex I that are under the management and control of the Contracting Parties and in the public domain". In this connection it should be noted that, according to the first Report on the State of the World's Plant Genetic Resources for Food and Agriculture, some $88 \%$ of global PGRFA held ex situ is indeed maintained in national collections.

The expression "under the management and control" of a Contracting Party is a factual as well as a legal qualification. If the collection is actually managed and controlled by the Contracting Party, then this qualification is met: if on the other hand the collection is managed and controlled by a separate entity over which the State does not have any control, then the qualification is not met. The issue may become more significant in countries that have a federal system and where genebanks are under state or provincial control, or in other countries where genebanks have been set up as public entities outside the government's direct control. In such countries, it would appear that such collections are not prima facie covered, and the extension of the system to cover those collections would need to take place with the consent of the institutions concerned. This is provided for under Article 11.3 of the Treaty. 
The expression "in the public domain" is a qualification of a legal nature. The term "public domain" means either public property or, in intellectual property law, materials which are not protected by intellectual property rights. In the present context, the expression "in the public domain" clearly has the latter meaning. This is not to say that the Multilateral System cannot include material that is protected by intellectual property rights. Such material can, of course, always be included in the Multilateral System voluntarily by the holder of such rights under Article 11.2. But those PGRFA are not automatically included within the purview of the Multilateral System.

The Multilateral System thus essentially applies to plants, seeds, cuttings, etc. that are managed and controlled by governments of Contracting Parties and free from intellectual property rights. This would exclude all provincial government, public (non-governmental) entity and private holdings of plant genetic resources, and any material over which intellectual property rights are claimed. As property rights in the material found in the collections are to be respected (see Article 12(3)(f)), a number of delegates thought these additional restrictions were unnecessary. However, the limitation is balanced by four provisos:

- First, all other holders of PGRFA listed in Annex I are invited to include those genetic resources in the Multilateral System, with the aim of achieving the fullest possible coverage of the multilateral system (Article 11(2)); ${ }^{100}$

- Second, parties agree to take measures to encourage natural and legal persons under their jurisdiction to include in the multilateral system the listed PGRFA that they hold (see Article 11(3));

- Third, there is a built-in review by the Governing Body to assess progress on including PGRFA held by natural and legal persons within the Multilateral System within 2 years of the entry into force of the Treaty (Article 11(4)); and

- Fourth, there is a provision for the Governing Body, following the review, to decide (consistent with the provisions of Art. 19.2) whether or not access shall continue to be facilitated for those natural and legal persons that have not included their holdings of PGRFA in the Multilateral System (Article 11(4)).

The review provisions, and threat of possible exclusion from the benefits of the Multilateral System, are intended to encourage the holders of semi-public and private collections, such as provincial governments, universities and independent research institutes, and private collectors, to place their PGRFA voluntarily within the multilateral system.

\subsection{The Multilateral System shall also include the plant genetic resources for food and agriculture listed in Annex I and held in the ex situ collections of the International Agricultural Research Centres of the Consultative Group on International Agri- cultural Research (CGIAR), as provided in Article 15.1a, and in other interna- tional institutions, in accordance with Article 15.5.}

The Treaty recognises in Article 15.1 the importance to the Treaty of the $e x$ situ collections of PGRFA held by the IARCs of the CGIAR in trust for the international community, as well as ex situ collections held by other international institutions. Article 11.5 includes within the

100 Article 11.2 refers to "all other holders" of Annex 1 PGRFA. Would this also apply to holders of Annex I PGRFA in a Non-Contracting Party? In principle it would seem not. Article 11.2 addresses the coverage of the Multilateral System as between Contracting Parties, and the second sentence would seem to complete the concept of coverage in the same context. In any case, nothing would prevent the holder of PGRFA listed in Annex 1 from making such material available under the same terms as the Multilateral System. Conversely, a unilateral voluntary action by the holder of such PGRFA that is not within the jurisdiction of a Contracting Party, would not create any rights of obligations on the part of that non-Contracting Party. 
multilateral system the PGRFA held in those collections and listed in Annex I, subject to the provisions of Article 15. In this connection, it is interesting to note that the criteria established in Article 11.2 do not apply to PGRFA held by the IARCs. In practice, of course, PGRFA held in the in-trust collections are not under the management and control of a Contracting Party. The in-trust collections also do not normally include material that is subject to intellectual property rights, although they could include such material.

Article 11.5 also provides for the inclusion within the multilateral system of the ex situ collections of other international institutions that sign agreements with the Governing Body. This is further described at Article 15.5.

For plant genetic resources listed in Annex 1 , access and benefit sharing are to be in accordance with the Treaty (Article 12 and 13). Plant genetic resources not listed in Annex 1 and collected before the entry into force of the Treaty, are to be made available in accordance with MTAs currently in use between the FAO and the IARCs (see Articles 15.1(a) and (b)). ${ }^{10}$

The role of the IARCs and other international institutions, and the collections they hold, is dealt with in more detail in Article 15.

101 Article 15.1(a) and (b) of the Treaty. 
Explanatory Guide to the International Treaty on Plant Genetic Resources for Food and Agriculture 


\section{Article 12 - Facilitated access to plant genetic resources for food and agriculture within the Multilateral System}

FAO Conference Resolution 7/93, which established the negotiations to revise the International Undertaking, noted that "the Fourth Session of the FAO Commission on Plant Genetic Resources [had] agreed that conditions of access to plant genetic resources that needed further clarification". A significant role of the Treaty is to make easy (to expedite or to make routine) all access to PGRFA of crops included within the Multilateral System. In the words of the Treaty, "facilitated" access. Article 12 specifies the modalities for this facilitated access.

The negotiation of these provisions was difficult and was characterized by the need to maintain a balance between the facilitation of access to PGRFA and benefit-sharing. They were also characterized by the desire of a number of delegations to ensure that facilitated access should be restricted to access for the purposes of research, breeding and training for food and agriculture, and should not in any way extend to access for chemical, pharmaceutical or other non-food/feed industrial purposes. There was also some tension in the negotiations between the need to ensure that the procedures for access are indeed designed to facilitate and expedite access transactions, without the need to track individual accessions, and the need to ensure that the obligations under the Multilateral System can be passed on to other recipients and can be enforceable against such recipients. Finally there was the overriding need to ensure that the terms and conditions under which facilitated access is granted are clear and definite and to avoid some of the ambiguities present in the International Undertaking.

\subsection{The Contracting Parties agree that facilitated access to plant genetic resources for food and agriculture under the Multilateral System, as defined in Article 11, shall be in accordance with the provisions of this Treaty.}

The statement that facilitated access to these plant genetic resources is to be "in accordance with the provisions of this Treaty" stresses the special nature of the regime established by the Treaty. In other words, for these PGRFA facilitated access is to be in accordance with the terms set out in the Treaty, which themselves are an implementation on a multilateral basis of the requirements of Article 15 of the CBD. By this, it might be assumed that we do not need to determine "mutually agreed terms" or require "prior informed consent" on a case by case basis: the terms set out in the Treaty are themselves the mutually agreed terms and constitute prior informed consent, established on a multilateral basis. Article 12.1 also implies that the provisions relating to facilitated access to PGRFA under the multilateral system should not be taken in isolation, but should take into account all the relevant provisions of the Treaty, including, of course, the benefit-sharing provisions provided for in Article 13.

12.2 The Contracting Parties agree to take the necessary legal or other appropriate measures to provide such access to other Contracting Parties through the Multilateral System. To this effect, such access shall also be provided to legal and natural persons under the jurisdiction of any Contracting Party, subject to the provisions of Article 11.4.

Article 12.2 lays particular stress on legal measures, implying that in some countries (but not all) new or revised legislation or regulations may be required. Facilitated access is to be provided to other Contracting Parties and to legal and natural persons under the jurisdiction 
of any Party. This means that access will be provided to individuals, as well as to institutions or organizations that have a "legal personality", such as private companies, civil society organizations, etc. that are located in the territory of a Contracting Party, or organized and operating under its jurisdiction. As noted above, the provision of facilitated access for legal and natural persons is subject to a review by the Governing Body of the progress in including other PGRFA (e.g. material in private genebanks) in the Multilateral System.

It is to be noted that this provision does not prevent Contracting Parties from granting access to non-Parties to the Treaty. Moreover, a decision by the Governing Bodies to discontinue facilitated access to private persons and businesses, pursuant to Article 11.4, does not mean that all access should in the future be denied to them. The consequence, however, would be that such access would not be facilitated within the meaning of the Treaty, and not necessarily accord with its terms.

The reference to providing facilitated access to other Contracting Parties and persons and legal entities under the jurisdiction of any Contracting Party also raises a question of interpretation as to whether material obtained domestically under the Multilateral System would be subject to the conditions set out in Article 12.3 and the benefit-sharing arrangements set out in Article 13. Certainly there is no doubt that international transfers, i.e. requests from a person in one country to a genebank in another country, would be so covered. But what is the situation if a natural person in one country requests facilitated access to material in a genebank in the same country? And what is the situation, for example, if a researcher in an IARC accesses material listed in Annex I from the genebank of the same IARC?

Normally international treaties govern relations between Contracting Parties and do not create rights and obligations as between Contracting Parties and their own nationals, unless the particular treaty so expressly states. In this case, the wording of Article 12.2 requires facili- tated access to be provided to legal and natural persons under the jurisdiction of "any" Contracting Party, (i.e. including legal and natural persons under the jurisdiction of the Contracting Party providing access) and does not limit the rights of access to legal and natural persons under the jurisdiction of "any other" Contracting Party. Under the Vienna Convention on the Law of Treaties, treaties are to be interpreted "in good faith in accordance with the ordinary meaning to be given to the terms of the treaty in their context and in the light of its object and purpose." ${ }^{103}$ Quite apart from the literal meaning of Article 12.2, it could well be argued, in this particular case, that to interpret domestic access transactions as being outside the coverage of the Multilateral System would create a "loophole" in the Treaty that would defeat the objectives of the Treaty as set out in Article 1. If recipients of PGRFA were able to demand access to Annex I materials from their own national genebanks outside the framework of the Treaty and then export those materials to other companies, or their own subsidiaries, in other jurisdictions free of all obligations under the Multilateral System, then the whole Multilateral System would soon become unworkable.

However, despite the above, the situation with respect to domestic transfers remains unclear and is being interpreted in different ways by various Contracting Parties.

The situation with respect to the use by IARC researchers of material within the same IARC's genebank is also less than clear. The objectives of the Treaty would favour treating this use as an accession obtained under the Multilateral System. That interpretation, however, is less clearly supported by the actual words used in Article 12.2. In this case the accession is not obtained by a separate entity, but by the IARC itself, albeit of material "held in trust" for the international community. It will be interesting to see how the Contracting Parties, and the IARCs themselves, implement these provisions in practice. Similar considerations would be applicable to the use by Government plant breeders of materials maintained in national government genebanks. 
Under the Treaty, a Contracting Party is obliged to provide access to PGRFA in the multilateral system when requested to do so by another Contracting Party, when requested by any legal or natural person under the jurisdiction of a Party, or when requested by a IARC or other international institution that has signed an agreement with the Governing Body under Article 15. These then are the cases in which facilitated access must be accorded as set out in the Treaty. As noted above, this does not preclude Contracting Parties from granting access to other materials in other cases, nor does it preclude a Contracting Party from applying the same terms and conditions to those other materials and cases. In practice, and in order to apply a single set of conditions for all transfers, parties and international institutes could decide to provide all material according to the terms of the facilitated access in Articles 12.3 and 12.4, thus both simplifying the administration of access and optimizing the sharing of benefits on a multilateral basis. Given the benefits of access to as broad a range of PGRFA as possible, this should be strongly encouraged.

\subsection{Such access shall be provided in accordance with the conditions below:}

The agreed conditions set out in Article 12.3 apply to "facilitated access" under the Multilateral System. The conditions for such access are set out in the eight paragraphs of Article 12.3. As noted above in the commentary on Article 9 on Farmers' Rights, the question arises as to whether these conditions are exclusive or whether new conditions could be imposed. Certainly in so far as conditions outside the Treaty are concerned, these are excluded by the wording of Article 12.1., i.e. the agreement that facilitated access under the Multilateral System shall be in accordance with the provisions of the Treaty. In so far as other provisions of the Treaty are concerned, as for example the right of farmers to participate equitably in the sharing of benefits arising from the utilization of PGRFA, this is a matter for interpretation by the Contracting Parties themselves, although it seems clear as a general principle that the Treaty intended that benefit-sharing under the Multi- lateral System should be on a multilateral basis and not on a bilateral one.

Articles 12.3(a) through (h) specify conditions under which access is provided and identify circumstances under which access might be denied legitimately. These paragraphs are critical to the working of the Multilateral System. In general, they acknowledge the applicability of intellectual and other property rights over the material. They call for Contracting Parties to make available not just the genetic material, but also associated, descriptive, non-proprietary information, including information on the history of the accession.

However, it is important to note that the paragraphs do leave open some practical implementation points. These will need to be resolved by the Governing Body.

\section{(a) Access shall be provided solely for the purpose of utilization and conservation for research, breeding and training for food and agriculture, provided that such purpose does not include chemical, pharmaceutical and/or other non-food/feed industrial uses. In the case of multiple-use crops (food and non-food), their importance for food security should be the determinant for their inclusion in the Multilateral System and availability for facilitated access.}

It was agreed that material made available through the multilateral system should be "provided solely for the purpose of utilization and conservation for research, breeding, and training" for food and agriculture. It is therefore fundamental to note that it is the use of the material, and not the material itself, that will decide whether the Multilateral System will apply. This is particularly relevant in the case of multi-use crops. The paragraph clearly states that chemical, pharmaceutical and other industrial uses beyond food and animal feed are excluded from the facilitated access under the multilateral system. Consequently, those seeking access for such purposes will need to make separate arrangements. However, the text does not exclude the development of other agreements for particular uses, or regional agreements covering such uses. This means that holders of PGRFA under the Multilateral Sys- 
tem can supply them for purposes other than those stipulated by the Treaty, including industrial uses, but in such cases the preferential conditions provided for under the Multilateral System will not automatically apply.

Article 12.3(a) does not specifically allow nor sanction access for the purpose of direct use by farmers for cultivation. However, the negotiators clearly did not want genebanks to compete with ordinary distribution of seed or propagating material to farmers, and such access for direct use must be considered to be out of the ordinary. This situation occurs, for example in cases where an accession is desired for a particular niche market (a colourful potato, for instance) and no further breeding work is needed, as well as in cases where the crop itself is the subject of little breeding work (e.g., pulses) or to enrich the genetic diversity in farmers' fields for subsequent selection. Article 12.3(a) does not expressly provide for facilitated access for direct use or multiplication. This omission may be interpreted as an intentional exclusion of such a use from the scope of facilitated access under the Multilateral System. The situation is of particular significance for, but by no means unique to, the IARCs of the CGIAR. Currently, the MTA used under the FAO-CGIAR in-trust Agreements allows for access for such purposes. In adopting the interim MTA to be used by the IARCs under the in-trust Agreements with FAO, the Commission, at its Ninth Session (2002), agreed on the following footnote:

This does not prevent the recipients from releasing the material for purposes of making it directly available to farmers or consumers for cultivation, provided that the other conditions set out in this MTA are complied with.

A possible interpretation, that would not run counter to either the actual wording of the Article 12.3(a) or the objectives of the Treaty, could be that while direct use for cultivation is not a use for which facilitated access can be demanded, this would not prevent the release of material for direct use for cultivation where this is in accordance with the objectives of the Treaty and is necessary for the fulfilment of the mandates of the institutions concerned. This may happen more and more often as genebanks provide a safe haven for material used on-farm that is becoming increasingly threatened.

The last sentence of Article 12.3(a) is a little troublesome. The sentence provides that "In the case of multiple-use crops (food and non-food), their importance for food security should be the determinant for their inclusion in the Multilateral System and availability for facilitated access." It is strange that this sentence is sited here rather than in Article 11.1, since that provision, too, appears to be dealing with the coverage of the Multilateral System rather than with conditions of facilitated access. In fact the sentence seems to fall somewhere in between the concept of "conditions of access" and that of "coverage". Perhaps the keyword in the provision is the word "determinant", which raises the question, "who is to determine that a particular multi-use crop should be in the multilateral System?" If the decision is made at the time of the inclusion of the crop in Annex I, then the decision is made in a collegiate fashion by consensus of the Contracting Parties. If on the other hand the decision is made at the time of a request for the PGRFA in question, then the decision would be made by primarily by the Contracting Party providing the PGRFA in the light of the circumstances of the request. In the context of Article 12.3(a), it would appear that the intent is to leave this decision to the Contracting Party providing the sample, in dialogue with the Contracting Party (or natural or legal person) requesting it. The provisions of Article 12.3(a) presuppose that the PGRFA is included in Annex I and that the last sentence is not intended to be a way to extend that list. It must therefore be seen as a way of reinforcing the provisions of the first sentence of the Article.

\section{(b) Access shall be accorded expeditiously, without the need to track individual acces- sions and free of charge, or, when a fee is charged, it shall not exceed the minimal cost involved;}

Paragraph (b) attempts to ensure the efficient operation of the multilateral system by reducing transaction costs and maintaining speedy access to PGRFA.
The requirement that access be accorded expeditiously requires no comment, beyond indicating that the requirement must be interpreted in a reasonable way. For example, it may 
be the case that a genebank runs out of material and therefore has to regenerate it before being able to meet supply commitments. This would of course not run counter to the requirement that the access be accorded expeditiously, provided that the delay is reasonable in the circumstances. Nor would the inability to provide samples for reasons of force majeure.

The specific statement that there is no need to track individual accessions requires comment. It was the expectation of many of the negotiators that all PGRFA contained in the Multilateral System would be covered automatically, and that there would be no need to track individual accessions or to provide for any form of MTA. Obligations under the Multilateral System would thus be enforced through national legislation, and not necessarily through a contractual nexus between the holder and recipient of the plant genetic resources. With the decision late in the negotiations to include only material under the management and control of Contracting Parties, and other material put voluntarily into the system, and the adoption of an MTA as the vehicle for imposing obligations, the meaning of this particular requirement seems to have changed somewhat. To a certain extent, the use of MTAs means that individual transfers are automatically formally recorded. Subsequent transfers too will require MTAs. The requirement now apparently means that holders of PGRFA will not be required to track all subsequent transfers of the material accessed. Any "tracking" of the provenance of materials accessed from the Multilateral System will be done where necessary "after the event", i.e. where a product has been produced that incorporates material access from the Multilateral System, and if and when there is any dispute regarding non-compliance with the terms and conditions of access by subsequent recipients.

With respect to the requirement that access be accorded free of charge, there is general recognition that administrative fees may be charged, but that these should not exceed the costs involved nor constitute a hidden access fee.

\section{(c) All available passport data and, subject to applicable law, any other associated available non-confidential descriptive information, shall be made available with the plant genetic resources for food and agriculture provided;}

Paragraph (c) specifies what types of information, in addition to the germplasm, shall be made available.

Passport data is the basic data that describes and identifies the particular material. It will normally include the accession identifier number or other identifier assigned by the donor or collector (or, in the United States' system, the Plant Introduction number); species, subspecies and other taxonomic descriptor; the varietal or local name; the biological status, e.g. cultivated or wild; the providing country or international collection; data such as the geographical location and date of collection and the identity of the collector. A list of minimum passport data is included in the FAO/IPGRI descriptor lists, available through the IPGRI website. This may, however, later be defined in the standard MTA, when adopted.

Other associated available information would normally include characterization information, and evaluation data. These are discussed in the Guide under Article 5.1(e).
The scope of this obligation, however, may be subject to further qualification and definition in the drafting of the standard MTA since providing all relevant descriptive information may be expensive and time-consuming. How the information is to be distributed may also need to be resolved. For example, would a reference to information available on the Internet be sufficient?

In referring to other associated available information, Paragraph (c) makes the qualification that this material is to be made available "subject to applicable law". The implicit reference here is to any information covered by intellectual property rights. Copyright and trade secret are particularly relevant in the case of evaluation data.

Note that the subject of information exchange is addressed more generally in Article 13.2(a), though not necessarily in the context of individual accessions. 
(d) Recipients shall not claim any intellectual property or other rights that limit the facilitated access to the plant genetic resources for food and agriculture, or their genetic parts or components, in the form received from the Multilateral System;

The provision on intellectual property rights in Article 12.3(d) was one of the most controversial points in the Treaty negotiations. During the negotiations, all countries agreed that intellectual property rights, such as patents and Plant Breeders' Rights, should not be applied to the PGRFA in the form that they are actually received from the Multilateral System. A similar provision is con- tained in the "in-trust" agreements between the FAO and the IARCs. This paragraph is crucial in determining the extent to which intellectual property rights can be applied to material accessed from the Multilateral System. Unfortunately, this provision contains some ambiguities that leave it open to different interpretations. This is largely due to three principal issues:

\section{(1) Intellectual property or other rights that limit the facilitated access...}

The provision prohibits the recipients from claiming "intellectual property or other rights that limit facilitated access". Intellectual property rights would refer to any kind of intellectual property rights, notably including patents, breeders' rights and trade secrets. "Other rights" may include ownership claims with regard to the samples received.

For this purpose, the term "facilitated access" is not defined in the Treaty. But it is clear that facilitated access is the type of access to PGRFA under the Multilateral System that Contracting Parties have bound themselves to provide in accordance with the provisions of Article 12. Article 12.3(a) specifies that facilitated access shall be provided "solely for the purpose of utilization and conservation for research, breeding and training for food and agriculture". Article 12.3(d) would thus appear not to prohibit recipients from taking out Plant Breeders' Rights and patents that include a breeders' exemption over the material received, as these would not have the effect of limiting further facilitated access to the PGRFA for these purposes.

Of course, intellectual property offices may well normally refuse claims to intellectual property protection over material received from the Multilateral System without any subsequent improvement of the material. But quite apart from that, it seems unlikely that it was the intention of negotiators to allow recipients to seek Plant Breeders' Rights or patents with research exemptions over material received from the Multilateral System in the form received. Certainly it would not be in line with previous practice, as in the MTAs used by the IARCs of the CGIAR under the "in-trust" agreements with FAO. In view of the above, this is a matter that the Governing Body may wish to clarify, perhaps in the context of the adoption of the standard MTA. ${ }^{104}$

From the structure of the sentence, the prohibition would appear to be not against claiming intellectual property or other rights over the material in the form received from the Multilateral System, but rather against claiming intellectual property or other rights that limitfacilitated access to the material in the form received from the Multilateral System. ${ }^{105}$ If this is the correct interpretation, the implication is that no intellectual property rights can be taken out over the material, or subsequent products derived from that material, if the effect would be reach back and limit facilitated access by others to the original material accessed. Normally, intellectual property rights do not limit such access.

However, the meaning of the sentence does appear to be ambiguous, in that many commentators still view the provision as simply meaning that recipients cannot claim intellectual property rights over the material in the form received from the Multilateral System.

104 Under Article 12.4 of the Treaty, the standard MTA to be adopted by the Governing Body is to contain, inter alia, the provisions of Article 12.3(d).

It is difficult to construe the sentence to read otherwise. The words "that limit facilitated access" appear to qualify both "intellectual property" and "other rights". Even if the words "intellectual property" were to be construed to mean "intellectual property rights" and to stand on their own, the limitation "that limit facilitated access" is necessarily brought in by the use of the word "other". 


\section{(2) "PGRFA or their genetic parts or components"}

In Article 2 of the Treaty, the terms "PGRFA" and "genetic material" are defined. The same cannot be said, however, for the concept of "genetic parts or components". While unclear, this term would presumably include genes, or any parts thereof, found in the accessed materials.

\section{(3) "In the form received"}

The words "in the form received" would obviously mean that intellectual property rights cannot be taken out over the material as received from the Multilateral System, as this would by definition limit facilitated access by other people to that material. Nor could such intellectual property rights be taken out over products derived from that material if the effect of those intellectual property rights is to limit access to the original material, or their genes or any parts thereof, in the form received.

However, what would constitute "in the form received". Would this exclude genes isolated from the material received, because the PGRFA were not received in the form of isolated genes? Would the addition of a single 'cosmetic' gene (e.g. through transformation or conventional back-crossing) to an accession as received be sufficient to differentiate a new product from the material received from the Multilateral System? Is inclusion of an essentially unaltered gene within a new construct sufficient?
If this is indeed so, then the wording of Article 12.3(d) would mean that no intellectual property rights may be taken out over the material accessed from the Multilateral System that would limit facilitated access to the original PGRFA, or their genes or any parts thereof, "in the form received" from the Multilateral System.

Such issues are believed to be addressed in intellectual property law and practice, as reflected in relevant international agreements and national laws. They will presumably be addressed by countries in due course, either in their individual capacities within the context of their own intellectual property rights systems, or acting collectively in the Governing Body or other appropriate international forum. In the meantime, the ambiguities of Article 12.3(d), and in particular of the words "in the form received" have caused a number of developed countries to stress their understanding, at the time of adoption of the Treaty, that the provision does not in any way modify or limit intellectual property rights as protected by existing or specific intellectual property agreements. ${ }^{108}$ In interpreting this paragraph, however, Contracting Parties may wish to consider the context of Article 12 as a whole, which appears to indicate that the reason for preventing intellectual property rights under certain circumstances is to ensure access for the purpose of research and breeding of the material received.

\section{(e) Access to plant genetic resources for food and agriculture under development, including material being developed by farmers, shall be at the discretion of its developer, during the period of its development;}

As with proprietary information, Article 12 provides some exceptions relating to the kinds of genetic materials that must be made available, and when. Genetic material "under development" need not be made available during its period of development, although farmers and breeders can make it available if they choose. While the intention of Article 12.3(e) may be reasonably clear, the wording of this provision is somewhat flexible in that it does not specify what "under development" means, nor does it define when the "period of development" ends. The practical result, nevertheless, appears to be that breeders' lines and farmers' breeding material do not have to be released during the period that they are being developed and retained for use in producing a new variety. The provision follows the concept introduced into the Interna-

106 See the statements made by the delegates of Australia, Canada, Japan, USA, and the European Community at the time of adoption of the Treaty by the FAO Conference. 
tional Undertaking under the third Agreed Interpretation of the International Undertaking in 1991 (Conference Resolution 3/91), which specified in its operative paragraph 2 " $t$ that breeders' lines and farmers' breeding material should only be available at the discretion of their developers during the period of development". In Paragraph (e) the explicit reference to breeders' lines has been dropped, but breeder's lines are of course included in the general reference to PGRFA under development.

(f) Access to plant genetic resources for food and agriculture protected by intellectual and other property rights shall be consistent with relevant international agreements, and with relevant national laws;

Article 12.3(f) ensures that intellectual property rights, such as Plant Breeders' Rights and patents, are not extinguished in PGRFA when they are included in the Multilateral System, or when a sample is acquired from the Multilateral System. Since only PGRFA in the public domain and under the management and control of the Contracting Parties are included automatically in the Multilateral System, this paragraph must refer mainly to material included voluntarily in the Multilateral System by their holders at the invitation and with the encouragement of the
Contracting Parties. Intellectual property rights are, in general, rights to control access to or use of material. When a rights holder permits use, that individual can track the material, charge for certain uses, and otherwise control the material. Rights holders can also choose not to exercise these rights. Intellectual property rights are also basically territorial in nature, i.e. they are protected only in the individual jurisdictions where they have been registered. The protection they afford thus depends on national laws. National laws on intellectual property rights, in turn,

\section{Box 11. Intellectual Property Rights over PGRFA}

Article 27.3(b) of the WTO TRIPS Agreement provides that parties may exclude from patentability plants and animals other than micro-organisms, and essentially biological processes for the production of plants and animals, other than non-biological and microbiological processes. They must, however, provide for the protection of plant varieties either by patents or by an effective sui generis system or by any combination of both. This box will briefly examine the most common types of intellectual property rights: patents, Plant Breeders' Rights, and undisclosed information (trade secrets).

\section{Patents}

Patents are a form of intellectual property protection available for inventions, whether products or processes, that are new, involve an inventive step (non-obvious) and are capable of industrial application (useful). Patents entail a prohibition (ius excluendi) on the unauthorised use of the patented material by third parties, usually for a period of 20 years. Under Article 28.1(a) of the TRIPS Agreement, patents relating to products confer the right to prevent third parties from "making, using, offering for sale, selling, or importing for these purposes" the product, without the patentee's consent. In the case of process patents, the patentee may prevent the unauthorised use of the process as well as the commercialization of a product "obtained directly by that process".

Arguably, if a plant variety is patent-protected, it may not be possible to use the propagating material of that variety for commercial purposes, including breeding new varieties. Similarly, if modified plant cells are patented, commercialization of any plant composed of those cells would infringe the patent. This is one of the main concerns of Indian cotton producers in view of the patent on all transgenic cotton conferred on Agracetus (US patent No. 5,159,135), and of Andean farmers with respect to the patent granted to Colorado State University (US patent No. 5,304,718). As noted above, the TRIPS Agreement allows parties to exclude plants from patenting, although that exclusion cannot extend to micro-organisms, or to non-biological and microbiological processes. The relationsship between plants and patents varies greatly among jurisdictions. Plant varieties can be excluded from patentability, and are so excluded, for example in European countries by virtue of the European Patent Conven- 
tion. ${ }^{107}$ In the USA, on the other hand, patents can and have been granted for plant varieties. There are also differences among countries in the extent to which naturally occurring substances can be subject to patent protection. The normal rule is that substances freely occurring in nature can only be discovered and thus are not patentable. Even here, however, it may be possible to obtain patent protection for biological material (e.g. DNA) isolated from its natural environment or produced by means of a technical process. Moreover, if the substance has first to be isolated, the process for isolating it may itself be patentable. There are also some differences with respect to the scope of the protection afforded to patent holders.

Patents in some jurisdictions, such the USA, restrict the use of protected materials for further research and variation. In other jurisdictions, such as those in Europe, patent protection allows for experimentation, even for commercial purposes, as an exception to the exclusive patent rights. Patents, like other intellectual property rights are territorial in nature, in that the protection they afford is only available in the national jurisdiction in which registration has been granted. This means that the title-holder cannot exercise his rights outside the jurisdiction where the patent has been registered. However, he can prevent the importation into the jurisdiction of products containing the invention that are made elsewhere.

\section{Plant Breeders' Rights}

Plant Breeders' Rights can be claimed over new plant varieties, provided that they are distinct, uniform and stable. ${ }^{108}$ Anyone can be awarded a Plant Breeders' Right, as long as the variety fulfills these criteria. As with patents, Plant Breeders' Rights give the holder the right to exclude third parties from using those materials for production or reproduction (multiplication) and related acts (conditioning for propagation, offering for sale, selling, importing/exporting, stocking) without the holder's consent. Unlike patents, which can cover an inventive process without any need for the physical existence of a product, Plant Breeders' Rights can only apply to a specific variety, which must physically exist. Plant Breeders' Rights also differ from patents in specifically enabling others' use of the product (variety) for further research and breeding (the "breeders' exemption"). Under the UPOV Convention of 1991, countries may also provide for the right of farmers to reuse farm-saved seed on their own holdings (the so-called "farmers' privilege"). The UPOV Convention arguably qualifies under Article 27.3(b) of the TRIPS Agreement, as a sui generis system. Countries may devise other systems, as well, to replace or supplement it. But the UPOV Conventions are currently the only international agreements that provide a ready-made sui generis system of plant varietal protection and one advantage is that its Plant Breeders' Rights are accepted in all countries party to that Convention. Fifty-four countries, mainly industrialized, are members of UPOV. Few developing countries have yet joined, but this situation may be changing as a result of the TRIPS Agreement, and the fact that most developing countries are more likely to choose a sui generis system of plant protection, rather than patents. (See generally, Carlos Correa: Sovereign and Property Rights over Plant Genetic Resources, FAO Background Study Paper no. 2, 1994 and Box 9 above).

\section{Undisclosed information (trade secrets)}

Patents and Plant Breeders' Rights are not the only intellectual property rights that may be claimed in respect of plant genetic resources. Other examples include trade secrets or other forms of undisclosed information. Where trade secret laws exist, innovators can protect undisclosed information from being used by others without their consent, if the information is secret, has commercial value because it is secret, and the holder has taken reasonable steps to keep it secret.

107 Convention on the Grant of European Patents, 13 I.L.M. 268 (1974) (amended by Decision of the Administration Council of the European Patent Organization of 21 December 1978).

108 The criterion of distinctness can be seen not only as a condition for protection, but also as defining the borders of protection. A variety that is distinct from a protected variety cannot infringe the latter. Moreover, it may (if the other conditions are also met) obtain protection on its own right. 
must conform with relevant international agreements, such as the TRIPS Agreement, for Parties to those agreements. If the recognition of intellectual property rights over PGRFA in the Multilateral System under this paragraph means that the holder of the rights can charge fees to users as part of the exercise of those rights, then the issue arises as to whether this is in conflict with the requirements of Article 12.3(b).

(g) Plant genetic resources for food and agriculture accessed under the Multilateral System and conserved shall continue to be made available to the Multilateral System by the recipients of those plant genetic resources for food and agriculture, under the terms of this Treaty; and

Paragraph (g) specifies that when a recipient has accessed PGRFA for the purpose of conservation, the materials accessed should continue to remain available to the Multilateral System, so long as the recipient has them. It does not, however, place an obligation on recipients to actually conserve material received. Some genebanks or breeders, for example, may discard material that is no longer useful or viable. But if the material is conserved, then it must continue to be available, in the same way as the original accession.

The original intention of this paragraph seems to have been to ensure that material accessed from the Multilateral System should remain in the Multilateral System and not leak out of the system once it enters into private hands. A question arises however as to the extent, or reach, of the obligation. If PGRFA is accessed from the Multilateral System and conserved, then certainly that original material accessed should continue to be made available to the Multilateral System, and made available under the standard MTA. But would this also apply to products derived from the original material accessed, albeit subject to respect of any intellectual or other property rights over those products? The implication of Article 13.2(d)(ii) would appear to be that the continued availability of such products can indeed be denied, although that practice is actively discouraged: Article 13.2(d)(ii) requires a mandatory payment to be made where continued availability of a product incorporating material accessed from the Multilateral System is restricted. Where products are made available, the further question arises as to whether such transfers must be under the standard MTA and subject to the continuing benefit-sharing provisions. The question is important, given that many of the transfers of PGRFA are of material that has already been subject to development, but are not yet in the form of a final product or variety. If the obligation to use the standard Material Transfer Agreement ceases at the time of the production of interim products, then the obligation of benefit-sharing will also not be passed on to the production of final products. On this point, there are different viewpoints. In the end, the question revolves around the interpretation given to the words "transfers of plant genetic resources for food and agriculture to another person or entity, as well as to any subsequent transfers of those plant genetic resources for food and agriculture" in Article 12.4.

(h) Without prejudice to the other provisions under this Article, the Contracting Parties agree that access to plant genetic resources for food and agriculture found in in situ conditions will be provided according to national legislation or, in the absence of such legislation, in accordance with such standards as may be set by the Governing Body

Paragraph (h) confirms that access will also be provided to PGRFA covered by the Multilateral System found in in situ conditions, although such access is to be provided according to national legislation. Presumably such national legislation, in so far as it deals with implementation of the International Treaty, would deal primarily with the mechanics of implementation (countries were concerned, for instance, with the modalities of access to materials in national parks and other protected or vulnerable areas) and with procedures for plant collecting. In any case, the national legislation of Parties to the Treaty in general should not impose new requirements or conditions that are inconsistent with the Treaty and with Article 12 in particular. National legislation pertaining to in situ materials must allow for access if this provision is to be "without prejudice to the other provisions under this Article," as the paragraph states. 


\section{Box 12. International Code of Conduct for Plant Germplasm Collecting and Transfer}

The International Code of Conduct on Plant Germplasm Collecting and Transfer (the "Code") was adopted by the FAO Conference at its $27^{\text {th }}$ Session in November 1993. It is voluntary and is based on the principle of national sovereignty over plant genetic resources. Its primary purpose is to provide a set of general principles, which governments may use in developing their own regulations for germplasm exploration and collection, conservation, exchange and utilization, or in formulating bilateral agreements. The Code proposes procedures for requesting and/or issuing permits for collecting missions, provides guidelines for collectors, and provides for the responsibilities of sponsors of collecting missions, curators of genebanks, and subsequent users of germplasm. It calls for the participation of farmers and local institutions in collecting missions and proposes that users of germplasm should share the benefits derived from the use of plant genetic resources with the host country and its farmers.

The Code was designed to be fully compatible with the CBD, and the International Plant Protection Convention. With respect to benefit-sharing, the Code leaves these matters to the discretion of the collectors, sponsors or users, presumably recognising that these persons will be involved in contractual or other dealings with the providers of genetic resources. The Code is to be implemented in harmony with both conventions, and with the national laws of the host country and any agreements between the collector, the host country, sponsors and the genebank storing the germplasm.

Legislation in place in some countries that poses additional conditions on access to PGRFA under the Multilateral System may need to be adjusted, if those conditions are incompatible with the provisions of Article 12.

For the most part, of course, plant material found in in situ conditions, other than those in national parks or other state land, will not typically be qualified as being in the public domain and under the management and control of a Contracting Party, but their status as 'genetic resources' under the CBD might be a separate issue. They would thus not be part of the Multilateral System unless included voluntarily by their holders under Article 11.2.

In the absence of any national legislation, or pending the establishment of new legislation, access is to be in accordance with standards set by the Governing Body. What scope any such standards may cover is of course a matter to be decided by the Governing Body. One example of relevant standards is the International Code of Conduct for Plant Germplasm Collecting and Transfer adopted by the FAO Conference in 1993 (see Box 12). Any standards eventually adopted by the Governing Body are likely to influence the pattern of national legislation in the future.

The implementation of this paragraph in national legislation, as well as the rest of Article 12 and 13, is likely to be a delicate task, given that the access and benefit-sharing provisions of the Multilateral System apply only to PGRFA for the purpose of utilization and conservation for research, breeding and training for food and agriculture. In some cases the same genetic resources may very well be subject to different access regimes depending on the uses for which those genetic resources are being accessed.

12.4 To this effect, facilitated access, in accordance with Articles 12.2 and 12.3 above, shall be provided pursuant to a standard material transfer agreement (MTA), which shall be adopted by the Governing Body and contain the provisions of Articles 12.3a, $d$ and $g$, as well as the benefit-sharing provisions set forth in Article 13.2d(ii) and other relevant provisions of this Treaty, and the provision that the recipient of the plant genetic resources for food and agriculture shall require that the conditions of the MTA shall apply to the transfer of plant genetic resources for 


\section{food and agriculture to another person or entity, as well as to any subsequent transfers of those plant genetic resources for food and agriculture.}

A provision requiring a standard MTA was introduced during the penultimate negotiating session in June 2001 as part of a package that accepted mandatory sharing of the commercial benefits of the use of PGRFA under the terms of Article 13.2(d)(ii) and limited the obligation to provide facilitated access to material under the management and control of Contracting Parties and in the public domain. The MTA is in effect the legal instrument that allows the legal obligations provided for in the Treaty to be passed on to recipients and from them to subsequent recipients, by means of a contractual nexus. Any dispute concerning, or non-compliance with, the terms of the MTA is to be dealt with by the parties to the MTA in national courts (see Article 12.5 below). While the requirements of the Multilateral System are thus implemented through the realm of contract law, this does not change the basic obligation in Article 12.2, which stipulates that Contracting Parties agree to take measures to provide facilitated access to other Contracting Parties.

Facilitated access must be pursuant to a standard MTA to be adopted by the Governing Body. 109

As stated in Article 12.4, the standard MTA "shall contain" certain provisions of the Treaty, namely Article 12.3(a), (d) and (g), as well as the benefit-sharing provisions of Article 13.2(d)(ii) and other relevant provisions of the Treaty. The wording used by the Treaty here is important. It will not be sufficient to draft clauses for the standard MTA based on or somehow taking into account such provisions: the latter must be contained in the agreement. Thus, the

109 In view of the central importance of the standard MTA for the functioning of the Multilateral System, the Interim Arrangements for the implementation of the Treaty adopted by the FAOConference in 2001 under Resolution 3/2001 provide for the Commission on Genetic Resources for Food and Agriculture, acting as the Interim Committee for the Treaty, to prepare a draft standard MTA for consideration by the Governing Body at its first Session. The Resolution also provides that the draft MTA should include recommended terms for commercial benefit-sharing under Article 13.2d(ii) of the Treaty" (see the comment on Article 13.2d(ii) below). The Conference decided to establish an Expert Group to develop and propose recommendations on the terms of the standard MTA. The Group was to be composed of experts with technical or legal expertise with respect to the exchange of PGRFA and relevant commercial practice. In drawing up a draft standard MTA, the Expert Group were to address a number of issues which had been left open in the Treaty. Some of these issues are reflected in the Terms of Reference for the Expert Group, agreed at the first meeting of the Interim Committee. They include the following:

- What should be the level, form and manner of payments in line with commercial practice?

- Whether different levels of payment should be established for various categories of recipients who commercialize such products or for different sectors and, if so, what those levels, various categories of recipients, and sectors should be?

- Whether to exempt small farmers in developing countries and in countries with economies in transition from the payments, and if so, who qualifies as a small farmer?

- What constitutes commercialization in terms of Article 13.2(d)(ii) of the Treaty?

- What constitutes incorporation of material accessed from the Multilateral System?

- When would a product be considered to be available without restriction to others for further research and breeding?

- How will monetary and other benefits be defined for the purposes of the standard MTA?

- By what means will the MTA ensure the application of Article 12.3?

- What terms should be included in the MTA so that recipients are bound by it on acceptance of the material from the Multilateral System?

The The Expert Group met in Brussels in September 2004. Its report, which explored options regarding the above points, was considered by the Second Session of the FAO Commission on Genetic Resources for Food and Agriculture acting as Interim Committee for the International Treaty in November 2004. 


\section{Box 13. Material Transfer Agreements (MTAs)}

MTAs are contracts which are used for the transfer of genetic materials and which contain the terms and conditions on which the material is transferred. They may take various forms, ranging from a short shipment document, delivery notice or standard invoice containing minimal conditions, to a fullyfledged negotiated and signed contract containing mutually agreed terms. MTAs are routinely used by commercial firms, and have also been used by the CGIAR Centres since 1995. Article 12.4 provides that facilitated access to material under the Multilateral System shall be accorded by means of a standard MTA to be adopted by the Governing Body of the Treaty. Article 15.1(b) further provides that PGRFA other than those covered by the Multilateral System, and held by the CGIAR Centres, shall be made available under the MTA currently in use by the Centres under the in-trust agreements with FAO. This MTA is to be amended by the Governing Body, in consultation with the Centres, not later than its second regular session.

\section{The MTAs currently in use by the CGIAR Centres}

The Agreements signed between 12 CGIAR Centres and FAO in October 1994, placing the collections of plant germplasm held by the Centres under the auspices of FAO, provided that the Centres should hold the germplasm designated under the agreements in trust for the benefit of the international community, and should not claim legal ownership over the germplasm or any intellectual property rights over it or related information. The Centres undertook to manage and administer the designated germplasm in accordance with internationally accepted standards. Under the agreements, the Centres are required to make samples of the designated germplasm and related information available for the purpose of scientific research, plant breeding or genetic resources conservation, without restriction. In making the germplasm available, however, they are required to ensure that the recipients, and any subsequent recipients, are bound by the same requirements regarding ownership, intellectual property rights and standards of conservation management. The Centres pass on these obligations to subsequent recipients by means of a standard MTA developed for the whole of the CGIAR system. While some of these agreements were originally in the form of signed agreements between certain Centres and the recipients, they were all later simplified into standard conditions that the recipients were deemed to have accepted by virtue of their acceptance of the germplasm, similar to the obligations assumed by users of computer software upon opening its packaging. At the Ninth Regular Session of the FAO CGRFA in October 2002, this MTA was revised by the Commission to reflect some of the provisions of the new Treaty.

\section{The Standard MTA to be used for the Multilateral System}

Article 12.4 of the Treaty requires facilitated access to PGRFA under the Multilateral System to be by means of a standard MTA to be adopted by the Governing Body. The standard MTA is to contain the provisions of Article 12.3(a) (access to be provided solely for utilization and conservation for research, breeding and training for food and agriculture), (d) (no claiming of intellectual property rights over the material in the form received) and ( $\mathrm{g}$ ) (material accessed from the system to continue to be made available to the Multilateral System) as well as the benefit sharing provisions of Article 13.2(d)(ii) and other relevant provisions of the Treaty. For a description of the issues relating to the standard MTA, see the commentary on Article 12.4 above.

\section{MTA to be used by CG Centres for transfer of PGRFA outside the Multilateral System}

Materials of crops which are not listed under the Multilateral System, held by CGIAR Centres and collected before the entry into force of the Treaty, are to be made available in accordance with the MTA currently being used by the Centres as amended by the Governing Body no later than its second regular session, in consultation with the Centres.

(See Report on the Outcome of the Expert Group on the Terms of the Standard Material Transfer Agreement, FAO doc. CGRFA/IC/MTA-1/04/Rep, October 2004) The Interim Committee decided to establish a Contact Group to draw up a draft standard MTA for consideration by the Governing Body. 
MTA must reflect the conditions of use, limitation on intellectual property rights and continued availability for access, set out in Article 12.3(a), (d) and $(\mathrm{g})$, as well as conditions for commercial benefit sharing set out in Article 13.2(d)(ii). It is also to include "other relevant provisions of the Treaty". What exactly these other relevant provisions are to include will be decided by the Governing Body. It is important to point out that these decisions, like all decisions by the Governing Body, must be taken by consensus (unless, by consensus, they decide on another method).

It is clear from the wording of Article 12.4 that all transfers of PGRFA under the Multilateral System between Contracting Parties or entities within the jurisdiction of Contracting Parties must be pursuant to the standard Material transfer Agreement. But what of transfers of Annex 1 material to non-contracting parties? The wording of Article 12.4 does not expressly limit itself to transfers between Contracting Parties. Nevertheless, the normal rules of interpretation of treaties would indicate that Contracting Parties would not be prohibited from transferring PGRFA to noncontracting parties, nor would they be under an obligation to use the standard Material Transfer Agreement if they did choose to make such transfers. Such obligations towards third parties, or in respect of dealings with third parties would need to be expressly stated in the Treaty and would not be lightly presumed. Nevertheless, the practical effect of allowing transfers to non-contracting parties on conditions that may be less onerous than those applicable to transfers between Contracting Parties, particularly with respect to benefit-sharing, might well operate to make the Treaty unworkable.

On the issue of the transfer of PGRFA that is a product, see the comments on Article 12.3(g) above.

\subsection{Contracting Parties shall ensure that an opportunity to seek recourse is available, consistent with applicable jurisdictional requirements, under their legal systems, in case of contractual disputes arising under such MTAs, recognizing that obliga- tions arising under such MTAs rest exclusively with the parties to those MTAs.}

Paragraph 12.5 simply states that Contracting Parties will ensure that there is some mechanism available to parties to standard MTAS under their legal system for addressing violations of the standard MTA. This provision addresses the practical problems that have already arisen with respect to the legal ability of donors of genetic resources to enforce, in the courts of other countries, the conditions under which genetic resources are made available. These problems are being discussed inter alia in the Ad Hoc Open-ended Working Group on Access and Benefit-sharing set up by the Conference of Parties to the CBD to negotiate an International Regime on Access and Benefit-sharing. ${ }^{110}$

It should be noted that the Treaty does not specify the law or judicial jurisdiction applicable to the MTA. Of curse, a uniform provision may be included in the standard MTA to be adopted by the Governing Body. In the absence of any such uniform provision, each MTA will need to set its own rules. Where no specific choice of applicable law or judicial jurisdiction is made in the contract, it will fall to the courts of the individual states in which legal actions are brought to determine the applicable law and the proper judicial jurisdiction under their own contract law and conflict of laws rules.

It is to be noted that Paragraph 12.5 recognizes that the obligations arising under an MTA rest exclusively with the parties to that MTA, and not with Contracting Parties of the Treaty. This raises a question concerning effective enforcement of MTAs between recipients of PGRFA from the Multilateral System. While the original donor of material may be able to enforce an MTA against the original recipient of the material, it may not be in a position to enforce the MTA as against subsequent recipients, since it will have no contractual nexus with those subsequent recipients. The contractual lien will be between the recipient and the subsequent recipient only. However, the recipient, in such a scenario, may have little or no incentive to take legal action to enforce the obligations of the subsequent recipient. This is a matter that may need to be either addressed in the terms

110 See Report of the Ad Hoc Working Group on Access and Benefit-sharing on the Work of its Third Meeting, Bangkok 3 March 2005, document UNEP/CBD/WG-ABS/3/7. 
of the MTA (in many countries there are contractual mechanisms for ensuring such contracts) or otherwise taken up in the context of Article 21 on compliance. Article 21 provides for cooperative and effective procedures and operational mechanisms to promote compliance with the Treaty and to address issues of non-compliance. The question may also be addressed by the Governing Body in drafting the standard MTA. For example, the Governing Body might look at the possibility of recipients assigning their rights and duties to subsequent recipients under the original standard MTA ratherthanenteringintonew standard MTAs, or of providing in the standard MTA for the initiation of dispute settlement procedures by a representative of the Multilateral System as a third party beneficiary under the standard MTA.

One question that has already been raised in the context of the meeting of the Expert Group on the terms of the Standard MTA is whether the wording of Article 12.5 would exclude reference to international arbitration as the preferred mode of dispute resolution under the standard MTA. On that occasion, the Legal Adviser to the meeting advised that "it was up to the Contracting Parties to decide the opportunities for recourse to be made available, including both resort to national courts and arbitration. For the Contracting Parties, in the exercise of their sovereign rights, to provide for binding international arbitration, would not, in his opinion, be contrary to the provisions of article 12.5. In any case it would still be open to parties to the MTA to have recourse to national courts to enforce international arbitral decisions, should this prove necessary." "In the event, the Expert Group put forward international arbitration by an existing international arbitration mechanism, such as the International Chamber of Commerce, as an option for dispute settlement under the standard MTA, together with recourse to national legal forums. The advantages of international arbitration in allowing for a more consistent interpretation of the Treaty and avoiding a multitude of divergent and dispersive decisions from various national courts was noted. The possibility of the Multilateral System, as a third party beneficiary under the MTA, ${ }^{112}$ being represented in, or even initiating the dispute resolution through international arbitration was also raised during the Expert Group Meeting.

With respect to choice of law, the Expert Group also raised the possibility of denominating General Principles of Law, ${ }^{113}$ the Treaty and decisions of the Governing Body as the applicable law.

\subsection{In emergency disaster situations, the Contracting Parties agree to provide facili- tated access to appropriate plant genetic resources for food and agriculture in the Multilateral System for the purpose of contributing to the re-establishment of agricultural systems, in cooperation with disaster relief co-ordinators.}

Article 12.6 provides for the provision of materials needed to restore agricultural systems in disaster situations regardless of whether the recipients are Contracting Parties to the Treaty or not. As discussed in a later chapter, the GPA also has Priority Activity Area 3 devoted to this issue. Although not providing any special conditions, the presence of this provision reinforces the recognition of the need for expeditious access in such cases. It is also clear that the intent is not to replace or compete with habitual providers of seed under ordinary conditions.

111 See Report on the Outcome of the Expert Group on the Terms of the Standard Material Transfer Agreement, FAO doc. CGRFA/IC/MTA-1/04/Rep, October 2004, p. 21.

112 The standard MTA will need to provide for payments to be made to a mechanism established by the Governing Body to be used for the benefit of farmers in all countries, especially in developing countries and countries with economies in transition. The mechanism established under the Multilateral System and ultimately the farmers themselves are in this sense third party beneficiaries under the standard MTA.

113 This formula is standard usage in the case of agreements entered into by organizations of the United Nations system. In this case reference to general principles of law, the Treaty and decisions of the Governing Body might reduce the tendency for divergences in the interpretation of the obligations under the standard MTA and allow for a greater position of influence for the Governing Body itself in the development of interpretations. 


\section{Box 14. National Sovereignty and Property Rights}

Article 10 of the Treaty recognizes the sovereign rights of States over PGRFA situated within their territorial boundaries. In dealing with the conditions for facilitated access to PGRFA, Article 12.3(f) makes reference to property rights, including intellectual property rights. Sovereign rights are not synonymous with property rights. What then is the nature of each type of right, and how are they different?

Sovereign rights are the rights, which appertain to independent sovereign states, to legislate, manage, exploit and control access to their own natural resources. They include the right to determine property regimes applicable to those resources, who owns them, what rights of ownership can be entertained, and how ownership can be established.

Sovereignty and sovereign rights imply independence and exclusivity: the rights appertain only to the sovereign power concerned and not to any outside power. This is not to say that sovereignty and sovereign rights cannot be subject to limitations or restrictions. In particular sovereign states, in the exercise of their sovereignty, can agree to exercise their sovereign rights in a particular way and subject to agreed rules, which then become binding on them. This is in essence the principle of pacta sunt servanda (agreements are to be kept) which is the principle on which all international law is based.

In international environment and development treaties, statements recognizing the sovereign rights of States over their natural resources are normally coupled with affirmations of their responsibilities to manage those resources in such a way as to avoid causing harm to other states, or to avoid harming interests, which are of common concern to all countries or to humanity as a whole. Thus the Preamble to the Treaty recognizes PGRFA to be a common concern of all countries, in that all countries depend very largely on PGRFA. Article 10 of the Treaty is careful to state that it is in the exercise of their sovereign rights that the Contracting Parties have agreed to establish a multilateral system for access and benefit sharing for some PGRFA important for reasons of food security and interdependence, which is then binding on them.

Sovereign rights are not property rights, though a State may very well determine in the exercise of its sovereign rights, that certain natural resources are the property of the State. The State may also own property, like other natural or legal persons, under the property regime that it has established in the exercise of its sovereign rights.

Property rights, on the other hand, are rights to own, control and alienate property, within the system of property law established by the State. Property rights may be rights over material or tangible property, such as the crops growing on a farmer's land. They may also be rights over intangible property, including information or innovations, such as patent rights or Plant Breeder's Rights.

Intellectual property rights are intangible property rights. They differ from rights over material or tangible property in that they are limited in time (up to 20 years in general for patents, and 20/25 years under the UPOV 1991 Act for Plant Breeders' Rights), are exercisable only in the territory in which protection rights have been granted (the so-called principle of territoriality), and relate only to the intangible content of goods or processes. In the case of patented living organisms (where allowed), for example, it is possible that such rights may, in certain circumstances, be thought to apply to the information contained in genes or other sub-cellular components, or in cells, propagating material or plants.

Intellectual property rights confer a right to exclude others from producing, replicating, using, or selling protected information or innovation, or individual specimens or products produced using this information or by way of these innovations. The different types of intellectual property rights relevant to PGRFA are examined in Box 11 above.

On sovereign rights and property rights over PGRFA see generally, Carlos Correa, Sovereign and property rights over plant genetic resources, Background Paper no. 2 prepared for the FAO Commission on Plant Genetic Resources (now the CGRFA) at its first session in November 1994. 


\section{Article 13 - Benefit-sharing in the Multilateral System}

The implementation of fair and equitable sharing of benefits arising out of the utilization of genetic resources is central to both the CBD and the Treaty. The third objective of the CBD calls for the fair and equitable sharing of benefits arising from the use of genetic resources, "including by appropriate access, transfer of relevant technologies [...] and by appropriate funding" (Article 1). This objective is partially implemented by Article 15.7 which specifies that the results of research and development should be shared as well as the benefits arising from the commercial and other utilization of genetic resources. The Treaty, on the other hand, provides for a multilateral system of benefit-sharing, as a necessary complement to the multilateral system of facilitated access. In this connection, the Treaty views "benefits" to include the important notion that facilitated access is itself a major benefit that is shared by Contracting Parties to the Treaty. Other benefits arising from the use, including commercial use, of
PGRFA under the multilateral system are to be shared fairly and equitably through:

- The exchange of information (Article 13.2(a));

- Access to and transfer of technology (Article 13.2(b));

- Capacity-building(Article 13.2(c)); and

- The sharing of monetary and other benefits of commercialization (Article 13.2(d)).

Additionally, the Contracting Parties are to consider modalities of a strategy of voluntary benefit-sharing contributions from foodprocessing industries. It is through this approach that the fair and equitable sharing of the benefits arising from the use of PGRFA is fundamental to the Multilateral System, to the entire Treaty, and indeed to the long-term conservation and sustainable use of PGRFA.

\subsection{The Contracting Parties recognize that facilitated access to plant genetic resources for food and agriculture which are included in the Multilateral System constitutes itself a major benefit of the Multilateral System and agree that benefits accruing therefrom shall be shared fairly and equitably in accordance with the provisions of this Article.}

Article 13.1 recognizes that facilitated access itself is a major benefit of the multilateral system. Without the possibility for countries to easily access the plant genetic resources they need to improve their crops, agriculture and food security will suffer not only at the global level, but also at the level of each country. In Article 13.1 the Contracting Parties also agree that benefits arising from the use of PGRFA under the Multilateral System must be shared fairly and equitably in accordance with the mechanisms set out in the rest of the Article. Some of these mechanisms are voluntary in nature and some of them are mandatory. The paragraph uses the phrase "fairly and equitably" in relation to benefit-sharing, which reflect the wording of the CBD. In the case of the Treaty, many mechanisms are multilateral. In other cases, the decision as to what is fair and equitable will lie with the Contracting Parties themselves in implementing the Treaty, although these national decisions may be open to review in the Governing Body. In setting the level of payments to be made under the standard MTA, the decision as to what is equitable will be made directly by the Governing Body.

13.2 The Contracting Parties agree that benefits arising from the use, including commercial, of plant genetic resources for food and agriculture under the Multilateral System shall be shared fairly and equitably through the following mechanisms: the exchange of information, access to and transfer of technology, capacitybuilding, and the sharing of the benefits arising from commercialization, taking 
into account the priority activity areas in the rolling Global Plan of Action, under the guidance of the Governing Body:

This provision lists the Treaty's mechanisms for benefit-sharing (exchange of information, access to and transfer of technology, capacity building, and sharing of commercial benefits) and serves as a chapeau for the sub-paragraphs on each item. Three points can be made in respect of this chapeau:

1. The benefits arising from the use of PGRFA cover all uses, not just commercial use, but including commercial use;

2. In considering the fair and equitable sharing of benefits, the GPA should be taken into account, and in effect used as a guide to implementation (see Box 15);

3. The whole process of implementation of this, as well as other provisions of the

(a) Exchange of information:

Due to the inherent importance of this concept, a provision on information exchange has become a standard provision in many international agreements. Global problems require common action by States, and the experience of one country can be invaluable to others facing similar problems. A general provision relating to the exchange of appropriate information and tech-
Treaty, will be under the guidance of the Governing Body.

Indeed there are a number of issues of implementation, particularly in this Article, that will require firm and creative guidance from the Governing Body. Not all issues could be fully negotiated before the adoption of the Treaty, and a number of issues, including the wording of the standard MTA and details of its commercial benefit sharing provisions and enforcement procedures remain to be settled by the Governing Body. In this sense the Treaty is a dynamic instrument, which will depend for its success on the future work of its Contracting Parties, meeting as the Governing Body of the Treaty. nology is set out in Article 7.2(b) in the general context of international cooperation. The particular provision on information exchange in the present paragraph, however, must be seen more in its context of benefit sharing, and in particular in connection with the utilization of PGRFA.

\begin{abstract}
The Contracting Parties agree to make available information which shall, inter alia, encompass catalogues and inventories, information on technologies, results of technical, scientific and socio-economic research, including characterization, evaluation and utilization, regarding those plant genetic resources for food and agriculture under the Multilateral System. Such information shall be made available, where non-confidential, subject to applicable law and in accordance with national capabilities. Such information shall be made available to all Contracting Parties to this Treaty through the information system, provided for in Article 17.
\end{abstract}

The information that the Contracting Parties agree to share in this paragraph is information about PGRFA in the Multilateral System, and it is mainly information which will be useful for the utilization of those resources, in using them to improve crops and hence agriculture. The different types of information referred to are more extensively described in the comments concerning Article 5.2(e). Much of the information, including information on technologies, lies in the hands of the holders of ex situ collec- tions, in particular developed countries and international institutions. Unlike the benefit sharing provisions of the $\mathrm{CBD}$, the information is to be exchanged on a multilateral basis, through the Global Information System provided for in Article 17. Information linked to specific transfers of genetic resources is addressed in Article 12.3(c).

Article 13.2(a) requires Contracting Parties, and Centres that have signed agreements 
with the Governing Body, to make available information about the PGRFA under the Multilateral System, which is to include:

- Catalogues and inventories;

- Information on technologies; and

- Results of technical, scientific and socio-economic research.

- Thereference to characterization, evaluation and utilization appears to be a separate category of "information to be made available": characterization, evaluation and utilization data are of fundamental importance to the utilization of PGRFA.

The conditions under which information is to be made available are three:

1. A Contracting Party is only required to make information available where that information is non-confidential. Confidential information can, of course, be

\section{(b) Access to and transfer of technology}

The wording of this paragraph closely follows that of similar provisions in Article 16 of the CBD.

According to the United Nations Conference on Trade and Development (UNCTAD), technology transfer is the "transfer of systematic knowledge for the manufacture of a new product, for the application of a process or for the rendering of a service". "114 Technology flows between a supplier and a recipient, whether within a country or between States. Technology can take many different forms, but generally falls into two general categories: made available, but only at the discretion of the Contracting Party concerned;

2. The information is to be made available subject to applicable national law, which includes intellectual property law, including copyright and patents;

3. The information shall be made available "in accordance with national capabilities".

The meaning of this third condition is not entirely clear, but would appear to recognise that certain countries do not possess high levels of information collection, analysis and sharing capacity, or the personnel and funds that are sometimes required; and to recognise as a consequence, that compliance with this obligation cannot be judged on a purely comparative basis, but only as adjusted by these considerations. Thus countries would not be expected to meet standards that are beyond their national capacity, in their efforts to make information available.

- Soft technologies: know-how, skills and techniques, such as the conservation techniques of a local farming community, or a research collaboration that imparts new biotechnological techniques to researchers.

- Hard technologies: tangible goods such as equipment, hardware, or seed from a particular plant variety developed by a farmer. Hard technologies can rarely be transferred without some form of accompanying soft technology transfer.

(i) The Contracting Parties undertake to provide and/or facilitate access to technologies for the conservation, characterization, evaluation and use of plant genetic resources for food and agriculture that are under the Multilateral System. Recognizing that some technologies can only be transferred through genetic material, the Contracting Parties shall provide and/or facilitate access to such technologies and genetic material which is under the Multilateral System and to improved varieties and

114 This definition was considered, but not adopted, by the CBD in its work on technology transfer. 
genetic material developed through the use of plant genetic resources for food and agriculture under the Multilateral System, in conformity with the provisions of Article 12. Access to these technologies, improved varieties and genetic material shall be provided and/or facilitated, while respecting applicable property rights and access laws, and in accordance with national capabilities.

Article 13.2(b)(i) provides that Contracting Parties shall provide and/or facilitate access to technology for certain specified purposes. The subparagraph uses wording drawn from Article 16.1 of the CBD, particularly in specifying the obligations of the Contracting Parties "to provide and/or facilitate". It is not clear what the term "provide" refers to. For instance, does it mean "provide technologies" themselves, or more indirectly "provide access to technologies"? It would seem that the latter interpretation is more in line with the title of the paragraph "Access to and transfer of technology". It is also more in line with the structure of Article 16.1 of the CBD. In this sense, then, the obligation of the Contracting Parties is to provide access to, or facilitate access to, technologies. Each Contracting Party then has a choice as to whether it provides such access or merely facilitates it. Presumably it will in general be more appropriate for Contracting Parties to provide access to technologies that are publicly owned or are otherwise within the purview of the Contracting Party itself, and to facilitate access to technologies that are subject to private ownership. In any case, the minimum obligation of the Contracting Party will be to facilitate access.

There are many different ways in which Contracting Parties may facilitate access to technologies. As a first step, a Contracting Party may wish to review existing policies and practices to determine which are the most effective, then implement such additional measures as may be appropriate. Measures to facilitate access could include:

- Tax and other economic incentives in supplier Parties to encourage exports and in recipient Parties to encourage imports;

- Reforming foreign investment laws;

- Trade assistance;

- Expanded intellectual property rights protection;

- Collaborative research and development arrangements;

- Establishing national, regional or global technology clearing-houses or other enabling mechanisms;
- Grants; or

- The purchase of intellectual property rights on behalf of another Party.

Access is to be provided and/or facilitated for the following purposes:

- The conservation of PGRFA ;

- The characterization of PGRFA ;

- The evaluation of PGRFA ; and

- The use of PGRFA .

Each of these categories is important, and together the categories cover pretty well the whole scope of PGRFA. "Conservation" technologies would cover technologies relating to the storage of germplasm, including in vitro techniques, regeneration, testing for plant health and treating diseases in stored material as well as technologies relating to in situ conservation, e.g. those relating to monitoring the existing genetic diversity. "Characterization" technologies would include those relating to the categorization of morphological data and data on heritable characteristics, such as colour of flowers, which are constant in any environment, and technologies, including molecular technologies, to determine the nature and extent of genetic diversity. "Evaluation" technologies, on the other hand would include technologies, including molecular technologies, relating to determining the potential value for use of the PGRFA, including valuable agronomic traits of the material, and any disease or drought resistance. "Use" technologies would cover both traditional plant breeding techniques and biotechnological technologies, such as molecular markers and recombinant DNA technology. While the emphasis is obviously on the transfer of technology from technologically rich countries, it is to be noted that this paragraph, as well as the preceding paragraph on information exchange, is not limited to modern technologies, and would include, for example, also access to traditional knowledge and technologies.

It is also important to note that the obligations of Contracting Parties in the area of access to and transfer of technology under this whole paragraph are limited to PGRFA that are within 
the Multilateral System (i.e. PGRFA of those crops that are listed in Annex I to the Treaty).

The second sentence recognizes that the utilization of certain technologies has been incorporated into new genetic resources. Contracting Parties are required to provide and/or facilitate access to such technologies through providing or facilitating access to the relevant genetic materials, including improved varieties, which were developed through the use of PGRFA under the Multilateral System, as well as to the technology itself. Even if access to products incorporating material accessed under the Multilateral System may be restricted, Contracting Parties are to provide or facilitate access to the technologies contained in such products, and indeed to the genetic material itself, under the terms and conditions of Article 12. Such access fully respects applicable property rights and access laws. Presumably, the reference to access laws, in this instance, is meant to refer primarily to national legal requirements for obtaining the consent of the owner, or intellectual property holder, as referred to in Article 12.3(f) of the Treaty.

The reference to such access being subject to "national capabilities" is more problematic. It cannot mean that Contracting Parties do not have to provide access to technologies if they do not have them: that would be a useless statement of the obvious. It must then have a similar meaning to that in the previous paragraph, i.e. that countries should provide access to the technologies in a way that does not overburden their capabilities. In other words, it would not, for example, be required that a developing Contracting Party spend millions of dollars on researching traditional conservation techniques in order to meet a request from another Contracting Party, or that it provide unreasonable quantities of photocopies of documents. On the other hand, richer countries would be expected to be more forthcoming in their transfer of technology.

(ii) Access to and transfer of technology to countries, especially to developing countries and countries with economies in transition, shall be carried out through a set of measures, such as the establishment and maintenance of, and participation in, cropbased thematic groups on utilization of plant genetic resources for food and agriculture, all types of partnership in research and development and in commercial joint ventures relating to the material received, human resource development, and effective access to research facilities.

This subparagraph introduces measures that can be taken by Contracting Parties to provide access to, and transfer of, technologies, particularly to developing countries and countries with economies in transition.

The promotion of crop-based thematic groups and networks is viewed as an important platform for scientific exchange, information sharing, technology transfer and research collaboration in the GPA (Priority Activity Area 16). Thematic groups and networks are also seen as important for sharing responsibilities for collecting, conservation, distribution, evaluation and genetic enhancement. Indeed, the encouragement of international plant genetic resources networks is provided for in Article 16 of the Treaty as one of its essential supporting components. This paragraph focuses on their importance as a vehicle for technology transfer.
The establishment of partnerships in research and development, including commercial joint ventures, is also seen as a suitable vehicle for technology transfer. In this connection, it is to be noted that these partnerships relate to "the material received". Although it is not specifically stated, the implied reference is presumably to partnerships and commercial joint ventures with the country, or entity in the country, supplying the PGRFA.

The reference to "effective access to research facilities" mirrors Article 15.6 of the CBD, which encourages Contracting Parties to carry out scientific research on material provided by other Contracting Parties, with the full participation of Contracting Parties providing the materials and where possible in such countries. 
(iii) Access to and transfer of technology as referred to in (i) and (ii) above, including that protected by intellectual property rights, to developing countries that are Contracting Parties, in particular least developed countries, and countries with economies in transition, shall be provided and/or facilitated under fair and most favourable terms, in particular in the case of technologies for use in conservation as well as technologies for the benefit of farmers in developing countries, especially in least developed countries, and countries with economies in transition, including on concessional and preferential terms where mutually agreed, inter alia, through partnerships in research and development under the Multilateral System. Such access and transfer shall be provided on terms which recognize and are consistent with the adequate and effective protection of intellectual property rights.

The first part of Article 13.2(b)(iii) states that access to and transfer of technology, including that protected by intellectual property rights, must be provided to developing countries under "fair and most favourable terms". This is particularly the case with:

- technology for use in conservation; and

- technology for the benefit of farmers in developing countries, especially in least developed countries and countries with economies in transition.

The second part of this paragraph identifies the manner in which this is to be achieved. It states that "fair and most favourable terms" includes "concessional and preferential terms", where mutually agreed. These, in turn, can be achieved through mechanisms such as partnerships in research and development under the multilateral system.

The terms "fair and most favourable terms" and "concessional and preferential terms" are not defined in the Treaty. The same terms are used in Article 16(2) of the CBD as well as the UN Framework Convention on Climate Change, the Protocol on Substances that Deplete the Ozone Layer, and Agenda 21. In none of these documents is the term defined. The same wording is also used in Priority Activity Area 15 of the GPA. In general "fair and most favourable terms" would seem to imply terms that are equitable and which are the best terms offered to other countries, i.e. a reference to the notion of "most favoured nation". "Concessional and preferential" seem to imply terms that are more favourable than those normally offered on the open market: the obligation to offer such terms is limited to situations where such terms are mutually agreed.

Finally, as in the Article 16.2 of the CBD, and indeed in Article 13.2(b)(i) of the Treaty, the paragraph reiterates that access to and transfer of technology must respect intellectual property rights. The phrase "adequate and effective protection" again reflects similar wording in the Article 16.2 of the CBD, and establishes a link with the TRIPS Agreement. The first paragraph of the preamble of the TRIPS Agreement refers to "the need to promote effective and adequate protection of intellectual property rights", while Article 17.3(b) provides that Members of the WTO "shall provide for the protection of plant varieties either by patents or by an effective sui generis system or by any combination thereof'.

(c) Capacity-building. Taking into account the needs of developing countries and countries with economies in transition, as expressed through the priority they accord to building capacity in plant genetic resources for food and agriculture in their plans and programmes, when in place, in respect of those plant genetic resources for food and agriculture covered by the Multilateral System, the Contracting Parties agree to give priority to (i) establishing and/or strengthening programmes for scientific and technical education and training in conservation and sustainable use of plant genetic resources for food and agriculture, (ii) developing and strengthening facilities for conservation and sustainable use of plant genetic resources for food and agriculture, in particular in developing countries, and countries with economies in transition, and (iii) carrying out scientific research preferably, and where possible, in developing 
countries and countries with economies in transition, in cooperation with institutions of such countries, and developing capacity for such research in fields where they are needed.

Article 13.2(c) focuses on three primary areas of capacity-building, reflecting the provisions of Priority Activity Areas 15 and 19 of the GPA:

- The establishment or strengthening of programmes for scientific and technical education, as well as training in conservation and sustainable use of PGRFA;

- The development and strengthening of facilities for the conservation and sustainable use of PGRFA, particularly in developing countries and countries with economies in transition; and

- The execution of scientific research, particularly in developing countries and countries with economies in transition, in cooperation with institutions of such countries, and developing capacity for such research in fields where they are needed.

National capacity building is essential to allow countries, particularly those that are developing countries or countries with economies in transition, to conserve their PGRFA and to make the best use of them in a sustainable way. It is also essential to allow them to make the best use of transferred technologies. Financial and technical assistance in upgrading and maintaining ex situ collections of PGRFA, including national capacity building, is one of the objectives of the new Global Crop Diversity Trust (see Box 20).

The phrase "taking into account the needs of developing countries ... as expressed through the priority they accord to building capacity in plant genetic resources for food and agriculture in their plans and programmes" was added to reflect the fact that overseas development aid is intended to be recipient country driven and not donor driven, and should thus reflect the priorities expressed by the developing countries themselves. If the countries themselves do not recognize such capacity building as being a priority, then it is difficult for donor countries to insist on providing the support that may in fact be required.

\section{(d) Sharing of monetary and other benefits of commercialization}

The provisions of the Treaty that deal with sharing the monetary benefits from the commercial use of genetic resources represent a real conceptual break-through, particularly those requiring, in certain circumstances, the payment of an equitable share of commercial benefits to a multilateral mechanism.

(i) The Contracting Parties agree, under the Multilateral System, to take measures in order to achieve commercial benefit-sharing, through the involvement of the private and public sectors in activities identified under this Article, through partnerships and collaboration, including with the private sector in developing countries and countries with economies in transition, in research and technology development;

This subparagraph looks back to the other provisions of the Article, and in particular paragraph 2 of the Article, as well as forward to the specific commercial monetary benefit-sharing provisions of the next subparagraph.

(ii) The Contracting Parties agree that the standard Material Transfer Agreement referred to in Article 12.4 shall include a requirement that a recipient who commercializes a product that is a plant genetic resource for food and agriculture and that incorporates material accessed from the Multilateral System, shall pay to the mechanism referred to in Article 19.3f, an equitable share of the benefits arising from the commercialization of that product, except whenever such a product is available without restriction to others for further research and breeding, in which case the recipient who commercializes shall be encouraged to make such payment. 
The Governing Body shall, at its first meeting, determine the level, form and manner of the payment, in line with commercial practice. The Governing Body may decide to establish different levels of payment for various categories of recipients who commercialize such products; it may also decide on the need to exempt from such payments small farmers in developing countries and in countries with economies in transition. The Governing Body may, from time to time, review the levels of payment with a view to achieving fair and equitable sharing of benefits, and it may also assess, within a period of five years from the entry into force of this Treaty, whether the mandatory payment requirement in the MTA shall apply also in cases where such commercialized products are available without restriction to others for further research and breeding.

Article 13.2(d)(ii) is arguably the most interesting and controversial provision related to benefit-sharing. This paragraph establishes a mandatory benefit-sharing scheme connected to the commercialization of PGRFA incorporating materials from the Multilateral System, in harmony with Article 15.7 of the CBD. The standard MTA provided for in Article 12.4 is to contain the benefit-sharing requirement that will bind the recipient, and all future recipients, of germplasm from the Multilateral System to pay a share of the monetary benefits arising from commercialization of products incorporating material accessed from the System, in certain circumstances.

The first part of Article 13.2(d)(ii) sets out those circumstances. When a recipient receives material from the Multilateral System and uses that material to produce a product that "is a PGRFA," and then commercializes that product, then the recipient will be obliged to pay "an equitable share of the benefits arising from its commercialization". This requirement, it should be understood, will not apply to the commercialization of a product that is not itself a plant genetic resource for food and agriculture. (Some of those products must be addressed in relation to Article 15 of the CBD.) It would also not apply to the trading of a normal commercial product, or commodity, such as a breakfast cereal containing wheat produced by a new variety produced by incorporating material obtained from the Multilateral System. This was already made clear in the chapeau to Article 13.2. It will, however, apply to the commercialization of the seed or other propagating material of a new plant variety - to the plant genetic resource itself - provided that that new variety incorporates material that has been accessed from the Multilateral System.

The obligation to pay, however, does not apply where the developer has enabled all users, without restriction, to utilize the new product for further research and breeding. ${ }^{115}$ In those cases, then there is no obligation on the recipient to make such a payment, although he or she is to be encouraged to make such a payment.

Where the recipient is obliged to make a payment, the obligation is triggered by the act of commercialization and not by the act of applying for intellectual property rights that would restrict further access to the product.

While the provisions of Article 13.2(d)(ii) are innovative and important, there are still a number of issues that will need to be resolved by the Governing Body.

The first of these issues is specifically provided for in the second part of Article 13.2(d)(ii). The Governing Body is to determine the level, form and manner of payment to be made at its first meeting, in line with commercial practice. One of the first decisions that the Governing Body will have to take will be the form of the payments. In particular it will have to decide whether these should take the form of royalties, a percentage of profits, or a lump sum payment or graduated payments according to the type of product or circumstances. It will also have to determine the level of payment. The relatively low profitability of the seed sector would suggest an upper limit on the

115 This is applicable to a product that incorporates material accessed from the Multilateral System. According to Article 12.3(d), recipients cannot claim intellectual property rights that limit access to the PGRFA in the form received. 
level. But if the level is set too low, the result could undermine the implementation of the Treaty. The reference to commercial practice may assist the Governing Body in making its determinations, or at least in defining the limits. However, the Governing Body is likely to have a great deal on its hands, given that there may be different views as to what constitutes relevant commercial practice.

The Governing Body may also review the levels of payment from time to time, in order to achieve a fair and equitable sharing of benefits. It may also assess, within a period of five years from the entry into force of the Treaty, whether the mandatory payment requirement should also be extended to cases where no restrictions have been placed on the further availability of the product. The latter provision is strangely worded, but it is unlikely that the intention was to limit the opportunity to review to the first five years. The Treaty is silent as to whether or not a review might be carried out after this five-year period. Given that plant breeders may take up to a decade after the entry in force of the Treaty to create new products using PGRFA obtained from the Multilateral System, the time frame of five years may be much too early to assess the impact of this benefit-sharing mechanism.

There are also a number of other issues or ambiguities that remain unclarified in the text. One of these is the precise meaning of the clause "whenever such a product is available without restriction to others for further research and breeding". Criteria for determining whether or not "a product is available without restriction to others for further research and breeding" are not given in the Treaty. However, the understanding underlying the negotiations was that mandatory monetary benefit-sharing would apply to commercialized products, protected in a way that would limit the further availability of the product for research or breeding, or where practical, legal or physical conditions restrict the availability of the product. It may also apply where patents or other intellectual property rights are taken out over any genetic parts or components of the new product, where this would have the effect of similarly restricting the availability of the product.

Varieties incorporating material from the Multilateral System that are protected by UPOVstyled Plant Breeders Rights, would not be subject to mandatory monetary benefit-sharing assuming that such varieties are freely available for further research and breeding. In jurisdictions, patents rights do not exclude the use of plant genetic material for further research purposes including breeding. In other jurisdictions, they do exclude such uses. It is not clear whether a patent holder in such jurisdictions could renounce those and thus escape the mandatory benefit-sharing provision. Would so-called "protective patenting" ever qualify for exclusion from Article 13's monetary benefit-sharing requirement? For example, could one patent a variety or line and then undertake to grant any and everyone a license to use the material freely for research and breeding, and not have to make the mandatory payment? One advantage for governments of the contractual approach is that individual recipients and users of PGRFA obtained from the Multilateral System will need to make their own legal determination of their contractual obligations, in particular whether a payment is optional in any given circumstance. This may need clarification by the Governing Body.

A second potential issue lies in the meaning of the term "commercialization". Monetary benefit sharing is triggered by any commercialization, but what exactly does this term mean? At what point in the continuum of trading of a product would the obligation arise? Would it arise when the product is offered for sale, or when the offer is accepted, or when profits arise? In principle, it would seem that the term commercialization should actually refer to when a sale has been concluded. Whether one would need to wait until profits have actually arisen, will depend on the form of payments determined by the Governing Body.

A third potential issue is what constitutes "incorporation" of material accessed from the Multilateral System. There will of course be different methods of incorporation, including both conventional breeding and biotechnological methods. However, the wording of the provision would suggest that material accessed from the Multilateral System has been "incorporated" in a product when there is presence of the genetic information of the accessed material in that product. But technical questions may still arise as to the extent of the incorporation required. For example, would any incorporation of the material be sufficient to satisfy the requirement? Or would the incorporation of an essential part of the material necessary for the desirable traits be required? Or would different 
levels of incorporation be used to guide the determination of different levels of payment?

All of the above issues will require consideration by the Governing Body.

Article 13.2.(d)(ii) applies to all material accessed from the Multilateral System. It would thus cover all Annex I material accessed from Contracting Parties, IARCs, and other international institutions. Because CGIAR Centres have their own independent legal status and will sign separate agreements with the Governing Body, access of materials by one centre from another centre (like access by a Contracting Party from a centre) would be considered as access from the multilateral system. An MTA would thus be required for such a transfer. Transfers within a centre (e.g., from the genebank to a breeder or researcher) may or may not be considered an act of access from the multilateral system. In effect, this would be a transfer from one "legal person" to the same "legal person." IARCs, however, are in a rather different situation than Contracting Parties. CGIAR Centres claim no ownership over the materials, and they are holding the materials in trust. It will be interesting to see if centres agree to employ the benefit-sharing provisions of the Treaty, were they to commercialize PGRFA developed on the basis of materials in their own genebank and protect these in such a way as to limit further access and use for research and breeding.

13.3 The Contracting Parties agree that benefits arising from the use of plant genetic resources for food and agriculture that are shared under the Multilateral System should flow primarily, directly and indirectly, to farmers in all countries, especially in developing countries, and countries with economies in transition, who conserve and sustainably utilize plant genetic resources for food and agriculture.

As in other articles in this Treaty, the role of farmers is specifically acknowledged, and rewarded, in this paragraph. The benefit-sharing, as in the definition of Farmers' Rights in the Agreed Interpretations to the International Undertaking, is designed not only to recognize past contributions, but also to encourage present and future contributions. Thus, Article 13.3 states that the benefits arising from the use of PGRFA shared under the multilateral system should flow primarily to farmers who conserve and sustainably use PGRFA, particularly in developing countries and countries with economies in transition. The benefits may flow directly to those farmers, e.g. through direct assistance in on-farm management and conservation of PGRFA, or indirectly, e.g. through the financing of programmes that will indirectly benefit them, such as broadening the genetic base of crops. While farmers in developing countries and countries with economies in transition will obviously be the main focus, the wording does not exclude benefit sharing with farmers who conserve and sustainably use PGRFA in developed countries, particularly where the benefits are indirect.

13.4 The Governing Body shall, at its first meeting, consider relevant policy and criteria for specific assistance under the agreed funding strategy established under Article 18 for the conservation of plant genetic resources for food and agriculture in developing countries, and countries with economies in transition whose contribution to the diversity of plant genetic resources for food and agriculture in the Multilateral System is significant and/or which have special needs.

13.5 The Contracting Parties recognize that the ability to fully implement the Global Plan of Action, in particular of developing countries and countries with economies in transition, will depend largely upon the effective implementation of this Article and of the funding strategy as provided in Article 18.

Articles 13.4 and 13.5 explicitly link benefit sharing and the funding strategy. While Article 18 will be discussed in more detail below, the
Treaty establishes a funding strategy that will mobilize funding for priority activities, plans, and programs, in particular in developing coun- 
tries and transition economies. Contracting Parties explicitly agree to take the necessary and appropriate measures within the governing bodies of relevant international agreements, funds, and bodies to ensure that due priority and attention are given to effectively allocating predictable and agreed resources, taking into account the priorities established in the rolling GPA.

Decisions as to how the proceeds of the funding strategy will be used will be taken by the Governing Body. Article 13.5 also recognizes that the ability of developing countries and countries with economies in transition to fully implement the GPA will depend largely upon effective implementation of benefit sharing and of the funding strategy. The provision of financial resources to assist developing countries in implementing the GPA was a contentious issue at the Leipzig Conference that adopted the Plan.

In spite of the fact that the Commission agreed to discuss funding issues in the context of the negotiations to revise the International Undertaking, many developing countries had sought commitments from developed countries to provide new resources for this purpose, over and above those committed under the CBD. In the end the Leipzig Conference reaffirmed the commitments for new and additional funds, as stated in Agenda 21 and the CBD, and specified that funds should be made available under those commitments to finance the implementation of the GPA by developing countries and countries with economies in transition. The Treaty's funding strategy is one way of implementing these commitments.

There are distinct differences between this provision and similar provisions in the CBD and the UN Framework Convention on Climate Change ${ }^{116}$ (UNFCCC). Both of these Conventions limit financing provisions based on the ability of the Contracting Parties to implement their commitments. In the International Treaty, however, the limitation applies only to the Contracting Parties' ability to implement the GPA and not their Treaty obligations. A broader provision that tracks the wording of the CBD and the UNFCCC provisions is found in Article 18.4(b) of the Treaty.

\subsection{The Contracting Parties shall consider modalities of a strategy of voluntary benefit-sharing contributions whereby Food Processing Industries that benefit from plant genetic resources for food and agriculture shall contribute to the Multilateral System.}

Contracting Parties have agreed in Article 13.6 to consider, at some point in the future, "modalities of a strategy of voluntary benefitsharing contributions" from food processing industries. This is in addition to the voluntary benefit-sharing arrangements under Article 13.2(d)(ii). The rationale is that the food processing industry benefits most directly from the utilization of PGRFA. As such, this is strongly linked to Article 18.4(f). 
Explanatory Guide to the International Treaty on Plant Genetic Resources for Food and Agriculture 


\section{PART V - SUPPORTING COMPONENTS}

Part V of the Treaty deals with "supporting components", namely the GPA, ex situ collections held by IARCs and other international institutions, International Plant Genetic Resources Networks and the Global Information System on plant genetic resources for food and agriculture. The term "supporting components" refers to mechanisms that support the entire Treaty, but also have an independent existence outside the Treaty, in particular in relation to the role of the FAO CGRFA.

\section{Box 15. The Report on the State of the World's Plant Genetic Resources and the Global Plan of Action for the Conservation and Sustainable Use of Plant Genetic Resources for Food and Agriculture}

The first Report on the State of the World's Plant Genetic Resources was prepared by an international secretariat located in FAO, through a participatory, country-driven process. The Report assessed the state of plant genetic diversity, and capacities at the local and global levels for in situ and ex situ management, conservation and utilization of plant genetic resources. It was presented to the Fourth International Technical Conference held in Leipzig, Germany, in June 1996.

The GPA, which is a voluntary (i.e. it not legally binding) instrument, was prepared on the basis of the Report, and was negotiated and formally adopted by 150 countries at the Leipzig Conference through the Leipzig Declaration. The GPA lists twenty agreed priority activity areas organized into the following four main groups: In Situ Conservation and Development; Ex Situ Conservation; Utilization of Plant Genetic Resources; and Institutions and Capacity Building. The GPA is intended to be a rolling plan that will be monitored, reviewed and updated by the FAO CGRFA.

The main aims and strategies of the GPA are:

- To ensure the conservation of PGRFA as a basis for food security;

- To promote sustainable utilization of PGRFA, in order to foster development and to reduce hunger and poverty particularly in developing countries; and

- To promote a fair and equitable sharing of the benefits arising from the use of PGRFA, recognizing the desirability of sharing equitably benefits arising from the use of traditional knowledge, innovations and practices relevant to the conservation of PGRFA and their sustainable use.

The GPA aims

- To assist countries and institutions responsible for conserving and using PGRFA to identify priorities for action; and

- To strengthen, in particular, national programmes, as well as regional and international programmes, including education and training, for the conservation and utilization of PGRFA and to enhance institutional capacity.

The GPA was endorsed by the FAO Conference at its Twenty-ninth Session in 1997.

With the adoption of the Treaty, the GPA assumes even greater significance. The GPA is recognized in Article 14 of the Treaty as an important supporting component of the Treaty. The Contracting Parties are called upon to ("should") promote its effective implementation, including through national actions and, as appropriate, international cooperation to provide a coherent framework, inter alia, for capacitybuilding, technology transfer and exchange of information. 
Explanatory Guide to the International Treaty on Plant Genetic Resources for Food and Agriculture 


\section{Article 14 - Global Plan of Action}

Recognizing that the rolling Global Plan of Action for the Conservation and Sustainable Use of Plant Genetic Resources for Food and Agriculture is important to this Treaty, Contracting Parties should promote its effective implementation, including through national actions and, as appropriate, international cooperation to provide a coherent framework, inter alia, for capacity-building, technology transfer and exchange of information, taking into account the provisions of Article 13.

Contracting Parties are encouraged to promote the effective implementation of the GPA (see Box 15) as an international, yet voluntary, framework for PGRFA-related efforts. This is to be accomplished through:

- national actions; and

- appropriate international cooperation to provide a coherent framework for capacity building, technology transfer and the exchange of information.

In so doing, the Parties are encouraged to take into account Article 13 on benefit-sharing.

While the wording used in Article 14 is not binding, the GPA is seen as an essential scien- tific and technical framework for action at both the national and international levels, and in particular for the benefit-sharing provisions of Article 13. The first GPA was adopted in 1996, and it is envisaged that the Plan will be periodically updated; hence the expression "rolling".

The implementation of the GPA will be guided and monitored by countries through the FAO CGRFA. In addition to progress reports issued by the CGRFA, a series of regional and sub-regional meetings to promote implementation of the GPA have been held, co-sponsored by the System-wide Genetic Resources Programme of the CGIAR and relevant regional agricultural research organizations. 


\section{Box 16. Facilitating Mechanism for the Global Plan of Action}

Since the time of the adoption of the GPA, considerable experience has been gained in many areas critical for the implementation of the Plan. This includes work concerning on-farm management of plant genetic resources, participatory plant breeding, and furthering the understanding of local seed systems. National plant genetic resources programmes have been put into place in many countries and established networks in most sub-regions provide appropriate platforms for stakeholder involvement and the integration of conservation with the sustainable use in the plant breeding and seed sector. ${ }^{117}$

However, the wish of many stakeholders that the GPA should provide for coherent action in the fields of in situ and ex situ conservation, sustainable utilization of plant genetic resources, and institution and capacity-building has not been fully realized. Among the reasons for this is the absence, as yet, of an effective international arrangement to facilitate the implementation of the GPA.

Building on the successful example of a facilitating mechanism provided by the Global Programme on Integrated Pest Management, the FAO has established a facilitating mechanism to develop a more comprehensive and integrated approach to further implementation of the GPA. The proposal was presented to the CGRFA at its Ninth Session in October 2002, which "stressed that the implementation of the Plan should be country-driven, but efforts should also focus on facilitating the provision of technical and financial resources to developing countries (especially least developed countries), and to countries with economies in transition. High priority should also be given to enhancing or creating partnerships for implementation of the Plan, promoting linkages among plant genetic resources management, plant breeding and seed sector, and networking, and facilitating communication with international organizations and donors."

The proposal was further discussed at the Second Session of the Commission's Working Group on Plant Genetic Resources in November 2003. The Working Group, which reports to the Commission, left the wording of the objectives of the Facilitating Mechanism to the Commission itself, but agreed on its operating principles, activities and operational structure. The Facilitating Mechanism will receive overall guidance from the Commission and its working Group on PGRFA. It will be hosted by FAO and operated in partnership with IPGRI in a way that attracts and accommodates other international organizations to become partners. Its activities will include providing information on:

i. Sources and availability of financial, technical, material and information resources;

ii. Linkages among stakeholders;

iii. Donor and recipient priorities, roles and conditions;

iv. Best practices and standards and procedures;

v. Success stories;

vi. Networking;

vii. Plans, commitments, targets and indicators; and

viii. Any other information regarding resources necessary to implement the GPA. ${ }^{118}$

At its tenth session in November 2004, the CGRFA reviewed the Technical Working Group's proposal, and agreed that the objective of the Facilitating Mechanism should be to facilitate the implementation of the GPA, and to encourage the mobilization of technical and financial resources to do so. The Commission supported the operational principles, activities, and operational structure of the Facilitating Mechanism.

117 See FAO Commission on Genetic Resources for Food and Agriculture, A Facilitating Mechanism for the Implementation of the Global Plan of Action for the Conservation and Sustainable Utilization of Plant Genetic Resources for Food and Agriculture, CGRFA-9/02/9, Ninth Regular Session (Rome, 9 and 14-18 October 2002).

118 See Report of the Second Session of the Working Group on Plant Genetic Resources for Food and Agriculture, FAO Doct. CGRFA/WG-PGR-2/03/Report, November 2003. 


\section{Article 15 - Ex Situ Collections of Plant Genetic Resources for Food and Agriculture held by the International Agricultural Research Centres of the Consultative Group on International Agricultural Research and other International Institutions}

The IARCs of the CGIAR hold important ex situ collections of PGRFA and also have major crop improvement programmes, organized in collaboration with national agricultural research systems. While CGIAR Centres currently maintain only approximately $12 \%$ of the accessions held in ex situ conditions worldwide, they conserve a comparatively higher percentage of known diversity, due in large part to the composition of the collections. On average, landraces and wild relatives comprise only $16 \%$ of national collections. The comparable figure for the CGIAR Centres is $73 \% .^{119}$ In addition, CGIAR collections are generally well maintained and well documented. The combination of these factors makes these collections a unique resource and one of great utility to breeders. Not surprisingly, the collections are used extensively: research on flows of accessions into and out of CGIAR genebanks demonstrates that virtually every country in the world is a major net beneficiary of germplasm flows. ${ }^{120}$ CGIAR collections, therefore, are important not just for CGIAR plant breeders, but serve as an important resource for any international system of germplasm conservation and management.

Much of the material collected has come through joint missions. Duplicate samples of the collected materials have always been made available to national programs and national genebanks. Research results, (such as characterization and evaluation data) have subsequently been made available to national programmes to enable them to use and develop these resources more fully and efficiently. In many cases, national scientists received training and funds to work with the materials.
Countries have been able to obtain far more materials from the CGIAR than they, individually, could ever have contributed. Even during the height of collecting activities, developing countries were requesting 4 samples for every 1 they contributed. In recent years, the ratio has widened to at least 60 to 1 . Since 1994, Centres have distributed more samples to developing countries than they collected since the founding of the CGIAR.

Centre collections serve as an "insurance policy" for countries against the loss of diversity at the national level. More than 40 countries have benefited from being able to obtain materials from the CGIAR that are no longer available within the country that first provided them to the Centre.

Centres produce and provide valuable, improved germplasm free to countries. Each year the Centres send out hundreds of thousands of samples, products of their research, to national programs and others. In terms of sheer numbers, distribution of improved materials dwarfs that of landraces, wild relatives, etc., that constitute the bulk of materials covered under the Agreement with FAO. The products of Center research provide enormous economic benefits to developing countries. Two examples serve to illustrate that point: (a) over the past 30 years, $85 \%$ of all spring bread and $86 \%$ of all spring durum varieties released by developing countries and sown by their farmers had CIMMYT-produced wheat in their ancestries; (b) while yams are one of the most important crops in the world, particularly for low-income people, few developing countries have a single

119 FAO (1998) The State of the World's Plant Genetic Resources for Food and Agriculture. Rome: FAO.

120 Fowler, C., Smale, M. and Gaiji, S. (2001) “UnequalExchange? Recent Transfers of Agricultural Resources and their Implications for Developing Countries," Development Policy Review. Vol. 19, No. 2. 
public-sector plant breeder working on the crop. Most national programs and the millions of farmers they serve, therefore, depend heavily on the International Institute of Tropical Agriculture (IITA) in Africa to supply them with disease-resistant productive yam varieties.

The legal status of the CGIAR collections has always been ambiguous. In 1994, 12 of the CGIAR Centres signed agreements with FAO placing collections of plant germplasm held by them under the auspices of FAO. The collections were recognized under those agreements as being held by the Centres in trust for the benefit of the international community. Their status was discussed extensively in the negotiations leading to the Treaty, resulting in Article 15 , devoted to these collections.

Generally speaking, Article 15 calls on the IARCs of the CGIAR to sign agreements with the Governing Body to bring their ex situ collections under the terms of the Treaty. Such agreements are necessary in order to bring the collections within the purview of the Treaty, as the IARCs have their own legal personality and governance system, and cannot be bound by the provisions of the Treaty without their consent. But since they are not States, they cannot become Parties to the Treaty in their own right. Under these agreements, PGRFA falling under the Multilateral System would be distributed under the terms of the standard MTA common to Contracting Parties and Centres.

Non-Annex I PGRFA assembled prior to the coming into force of the Treaty would also be distributed under a different MTA (based on the current MTA as amended and approved by the Governing Body). Material not covered by the multilateral system that is received and conserved after the coming into force of the Treaty would be available on terms mutually agreed with the country of origin or other country that acquired them in accordance with the CBD or other applicable law. Other provisions of the Treaty related to the Centres are similar to those now in effect under the FAO-CGIAR Agreements. No provisions are specified for differential treatment of Contracting Parties and non-Parties in relation to materials made available by Centres under the Treaty.

\subsection{The Contracting Parties recognize the importance to this Treaty of the ex situ collections of plant genetic resources for food and agriculture held in trust by the International Agricultural Research Centres (IARCs) of the Consultative Group on International Agricultural Research (CGIAR). The Contracting Parties call upon the IARCs to sign agreements with the Governing Body with regard to such ex situ collections, in accordance with the following terms and conditions:}

Article 15.1 defines the scope of the Treaty with respect to the Centres. Specifically, it uses language similar to the previous agreement with the FAO in its reference to ex situ collections being held in trust by the Centres. Moreover, it calls upon Centres to sign agreements with the Governing Body of the Treaty regarding such ex situ collections. "121 "Calling upon" the Centres to sign such agreements is more vigorous language than simply "inviting" them to do so, but does not presume to replace CGIAR governance as would occur if the Treaty explicitly declared that the collections are part of the Multilateral System. In effect, the Treaty's provisions extend to:

- all materials held "in trust" by the Centres as of the date on which the Centres sign formal agreements with the Governing Body, regardless of whether these materials are of crops listed in Annex I or not; and

- PGRFA of Annex I crops acquired after the coming into force of the Treaty.

121 The Treaty makes specific reference to materials held "in trust," i.e., to those formally designated under agreements with FAO. 
The Treaty's provisions on providing facilitated access and benefit-sharing will not apply, however, to materials of non-Annex I crops such as groundnut, soyabean, and most tropical forages, acquired after the entry into force of the Treaty. Such materials would be acquired, in the case of Parties to the CBD, in accordance with the provisions of the CBD on the basis of "prior informed consent" and "mutually agreed terms", or, in the case of parties who are not Parties to the CBD, on other bilateral terms. Importantly, this would not preclude a Centre from acquiring such materials on terms that are consistent with the Treaty and that would allow them to be distributed under the same standard MTA. The subparagraphs of Article 15 differentiate between Annex I and non-Annex I PGRFA in terms of how Centres will manage these materials.

(a) Plant genetic resources for food and agriculture listed in Annex I of this Treaty and held by the IARCs shall be made available in accordance with the provisions set out in Part IV of this Treaty.

Under this subparagraph, Centres are to make available Annex I materials, which constitute the vast majority of accessions held by Centres, in the same way as Contracting Parties to the Treaty. This means that the rules for handling most Centre-held germplasm will be exactly the same as those applicable to countries that are
Contracting Parties. As noted elsewhere in this Guide, those rules as set out in the Treaty still contain certain ambiguities. Once those ambiguities are resolved for the Contracting Parties, they will automatically be resolved also for the IARCs.

(b) Plant genetic resources for food and agriculture other than those listed in Annex I of this Treaty and collected before its entry into force that are held by IARCs shall be made available in accordance with the provisions of the MTA currently in use pursuant to agreements between the IARCs and the FAO. This MTA shall be amended by the Governing Body no later than its second regular session, in consultation with the IARCs, in accordance with the relevant provisions of this Treaty, especially Articles 12 and 13, and under the following conditions:

Article 15.1(b) lays out the terms under which Centres will manage and make available nonAnnex I materials collected prior to the coming into force of the Treaty.

The intention of the Treaty appears to be for Centres to manage non-Annex I materials held "in trust" by the Centres in roughly the same way as Annex I materials. There are a few differences, however, as well as some possible ambiguities in the text of this Article. The text calls for non-Annex I PGRFA collected prior to the entry into force of the Treaty to be made available in accordance with the terms of the MTA currently being used by the Centres until it is amended by the Governing Body of the Treaty to reflect the provisions of the Treaty dealing with access and benefit-sharing: the term "currently in use" means currently in use at the time of entry into force of the Treaty. The general formulation may cause some problems, in that some materials collected by Centres prior to the coming into force of the Treaty will have been acquired with conditions attached that may preclude their being treated this way. Since the coming into force of the CBD, and even earlier, Centres have collected materials on the basis of terms mutually agreed with the country in which they were collected. For most non-Annex I materials that were collected on this basis, managing them in a manner consistent with the Treaty should not be problematic. This may not be the case, however, in some cases where the materials were collected with conditions attached. Treaty negotiators clearly did not intend the language of Article 15.1(b) to negate agreements that Centres might have made with countries when collections were made. This problem may therefore need to be resolved in the agreements that Centres conclude with the Governing Body of the Treaty. These agreements may need to clarify that Centres will manage non-Annex I PGRFA according to Article 15 , subject to cases where the terms under 
which the materials were acquired will not allow for this.

A similar situation may also arise in some cases with Annex I materials. Through the Treaty, Contracting Parties will have bound themselves to providing facilitated access to PGRFA of materials in the multilateral system. However, non-Contracting Parties will not have committed themselves to this, and Centres may not be able to renegotiate or abrogate agreements with such countries that included conditions relating to how the Centres might use or distribute these PGRFA.

Article 15.1(b) also provides that Centres will continue to use the MTA currently in use by the Centres until an amended MTA, reflecting the relevant provisions of the Treaty, is agreed upon by the Governing Body. The text of the paragraph charges the Governing Body with finalizing the amendments to the MTA no later than its second meeting.

The MTA currently in use by the Centres incorporates certain changes agreed upon by the FAO CGRFA at its Ninth Regular Session in 2002 , as an interim measure, to bring it into line with some of the concepts used in the Treaty. The changes agreed by the Commission have been agreed to by all the Centres concerned and have been adopted by those Centres on 1 May 2003. Those interim changes do not yet incorporate the mandatory benefit sharing provisions of Article 13.2(d)(ii).

(i) The IARCs shall periodically inform the Governing Body about the MTAs entered into, according to a schedule to be established by the Governing Body;

Article 15.1(b)(i) again applies only to nonAnnex I materials held in trust by the Centres and collected before the Treaty enters into force. The Centres are to make periodic reports to the Governing Body on the MTAs they have entered into. Such reports will presumably list the recipients of materials provided under those MTAs. Such records are already routinely kept by Centres at this time, and therefore, the obligation should be easily met. It is to be noted that the obligation on the Centres is to inform the Governing Body about the MTAs entered into by the Centres. It does not require the Centres to track subsequent transfer of the material (see discussion of Article 12.3(b)).

(ii) The Contracting Parties in whose territory the plant genetic resources for food and agriculture were collected from in situ conditions shall be provided with samples of such plant genetic resources for food and agriculture on demand, without any MTA;

Article 15.1(b)(ii) allows for the restoration of genetic resources to Parties that supplied the materials to the Centre, without resort to an MTA. A provision similar to this is found in the current agreements with FAO, with the exception that the current agreements with FAO speak of repatriation to the "country that provided such germplasm." This may not necessarily be the country where the material was collected from in situ conditions.

This provision may give rise to practical difficulties in implementation, as it is under- stood that Centres may not always know where the material was collected in in situ conditions. The practical impact of this distinction between the two agreements (i.e. the "in-trust" agreements and the new agreements with the Governing Body) may not be substantial. The material will be available in any case, the question is simply whether an MTA should be required or not. Under the Treaty, "restoration" applies only to countries from which the material was collected in in situ conditions. Otherwise, access is handled under the normal rules governing access pursuant to Articles 12 and 13.

(iii) Benefits arising under the above MTA that accrue to the mechanism mentioned in Article 19.3f shall be applied, in particular, to the conservation and sustainable use of the plant genetic resources for food and agriculture in question, particularly in national and regional programmes in developing countries and countries with 
economies in transition, especially in Centres of diversity and the least developed countries; and

This subparagraph presupposes that the MTA that is to accompany non-Annex I material will also contain a similar provision on benefit sharing to that used in the Multilateral System, including the sharing of monetary and other benefits of commercialization under Article 13.2(d)(ii). Article 13.3 of the Treaty provides for the way in which shared benefits arising from the use of PGRFA under the Multilateral System are to be used. They are to flow primarily, directly and indirectly, to farmers in all countries, especially in developing countries and countries with economies in transition who conserve and sustainably utilize PGRFA. The benefits arising under the MTA that is to accompany non-Annex I material, are outside the Multilateral System. They therefore fall outside the general prescription of Article 13.3 and the way in which they are to be used needs to be dealt with in a specific provision.
Article 15.1(b)(iii) specifies that benefits that arise as a result of the MTA will be applied, in particular for the conservation and sustainable use of the PGRFA in question, particularly in national and regional programmes in developing countries and countries with economies in transition, especially in Centres of diversity and the least developed countries. In other words, if a germplasm recipient uses the received materials in ways that trigger the benefit-sharing provisions of the MTA, then the funds generated will be directed towards conservation and sustainable use of those particular PGRFA in developing countries and so on. This would imply that some separate record will need to be kept of the resources generated and the use to which they are put. It is to be noted that this paragraph, in using the words "in particular" indicates priorities for the use of the accrued benefits, and does not completely rule out other uses.

\section{(iv)The IARCs shall take appropriate measures, in accordance with their capacity, to maintain effective compliance with the conditions of the MTAs, and shall promptly inform the Governing Body of cases of non-compliance.}

Article 15.1(b)(iv) addresses the issue of the responsibilities of Centres for maintaining compliance with the terms of the MTAs. This paragraph, which covers only non-Annex I PGRFA, is substantially similar to the agreement already in place between FAO and the CGIAR Centres. In the current agreement with FAO, Centres are not required, for example, to monitor compliance, nor are they are required to enforce compliance, for instance, by resorting to legal action. This matter was clarified in Joint Statements made to the FAO Commission Genetic Resources for Food and Agriculture by FAO and IPGRI on behalf of the CG Centres at the time of reporting on the signature of the in trust agreements and later on the implementation of the agreements. ${ }^{122}$
Use of the word "maintain" instead of "ensure" indicates that countries do not expect Centres to guarantee compliance; they simply expect Centres to distribute materials properly, under the standard MTA, to take appropriate measures within their capabilities to bring about compliance and report cases of non-compliance when these come to the attention of the Centres. This approach has produced a very high level of compliance with the MTAs currently in use by Centres.

It should also be noted that Article 12.5 requires Contracting Parties to provide recourse procedures for non-compliance with the terms of MTAs under their national legal systems.

122 See Report of the First Extraordinary Session of the Commission on Plant Genetic Resources, November 1994, para. 37 (the text of the first Joint Statement is reproduced in document CPGR Ex1/ 94/Inf. 5/Add. 1); and Progress Report on the International Network of Ex Situ Collections under the Auspices of FAO, presented to the Eighth Regular Session of the Commission on Genetic Resources for Food and Agriculture in April 1999, document CGRFA-8/99/7. 
(c) IARCs recognize the authority of the Governing Body to provide policy guidance relating to ex situ collections held by them and subject to the provisions of this Treaty.

(d) The scientific and technical facilities in which such $e x$ situ collections are conserved shall remain under the authority of the IARCs, which undertake to manage and administer these $e x$ situ collections in accordance with internationally accepted standards, in particular the Genebank Standards as endorsed by the FAO Commission on Genetic Resources for Food and Agriculture.

(e) Upon request by an IARC, the Secretary shall endeavour to provide appropriate technical support.

(f) The Secretary shall have, at any time, right of access to the facilities, as well as right to inspect all activities performed therein directly related to the conservation and exchange of the material covered by this Article.

(g) If the orderly maintenance of these $e x$ situ collections held by IARCs is impeded or threatened by whatever event, including force majeure, the Secretary, with the approval of the host country, shall assist in its evacuation or transfer, to the extent possible.

Articles 15.1(c) through (g) apply to all IARCheld materials covered by the Treaty. Each of these five paragraphs finds a precedent in the existing agreements with FAO. Indeed, the lan- guage in those agreements was used as the basis in drafting this section of the Treaty. For ease of comparison, the table below provides the relevant reference for each paragraph:

\begin{tabular}{|l|l|}
\hline Treaty Text & Corresponding Paragraph in FAO-CGIAR Agreements \\
\hline 15.1.(c) & Article 6 \\
\hline 15.1.(d) & Article 4(a) and Article 5(a) \\
\hline 15.1.(e) & Article 5(b) and Article 7(b) \\
\hline 15.1.(f) & Article 4(b) \\
\hline 15.1.(g) & Article 5(c) \\
\hline
\end{tabular}

The most obvious change in wording in the above paragraphs between the existing FAOCGIAR Agreements and the Treaty is in Article 15.1(c). The FAO-CGIAR Agreements speak of the Centres recognizing the authority of FAO and its Commission "in setting policies" for the International Network. The Treaty refers, perhaps more accurately, to the authority of the Governing Body to "provide policy guidance" relating to the ex situ collections held by the Centres and covered by the Treaty. In practice, however, it is difficult to imagine circumstances under which the Centres would not follow the guidance of the Governing Body.
In effect, however, the change between the Treaty language and the FAO-CGIAR Agreement language is largely cosmetic. Centres have indicated that they will continue to welcome the policy advice of governments, collectively expressed through the Governing Body and the FAO Commission, and will follow that guidance. In practice, the Centres have on occasions actively sought such guidance on specific issues, such as the interpretation of the phrase "germplasm and related information" in the FAO-CGIAR Agreements.

15.2 The Contracting Parties agree to provide facilitated access to plant genetic resources for food and agriculture in Annex I under the Multilateral System to IARCs of the CGIAR that have signed agreements with the Governing Body in 
accordance with this Treaty. Such Centres shall be included in a list held by the Secretary to be made available to the Contracting Parties on request.

Article 15.2 provides for "reciprocity" by requiring Contracting Parties to provide centres with "facilitated access" to PGRFA covered by Annex I. The phrase "facilitated access" is used in describing what Contracting Parties are required to provide to each other, and thus this paragraph provides that access will be provided to centres under the same arrangements as those for governments that are Contracting Parties to the Treaty. This will facilitate the centres' collecting work.

15.3 The material other than that listed in Annex I, which is received and conserved by IARCs after the coming into force of this Treaty, shall be available for access on terms consistent with those mutually agreed between the IARCs that receive the material and the country of origin of such resources or the country that has acquired those resources in accordance with the Convention on Biological Diversity or other applicable law.

Article 15.3 expresses existing policy within the CGIAR, namely that Centres now acquire new materials in accordance with the terms of the CBD, namely, with "prior informed consent," and on the basis of "mutually agreed terms" or other applicable law. Subsequent distributions of such materials are in accordance with the terms agreed at the time of acquisition. This paragraph requires that Centres continue to observe this practice. This approach could also apply to those Annex I materials collected in the past under specific conditions, particularly if acquired from non-Parties to the Treaty. It is to be noted that the reference to "country of origin of such resources" differs from the wording used in the CBD. Article 15 of the CBD refers to the "country providing those resources, provided that that country is the country of origin of those resources or has acquired the genetic resources in accordance with the Convention."

15.4 The Contracting Parties are encouraged to provide IARCs that have signed agreements with the Governing Body with access, on mutually agreed terms, to plant genetic resources for food and agriculture not listed in Annex I that are important to the programmes and activities of the IARCs.

Article 15.4 provides Centres with a tool unavailable to Contracting Parties to the Treaty. This paragraph implicitly acknowledges the importance of Centre research on non-Annex I crops. It encourages Contracting Parties to provide access to PGRFA of these crops. While some crops of importance to the CGIAR were not included in Annex I, Article 15.4. provides some support for the Centres' work on those crops. Presumably, Centres will be able to report to the Governing Body on their experiences with gaining access to non-Annex I materials, and in this way will be able further to encourage compliance with this provision.

\subsection{The Governing Body will also seek to establish agreements for the purposes stated in this Article with other relevant international institutions.}

Article 15.5 simply states that the Governing Body may establish agreements with other institutions in conformity with Article 15.

No information, however, is provided as to what constitutes a "relevant international institution". Presumably, the wording was left in- tentionally broad to allow any institution with a PGRFA collection to be a party to an agreement. One such example could be the Tropical Agriculture Research and Higher Education Center (Centro Agronómico Tropical de Investigación y Enseñanza - CATIE). 


\title{
Box 17. The International Agricultural Research Centres of the CGIAR
}

\author{
CIAT - Centro Internacional de Agricultura Tropical \\ Apartado Aereo 6713, Cali, Colombia \\ E-mail: ciat@cgnet.com
}

Research and related activities on the improvement of beans, cassava, tropical forages, and rice for Latin America and on resource management in humid agro-ecosystems in tropical America including hillsides, forest margins and savannas.

\section{CIFOR - Center for International Forestry Research}

P.O. Box 6596, JKPWB Jakarta 10065, Indonesia

E-mail: cifor@cgnet.com

Collaborative research and related activities in forest systems and forestry, especially in the tropics, and promoting the transfer of technology and the adoption of new methods of social organization for national development.

\section{CIMMYT - Centro Internacional de Mejoramiento de Maiz y Trigo}

Lisboa 27, P.O. Box 6-641, 06600 Mexico, D.F., Mexico

E-mail: cimmyt@cgnet.com

Research on increasing the sustainable productivity of resources committed to maize and wheat in developing countries with a special focus on genetic improvement.

\section{CIP - Centro Internacional de la Papa}

Apartado 5969, Lima, Peru

E-mail: cipa@ cgnet.com

Coordinated multidisciplinary research and training on the generation and transfer of improved, sustainable production systems including the genetic improvement of potato, sweet potato, and Andean root and tuber crops.

ICARDA - International Center for Agricultural Research in the Dry Areas

P.O. Box 5466, Aleppo, Syria

E-mail:icarda@cgnet.com

Research and training to improve the productivity of crop and livestock systems in West Asia and North Africa including the genetic improvement of wheat, barley, lentil, chickpea, faba bean, and forages.

ICLARM - International Center for Living Aquatic Resources Management

MC P.O. Box 2631, 0718 Makati, Metro Manila, Philippines

E-mail: iclarm@cgnet.com

Research and related activities to improve the productivity and management of aquatic resources including coastal, coral reef, and integrated agriculture-aquaculture systems.

\section{ICRAF - International Center for Research in Agroforestry}

United Nations Avenue, P.O. Box 30677, Nairobi, Kenya

E-mail: icraf@cgnet.com

Research and Training to improve agroforestry systems focusing on alternatives to slash and burn agriculture in the humid tropics and overcoming land depletion in sub-humid and semiarid Africa. 
ICRISAT - International Crops Research Institute for the Semi-Arid Tropics

Patancheru P.O., Andhara Pradesh 502 324, India

E-mail: icrisat@cgnet.com

Research and related activities to increase the productivity and sustainability of semiarid tropical agriculture including the improvement of sorghum, pearl, and finger millet, chickpea, pigeonpea, and groundnut.

\section{IFPRI - International Food Policy Research Institute \\ $120017^{\text {th }}$ Street, N.W., Washington, DC 20036-3006, USA \\ E-mail: ifpri@cgnet.com}

Research and dissemination of knowledge and information on alternative national and international strategies and policies for meeting the needs of the developing world on a sustainable basis.

IIMI - International Irrigation Management Institute

P.O. Box 2075, Colombo, Sri Lanka

E-mail: iimi@cgnet.com

Research and related activities to improve water resource systems and irrigation management in developing countries and support for the introduction of improved technologies, policies, and management approaches.

IITA - International Institute of Tropical Agriculture

PMB 5320, Ibadan, Nigeria

E-mail: iita@cgnet.com

Research and related activities to help sub-Saharan African countries increase food production on an ecologically sustainable basis including the genetic improvement of cassava, maize, cowpea, soybean, yam, and banana and plantain.

\section{ILRI - International Livestock Research Institute}

P.O. Box 30709, Nairobi, Kenya

E-mail: ilri@cgnet.com

Research and related activities to improve animal health, nutrition, and productivity on small-scale farms in developing countries including characterizing and conserving the genetic diversity of tropical forages and livestock breeds.

\section{IPGRI - International Plant Genetic Resources Institute}

Vial delle Sette Chiese 142, 00145 Rome, Italy

E-mail: ipgri@cgnet.com

Research, training and information activities to support the conservation and use of agricultural and forestry genetic resources worldwide, especially in developing countries. Special focus on banana and plantain and on important species not covered by other Centres.

\section{IRRI - International Rice Research Institute}

P.O. Box 933,1099 Manila, Philippines

E-mail: irri@cgnet.com

Research and related activities to generate and disseminate rice-related knowledge and technology of short- and long-term environmental, social, and economic benefit and by helping to enhance national rice research efforts in developing countries.

continued next page 
ISNAR - International Service for National Agricultural Research

Addis Ababa, Ethiopia

E-mail: isnar@cgnet.com

Support for national agricultural research systems through promoting appropriate policies, strategies and funding, developing improved research management techniques, and disseminating relevant information.

WARDA - West Africa Rice Development Association

01 B.P. 2551, Bouake 01, Cote d'Ivoire

E-mail: warda@cgnet.com

Research and related activities to increase the sustainable productivity of rice-based cropping systems in West Africa, especially rice grown in mangrove swamps, inland valleys, upland conditions, and under irrigation. 


\section{Article 16 - International Plant Genetic Resources Networks}

Networks are important platforms for scientific exchange, information sharing, technology transfer, research collaboration, and for determining and sharing responsibilities for such activities as collecting, conservation, distribution, evaluation, and genetic enhancement. By establishing links among those involved in the conservation, management, development and utilization of PGRFA, networks can promote exchange of materials on the basis of mutually agreed terms and enhance the utilization of germplasm. In addition, they can serve to help set priorities for action, develop policy, and provide means whereby crop-specific and regional views can be conveyed to various organizations and institutions. Both the GPA (see Priority Activity Area 16) and the Treaty recognize the importance of networks as mechanisms for implementation of their objectives. It is important to note that this refers to all PGRFA, and not only those listed in Annex I.

For the purpose of this Guide, emphasis has been placed on three types of networks identified in the GPA: crop-based networks, regional networks, and thematic networks.

Crop Networks - As an early category of plant genetic resources networks, crop-based networks are often strongly user oriented. Breeders and researchers may play a central role along with plant genetic resources managers, and the conservation of germplasm is achieved in conjunction with its utilization, as plant genetic resources are often instrumental in increasing productivity. These networks tend to focus less on policy aspects, although the exchange of germplasm may be an important activity. For the purpose of the current study, seed networks are also described within this category, although they could also be considered thematic networks.

- The International Network for Bamboo and Rattan (INBAR).

- World Beta Network.

- Coconut Genetic Resources Network (COGENT).

- International Barley Genetic Resources Network.

- International Rice Genetic Resources Network.
- Asian Network for Sweet Potato Genetic Resources (ANSWER).

- Forest Seed Research Network on Handling and Storage of Recalcitrant and Intermediate Tropical Tree Seed.

- Global experiment on in vitro slow growth of sweet potatoes.

Regional Networks - Regional plant genetic resource networks play a major role in the conservation and to some extent in the utilization of plant genetic resources, as is apparent from their objectives. They tend to focus primarily on conservation; genebanks and plant genetic resources collection holders take a central position. Within the framework of conservation, these networks often address many issues featuring in the GPA and their agenda may involve a wide array of activities concerning collecting, regeneration, characterization, evaluation and documentation of genetic resources, as well as research, training, policy support to governments, and public awareness-raising. Many of the networks refer explicitly to the GPA in their documentation.

Regional Committee for South East Asia (RECSEA). Established in 1977, RECSEA includes five countries.

European Cooperative Programme for Crop Genetic Resources Networks (ECP/ GR). Established in 1980, this network is fully funded by its members.

West Asia and North Africa Plant Genetic Resources Network (WANANET).

South Asia PGR Coordinators Network (SAC); East-Asia PGR Network (EANET).

European Forest Genetic Resources Programme (EUFORGEN).

Banana Research Network for Eastern and Southern Africa (BARNESA).

Genetic Resources Network for Western and Central Africa (GRENEWECA). 
Meso-American Network on Plant Genetic Resources (REMERFI).

The Andean Network on Plant Genetic resources (REDARFIT).

The Amazonian Network on Plant Genetic Resources (TROPIGEN).

The North American Network on Plant Genetic Resources (NORGEN).

Thematic Networks - This type of network includes a wide range of arrangements to address specific themes, which could potentially be classified into numerous sub categories. Some thematic networks, such as the West African Farming Systems Research Network and the Consortium for the Sustainable Development of Andean Ecoregion (CONDESAN), are heavily focused on sustainability of ecosystems, and often take an integrated approach, combining conservation and development goals, and paying attention to all components and integration levels of agro-ecosystems and interactions between these components. In some cases, the focus of the network may be on development and transfer of a particular technology, such as the Technical Cooperation Network on Plant Biotechnology in Latin America and the Caribbean (REDBIO) or networks concerned with sharing information. Others are directly focused on aspects of biodiversity and plant genetic resources, for example the Southern African Botanical Diversity Network and the African Ethnobotany Network. Thematic networks are sometimes characterised by a strong field orientation or regional linkages (e.g. CONDESAN). Policy aspects and public awareness raising play an important role. The background of these networks can be very diverse, however civil organisations (e.g. NGOs) are often strongly represented.

\subsection{Existing cooperation in international plant genetic resources for food and agricul- ture networks will be encouraged or developed on the basis of existing arrange- ments and consistent with the terms of this Treaty, so as to achieve as complete coverage as possible of plant genetic resources for food and agriculture.}

The wording of this paragraph indicates a policy decision of the Treaty negotiators to focus on the building up of existing networks rather than trying to set up a whole new set of networks. This is of course not to rule out the possibility of setting up new networks as and when they may be required.

Not all networks are as successful as others. Some factors that may have a bearing on the efficiency and effectiveness of networks include:

- Financing-Networks are often funded as projects, receiving support for 3-4 year periods, which may be difficult to renew. This can sometimes lead to networks becoming inactive at the end of the project. A chronic problem remains the difficulty of ensuring resources over time. Networks funded by donors within a project may choose to utilize the project cycle to consciously "phase" its evolution. Networks "evolve" constantly, and the need for periodic internal reassessment can be worked into a cycle of 3-4 years. The Asian Vegeta- ble Research and Development Centre (AVRDC) networks are planned in this way, enabling the networks to provide evidence of impacts at the appropriate time. In this situation it is important for supporters to indicate whether networks will receive funding, under which conditions, for which objectives, and potentially for how long. Other models of financing include self-financing (for example, the European Cooperative Programme for Crop Genetic Resources Networks (ECP/GR)). Self-financing may only be possible in mature networks, and in most developing countries the potential for complete selffinancing is limited.

- Balance of interests - Problems such as domination of a network by donors, or over centralization of the network, can mean that the intended participants have less say in the network activities. Care must be taken to identify stakeholders and beneficiaries of the network in line with clear objectives, and ensure that they have a voice in the 
direction of the network and a role in monitoring and/or evaluation. The trend for those providing financial input to have the greatest voice in the direction of the network should be balanced by the understanding of the importance of member ownership. Networks with a strong feeling of ownership among members often survive in the face of financial limitations, through the contributions of members in time and resources. Likewise the balance of public, private and civil sector involvement should be kept in line with the objectives of the network.

- Management - Whether formal or informal, the management of a network is critical to its effectiveness. The existence of a lead country or lead institution with clear comparative advantages can provide a network with good management. Collective decisions on major issues, such as future strategy, workplans and budget, are also important: for example, frequent steering committee meetings, involving all network members, may be needed to take collective decisions on network activities and resource allocation. Frequent technical coordination meetings can also be important in developing workplans and budgets for approval.

- Clarity of focus and planning - Some networks are started with a good deal of promise but lacking a clear definition of what they hope to achieve. If objectives are not clearly defined, it is impossible to ensure that participants are included who wish to further these objectives. Networks need specific goals in order to develop dynamic, monitorable programmes, with distinct targets that can be met, ensuring that participants can work towards the same ends and thereby increasing the potential for good participation and a feeling of ownership.

- Awareness of mutual interests - It is essential that members of networks recognize their mutual interest, and that the benefits are realized by all members, to support complementary efforts by the totality of stakeholders: it needs to be apparent to all members that their collective efforts will result in a more efficient use of their limited human and physical resources.

- Ownership - Ownership in a network is often determined through participation in important decisions, particularly those relating to the distribution of funds. The question of ownership is also closely linked to important questions of clarity of objectives and level of participation in the networks, factors for which in depth analysis would require further communication with people involved in the networks.

- Adaptability - Network organization evolves in response to diverse factors. Networks need to be adaptable to be sustainable. Networks need to plan for change and evolution, monitor their activities and reassess their goals.

The following steps are sometimes recommended in order to strengthen networks and their role in the implementation of the Treaty:

- Encourage countries to complete the inventory of networks, including relevant thematic and in situ-oriented networks;

- Endorse further assessment of the contribution of existing networks to the implementation of the GPA and the Treaty, including their effectiveness, possibly through enhanced sub-regional-level examination of network issues, their functions, and the communication and synergies they provide, or could potentially provide, among different groups working toward the conservation and sustainable use of PGRFA, and further examination of the linkages and synergies among the different kinds of relevant networks, both within and between countries and regions;

- Agree to the further development of the framework for internal evaluation of networks, in collaboration with networks including identification of "model" networks and production of case studies illustrating different types of networks; and

- Endorse formal collaboration with the UNESCO Man and the Biosphere programme. 


\section{Box 18. International Networks for Plant Genetic Resources}

The term "network" can refer to many different arrangements between people, institutions and countries, both formal and informal, and a wide range of definitions have been applied to agricultural research networks. However, several common principles emerge from these definitions:

- Voluntary membership;

- Common goals to address complex problems better solved by more than one individual or institute;

- "Multilateral" exchange (of research results, materials, information, technologies, etc.);

- Participatory management; and

- Benefits to members from collaboration.

However, aside from these common characteristics, networks that contribute to the conservation and sustainable use of PGRFA vary considerably in many ways, for example in their membership, objectives, modus operandi, funding and organizational structure. An important aspect to take into consideration is the level of formality at which a network operates. This may depend not only on the network's age and stage of organizational development, but also on its function. The international network of ex situ collections under the auspices of FAO, for example, is necessarily a highly formal network, whereas a working group of scientists on a targeted technical subject may be able to network effectively for many years without a formal status.

Networks have the capacity to contribute to the implementation of the Treaty in the following ways:

- In Situ Conservation - In situ conservation is addressed by many regional plant genetic resource networks and by in situ-oriented networks such as the Man and the Biosphere world network of biosphere reserves. Thematic networks focused on agroecology and community development may also contribute by promoting sustainable agricultural practices and more diverse agricultural ecosystems. Some regional and crop-based networks also address in situ conservation. In general, linkages between these different kinds of networks appear to leave considerable room for improvement.

- Ex Situ Conservation - Ex situ conservation of plant genetic resources is addressed by the international network of ex situ collections under the auspices of FAO, which includes the collections of the CGIAR centres and COGENT. Many crop-based networks are closely involved with linking and providing a global overview of ex situ collections, also providing a mechanism for testing and further development of new materials. Regional plant genetic resources networks also contribute to the ex situ conservation of plant genetic resources, and often link partners that manage large PGRFA collections. The role of the international network of botanic gardens in conserving crop plant genetic resources is also well recognised although the GPA noted that their implementation needs to be strengthened.

- Utilization of PGRFA - Crop-based networks are generally strongly focused on the utilization of plant genetic resources and cooperative testing and development of improved materials. They often contribute to genetic enhancement of the crop and in many cases to base-broadening efforts. While crop development (breeding) and conservation need not be contradictory objectives, it may not be taken for granted that the presence of a crop network implies a contribution to the conservation or sustainable use of the crop's genepool. Regional plant genetic resource networks, as well as the networks on under-utilized crops and medicinal species, contribute to promoting the development and commercialization of under-utilized crops and species, as well as developing new markets for local varieties and "diversity rich" products. In addition, seed networks are important in supporting seed production and distribution.

- Exchange of Information - Information exchange is one of the most important functions of all networks, and the harmonization of databases and information systems, as well as building capacity for electronic communications, should be recognised as a major priority. The System-wide Information Network for Genetic Resources (SINGER), the World Information and Early Warning System on PGRFA (WIEWS), and the European Central Crop Databases are examples of global and regional networks which link activities of network partners in the area of information exchange. 
16.2 The Contracting Parties will encourage, as appropriate, all relevant institutions, including governmental, private, non-governmental, research, breeding and other institutions, to participate in the international networks.

As stated in Article 16.1, the goal of this provision is to achieve as complete coverage as possible of PGRFA. This requires the participation of a large variety of actors as listed.

While no set obligations are imposed, leaving the Contracting Parties with a wide scope to determine what constitutes "encouragement", this article nevertheless acknowledges the role that parties to the Treaty have in building strong and comprehensive networks. 
Explanatory Guide to the International Treaty on Plant Genetic Resources for Food and Agriculture 


\section{Article 17 - The Global Information System on Plant Genetic Resources for Food and Agriculture}

An effective global information system on PGRFA, their conservation both in situ and $e x$ situ, and ways in which they can be sustainably utilized, is an essential supporting component for the Treaty. At present, many of the world's PGRFA are insufficiently and/or poorly documented in relation to what should be known about them for optimal conservation, access and use. Documentation of wild relatives of crops and on-farm genetic resources located in situ is particularly poor. Information is also poorly distributed among countries. Proper documentation of plant genetic resources and exchange of information on those resources can not only be used to assist conservation efforts, but also to guide and assist utilization of PGRFA and in adding value to them. The most effective way of gathering and exchanging of information is through networking cooperation among countries.

Building on Article 13.2(a), which stated that the benefits arising from the use of PGRFA shall be shared fairly and equitably through an exchange of information mechanism, Article 17 provides for the creation of a Global Information System on PGRFA.

17.1 The Contracting Parties shall cooperate to develop and strengthen a global information system to facilitate the exchange of information, based on existing information systems, on scientific, technical and environmental matters related to plant genetic resources for food and agriculture, with the expectation that such exchange of information will contribute to the sharing of benefits by making information on plant genetic resources for food and agriculture available to all Contracting Parties. In developing the Global Information System, cooperation will be sought with the Clearing House Mechanism of the Convention on Biological Diversity.

Article 17.1 requires Contracting Parties to develop and strengthen a Global Information System to facilitate the exchange of information on scientific, technical and environmental matters related to PGRFA, with the expectation that such exchange of information will contribute to the sharing of benefits.

While little substantive content is mandated by the Treaty, Article 13.2(a) states that the Global Information System will include information about the PGRFA under the multilateral system, including "catalogues and inventories, information on technologies, results of technical, scientific and socio-economic research, including characterization, evaluation and utilization".

The Global Information System to be "developed and strengthened" is to build on existing information systems. One such existing system is the World Information and Early Warning System on Plant Genetic Resources for Food and Agriculture (WIEWS), established by the FAO. Other databases on PGRFA are operated by other international, regional and national institutions, such as the CGIAR System-wide Information Network for Genetic Resources (SINGER) (see Box 19).

The Article also makes an explicit link to the Clearing House Mechanism established by Article 18 of the CBD to ensure that all governments have access to the information and technologies they need for their work on biodiversity. The Clearing House has as its mission the promotion and facilitation of technical and scientific cooperation, within and between countries; the development of a global mechanism for exchanging and integrating information on biodiversity; and the development of the necessary human and technological network. 
17.2 Based on notification by the Contracting Parties, early warning should be provided about hazards that threaten the efficient maintenance of plant genetic resources for food and agriculture, with a view to safeguarding the material.

Article 17.2 states that the Global Information System should also provide for early warning, based on notification by the Contracting Parties, to warn against threats against the efficient maintenance of PGRFA.

The existing WIEWS established by the FAO already contains a preliminary Early Warn- ing System on Genetic Erosion. The scope of the information covered by WIEWS is currently being expanded to include the Seed Information System developed by FAO in the 1970's and an Early Warning System for Monitoring Plant Genetic Erosion (presently in a design phase) (see Box 19).

\subsection{The Contracting Parties shall cooperate with the Commission on Genetic Re- sources for Food and Agriculture of the FAO in its periodic reassessment of the state of the world's plant genetic resources for food and agriculture in order to facilitate the updating of the rolling Global Plan of Action referred to in Article 14.}

The first Report on the State of the World's Plant Genetic Resources (see Box 15) was prepared by an international secretariat located in FAO, through a participatory, country-driven process. The Report assessed the state of plant genetic diversity, and capacities at the local and global levels for in situ and ex situ management, conservation and utilization of plant genetic resources. It was presented to the Fourth International Technical Conference held in Leipzig, Germany, in June 1996. The Report was the scientific and technical baseline for the preparation of the GPA endorsed by the Leipzig Conference. This paragraph indicates that a similar process should be followed for future updating of the rolling GPA.
The rolling GPA itself forms an essential supporting component for the Treaty. It provides an agreed technical framework for both national and international action. The GPA was a cooperative effort of all countries, put together from the inputs of all countries in a highly participatory manner. Article 17.3 seeks to ensure the continuation of this cooperative effort. As the GPA is a supporting component for the Treaty, rather than one of its intrinsic components, responsibility for the preparation of updates lies not with the Governing Body, but with the FAO CGRFA. The Contracting Parties are required to cooperate with the Commission to ensure that the updating process remains well coordinated with the Treaty's Governing Body.. 


\section{Box 19. World Information and Early Warning System (WIEWS)}

Article 17 of the Treaty requires Contracting Parties to cooperate to develop and strengthen a global information system and provides that early warning should be provided about hazards that threaten the efficient maintenance of PGRFA, as one of the supporting components for the Treaty. WIEWS was established by FAO as a world-wide dynamic mechanism to foster information exchange among Member Countries, by gathering and disseminating information on PGRFA, and as an instrument to assist in the periodic assessment of the state of the world's PGRFA. The system was set up in conformity with Articles 7.1(e) and (f) of the International Undertaking, and in accordance with the recommendations of the Commission on Plant Genetic Resources for Food and Agriculture (now the CGRFA).

WIEWS presently consists of:

- a number of relational databases, resulting from direct contributions from Member Countries and from data collating activities, including:

o a Country Profiles database;

o the Ex situ Collection database, containing summary records of plant genetic resource holdings (more than 5 million accessions belonging to more than 18,000 species) reported by more than 1,500 national, regional or international genebanks;

o the PGRFA and Seed Laws and Regulations database (70 countries);

o the World List of Seed Sources database (approx. 8,000 entries from 150 countries); and

o the List of Crop Varieties database (about 65,000 varieties from 1,249 cultivated crops).

- a Global Network of Country Correspondents on PGRFA Information Exchange, officially nominated by the Governments; and

- $\quad$ a repository directory of documents and proceedings related to:

o the activities of the Global Network on PGRFA Information Exchange;

o the Early Warning System on Genetic Erosion;

o the GPA; and

o computerized links with a large number of national and international PGRFA databases which provide information on their activities and collections.

The scope of the information covered by the System is currently being expanded to include the Seed Information System developed by FAO in the 1970's and an Early Warning System for Monitoring Plant Genetic Erosion (presently in a design phase).

Other databases on PGRFA are operated by other international, regional and national institutions, such as the CGIAR System-wide Information Network for Genetic Resources (SINGER). There are plans to enhance the linkages among such existing databases. 
Explanatory Guide to the International Treaty on Plant Genetic Resources for Food and Agriculture 


\section{PART VI - FINANCIAL RESOURCES}

\section{Article 18 - Financial Resources}

Article 18 of the Treaty provides for the implementation by the Contracting Parties of a funding strategy for the implementation of the Treaty. It is important to note that the funding strategy is not an actual fund or financial mechanism (although the establishment of an "appropriate mechanism such as a Trust account for receiving funds" is envisaged under Article 19). These provisions are entirely different from, and in no way connected to the financial mechanism established under Article 21 of the CBD - a role now permanently assigned to the Global Environmental Facility. Unlike CBD Article 20, the Article does not place any obligation on Contracting Parties to provide new funds. The funding strategy is rather an agreed strategy for mobilizing funds primarily from existing sources and through existing channels, though it will also cover financial resources provided for in the Treaty itself, such as the mandatory and voluntary payments to be made under Article 13.2(d)(ii).

18.1 The Contracting Parties undertake to implement a funding strategy for the implementation of this Treaty in accordance with the provisions of this Article.

Article 18.1 requires Contracting Parties to implement a funding strategy for the implementation of the Treaty in accordance with the provisions of this Article. The actual adoption, and periodic revision, of the funding strategy is the responsibility of the Governing Body under Article 19. This paragraph indicates that the Contracting Parties, severally and jointly, undertake to implement the funding strategy as adopted by the Governing Body. As we shall see, this may entail taking stances in other funding forums to ensure that the conservation and sustainable utilization of plant genetic resources for food and agriculture are adequately funded. It may also include cooperating in the establishment and operation of other funding mechanisms, such as the new Global Crop Diversity Trust (see Box 20).

18.2 The objectives of the funding strategy shall be to enhance the availability, transparency, efficiency and effectiveness of the provision of financial resources to implement activities under this Treaty.

Besides enhancing the availability of financial resources, Article 18.2 makes it clear that the funding strategy must also seek to enhance the transparency, efficiency and effectiveness of the provision of those resources. Transparency refers to the concern of countries that the mechanisms for the allocation and provision of financial resources do not operate behind closed doors, but take their funding decisions in a transparent and accountable manner. Efficiency and effectiveness refer to the provision of financial resources as well as their use.

The financial resources are to be used to implement activities under the Treaty. For the most part, these would obviously include activities under Articles 5, 6, 7, 8, 14, 16 and 17 of the Treaty, although the Treaty's supporting components could also be targeted. The balance will of course be for the Governing Body to decide.

18.3 In order to mobilize funding for priority activities, plans and programmes, in particular in developing countries and countries with economies in transition, and taking the Global Plan of Action into account, the Governing Body shall periodically establish a target for such funding.

As noted above, it is the Governing Body that is to adopt the funding strategy under Article 19, and Article 18.3 makes it clear that the Governing Body is also to periodically establish targets 
for funding under the strategy. The Treaty does not specify the criteria for establishing such targets; however, in giving the decision-making role to the Governing Body it requires that the decision take into account the rolling GPA, presumably necessitating some recognitions of priority activity areas established through the
GPA processes. It must be assumed by this reference that the Parties expect the GPA, as periodically revised, to provide an agreed scientific and technical framework for financial decisions (as it does for other national and international action in the area of plant genetic resources conservation and sustainable use.)

\subsection{Pursuant to this funding strategy:}

(a) The Contracting Parties shall take the necessary and appropriate measures within the Governing Bodies of relevant international mechanisms, funds and bodies to ensure due priority and attention to the effective allocation of predictable and agreed resources for the implementation of plans and programmes under this Treaty.

Paragraph (a) obliges Contracting Parties to actively seek support within "relevant international mechanisms, funds and bodies" to ensure that the proper priority and attention is given in those forums to the "effective allocation of predictable and agreed resources". The paragraph does not identify what those "relevant international mechanisms, funds and bodies" are. However, they may include, for example, the Global Environment Facility (GEF), the Global Crop Diversity Trust, the CGIAR and the World Bank.

The GEF, now permanently established as the Financial Mechanism of the CBD, specifically lists agricultural Biological Diversity as a focal area. Under its operational strategy, however, the use of GEF resources for biodiversity projects must to conform to the guidance received from the Conference of Parties to the CBD. Recent decisions by the GEF Council in response to decisions taken by the Conference of the Parties to the CBD, call for direct reference to the Revised Undertaking (Treaty), as well as the GPA, in the GEF operational programme on conservation and sustainable use of biological diversity important to agriculture, and note the importance of collaboration with FAO and other institutions working in the field of agriculture.

The Global Crop Diversity Trust is now being set up to provide endowment and other funds to support ex situ collections of PGRFA (see Box 20). Other "relevant international mechanisms, funds and bodies" would presumably include the CGIAR, the importance of whose activities is emphasized in the Treaty (see Article 15 in particular), as well as the World Bank, regional development banks, etc.

Use of the terms "agreed" and "predictable" mean that the financing should be agreed between the recipient countries and the financing mechanisms, and that the funds should be allocated in such a way as to allow the recipient to make plans for the disbursement of the funds and to rely upon the timeliness of delivery (i.e. annual, biennial and so on).

It is important to note that the obligation being undertaken by the Contracting Parties is not one of ensuring the effective allocation of predictable and agreed resources. It is merely the obligation to ensure that "due priority and attention" is given to allocating such resources. The negotiators made it clear that they could not bind themselves further than this, because each of these bodies has its own governance determining the body's respective priorities and budget allocation. However it does mean that Contracting Parties to the Treaty have bound themselves to make sure that funding for the Treaty is not overlooked by the appropriate funding bodies and that the Treaty activities are appropriately prioritized.

(b) The extent to which Contracting Parties that are developing countries and Contracting Parties with economies in transition will effectively implement their commitments under this Treaty will depend on the effective allocation, particularly by the developed country Parties, of the resources referred to in this Article. Contracting Parties that are developing countries and Contracting Parties with economies in 
transition will accord due priority in their own plans and programmes to building capacity in plant genetic resources for food and agriculture.

This paragraph reflects the provisions of Article 20.4 of the CBD. In the case of the Convention, the developing countries were referring to the commitments for new and additional financial resources to enable developing countries to meet the agreed full incremental costs to them of implementing measures to fulfil their obligations under the CBD and to benefit from its provisions. In the present paragraph of the Treaty, the reference is to the outcome of the efforts of the developed countries, in particular, in mobi- lizing financial resources, both through the mechanisms referred to in the preceding paragraph and through their own bilateral and regional assistance programmes. Developing countries and countries with economies in transition, on the other hand, are to give due priority in their plans and programmes to the capacitybuilding in PGRFA. In so doing, this Article reinforces the commitments set out in Articles $5,6,7$ and $13.2(\mathrm{c})$.

(c) The Contracting Parties that are developed countries also provide, and Contracting Parties that are developing countries and Contracting Parties with economies in transition avail themselves of, financial resources for the implementation of this Treaty through bilateral and regional and multilateral channels. Such channels shall include the mechanism referred to in Article 19.3f.

The wording of this paragraph is expressed as a description, rather than a commitment. The effect of the provision is thus to signify that existing, and future, flows of financial assistance using bilateral, regional and multilateral channels form a part of the funding strategy. These also include the "appropriate mecha- nism" to be set up by the Governing Body under Article 19.3(f) to receive financial resources accruing to it for the purpose of implementing the Treaty, including of course the monetary and other benefits arising from commercialization under Article 13.2(d)(ii), and voluntary resources made available under Article 13.6.

(d) Each Contracting Party agrees to undertake, and provide financial resources for national activities for the conservation and sustainable use of plant genetic resources for food and agriculture in accordance with its national capabilities and financial resources. The financial resources provided shall not be used to ends inconsistent with this Treaty, in particular in areas related to international trade in commodities.

This paragraph states that each Contracting Party will carry out national activities for the conservation and sustainable use of PGRFA and will be responsible for the financing of those national activities. The national activities referred to are primarily those listed in Article 5, 6 and 7. While the wording does not explicitly qualify those national activities as being its own national activities, it is clear that this is what is meant. The paragraph is thus supportive of the obligations in Articles 5,6 and 7. The obligation undertaken here is also qualified. It is qualified in that it does not refer to all national activities as set out in the Treaty, but merely to national activities. It is also qualified by the limitation "in accordance with its national capabilities and financial resources". The Contracting Parties have an obligation to carry national activities, but only to the extent of their national scientific, technical, financial and human resources. Subject to that limitation, each Contracting Party must make its best efforts to meet the goal that is set. The paragraph falls under the heading of "financial resources" and the accent is thus on the responsibility of each Contracting Party for the financing of its own national activities.

The final sentence of the paragraph states that that the financial resources provided are not to be used towards ends that are inconsistent with the provisions of the Treaty, particularly in areas related to international trade in commodities. The intended purpose of this sentence is to prevent Contracting Parties from providing subsidies and other support measures to agriculture that are not really for the purpose of implementing the Treaty, so much as for subsidizing agricultural production and in particular agri- 
cultural exports, and thus distorting trade patterns. The provision mirrors a similar caveat expressed in the expression "fair agricultural policies" in Article 6.2(a).

(e) The Contracting Parties agree that the financial benefits arising from Article 13.2d are part of the funding strategy.

As examined above, Article 13.2(d) addresses the sharing of benefits from the commercialization of PGRFA covered by the multilateral system. As can be expected, the financial benefits arising from that mechanism are to form part of the funding strategy. It is to be noted that the reference is to the entire Article 13.2(d), although the reference to financial benefits refers primarily to the mandatory and voluntary payments to be made under Article 13.2(d)(ii).

(f) Voluntary contributions may also be provided by Contracting Parties, the private sector, taking into account the provisions of Article 13, non-governmental organisations and other sources. The Contracting Parties agree that the Governing Body shall consider modalities of a strategy to promote such contributions.

These voluntary contributions appear to include:

- contributions in respect of commercial benefit-sharing from material where no restrictions are put on its further availability for research and breeding (see Article 13.2(d));
- voluntary contributions from the food industry (see Article 13.6); and

- all other voluntary contributions

The Governing Body is to consider how to promote such voluntary contributions.

18.5 The Contracting Parties agree that priority will be given to the implementation of agreed plans and programmes for farmers in developing countries, especially in least developed countries, and in countries with economies in transition, who conserve and sustainably utilize plant genetic resources for food and agriculture.

Building on Article 18.3, Article 18.5 states that priority will be given to the implementation of agreed plans and programmes for farmers who conserve and sustainably utilize PGRFA, particularly in developing countries, least developed countries, and in countries with economies in transition. Note that this priority for funding is consistent with the statement in Art.13.3 on sharing benefits arising from the use of PGRFA under the Multilateral System.

Consistent, with the rest of the Treaty, this Article acknowledges the contribution of farm- ers in their conservation and sustainable use of PGRFA, and the need to promote and support future contributions of farmers. The reference to "agreed" plans and programmes appears to mean that the plans and programmes will have to be agreed with the recipient countries themselves and with the full participation of both farmers and breeders. It may also in part constitute an oblique reference to the agreed plans and programmes set out in the rolling GPA. 


\section{Box 20. Global Crop Diversity Trust}

Article 5.1(e) of the Treaty provides that Contracting Parties shall, as appropriate, cooperate to promote the development of an efficient and sustainable system of ex situ conservation. Article 18 provides for a funding strategy for the implementation of the Treaty. Priority Activity Area 5 of the GPA calls, inter alia for appropriate financial support to be provided for sustaining existing ex situ collections.

As a step to implement the above, FAO and the CGIAR Centres, in particular through IPGRI, have promoted the establishment of an endowment fund, to be known as the Global Crop Diversity Trust, to provide funds in perpetuity to support the long-term conservation of the ex situ germplasm, and to ensure the conservation and availability of the plant genetic resources of greatest importance to global food security and sustainable agriculture. The Trust will, in particular, support the maintenance of eligible PGRFA that meets agreed standards of management and availability, and support the upgrading of collections and other providers of services needed to maintain them, so that they may become eligible for maintenance grants, with the objective of promoting an efficient goal-oriented, economically efficient and sustainable global system of ex situ conservation in accordance with the GPA. The Trust has been set up as an independent international fund, with its own Executive Board. It will, however, operate within the framework of the Treaty, will form an essential element of the Treaty's funding strategy, and will receive overall policy guidance from the Governing Body of the Treaty. The Executive Board will be composed of members nominated by the Governing Body of the Treaty and by the donors of funds (Donors' Council) as well as FAO and the CGIAR. There will also be a Donors' Council that will provide financial management oversight over the activities of the Trust. It is envisaged that the Trust will enter into a relationship agreement with the Governing Body of the Treaty.

The Agreement establishing the Trust entered into force on 21 October 2004 and the Trust has accordingly now been formally set up and indeed has already started fund disbursement. Pending the first session of the Governing Body of the Treaty, the functions of the Executive Board are being carried out by an Interim Panel of Eminent Experts. 
Explanatory Guide to the International Treaty on Plant Genetic Resources for Food and Agriculture 


\section{PART VII - INSTITUTIONAL PROVISIONS}

\section{Article 19 - Governing Body}

Article 19 is basically self-explanatory. It establishes the Treaty's highest organ: the Governing Body. The Governing Body is to be composed of representatives of all Contracting Parties to the Treaty. In addition, observers and non-governmental organizations may attend sessions of the Governing Body. Its basic function is to steer and supervise the entire process of implementing and further developing the Treaty. Given the fact that certain issues under the Treaty have not yet been fully resolved, particularly with respect to the operation of the Multilateral System, the decision-making role of the Governing Body will be particularly important.

\subsection{A Governing Body for this Treaty is hereby established, composed of all Contract- ing Parties.}

The Governing Body is to be composed of all Contracting Parties. There is no provision in the Treaty for the establishment of an executive body of restricted membership to guide the implementation of the Treaty during intersessional periods, although to some extent the Bureau to be established under Article 19.11 may perform that task. The Governing Body will have important decisions to take at its first meeting, including

- Determine the level, form and manner of payment to be made for commercialization (Article 13.2(d)(ii));

- Consider relevant policy and criteria for specific assistance under the agreed funding strategy established under Article 18 (Article 13.4);

- Adopt the funding strategy for the implementation of the Treaty (Article 19.3(c)); and

- Consider and approve procedures and operational mechanisms to promote compliance with the Treaty and address issues of non-compliance (Article 21).

Since only Contracting Parties will be able to participate in this first meeting, many countries will probably seek to speed up their ratification procedures to ensure that they are in a position to take part in it.

19.2 All decisions of the Governing Body shall be taken by consensus unless by consensus another method of arriving at a decision on certain measures is reached, except that consensus shall always be required in relation to Articles 23 and 24 .

Article 19.2 specifies that decisions of the Governing Body are to be adopted by consensus and not by voting. Consensus, in this context, means that the decision is taken without any Contracting Party expressing its opposition to the decision or refusing to join in the consensus. In effect it gives each Contracting Party a veto over the decisions of the Governing Body. In practice, many Contracting Parties may not be entirely happy with a potential decision of the Governing Body but may not wish to stand in the way of a consensus and exercise their rights of veto over that decision. While stressing the general requirement for consensus in decisionmaking, the Article does allow for the Governing Body to decide that some matters may be decided by another method of decision-making, presumably something less than consensus, provided that the decision to resort to that other method of decision-making is itself made by consensus. Such modified methods of decisionmaking, however, cannot be applied to the adoption of amendments to the Treaty (Article 23) or its annexes (Article 24), which are deemed to be of such importance that they require consensus at all times.

Most treaties seek to promote consensus in decision-making. The Treaty is consistent with the approach of the CBD, for example, which provides that the rules of procedure of the Conference of Parties (COP) to the Convention 
must be adopted by consensus: the detailed rules on decision making are then set out in the rules of procedure. The Rules of Procedure adopted by the COP to the CBD include some elements that, as of this writing, have never been able to be resolved, and remain bracketed 13 years after the Convention entered into force (CBD Rules of Procedure Article 40). As these rules stand (with bracketed text still unadopted), COP decisions on all matters of substance may only be taken by consensus. The only nonconsensus mechanisms in the CBD relate to the adoption of amendments (Article 29) and annexes (Article 30), which may occur by vote of two-thirds of the parties present and voting, but are not binding on Parties that do not wish to be bound (countries that do not ratify the amendment, or those that submit a notification regarding the annex, pursuant to Article 30.).

The Governing Body of the Treaty could also develop and adopt rules of procedure that would allow for decision-making by majority or supermajority vote in certain circumstances. In practice, the negotiators have always worked by consensus in drawing up the Treaty in the first place. And some of the decisions to be taken by the Governing Body are so important that all Contracting Parties must be on board if the decisions are to have any meaning. During the latter part of the negotiations, some countries tried to draw up a list of important decisions that would always require consensus. This became so long, that the attempt was eventually abandoned. Amendments to the Treaty itself and to the Annexes to the Treaty, and in the list of crops covered by the Multilateral System in Annex I, were of particular concern to certain countries, who wished to retain veto rights over any changes to the list that would threaten the overall balance of the System.

On the positive side, the consensus process is often preferable as a standard method of working in multilateral forums because voting on issues can divide membership and leave certain parties feeling unheard. Reaching consensus may raise also levels of commitment by group members because everyone is agreeing on a solution. Moreover, parties are more likely to implement decisions they accept, and consensus makes acceptance more likely. The consensus-building process, however, requires time and discipline.

\subsection{The functions of the Governing Body shall be to promote the full implementation of this Treaty, keeping in view its objectives, and, in particular, to:}

(a) provide policy direction and guidance to monitor, and adopt such recommendations as necessary for the implementation of this Treaty and, in particular, for the operation of the Multilateral System;

The general function of the Governing Body is to promote the implementation of the Treaty, and in essence to promote the achievement of its objectives. In so doing it will need to give policy direction and guidance, and to adopt decisions. Since a number of matters related in particular to the operation of the Multilateral System have been left unresolved in the Treaty, perhaps the most important matters in the immediate term will relate to that particular subject area. For example, the Governing Body will need to decide on the level, form and manner of payment to be made under Article 13.2(d)(ii) and indeed on the whole standard MTA. Other important matters will relate to the adoption of the funding strategy.

\section{(b) adopt plans and programmes for the implementation of this Treaty;}

(c) adopt, at its first session, and periodically review the funding strategy for the implementation of this Treaty, in accordance with the provisions of Article 18;

The provisions of paragraph (b) require no commentary. The adoption under paragraph (c) of the funding strategy for the Treaty will be of particular importance, particularly from the point of view of the confidence of developing coun- tries in the effectiveness of the benefit sharing provisions of the Treaty and the willingness of donors to provide the required financial resources. In this context, it is likely that the Governing Body will be asked to enter into a 
relationship agreement with the new Global Crop Diversity Trust under this agenda heading at its first meeting. It is envisaged that the Trust, which will provide endowment and other funds for ex situ collections, will be an element of the funding strategy.

\section{(d) adopt the budget of this Treaty;}

The budget of the Treaty will probably refer at least initially to operational costs of meetings and secretariat.

(e) consider and establish subject to the availability of necessary funds such subsidiary bodies as may be necessary, and their respective mandates and composition;

No provision is made under the Treaty itself for the establishment of subsidiary bodies, such as the Subsidiary Body on Scientific, Technical and Technological Advice established under Article 25 of the CBD. The Governing Body is thus given a free hand in deciding on such subsidiary bodies, if any, that it considers necessary. The Governing Body will need to have a report before it on the availability of the necessary funds before it takes any decision to establish any such bodies.

(f) establish, as needed, an appropriate mechanism, such as a Trust Account, for receiving and utilizing financial resources that will accrue to it for purposes of implementing this Treaty;

This provision is the nearest the Treaty comes to establishing a financial mechanism. Basically this will probably take the form of a Trust Account established under the Financial Regu- lations of FAO, to receive the commercial benefit sharing payments under Article 13.2(d) and various voluntary contributions.

(g) establish and maintain cooperation with other relevant international organizations and treaty bodies, including in particular the Conference of the Parties to the Convention on Biological Diversity, on matters covered by this Treaty, including their participation in the funding strategy;

The Governing Body will need to establish relations and cooperate with a number of other bodies dealing with PGRFA. This provision singles out the Conference of Parties to the CBD as a prime example. Indeed Article 1.2 of the Treaty makes it clear from the outset that the objectives of the Treaty can only be achieved by closely linking the Treaty to the CBD as well as to FAO. Relations will also need to be established with the new Global Crop Diversity Trust, for which the Governing Body will be asked to provide overall policy guidance.

(h) consider and adopt, as required, amendments to this Treaty, in accordance with the provisions of Article 23;

(i) consider and adopt, as required, amendments to annexes to this Treaty, in accordance with the provisions of Article 24;

The adoption of both amendments to the Treaty and to the annexes will require consensus. Given the somewhat limited scope of the crops listed in Annex 1, many countries will be looking to an extension of that list as soon as possible in the light of experience with the operation of the Treaty. The requirement of consensus, however, may slow down any such extension. 
(j) consider modalities of a strategy to encourage voluntary contributions, in particular, with reference to Articles 13 and 18;

This will be an important function of the Governing Body, given that confidence in the Treaty, particularly on the part of developing countries,

will depend on effective flows of resources being realized under the benefits sharing provisions of the Treaty.

(k) perform such other functions as may be necessary for the fulfilment of the objectives of this Treaty;

This is a normal catch-all provision to be found in most international agreements. For example, a number of Articles in the Treaty allow the Governing Body to take specific action for which no corresponding power is provided under Article 19, other than this general provision. These include:

- Article 11.4 - Provides for a built-in review by the governing body to assess progress on the measures to encourage natural and legal persons under their jurisdiction to include in the multilateral system the listed PGRFA that they hold;

- Article12.3(h) - In the absence of national legislation, set standards with respect to access to PGRFA found in in situ conditions; and

- Article 12.4 - The Governing Body is to adopt a standard MTA to provide for facilitated access in accordance with Articles 12.2 and 12.3.

(l) take note of relevant decisions of the Conference of the Parties to the Convention on Biological Diversity and other relevant international organizations and treaty bodies;

(m)inform, as appropriate, the Conference of the Parties to the Convention on Biological Diversity and other relevant international organizations and treaty bodies of matters regarding the implementation of this Treaty; and

These provisions define the nature of the relationship between the Governing Body of the Treaty and the Conference of Parties to the $\mathrm{CBD}$, as well as other relevant international organizations. The relationship is not one of subordination; it is one of cooperation. The
Governing Body will take note of relevant decisions in other bodies, and will in turn inform them on matters regarding the implementation of the Treaty. These governing bodies can also decide to extend their cooperation to other activities besides exchanging information.

(n) approve the terms of agreements with the IARCs and other international institutions under Article 15, and review and amend the MTA in Article 15.

Both matters are important matters to be decided by the Governing Body. The ex situ collections held by the IARCs are of vital importance to the success of the Treaty. The Treaty cannot govern these collections directly, since the IARCs have their own international legal personality but are not States, and therefore cannot become becomes Parties to the Treaty in their own right. Under international law, a treaty cannot impose obligations or rights on third parties without their consent. Thus the mechanism of the signature of separate agreement between the Governing Body and the IARCs was chosen as a means of bringing those collections within the purview of the Treaty. Article 15.1(b) provides that the MTA currently in use by the IARCs under the in-trust agreements with FAO is to be amended by the Governing Body, in consultation with the IARCs, not later than its second regular session. 
19.4 Subject to Article 19.6, each Contracting Party shall have one vote and may be represented at sessions of the Governing Body by a single delegate who may be accompanied by an alternate, and by experts and advisers. Alternates, experts and advisers may take part in the proceedings of the Governing Body but may not vote, except in the case of their being duly authorized to substitute for the delegate.

Through Article 19.4, the Treaty adopts the "one State, one vote" method, thereby ensuring that each State has an equal say in the decisionmaking process. This is a traditional rule of international law derived from the principle of sovereign equality. The only exception to this rule is in the case of regional economic integration organizations, such as the European Community, which will exercise on matters within their competence a number of votes equal to their members that are Contracting Parties to the Treaty.

19.5 The United Nations, its specialized agencies and the International Atomic Energy Agency, as well as any State not a Contracting Party to this Treaty, may be represented as observers at sessions of the Governing Body. Any other body or agency, whether governmental or non-governmental, qualified in fields relating to conservation and sustainable use of plant genetic resources for food and agriculture, which has informed the Secretary of its wish to be represented as an observer at a session of the Governing Body, may be admitted unless at least one third of the Contracting Parties present object. The admission and participation of observers shall be subject to the Rules of Procedure adopted by the Governing Body.

Identical to Article 23(5) of the CBD, this Article deals with two distinct matters: the admission of observers, and (once admitted) their right to participate in meetings of the Governing Body. It empowers the Governing Body to regulate both the admission and participation of observers through the rules of procedure adopted in accordance with Article 19.7.

Certain basic rules regarding admission are, however, already mentioned in this Article. There are two distinct cases. The first case includes institutions that, by their very nature, have a right to participate and, therefore, are ipso facto admitted. These include the United Nations, its specialized agencies and any State not a party to the Treaty. The second case includes all other institutions, whether govern- mental or not. These must submit to an admission procedure:

- qualification in the field dealt with by the Treaty;

- notification of the Secretariat that observer status is sought; and

- lack of objection on the part of at least $1 / 3$ of the Parties present at the particular meeting in question.

The last requirement indicates that the procedure does not grant blanket admission to all future meetings. Instead, the second category must reapply for observer status for all subsequent meetings. The Governing Body will also have to determine, once admitted, an observer's right to participate in the meeting.

\subsection{A Member Organization of FAO that is a Contracting Party and the member states of that Member Organization that are Contracting Parties shall exercise their membership rights and fulfil their membership obligations in accordance, mutatis mutandis, with the Constitution and General Rules of FAO.}

At present, only one Organisation meets the criteria for coverage under this section. In November 1991, the European Community (EC) was admitted to membership of FAO as its first Member Organization. The admission of the EC followed the adoption of amendments to the
FAO's Constitution and General Rules, allowing membership by regional economic integration organizations to which their members have transferred jurisdiction over matters within the purview of FAO. Since members countries of the EC have transferred competence in certain 
areas involvement in those matters, including the right to vote, must therefore be exercised by the EC itself. Under the Constitution and General Rules of FAO, a Member Organization of FAO exercises membership rights on an alternative basis with its member states that are Member Nations of FAO. That means that membership rights are exercised by the EC on matters on which it has exclusive competence, and by the individual Member States of the EC on matters that remain within their exclusive competence. On matters where competence is shared between the EC and its Member States, both may speak from the point of view of their own competence, but only one or the other may exercise the right to vote. The distribution of competences as between the EC and its Member States must be described in a notice to the Director-General of FAO and circulated to all Member Nations. More significantly, the EC and its Member States are required to notify FAO, prior to any meeting of the Organization, of the distribution of competences and of the right to vote in respect of each item of the agenda of the meeting. The present provision requires that the same scheme of membership should apply to membership by the EC and its Member States in the Governing Body of the Treaty.

\subsection{The Governing Body shall adopt and amend, as required, its own Rules of Procedure and financial rules which shall not be inconsistent with this Treaty.}

The Treaty does not provide for the Governing Body's procedural and financial rules. Rather, the Governing Body is given the responsibility to create those rules itself. As specified in Article 19.2, these are to be adopted by consensus.
The rules of procedure cannot of course change the rules applicable, for example, to the adoption of amendments to the Treaty or its annexes, as that would be inconsistent with the provisions of the Treaty.

\subsection{The presence of delegates representing a majority of the Contracting Parties shall be necessary to constitute a quorum at any session of the Governing Body.}

The purpose of a quorum requirement is to ensure that no decisions are taken without a sufficient number of Parties present. Under Article 19.8, a majority (50 percent plus one) of the current Parties constitutes a quorum at any session of the Governing Body. Regional eco- nomic integration organizations, such as the EC, can count towards a quorum on matters within their respective designated competences, to the extent of the number of votes that the organization is entitled to exercise on those matters.

\subsection{The Governing Body shall hold regular sessions at least once every two years. These sessions should, as far as possible, be held back-to-back with the regular sessions of the Commission on Genetic Resources for Food and Agriculture.}

In order to fulfil its purpose, the Governing Body needs to meet regularly. As noted above, the Treaty is a dynamic instrument, and there are a large number of matters on which the policy direction and guidance of the Governing Body will be required. However, as with other issues, the Treaty leaves it to the Governing Body to decide at what intervals it should meet, provided it is at least once every two years.

The Article encourages the Governing Body to hold its regular sessions back-to-back with the regular sessions of the CGRFA. This is because the CGRFA will retain some functions of relevance to the Treaty such as the preparation of reports on the state of the world's PGRFA and the updating of the rolling GPA. Ensuring that the meetings are held back-to-back will reduce costs, thereby contributing to the participation of representatives from developing countries. It will also make it easier to coordinate the actions of the Governing Body on the one hand and the Commission on the other. 
19.10Special Sessions of the Governing Body shall be held at such other times as may be deemed necessary by the Governing Body, or at the written request of any Contracting Party, provided that this request is supported by at least one third of the Contracting Parties.

Article 19.10 provides two separate bases by which a special session of the Governing Body may be convened:

- When deemed necessary by the Governing Body; and
- When requested in writing by a Contracting Party, with the support of at least one third of the Contracting Parties.

19.11 The Governing Body shall elect its Chairperson and Vice-Chairpersons (collectively referred to as "the Bureau"), in conformity with its Rules of Procedure.

Article 19.11 provides for the election of a Chairperson and Vice-Chairpersons in accordance with the Rules of Procedure, to be adopted under Article 19.7. While the powers of the Bureau are not specified, it may be requested to play a significant role in overseeing the imple- mentation of the Treaty during intersessional periods. However, the real power of decisionmaking on important matters is likely to remain with the Governing Body itself, operating by consensus. 
Explanatory Guide to the International Treaty on Plant Genetic Resources for Food and Agriculture 


\section{Article 20 - Secretary}

Article 20 defines the role of the Secretary within the Treaty and the manner of his or her appointment. Under Article 20, the Secretariat is required to provide practical and administrative support for the Governing Body. Experi- ence has shown that an international treaty can only function satisfactorily if it is complemented by a secretariat carrying out a number of functions between the meetings of the Governing Body.

20.1 The Secretary of the Governing Body shall be appointed by the Director-General of FAO, with the approval of the Governing Body. The Secretary shall be assisted by such staff as may be required.

Since the Treaty has been adopted under Article XIV of the FAO Constitution, there are certain rules in addition to Article 20.1 that must apply to his or her appointment. These rules would require, for example, that the Secretary must be a staff member of FAO. In this case the appointment must be "with the approval of the Governing Body". The Basic Texts of FAO, and in particular Part R, allow for a role for the Governing Body in support of the Director-Gener- al's the selection of the Secretary of the Treaty. However, it is not clear how this role will develop in the future. This will depend on the practice of the Governing Body. But it is to be expected that a proposal will be made to the Governing Body for the appointment of a Secretary, and the appointment will not become effective until such time as the Governing Body has expressed its approval.

\subsection{The Secretary shall perform the following functions:}

(a) arrange for and provide administrative support for sessions of the Governing Body and for any subsidiary bodies as may be established;

(b) assist the Governing Body in carrying out its functions, including the performance of specific tasks that the Governing Body may decide to assign to it;

Article 20.2(b) performs the function of a catchall provision, given that the Secretary is re-

quired to carry any specific tasks that the Governing Body may decide to assign to him or her.

(c) report on its activities to the Governing Body.

20.3 The Secretary shall communicate to all Contracting Parties and to the DirectorGeneral:

(a) decisions of the Governing Body within sixty days of adoption;

(b) information received from Contracting Parties in accordance with the provisions of this Treaty.

20.4 The Secretary shall provide documentation in the six languages of the United Nations for sessions of the Governing Body.

Normally for treaties concluded within the framework of the FAO Constitution, only the official languages of the Organization would be used for the proceedings of the Governing Body. Russian is not one of the official languages of FAO, given that the Russian Federation is not a 
Member of FAO. In the special case of the Treaty, the negotiators agreed to include Russian as an authentic language given that Russia is already a Party to the CBD, and they ex- pressed their desire to be as complete as possible in providing incentives for the membership coverage of the Treaty.

\subsection{The Secretary shall cooperate with other organizations and treaty bodies, includ- ing in particular the Secretariat of the Convention on Biological Diversity, in achieving the objectives of this Treaty.}

A particularly important function assigned to the Secretary involves cooperation with "other organizations and treaty bodies". The Treaty repeatedly emphasizes that the Treaty's imple- mentation must be done in coordination with other international instruments, particularly the CBD. 


\section{Article 21 - Compliance}

The Governing Body shall, at its first meeting, consider and approve cooperative and effective procedures and operational mechanisms to promote compliance with the provisions of this Treaty and to address issues of non-compliance. These procedures and mechanisms shall include monitoring, and offering advice or assistance, including legal advice or legal assistance, when needed, in particular to developing countries and countries with economies in transition.

Provisions relating to compliance with the provisions of a treaty are becoming more and more common in international agreements. Similar provisions to that contained in Article 21 of the Treaty are to be found in the Montreal Protocol on Substances that Deplete the Ozone Layer of $1987,{ }^{123}$ the 1998 United Nations Economic Commission for Europe Convention on Access to Information, Participation in Decision-making and Access to Justice in Environmental Matters, ${ }^{124}$ the 1997 Kyoto Protocol to the UN Framework Convention on Climate Change, ${ }^{125}$ and the 2000 Cartegena Protocol on Biosafety ${ }^{126}$ under the CBD. Compliance procedures are also being actively considered under a number of other international agreements. In 2002, UNEP has adopted a series of Guidelines on Compliance and Enforcement of Multilateral Environmental Agreements. The Guidelines contain a tool box of considerations, proposals, suggestions and potential measures that governments may wish to take into account in setting up or strengthening compliance procedures.

Compliance procedures are to be distinguished from dispute settlement mechanisms. In general terms, dispute settlement procedures are designed to deal with disputes between two or more Parties relating to a matter of interpre- tation or application of the treaty concerned. The dispute settlement procedure is limited by the scope of the actual dispute and by the parties to the dispute. Compliance procedures, on the other hand, deal more with general issues of compliance or non-compliance, including common treaty interests, and do not have to be raised by a party to any particular dispute. Dispute settlement procedures are adversarial in nature, while compliance procedures are non-adversarial. Dispute settlement procedures deal with disputes that have arisen in the past: compliance procedures deal more with formulating responses to difficulties that may arise in the future. The findings of any mechanism set up under compliance procedures are similarly not limited to the parties to any dispute, and conversely are normally not binding.

Article 21 requires that the Governing Body, at its first session, consider and approve "cooperative and effective" procedures and operational mechanisms to promote compliance and to address issues of non-compliance.

The temporal element requires no comment, beyond noting that the Governing Body will have a full agenda at its first session, and that the establishment of a fully-fledged compliance procedure and mechanism may require considerable debate.

The expression "cooperative" suggests that the compliance procedures to be established should be such as to stimulate amicable review and dialogue to address compliance issues, and should not be adversarial. The expression "effective" suggests that the response to a Contracting Party's compliance difficulties should be balanced against the cause, type, degree and frequency of such difficulties. The reference to

123 Montreal Protocol on Substances that Deplete the Ozone Layer, 16 September 1987, 26 I.L.M. 1550 (entered into force 1 January 1989), amended by 30 I.L.M. 539, amended by 32 I.L.M. 875 (1991).

124 UNECE Convention on Access to Information, Public Participation in Decision-Making and Access to Justice in Environmental Matters (Aarhus Convention), 25 June 1998, 38 I.L.M. 517 (1999).

Kyoto Protocol to the United Nations Framework Convention on Climate Change, 10 December 1997, 37 I.L.M. 22 (1998).

126 Cartagena Protocol on Biosafety to the Convention on Biological Diversity, 29 January 2000, 39 I.L.M. 1027 (2000). 
the promotion of compliance indicates that a generic approach should be taken to compliance issues, and parties assisted in achieving compliance. On the other hand, the reference to issues of non-compliance suggests that actual issues and difficulties relating to non-compliance should be dealt with, including perhaps the difficulties of individual Parties. The Article also makes specific reference to "operational mechanisms", which suggests the possibility of establishing a specific body or committee to consider compliance issues.

The procedures and mechanisms are to include monitoring of compliance with the Treaty provisions and offering advice or assistance. The reference to the possible offering of legal advice or assistance is particularly interesting. Since many of the compliance issues relating to the implementation of the Treaty are likely to lie in the realm of private law, especially in securing compliance with the provisions of the standard MTA, many developing countries and countries with economies in transition may welcome the formal provision of such assistance. It should be noted that providers of PGRFA have no direct financial interest to prosecute alleged non-payment of monies due under the MTA, in particular because such payments implementing Article 13.2(d)(ii) are made to the Treaty's funding strategy and not to the provider of the genetic resources. In addressing such occurrences legal advice or assistance from a Treaty-based source is perhaps therefore especially warranted. In this connection the well-developed capability of FAO in delivering legal assistance is to be noted.
Other methods of compliance include "soft law", knowledge sharing, collaborative mechanisms, and the marshalling of rhetoric. For example, the non-binding World Charter for Nature ${ }^{127}$ imposes broad duties of implementation on Member States, but provides no concrete mechanisms for compliance. Rather, the text stresses public education, dissemination of scientific knowledge, ongoing research, and cooperation among various international actors, public disclosure of planning and environmental assessment information and public consultation and participation therein.

A related question - how compliance with the MTAs (for Annex I as well as non-Annex I materials) will be enforced - was not specifically addressed in the negotiations, beyond implying, in Article 12.5 that the primary means will be through recourse to national legal systems. At present under the in-trust agreements between FAO and the CGIAR Centres, the system is largely self-regulating, and egregious violations are discouraged primarily through non-legal means and by the threat of bad publicity. General issues relating to the enforcement of MTAs (if each violation of an MTAs is determined to constitute a violations by the particular Contracting Party with jurisdiction over such MTA), could take up much of the time of compliance committee or other mechanism set up under Article 21. This issue will of course also be a focus of discussion in the Governing Body when drawing up the standard MTA. In addition, the general issues relating to compliance with the standard MTA are also likely to be one of the most important sets of issues to be dealt with by any operational mechanism.

127 The World Charter is, as a General Assembly Declaration, not strictly binding in international law; however, it contains expressions of customary international law and strongly normative language. See E. Brown Weiss, P.C. Szasz \& D.B. Magraw, International Environmental Law: Basic Instruments \& Reference (New York, Transnational, 1992). 


\section{Article 22 - Settlement of Disputes}

The obligation of States to settle disputes in a peaceful manner is well established in international law, and is enshrined in Article 33 of the United Nations Charter. Article 33 sets out a menu of dispute settlement mechanisms that are available to States including "negotiation, enquiry, mediation, conciliation, arbitration, judicial settlement, report to regional agencies or arrangements, or other peaceful means of their own choice." The mechanisms provided for in the Treaty draw on that list. They are fairly standard provisions and reflect virtually word for word the dispute settlement procedures set out in Article 27 of the CBD.

As noted above, a distinction should be drawn between the compliance procedures provided for in Article 21 and the dispute settlement procedures of Article 22. While the compliance procedures deal with ways of discussing and dealing with issues of non-compliance in general, the provisions of Article 22 apply when there is an actual dispute between two or more Contracting Parties concerning the interpretation or application of the Treaty. Any dispute that arises under the Treaty must be settled according to its provisions. The Treaty adopts a progressive process that facilitates dispute reso- lution by subjecting the dispute to gradually more intrusive and formal mechanisms. Negotiation requirements give the Parties the opportunity to resolve a dispute among themselves in a mutually satisfactory way. Non-binding thirdparty mechanisms, such as the use of good offices or mediation, allow disputing Parties to obtain an impartial perspective on the dispute. Finally, if all else fails, the Parties may submit the dispute to binding procedures such as arbitration or judicial settlement. The potential for subsequent binding arbitration or judicial settlement also puts pressure on the Parties to settle their dispute before they lose some measure of control over the process.

It should be noted that the dispute settlement procedures set out in Article 22 deal only with disputes between Contracting Parties to the Treaty. Separate dispute settlement procedures may need to be set out in the agreements between the IARCs and the Governing Body for disputes arising out of the interpretation or application of those agreements. Disputes arising out of the interpretation or application of the standard MTAs will apparently be settled under national law, in accordance with the procedures set out in those MTAs.

\subsection{In the event of a dispute between Contracting Parties concerning the interpreta- tion or application of this Treaty, the parties concerned shall seek solutions by negotiation.}

When a dispute arises and throughout the life of the dispute, the disputing Parties are often in the best position to reach an accommodation. It is for this reason that Article 22.1 states that the first step in resolving a dispute is through negotiation. This is a fundamental and traditional rule of conflict resolution.
The Treaty does not define "dispute". The term apparently refers to any situation among the Parties that they care to treat as a dispute. In particular, disputes are not limited to legal differences but may involve any combination of law, facts and policies.

\subsection{If the parties concerned cannot reach agreement by negotiation, they may jointly seek the good offices of, or request mediation by, a third party.}

When the Parties fail to settle their differences by negotiation between themselves, the Treaty calls for the introduction of a third party. The intervening third party does not decide the matter, but advises the parties. The difference between good offices and mediation, therefore, is largely a matter of the degree of initiative taken by the intervenor to secure a settlement.

- Good offices: The provision of good offices has often been referred to as "quiet diplomacy" since the process 
often involves entrusting the dispute to personalities with special qualification on whom both parties agree. This might involve, for example, heads of State or the Secretary-General of the United Nations, or their designees.

- Mediation: like good offices, mediation is an adjunct of negotiation, but with the mediator as an active partici- pant, authorized, and even expected, to advance his own proposals and to interpret, as well as to transmit, each party's proposals to each other.

In both cases, the third party could be another Treaty Party, one of the bodies created under the Treaty, an external body or organization, or even a professional mediator.

22.3 When ratifying, accepting, approving or acceding to this Treaty, or at any time thereafter, a Contracting Party may declare in writing to the Depositary that for a dispute not resolved in accordance with Article 22.1 or Article 22.2 above, it accepts one or both of the following means of dispute settlement as compulsory:

As in Article 27(3) of the CBD, a Party can make, at any time, a written declaration to the Treaty's Depositary accepting a compulsory dispute resolution by arbitration (Paragraph (a)), by the International Court of Justice (ICJ) (Paragraph (b)), or both when negotiation, mediation, or good offices have failed.

(a) Arbitration in accordance with the procedure laid down in Part 1 of Annex II to this Treaty;

In turning to arbitration, a line is crossed between diplomatic methods of settling disputes and adjudication. The contrast is sharpened by the fact that an arbitral award is a binding decision. In choosing arbitration, the parties to a dispute invite another entity to resolve it for them. However, arbitration allows the parties to constitute and to operate their own court. Consequently, it has the attraction for States in disputes that they can select individuals as arbitrators in whom they have confidence and thus can at least influence the procedure that will be employed to resolve their conflict.

The arbitration process, as set out in Part 1 of Annex II, is composed of the following elements:

- Notification to the Secretary (Article 1);

- Establishment of the arbitral tribunal (Articles 2 and 3);
- The scope of decision-making (Article 4);

- Powers of the arbitral tribunal: establish rules of procedure (Article 5) and recommend interim measures of protection (Article 6);

- Obligations of the Parties to provide information (Article 7)

- Confidentiality (Article 8);

- Costs (Article 9);

- Intervention (Article 10);

- Counterclaims (Article 11);

- Decision process (Article 12);

- Absence of a Party (Article 13);

- Deadline for decision (Article 14);

- Scope of decision (Article 15);

- Finality of decision (Article 16); and

- Controversy regarding the decision(Article 17).

(b) Submission of the dispute to the International Court of Justice.

Reference to the ICJ is a common provision of last resort in many international agreements. The procedures to be applied in cases before the ICJ are laid down in the Statute of the International Court of Justice.
Reliance on the ICJ is problematic, however, as ICJ jurisdiction will depend on agreement of the parties since relatively few countries have accepted compulsory ICJ jurisdiction. In addition, reference to the ICJ is likely to 
be costly and time consuming, and thus not suited to expeditious resolution of the dispute.

It is to be noted that submission to the ICJ is not an option when one of the parties to the dispute is an Organization, i.e. potentially the
European Community in respect of the Treaty, because the Court is open only to States. Disputes involving the EC would therefore need to be submitted to arbitration as a procedure of last resort.

\subsection{If the parties to the dispute have not, in accordance with Article 22.3 above, accepted the same or any procedure, the dispute shall be submitted to conciliation in accordance with Part 2 of Annex II to this Treaty unless the parties otherwise agree.}

In those cases in which Contracting Parties have not accepted any of the judicial procedures set out in Article 22.3 (arbitration and/or ICJ) and negotiation and mediation or good offices have failed, the dispute must be submitted to conciliation. Submitting the dispute to conciliation is an obligation, unless the Parties agree otherwise.

Conciliation has been defined by the Institute of International Law as:

A method for the settlement of international disputes of any nature according to which a Commission set up by the Parties, either on a permanent basis or an ad hoc basis to deal with a dispute, proceeds to the impartial examination of the dispute and attempts to define the terms of a settlement susceptible of being accepted by them or of affording the Parties, with a view to its settlement, such aid as they may have requested. $^{128}$

Whereas mediation is an extension of negotiation, conciliation puts third party intervention on an formal legal footing and institutionalizes it in a way comparable, but not identical, to arbitration.
Conciliation is essentially institutionalized negotiation. One of the distinctive features of conciliation is that a commission's report takes the form of a set of proposals, not a decision. Thus, even in cases where law has been a major consideration, the report is quite different from an arbitral award and not binding on the parties.

Part 2 of Annex II provides the following mechanism:

- Creation and composition of a conciliation commission (Article 1);

- Appointment of commission members (Articles 2 to 4);

- Decision process (Article 5); and

- Competence issues (Article 6).

While not provided for in Part 2 of Annex II, it is usual practice for the commission to give the parties a specified period of a few months in which to indicate their response. If its proposals are accepted the commission draws up an agreement recording the fact of conciliation and setting out the terms of the settlement. If the proposed terms are rejected, then conciliation has failed and the parties are under no further obligation. 
Explanatory Guide to the International Treaty on Plant Genetic Resources for Food and Agriculture 


\section{Article 23 - Amendments of the Treaty}

23.1 Amendments to this Treaty may be proposed by any Contracting Party.

23.2 Amendments to this Treaty shall be adopted at a session of the Governing Body. The text of any proposed amendment shall be communicated to Contracting Parties by the Secretary at least six months before the session at which it is proposed for adoption.

23.3 All amendments to this Treaty shall only be made by consensus of the Contracting Parties present at the session of the Governing Body.

23.4 Any amendment adopted by the Governing Body shall come into force among Contracting Parties having ratified, accepted or approved it on the ninetieth day after the deposit of instruments of ratification, acceptance or approval by twothirds of the Contracting Parties. Thereafter the amendment shall enter into force for any other Contracting Party on the ninetieth day after that Contracting Party deposits its instrument of ratification, acceptance or approval of the amendment.

23.5 For the purpose of this Article, an instrument deposited by a Member Organization of FAO shall not be counted as additional to those deposited by member states of such an organization.

Article 23 addresses amendments to the Treaty. It specifies:

- Who can propose them (Article 23.1);

- How they are to be adopted (Articles 23.1 to 23.3 );

- How and when they enter into force (Article 23.4); and

- Special provisions relating to Member Organizations of FAO (Article 23.5).

While certain parts of this Article are identical to Article 29 of the CBD (see Articles 23.1, 23.2 and 23.4), there are nevertheless important differences. Primary among these is the provision in Article 29(3) of the CBD to the effect that while every effort is to be made to reach consensus, amendments to the Convention can, as a last resort, be adopted by a two-third majority vote of the Parties present at the meeting. This option, however, does not exist within the context of the Treaty, which only provides that amendments can only be adopted by consensus. As stated earlier, this provision was viewed as essential by some countries during the negotia- tions as a way of ensuring that their essential interests would be taken into account in all aspects of the functioning of the Treaty, including its amendment. The requirement for consensus, in this context, amounts to a right of veto for each and every Contracting Party.

Article 23.4 provides that each country must agree individually to an amendment for it to apply to that country. This means that it is possible that amendments may come into force at different times for different countries.

Article 23.5 relating to Member Organizations is a standard provision designed to ensure that the instruments of the EC and its Member States are not counted twice. If the EC and all its Member States (currently 25) deposit instruments of ratification, acceptance or approval, the total number of instruments would be counted as 25 and not 26 .

As will be examined in Article 24, the procedure established under this Article also applies to any amendments to the Annexes. 
Explanatory Guide to the International Treaty on Plant Genetic Resources for Food and Agriculture 


\section{Article 24 - Annexes}

24.1 The annexes to this Treaty shall form an integral part of this Treaty and a reference to this Treaty shall constitute at the same time a reference to any annexes thereto.

\subsection{The provisions of Article 23 regarding amendments to this Treaty shall apply to} the amendment of annexes.

Like many international agreements, the Treaty contains annexes. This Article clarifies the relationship between the Treaty and its annexes (Article 24.1). It also confirms a traditional rule in treaty making that annexes form an integral part of the Treaty.
It is anticipated that changes will eventually be made to the annexes, and Article 24.2 provides for the procedure for modifying them. Again, the Annexes, and in particular Annex I, were considered so important to the balance of the Treaty, that consensus was insisted upon. 
Explanatory Guide to the International Treaty on Plant Genetic Resources for Food and Agriculture 


\section{Article 25 - Signature}

This Treaty shall be open for signature at the FAO from 3 November 2001 to 4 November 2002 by all Members of FAO and any States that are not Members of FAO but are Members of the United Nations, or any of its specialized agencies or of the International Atomic Energy Agency.

In many treaties, as in this Treaty, the process of giving initial consent is provided for by the act of signature. Article 25 states that the Treaty will be open for signature for one year. The Resolution approving the text of the Treaty was adopted by the FAO Conference on 3 November 2001. In general, a State's signature on a treaty does not signify its consent to be bound by the treaty, unless the treaty in question so specifies. The Treaty of course, indicates in Article 28 that it will enter into force only after ratification, acceptance, approval or accession. By signing a treaty, however, a State does agree to refrain from acts "which would defeat the object and purpose of the treaty," until it has made clear its intention not to become a treaty party (see Article 18 of the Vienna Convention on the
Law of Treaties). In the case of the Treaty, the objectives are set out in Article 1.

The list of States that are entitled to sign the Treaty is drawn from the so-called Vienna formula. In this case, however the first reference is to Members of FAO, rather than to Member Nations of FAO, to allow for signature by the EC as a Member Organization of FAO. However, non-FAO Member Nations, such as Russia, may also sign the Treaty.

After the end of the time period in which the text is open for signature, the States wishing to participate in the Treaty have to follow the procedure of accession provided in Article 27. 
Explanatory Guide to the International Treaty on Plant Genetic Resources for Food and Agriculture 


\section{Article 26 - Ratification, Acceptance or Approval}

This Treaty shall be subject to ratification, acceptance or approval by the Members and non-Members of FAO referred to in Article 25. Instruments of ratification, acceptance, or approval shall be deposited with the Depositary.

International law dictates that a State will be bound by the terms of a treaty only when it takes affirmative steps to demonstrate its consent to be bound. Theoretically, there is no limit on the ways a State may express this consent. As such, the terms used within Article 26: "ratification", "acceptance" and "approval" signify different types of declarations expressing a State's formal willingness to be bound by the Treaty.
The most common method of demonstrating consent is by ratification. Ratification processes are an internal constitutional matter for each country and they may frequently differ from one country to another.

In order to be effective, Article 26 requires the instruments of ratification, acceptance, or approval to be deposited with the Depositary. 
Explanatory Guide to the International Treaty on Plant Genetic Resources for Food and Agriculture 


\section{Article 27 - Accession}

This Treaty shall be open for accession by all Members of FAO and any States that are not Members of FAO but are Members of the United Nations, or any of its specialized agencies or of the International Atomic Energy Agency from the date on which the Treaty is closed for signature. Instruments of accession shall be deposited with the Depositary.

The effect of accession is the same as ratification. In both instances, a State agrees to be bound by the Treaty. The only difference is that signature leads to ratification (or its equivalent), whereas once a Treaty is closed for signature, a State can only join by acceding to it. In this sense, the expression of consent to be bound in the act of accession is a one-step procedure.
In accordance with Article 25, the Treaty was closed for signature on November 4, 2002. At that date, 78 States had signed. Any States or Member Organizations that have not signed the Treaty but wish to become a Contracting Party must now do so through the accession process. 
Explanatory Guide to the International Treaty on Plant Genetic Resources for Food and Agriculture 


\section{Article 28 - Entry into Force}

28.1 Subject to the provisions of Article 29.2, this Treaty shall enter into force on the ninetieth day after the deposit of the fortieth instrument of ratification, acceptance, approval or accession, provided that at least twenty instruments of ratification, acceptance, approval or accession have been deposited by Members of FAO.

28.2 For each Member of FAO and any State that is not a Member of FAO but is a Member of the United Nations, or any of its specialized agencies or of the International Atomic Energy Agency that ratifies, accepts, approves or accedes to this Treaty after the deposit, in accordance with Article 28.1, of the fortieth instrument of ratification, acceptance, approval or accession, the Treaty shall enter into force on the ninetieth day following the deposit of its instrument of ratification, acceptance, approval or accession.

The Parties to the Treaty are not bound by its terms until the Treaty enters into force. Article 24 of the Vienna Convention reiterates that the mode and moment a treaty enters into force depends upon the intention of the parties. Therefore, most treaties indicate that they will enter into force after a certain minimum number of States have ratified, even if other States have not.

Article 28.1 states that the Treaty will enter into force on the $90^{\text {th }}$ day after the deposit of the fortieth instrument, provided that at least twenty of the instruments have been deposited by Members of FAO. The qualification that at least twenty FAO Members must have signified their formal consent to be bound by the Treaty reflects the fact that the Treaty has been adopted within the framework of the FAO Constitution. On 31 March 2004, 13 instruments (including the European Community) were deposited with the Director-General of FAO. This resulted in the Treaty having reached the required number of instruments (40), so that it entered into force on 29 June 2004.

According to Article 28.2, for each subsequent Contracting Party that ratifies, accepts or approves the Treaty or accedes to it, the Treaty shall enter into force, with respect that Party, ninety days after the deposit of their instrument of ratification, acceptance, approval or accession. This means that the Convention's obligations may take effect for different Parties at different times.

As of January 13, 2005, sixty-five instruments of ratification, acceptance, approval or accession have been deposited with the Director-General of FAO (see Appendix 1). 
Explanatory Guide to the International Treaty on Plant Genetic Resources for Food and Agriculture 


\section{Article 29 - Member Organizations of FAO}

29.1 When a Member Organization of FAO deposits an instrument of ratification, acceptance, approval or accession for this Treaty, the Member Organization shall, in accordance with the provisions of Article II.7 of the FAO Constitution, notify any change regarding its distribution of competence to its declaration of competence submitted under Article II.5 of the FAO Constitution as may be necessary in light of its acceptance of this Treaty. Any Contracting Party to this Treaty may, at any time, request a Member Organization of FAO that is a Contracting Party to this Treaty to provide information as to which, as between the Member Organization and its member states, is responsible for the implementation of any particular matter covered by this Treaty. The Member Organization shall provide this information within a reasonable time.

29.2 Instruments of ratification, acceptance, approval, accession or withdrawal, deposited by a Member Organization of FAO, shall not be counted as additional to those deposited by its Member States.

Article 29.1 pertains to Member Organizations of FAO, such as the EC. Member Organizations are required to exercise their membership rights in FAO on an alternative basis with their Member States that are also Members of FAO. Under Article II.5 of the Constitution, regional economic integration organizations applying for membership in FAO are required to submit a declaration of competence at the time of application, specifying the matters in respect of which competence has been transferred to it by its Member States. Member States are presumed to retain competence over all matters in respect of which transfers of competence have not be specifically declared or notified to FAO. Under Article II.7 of the Constitution, any change regarding the distribution of competence between a Member Organization and its Member States must be notified to the Director-General of FAO, who must circulate it to other Members of FAO. Since the act of becoming Party can affect the distribution of competence, a Member Organization is normally required to notify the Director-General of FAO of any such changes.

Other Contracting Parties are understandably concerned to know who speaks for the EC and its Member States on any particular issue, and who should be held accountable for fulfilling membership obligations under international treaties. The second part of Article 29.1 therefore allows for any Contracting Party to query a Member Organization that is Party to the Treaty as to which, as between the Member Organization and its member states, is responsible for the implementation of any particular matter covered by the Treaty. The Member Organization is required to provide this information within a reasonable time.

Article 29.2 provides that the instruments of ratification, acceptance, approval, accession or withdrawal deposited by a Member Organization cannot be counted in addition to those deposited by its Member States. As noted above, this is a provision designed to ensure that neither the EC nor its Member States are given a "double voice" by the fact of membership by a Member Organization in addition to its Member States. Thus, a ratification instrument by the EC would not be counted in addition to those of its member states when determining whether 40 countries have ratified the Treaty. 
Explanatory Guide to the International Treaty on Plant Genetic Resources for Food and Agriculture 


\section{Article 30 - Reservations}

No reservations may be made to this Treaty.

According to Article 2 of the Vienna Convention on the Law of Treaties, a reservation is a unilateral statement made by a state, when signing, ratifying, accepting, approving, or acceding to a treaty, whereby it purports to exclude or to modify the legal effect of certain provisions of the Treaty in their application to that state. Article 19 of the Vienna Convention states:

A State may, when signing, ratifying, accepting, approving, or acceding to a treaty, formulate a reservation unless:

(a) the reservation is prohibited by the treaty;

(b) the treaty provides that only specified reservations, which do not include the reservation in question, may be made; or

(c) in cases not falling under sub-para- graphs (a) and (b), the reservation is incompatible with the object and purpose of the treaty.

Part R of the Basic Texts of the FAO, which governs the formulation and operation of conventions and agreements concluded under Article XIV of the FAO Constitution, like the Treaty, allows for reservations to be included in such conventions and agreements. Whether or not reservations are permitted, of course, depends on the relevant provisions of the agreement concerned. In this case, the Treaty prohibits all reservations, under Article 30.

The reason behind this strict rule is probably the desire to preserve the balance between the various obligations created by the Treaty, which could be threatened if Contracting Parties had the right to make reservations. 
Explanatory Guide to the International Treaty on Plant Genetic Resources for Food and Agriculture 


\section{Article 31 - Non-Parties}

\section{The Contracting Parties shall encourage any Member of FAO or other State, not a Contracting Party to this Treaty, to accept this Treaty.}

This Article is a reflection of the drafters' desire to have the Treaty have as wide an application as possible, and therefore to encourage nonparties to become Contracting Parties.

The issue of how non-Parties should be treated became controversial during the course of negotiations, particularly from the point of view of access to materials under the Multilateral System. The question was whether the Treaty should dictate the use of different, and potentially discriminatory, treatment of nonParties. In the end, no specific provision was included in the Treaty text. In essence, this choice leaves this matter up to each individual Contracting Party. There is no provision that would require Contracting Parties to deny access to PGRFA listed in Annex I to countries that have not agreed to be bound by the Treaty.
Nor is there anything that would require them to grant such access. The provisions of Article 11.3 and 11.4 , which deal with decisions as to whether access should continue to be facilitated to persons that have not included their PGRFA in the Multilateral System refer only to natural and legal persons under the jurisdiction of Contracting Parties and not to non-Contracting Parties.

Article 31 of the Treaty, in dealing with non-Parties, therefore confines itself to stating that Contracting Parties are to encourage any Member of FAO or other State who is not a Party to this Treaty, to become a Party. This is intended to achieve as broad a coverage of the Treaty's provisions as possible. While the obligation to encourage non-members is mandatory, the Treaty does not specify what means are to be used. 
Explanatory Guide to the International Treaty on Plant Genetic Resources for Food and Agriculture 


\section{Article 32 - Withdrawals}

32.1 Any Contracting Party may at any time after two years from the date on which this Treaty has entered into force for it, notify the Depositary in writing of its withdrawal from this Treaty. The Depositary shall at once inform all Contracting Parties.

32.2 Withdrawal shall take effect one year from the date of receipt of the notification.

Article 54(a) of the Vienna Convention on the Law of Treaties states that a Party may withdraw from a treaty, provided it is done in conformity with the provisions of the treaty.

Thus, Article 32.1 provides that a Contracting Party may withdraw at any time after two years after the coming into force of the
Treaty. Withdrawal is done by notifying the Depositary, in writing, of the decision to withdraw. The Depositary, in turn, must immediately inform all Contracting Parties.

According to Article 32.2, withdrawal takes effect one year after receipt of notification. 
Explanatory Guide to the International Treaty on Plant Genetic Resources for Food and Agriculture 


\section{Article 33 - Termination}

33.1 This Treaty shall be automatically terminated if and when, as the result of withdrawals, the number of Contracting Parties drops below forty, unless the remaining Contracting Parties unanimously decide otherwise.

33.2 The Depositary shall inform all remaining Contracting Parties when the number of Contracting Parties has dropped to forty.

33.3 In the event of termination the disposition of assets shall be governed by the financial rules to be adopted by the Governing Body.

Article 33 addresses the termination of the Treaty. Given the wording of this Article, the only manner in which the Treaty can be terminated is as a result of the number of Contracting Parties dropping below forty, unless the remaining Parties unanimously decide otherwise.

Given the automatic termination of the Treaty specified in Article 33.1, it is essential that the Depositary inform all remaining Contracting Parties when their number drops to forty.

Finally, Article 33.3 deals with the financial aspects that would be involved in any termination. 
Explanatory Guide to the International Treaty on Plant Genetic Resources for Food and Agriculture 


\section{Article 34 - Depositary}

The Director-General of FAO shall be the Depositary of this Treaty.

The Depositary of the Treaty has important formal functions. In particular, the Depositary serves as the repository and source of information on the Treaty. This includes:

- information with respect to the choice of dispute settlement, as between arbitration and/or submission to the ICJ (Article 22.3);

- instruments of ratification, acceptance, or approval (Article 26);

- instruments of accession (Article 27); and

- withdrawal notices (Article 32).
In addition, it is the task of the Depositary to inform Parties:

- of withdrawals (Article 32); and

- if the number of Parties has dropped to forty (Article 33).

The functions of depositary of the Treaty are assigned to the Director-General of FAO, as is normal for treaties concluded within the framework of the FAO Constitution. 
Explanatory Guide to the International Treaty on Plant Genetic Resources for Food and Agriculture 


\section{Article 35 - Authentic Texts}

The Arabic, Chinese, English, French, Russian and Spanish texts of this Treaty are equally authentic.

All authentic texts of the Treaty are equally authoritative, and the terms of the treaty are presumed to have the same meaning in each authentic text. However, cases of discrepancies between authentic language versions may happen. In those situations, the discrepancy can only be resolved by negotiation and amendment of one or more versions in accordance with Article 23. The addition of an authentic version necessitates the amendment of the relevant article (here 35) of the Treaty. 


\section{Box 21. National legislation and policy options for implementation}

Pursuant to Articles 26 and 28, the Treaty's obligations become effective upon a particular State only when:

- The State has formally expressed its willingness to be bound by the Treaty; and

- The Treaty is in force.

Ratification enables States to participate in all of the international framework set up under the provisions of the Treaty, including in particular the Multilateral System of access and benefit-sharing. It also enables Parties to participate in the Governing Body and to protect and advance their interests in the range of matters that the Governing Body will address in the course of promoting the effective implementation of the Treaty. Participation in the Treaty will of course involve costs to support international secretariat activities under the Treaty after it enters into force and for participation in the work of the Governing Body. Ratification would not, however, involve direct additional compulsory payments to other Contracting Parties, such as developing countries or countries with economies in transition. For the most part, it is assumed that the system of compulsory benefit-sharing envisaged under the Treaty will operate through and within the framework of national contract law through the standard MTAs.

On the other hand, if a State does not ratify the Treaty, the capacity of their domestic plant breeders to access PGRFA on which they rely from sources outside the country (including from the IARCs) could become more difficult and less cost effective. Similarly, their access to collections in a country which is a Party to the Treaty might then have to be governed by bilateral access agreements - with greatly increased transaction costs. ${ }^{129}$

Each Party to the Treaty incurs certain important obligations, including obligations to:

- promote an integrated approach to the exploration, conservation and sustainable use of PGRFA (Article 5.1);

- eliminate, or minimize threats to PGRFA (Article 5.2);

- $\quad$ promote the sustainable use of PGRFA (Article 6.1);

- realize Farmers' Rights (Article 9);

- provide facilitated access to plant genetic resources for food and agriculture covered by the Multilateral System in accordance with the provisions of Part IV of the Treaty(Article 12); and

- ensure that opportunities are available for seeking recourse under their national legal systems in case of contractual disputes arising under the standard MTAs (Article 13).

Once these obligations become effective, the Party must implement these commitments into national actions. Most often, it may appear that changes to domestic legislation may not be necessary to implement the Treaty. In many countries, it may be possible to implement the Treaty administratively, without the need for new national legislation. Some changes in the procedures of holders of ex situ PGRFA, particularly in relation to MTAs, will nevertheless be required so that their procedures conform with the requirements of the Treaty.

See generally, Bert Visser, Derek Eaton, Niels Louwars and Jan Engels, Transaction costs of germplasm exchange under bilateral agreements, in Strengthening partnerships in agricultural research for development in the context of globalization, Proceedings of the GFAR conference 21-23 May 2003, Dresden, Germany, GFAR/IPGRI, 2003, pp. $51-80$. 
For those countries that do decide to implement domestic legislation, numerous options exist. Generally speaking, the Treaty imposes broad obligations, leaving the manner in which they are implemented to the Parties' discretion. This was done in order to ensure that Parties would be able to meet their commitments under the Treaty in a manner that meets their own goals, policies, and resources. For this reason, it is outside the terms of reference of this guide to provide specific language that could be implemented into domestic legislation. Moreover, the responsibility for PGRFA may be shared among various levels of government: from national, and/or sub-national, to municipal, each with its own sphere of competence.

Therefore, as a broad principle, Parties will need to examine their current legislative and regulatory regimes with respect to the objectives of the Treaty and take the necessary and practical steps towards creating an improved legislative framework that supports the conservation and sustainable use of PGRFA. It should be noted that legislation is most effective when it is developed and used as part of an overall strategy that includes planning, education and incentives. For example, the Treaty's Article 7.1 talks about implementing an integrated approach, as well as promoting the sustainable use of PGRFA, into agricultural and rural development policies and programmes.

When implementing the Treaty's commitments into domestic law, if that becomes necessary, it would be important to determine whether PGRFA should be addressed through changes in existing laws, treated in a distinct piece of national legislation, or whether a single piece of legislation should cover the commitments of both the Treaty and the CBD. Prima facie, in light of the complementary nature of the two regimes, there is nothing that is inherently contradictory that would prevent the adoption of a unified legislation.

There are, nevertheless, important distinctions between the CBD and the Treaty. Primary among these is their focus. The CBD addresses biological diversity very broadly, including the conservation and sustainable use of genetic resources, as well as access and benefit sharing. The Treaty, on the other hand, has a narrower scope, addressing in a more detailed way the conservation and sustainable use of PGRFA. With respect to the PGRFA listed in Annex I, Parties to the Treaty have agreed to a special multilateral system of access and benefit sharing. As mentioned earlier, this mechanism is intended to be consistent with the $\mathrm{CBD}$, and to represent the first multilateral approach to its implementation.

Where national legislation has already been enacted or drafted for the implementation of the CBD, it will be necessary to review that legislation for compatibility with the provisions of the Treaty, particularly in so far as access is concerned. Where legislation for the implementation of the CBD provides a system of prior informed consent and mutually agreed terms on a bilateral basis for access to genetic resources in general, it may be necessary to discuss facilitated access to PGRFA under the Multilateral System with particularity. A review of national contract law and judicial procedures may also be needed to ensure that adequate opportunities for recourse are available in the national legal system in case of breaches of the obligations of the standard MTAs. 
Explanatory Guide to the International Treaty on Plant Genetic Resources for Food and Agriculture 


\section{ANNEX I}

\section{LIST OF CROPS COVERED UNDER THE MULTILATERAL SYSTEM}

\section{Food crops}

\section{Crop}

Breadfruit

Asparagus

Oat

Beet

Brassica complex
Genus

Artocarpus

Asparagus

Avena

Beta

\author{
Observations \\ Breadfruit only.
}

$\begin{array}{lll}\text { Pigeon Pea } & \text { Cajanus } & \\ \text { Chickpea } & \text { Cicer } & \\ \text { Citrus } & \text { Citrus } & \text { Genera Poncirus } \text { and Fortunella } \text { are included as root stock. } \\ \text { Coconut } & \text { Cocos } & \\ \text { Major aroids } & \text { Colocasia, } & \text { Major aroids include taro, cocoyam, dasheen and tannia. } \\ & \text { Xanthosoma } & \\ \text { Carrot } & \text { Daucus } & \\ \text { Yams } & \text { Dioscorea } & \\ \text { Finger Millet } & \text { Eleusine } & \\ \text { Strawberry } & \text { Fragaria } & \\ \text { Sunflower } & \text { Helianthus } & \\ \text { Barley } & \text { Hordeum } & \\ \text { Sweet Potato } & \text { Ipomoea } & \\ \text { Grass pea } & \text { Lathyrus } & \\ \text { Lentil } & \text { Lens } & \\ \text { Apple } & \text { Malus } & \\ \text { Cassava } & \text { Manihot } & \text { Manihot esculenta } \text { only. } \\ \text { Banana/Plantain } & \text { Musa } & \text { Except Musa textilis. } \\ \text { Rice } & \text { Oryza } & \\ \text { Pearl Millet } & \text { Pennisetum } & \\ \text { Beans } & \text { Phaseolus } & \text { Except Phaseolus polyanthus. } \\ \text { Pea } & \text { Pisum } & \\ \text { Rye } & \text { Secale } & \\ \text { Potato } & \text { Solanum } & \text { Section tuberosa included, except Solanum phureja. } \\ \text { Eggplant } & \text { Solanum } & \text { Section melongena included. } \\ \text { Sorghum } & \text { Sorghum } & \\ \text { Triticale } & \text { Triticosecale } & \\ \text { Wheat } & \text { Triticum et al. } & \text { Including Agropyron, Elymus, and Secale. } \\ \text { Faba Bean / Vetch } & \text { Vicia } & \\ \text { Cowpea } \text { et al. } & \text { Vigna } & \\ \text { Maize } & \text { Zea } & \text { Excluding Zeaperennis, Zeadiploperennis, andZealuxurians. }\end{array}$ Camelina, Crambe, Diplotaxis, Eruca, Isatis, Lepidium, Raphanobrassica, Raphanus, Rorippa, and Sinapis. This comprises oilseed and vegetable crops such as cabbage, rapeseed, mustard, cress, rocket, radish, and turnip. The species Lepidium meyenii (maca) is excluded.

\begin{tabular}{|c|c|c|}
\hline Chickpea & Cicer & \\
\hline Citrus & Citrus & Genera Poncirus and Fortunella are included as root stock. \\
\hline Coconut & $\operatorname{Cocos}$ & \\
\hline Major aroids & $\begin{array}{l}\text { Colocasia, } \\
\text { Xanthosoma }\end{array}$ & Major aroids include taro, cocoyam, dasheen and tannia. \\
\hline Carrot & Daucus & \\
\hline Yams & Dioscorea & \\
\hline Finger Millet & Eleusine & \\
\hline Strawberry & Fragaria & \\
\hline Sunflower & Helianthus & \\
\hline Barley & Hordeum & \\
\hline Sweet Potato & Ipomoea & \\
\hline Grass pea & Lathyrus & \\
\hline Lentil & Lens & \\
\hline Apple & Malus & \\
\hline Cassava & Manihot & Manihot esculenta only. \\
\hline Banana/Plantain & Musa & Except Musa textilis. \\
\hline Rice & Oryza & \\
\hline Pearl Millet & Pennisetum & \\
\hline Beans & Phaseolus & Except Phaseolus polyanthus. \\
\hline Pea & Pisum & \\
\hline Rye & Secale & \\
\hline Potato & Solanum & Section tuberosa included, except Solanum phureja. \\
\hline Eggplant & Solanum & Section melongena included. \\
\hline Sorghum & Sorghum & \\
\hline Triticale & Triticosecale & \\
\hline Wheat & Triticum et al. & Including Agropyron, Elymus, and Secale. \\
\hline Faba Bean / Vetch & Vicia & \\
\hline Cowpea et al. & Vigna & \\
\hline Maize & Zea & Excluding Zea perennis, Zea diploperennis, and Zea luxurians. \\
\hline
\end{tabular}




\section{Forages}

\section{Genera}

\section{LEGUME FORAGES}

Astragalus

Canavalia

Coronilla

Hedysarum

Lathyrus

Lespedeza

Lotus

Lupinus

Medicago

Melilotus

Onobrychis

Ornithopus

Prosopis

Pueraria

Trifolium

\section{GRASS FORAGES}

Andropogon

Agropyron

Agrostis

Alopecurus

Arrhenatherum

Dactylis

Festuca

Lolium

Phalaris

Phleum

Poa

Tripsacum

\section{OTHER FORAGES}

Atriplex

Salsola

\section{Species}

chinensis, cicer, arenarius

Ensiformis

Varia

Coronarium

cicera, ciliolatus, hirsutus, ochrus, odoratus, sativus

cuneata, striata, stipulacea

corniculatus, subbiflorus, uliginosus

albus, angustifolius, luteus

arborea, falcata, sativa, scutellata, rigidula, truncatula

albus, officinalis

Viciifolia

Sativus

affinis, alba, chilensis, nigra, pallida

Phaseoloides

alexandrinum, alpestre, ambiguum, angustifolium, arvense, agrocicerum, hybridum, incarnatum, pratense, repens, resupinatum, rueppellianum, semipilosum, subterraneum, vesiculosum

Gayanus

cristatum, desertorum

stolonifera, tenuis

Pratensis

Elatius

Glomerata

arundinacea, gigantea, heterophylla, ovina, pratensis, rubra hybridum, multiflorum, perenne, rigidum, temulentum

aquatica, arundinacea

Pratense

alpina, annua, pratensis

Laxum

halimus, nummularia

Vermiculata 


\section{ANNEX II}

\section{Part 1}

ARBITRATION

\section{Article 1}

The claimant party shall notify the Secretary that the parties to the dispute are referring it to arbitration pursuant to Article 22. The notification shall state the subject-matter of arbitration and include, in particular, the articles of this Treaty, the interpretation or application of which are at issue. If the parties to the dispute do not agree on the subject matter of the dispute before the President of the tribunal is designated, the arbitral tribunal shall determine the subject matter. The Secretary shall forward the information thus received to all Contracting Parties to this Treaty.

\section{Article 2}

1. In disputes between two parties to the dispute, the arbitral tribunal shall consist of three members. Each of the parties to the dispute shall appoint an arbitrator and the two arbitrators so appointed shall designate by common agreement the third arbitrator who shall be the President of the tribunal. The latter shall not be a national of one of the parties to the dispute, nor have his or her usual place of residence in the territory of one of these parties to the dispute, nor be employed by any of them, nor have dealt with the case in any other capacity.

2. In disputes between more than two Contracting Parties, parties to the dispute with the same interest shall appoint one arbitrator jointly by agreement.

3. Any vacancy shall be filled in the manner prescribed for the initial appointment.

\section{Article 3}

1. If the President of the arbitral tribunal has not been designated within two months of the appointment of the second arbitrator, the Director-General of FAO shall, at the request of a party to the dispute, designate the President within a further two-month period.

2. If one of the parties to the dispute does not appoint an arbitrator within two months of receipt of the request, the other party may inform the Director-General of FAO who shall make the designation within a further two-month period.

\section{Article 4}

The arbitral tribunal shall render its decisions in accordance with the provisions of this Treaty and international law.

\section{Article 5}

Unless the parties to the dispute otherwise agree, the arbitral tribunal shall determine its own rules of procedure.

\section{Article 6}

The arbitral tribunal may, at the request of one of the parties to the dispute, recommend essential interim measures of protection. 


\section{Article 7}

The parties to the dispute shall facilitate the work of the arbitral tribunal and, in particular, using all means at their disposal, shall:

(a) Provide it with all relevant documents, information and facilities; and

(b) Enable it, when necessary, to call witnesses or experts and receive their evidence.

\section{Article 8}

The parties to the dispute and the arbitrators are under an obligation to protect the confidentiality of any information they receive in confidence during the proceedings of the arbitral tribunal.

\section{Article 9}

Unless the arbitral tribunal determines otherwise because of the particular circumstances of the case, the costs of the tribunal shall be borne by the parties to the dispute in equal shares. The tribunal shall keep a record of all its costs, and shall furnish a final statement thereof to the parties to the dispute.

\section{Article 10}

Any Contracting Party that has an interest of a legal nature in the subject-matter of the dispute which may be affected by the decision in the case, may intervene in the proceedings with the consent of the tribunal.

\section{Article 11}

The tribunal may hear and determine counterclaims arising directly out of the subject-matter of the dispute.

\section{Article 12}

Decisions both on procedure and substance of the arbitral tribunal shall be taken by a majority vote of its members.

\section{Article 13}

If one of the parties to the dispute does not appear before the arbitral tribunal or fails to defend its case, the other party may request the tribunal to continue the proceedings and to make its award. Absence of a party to the dispute or a failure of a party to the dispute to defend its case shall not constitute a bar to the proceedings. Before rendering its final decision, the arbitral tribunal must satisfy itself that the claim is well founded in fact and law.

\section{Article 14}

The tribunal shall render its final decision within five months of the date on which it is fully constituted unless it finds it necessary to extend the time-limit for a period which should not exceed five more months.

\section{Article 15}

The final decision of the arbitral tribunal shall be confined to the subject-matter of the dispute and shall state the reasons on which it is based. It shall contain the names of the members who have 
participated and the date of the final decision. Any member of the tribunal may attach a separate or dissenting opinion to the final decision.

\section{Article 16}

The award shall be binding on the parties to the dispute. It shall be without appeal unless the parties to the dispute have agreed in advance to an appellate procedure.

\section{Article 17}

Any controversy which may arise between the parties to the dispute as regards the interpretation or manner of implementation of the final decision may be submitted by either party to the dispute for decision to the arbitral tribunal which rendered it.

\section{Part 2}

\section{CONCILIATION}

\section{Article 1}

A conciliation commission shall be created upon the request of one of the parties to the dispute. The commission shall, unless the parties to the dispute otherwise agree, be composed of five members, two appointed by each party concerned and a President chosen jointly by those members.

\section{Article 2}

In disputes between more than two Contracting Parties, parties to the dispute with the same interest shall appoint their members of the commission jointly by agreement. Where two or more parties to the dispute have separate interests or there is a disagreement as to whether they are of the same interest, they shall appoint their members separately.

\section{Article 3}

If any appointments by the parties to the dispute are not made within two months of the date of the request to create a conciliation commission, the Director-General of FAO shall, if asked to do so by the party to the dispute that made the request, make those appointments within a further twomonth period.

\section{Article 4}

If a President of the conciliation commission has not been chosen within two months of the last of the members of the commission being appointed, the Director-General of FAO shall, if asked to do so by a party to the dispute, designate a President within a further two-month period.

\section{Article 5}

The conciliation commission shall take its decisions by majority vote of its members. It shall, unless the parties to the dispute otherwise agree, determine its own procedure. It shall render a proposal for resolution of the dispute, which the parties shall consider in good faith.

\section{Article 6}

A disagreement as to whether the conciliation commission has competence shall be decided by the commission. 
Explanatory Guide to the International Treaty on Plant Genetic Resources for Food and Agriculture 


\section{APPENDIX 1}

The following instruments have been deposited on the dates indicated (as of 13 January 2005):

Participant

Algeria

Angola

Argentina

Australia

Austria

Bangladesh

Belgium

Bhutan

Brazil

Bulgaria

Burkina Faso

Burundi

Cambodia

Cameroon

Canada

Cape Verde

Central African Republic

Chad

Chile

Colombia

Congo, Republic of

Cook Islands

Costa Rica

Côte d'Ivoire

Cuba

Cyprus

Czech Republic

Democratic People's Republic of

Korea

Democratic Republic of the Congo

Dominican Republic

Denmark

Ecuador

Egypt

El Salvador

Eritrea

Estonia

Ethiopia

European Community

Finland

France

Gabon

Ghana

Germany

Greece

Guatemala

Guinea

Haiti

Honduras

Hungary

India

Iran, Islamic Republic of

Ireland

$\begin{array}{ll}\text { Signature } & \text { Ratification } \\ & \\ 10 / 10 / 2002 & \\ 10 / 6 / 2002 & \\ 10 / 6 / 2002 & \\ 6 / 6 / 2002 & \\ 17 / 10 / 2002 & 14 / 11 / 2003 \\ 6 / 6 / 2002 & \\ 10 / 6 / 2002 & 2 / 9 / 2003 \\ 10 / 6 / 2002 & \\ & \\ 9 / 11 / 2001 & \\ 10 / 6 / 2002 & \\ 11 / 6 / 2002 & \\ 3 / 9 / 2002 & \\ 10 / 6 / 2002 & 10 / 6 / 2002 \\ 16 / 10 / 2002 & \\ 9 / 11 / 2001 & 4 / 8 / 2003 \\ 11 / 6 / 2002 & \\ 4 / 11 / 2002 & \\ 30 / 10 / 2002 & \\ & \\ 10 / 6 / 2002 & \\ 9 / 11 / 2001 & 25 / 6 / 2003 \\ 11 / 10 / 2002 & 16 / 9 / 2004 \\ 12 / 6 / 2002 & 15 / 9 / 2003\end{array}$

Approval Accession

$13 / 12 / 2002$

$29 / 12 / 04$

$11 / 6 / 2002$

$14 / 9 / 2004$

$2 / 12 / 2004$

$31 / 3 / 2004$

$16 / 7 / 2003$

$5 / 6 / 2003$

$11 / 6 / 2002$

$6 / 6 / 2002$

$31 / 3 / 2004$

$29 / 8 / 2002$

$10 / 6 / 2002$

$10 / 6 / 2002$

$31 / 3 / 2004$

9/7/2003

$10 / 6 / 2002$

$12 / 6 / 2002$

$6 / 6 / 2002$

$6 / 6 / 2002$

$6 / 6 / 2002$

$10 / 6 / 2002$

$28 / 10 / 2002 \quad 28 / 10 / 2002$

$6 / 6 / 2002 \quad 31 / 3 / 2004$

$6 / 6 / 2002 \quad 31 / 3 / 2004$

$13 / 6 / 2002$

$11 / 6 / 2002$

$9 / 11 / 2001$

$11 / 6 / 2002$

$14 / 1 / 2004$

$4 / 3 / 2004$ 


\section{Participant}

Italy

Jordan

Kenya

Kuwait

Latvia

Lebanon

Luxembourg

Madagascar

Malawi

Malaysia

Mali

Malta

Marshall Islands

Mauritania

Mauritius

Morocco

Myanmar

Namibia

Netherlands

Nicaragua

Niger

Nigeria

Norway

Oman

Pakistan

Paraguay

Peru

Portugal

Saint Lucia

Senegal

Serbia and Montenegro

Sierra Leone

Spain

Sudan

Swaziland

Sweden

Switzerland

Syrian Arab Republic

Thailand

The Former Yugoslav Republic of

Macedonia

Togo

Trinidad and Tobago

Tunisia

Turkey

United Arab Emirates

United Kingdom

United Republic of Tanzania

United States of America

Uganda

Uruguay

Venezuela

Zambia

Zimbabwe

\section{Signature}

$6 / 6 / 2002$

$9 / 11 / 2001$

$4 / 11 / 2002$
$6 / 6 / 2002$
$30 / 10 / 2002$
$10 / 6 / 2002$

$10 / 6 / 2002$

$9 / 11 / 2001$

$10 / 6 / 2002$

$13 / 6 / 2002$

$27 / 3 / 2002$

$9 / 11 / 2001$

$6 / 6 / 2002$

$11 / 6 / 2002$

$10 / 6 / 2002$

$12 / 6 / 2002$

24/10/2002

$8 / 10 / 2002$

$6 / 6 / 2002$

$9 / 11 / 2001$

$1 / 10 / 2002$

$6 / 6 / 2002$

$10 / 6 / 2002$

$10 / 6 / 2002$

$6 / 6 / 2002$

$28 / 10 / 2002$

$13 / 6 / 2002$

$4 / 11 / 2002$

$10 / 6 / 2002$

$4 / 11 / 2002$

$10 / 6 / 2002$

$4 / 11 / 2002$

$6 / 6 / 2002$

$1 / 11 / 2002$

$10 / 6 / 2002$

$11 / 2 / 2002$

$4 / 11 / 2002$

$30 / 10 / 2002$

\section{Ratification Acceptance Approval Accession}

$18 / 5 / 2004$

$30 / 5 / 2002$

$\begin{array}{ll} & 27 / 5 / 2003 \\ & 2 / 9 / 2003 \\ & 27 / 5 / 2004\end{array}$

$6 / 5 / 2004$

$31 / 3 / 2004$

4/7/2002

$5 / 5 / 2003$

$11 / 2 / 2003$

$27 / 3 / 2003$

4/12/2002

$7 / 10 / 2004$

$22 / 11 / 2002$

$27 / 10 / 2004$

$3 / 8 / 2004$

$14 / 7 / 2004$

$2 / 9 / 2003$

$3 / 1 / 2003$

$5 / 6 / 2003$

$16 / 7 / 2003$

$20 / 11 / 2002$

$31 / 3 / 2004$

$10 / 6 / 2002$

$31 / 3 / 2004$

$22 / 11 / 2004$

$26 / 8 / 2003$

27/10/2004

$8 / 6 / 2004$

$16 / 2 / 2004$

$30 / 4 / 2004$

25/3/2003 


\section{INTERNATIONAL TREATY ON PLANT GENETIC RESOURCE FOR FOOD AND AGRICULTURE}

\section{PREAMBLE}

\section{The Contracting Parties,}

Convinced of the special nature of plant genetic resources for food and agriculture, their distinctive features and problems needing distinctive solutions;

Alarmed by the continuing erosion of these resources;

Cognizant that plant genetic resources for food and agriculture are a common concern of all countries, in that all countries depend very largely on plant genetic resources for food and agriculture that originated elsewhere;

Acknowledging that the conservation, exploration, collection, characterization, evaluation and documentation of plant genetic resources for food and agriculture are essential in meeting the goals of the Rome Declaration on World Food Security and the World Food Summit Plan of Action and for sustainable agricultural development for this and future generations, and that the capacity of developing countries and countries with economies in transition to undertake such tasks needs urgently to be reinforced;

Noting that the Global Plan of Action for the Conservation and Sustainable Use of Plant Genetic Resources for Food and Agriculture is an internationally agreed framework for such activities;

Acknowledging further that plant genetic resources for food and agriculture are the raw material indispensable for crop genetic improvement, whether by means of farmers' selection, classical plant breeding or modern biotechnologies, and are essential in adapting to unpredictable environmental changes and future human needs;

Affirming that the past, present and future contributions of farmers in all regions of the world, particularly those in centres of origin and diversity, in conserving, improving and making available these resources, is the basis of Farmers' Rights;

Affirming also that the rights recognized in this Treaty to save, use, exchange and sell farm-saved seed and other propagating material, and to participate in decision-making regarding, and in the fair and equitable sharing of the benefits arising from, the use of plant genetic resources for food and agriculture, are fundamental to the realization of Farmers' Rights, as well as the promotion of Farmers' Rights at national and international levels;

Recognizing that this Treaty and other international agreements relevant to this Treaty should be mutually supportive with a view to sustainable agriculture and food security;

Affirming that nothing in this Treaty shall be interpreted as implying in any way a change in the rights and obligations of the Contracting Parties under other international agreements;

Understanding that the above recital is not intended to create a hierarchy between this Treaty and other international agreements;

Aware that questions regarding the management of plant genetic resources for food and agriculture are at the meeting point between agriculture, the environment and commerce, and convinced that there should be synergy among these sectors;

Aware of their responsibility to past and future generations to conserve the World's diversity of plant genetic resources for food and agriculture;

Recognizing that, in the exercise of their sovereign rights over their plant genetic resources for food and agriculture, states may mutually benefit from the creation of an effective multilateral system for facilitated access to a negotiated selection of these resources and for the fair and equitable sharing of the benefits arising from their use; and 
Desiring to conclude an international agreement within the framework of the Food and Agriculture Organization of the United Nations, hereinafter referred to as FAO, under Article XIV of the FAO Constitution;

\section{Have agreed as follows:}

\section{PART I - INTRODUCTION}

\section{Article 1 - Objectives}

1.1 The objectives of this Treaty are the conservation and sustainable use of plant genetic resources for food and agriculture and the fair and equitable sharing of the benefits arising out of their use, in harmony with the Convention on Biological Diversity, for sustainable agriculture and food security.

1.2 These objectives will be attained by closely linking this Treaty to the Food and Agriculture Organization of the United Nations and to the Convention on Biological Diversity.

\section{Article 2 - Use of terms}

For the purpose of this Treaty, the following terms shall have the meanings hereunder assigned to them. These definitions are not intended to cover trade in commodities:

"In situ conservation" means the conservation of ecosystems and natural habitats and the maintenance and recovery of viable populations of species in their natural surroundings and, in the case of domesticated or cultivated plant species, in the surroundings where they have developed their distinctive properties.

"Ex situ conservation" means the conservation of plant genetic resources for food and agriculture outside their natural habitat.

"Plant genetic resources for food and agriculture" means any genetic material of plant origin of actual or potential value for food and agriculture.

"Genetic material" means any material of plant origin, including reproductive and vegetative propagating material, containing functional units of heredity.

"Variety" means a plant grouping, within a single botanical taxon of the lowest known rank, defined by the reproducible expression of its distinguishing and other genetic characteristics.

"Ex situ collection" means a collection of plant genetic resources for food and agriculture maintained outside their natural habitat.

"Centre of origin" means a geographical area where a plant species, either domesticated or wild, first developed its distinctive properties.

"Centre of crop diversity" means a geographic area containing a high level of genetic diversity for crop species in in situ conditions.

\section{Article 3 - Scope}

This Treaty relates to plant genetic resources for food and agriculture.

\section{PART II - GENERAL PROVISIONS}

\section{Article 4 - General Obligations}

Each Contracting Party shall ensure the conformity of its laws, regulations and procedures with its obligations as provided in this Treaty. 


\section{Article 5-Conservation, Exploration, Collection, Characterization, Evaluation} and Documentation of Plant Genetic Resources for Food and Agriculture

5.1 Each Contracting Party shall, subject to national legislation, and in cooperation with other Contracting Parties where appropriate, promote an integrated approach to the exploration, conservation and sustainable use of plant genetic resources for food and agriculture and shall in particular, as appropriate:

(a) Survey and inventory plant genetic resources for food and agriculture, taking into account the status and degree of variation in existing populations, including those that are of potential use and, as feasible, assess any threats to them;

(b) Promote the collection of plant genetic resources for food and agriculture and relevant associated information on those plant genetic resources that are under threat or are of potential use;

(c) Promote or support, as appropriate, farmers and local communities' efforts to manage and conserve on-farm their plant genetic resources for food and agriculture;

(d) Promote in situ conservation of wild crop relatives and wild plants for food production, including in protected areas, by supporting, inter alia, the efforts of indigenous and local communities;

(e) Cooperate to promote the development of an efficient and sustainable system of ex situ conservation, giving due attention to the need for adequate documentation, characterization, regeneration and evaluation, and promote the development and transfer of appropriate technologies for this purpose with a view to improving the sustainable use of plant genetic resources for food and agriculture;

(f) Monitor the maintenance of the viability, degree of variation, and the genetic integrity of collections of plant genetic resources for food and agriculture.

5.2 The Contracting Parties shall, as appropriate, take steps to minimize or, if possible, eliminate threats to plant genetic resources for food and agriculture.

\section{Article 6 - Sustainable Use of Plant Genetic Resources}

6.1 The Contracting Parties shall develop and maintain appropriate policy and legal measures that promote the sustainable use of plant genetic resources for food and agriculture.

6.2 The sustainable use of plant genetic resources for food and agriculture may include such measures as:

(a) pursuing fair agricultural policies that promote, as appropriate, the development and maintenance of diverse farming systems that enhance the sustainable use of agricultural biological diversity and other natural resources;

(b) strengthening research which enhances and conserves biological diversity by maximizing intra- and inter-specific variation for the benefit of farmers, especially those who generate and use their own varieties and apply ecological principles in maintaining soil fertility and in combating diseases, weeds and pests;

(c) promoting, as appropriate, plant breeding efforts which, with the participation of farmers, particularly in developing countries, strengthen the capacity to develop varieties particularly adapted to social, economic and ecological conditions, including in marginal areas;

(d) broadening the genetic base of crops and increasing the range of genetic diversity available to farmers;

(e) promoting, as appropriate, the expanded use of local and locally adapted crops, varieties and underutilized species;

(f) supporting, as appropriate, the wider use of diversity of varieties and species in onfarm management, conservation and sustainable use of crops and creating strong links to plant breeding and agricultural development in order to reduce crop vulnerability and genetic erosion, and promote increased world food production compatible with sustainable development; and 
(g) reviewing, and, as appropriate, adjusting breeding strategies and regulations concerning variety release and seed distribution.

\section{Article 7 - National Commitments and International Cooperation}

7.1 Each Contracting Party shall, as appropriate, integrate into its agriculture and rural development policies and programmes, activities referred to in Articles 5 and 6, and cooperate with other Contracting Parties, directly or through FAO and other relevant international organizations, in the conservation and sustainable use of plant genetic resources for food and agriculture.

7.2 International cooperation shall, in particular, be directed to:

(a) establishing or strengthening the capabilities of developing countries and countries with economies in transition with respect to conservation and sustainable use of plant genetic resources for food and agriculture;

(b) enhancing international activities to promote conservation, evaluation, documentation, genetic enhancement, plant breeding, seed multiplication; and sharing, providing access to, and exchanging, in conformity with Part IV, plant genetic resources for food and agriculture and appropriate information and technology;

(c) maintaining and strengthening the institutional arrangements provided for in Part V; and

(d) implement the funding strategy of Article 18.

\section{Article 8 - Technical Assistance}

The Contracting Parties agree to promote the provision of technical assistance to Contracting Parties, especially those that are developing countries or countries with economies in transition, either bilaterally or through the appropriate international organizations, with the objective of facilitating the implementation of this Treaty.

\section{PART III - FARMERS' RIGHTS}

\section{Article 9 - Farmers' Rights}

9.1 The Contracting Parties recognize the enormous contribution that the local and indigenous communities and farmers of all regions of the world, particularly those in the centres of origin and crop diversity, have made and will continue to make for the conservation and development of plant genetic resources which constitute the basis of food and agriculture production throughout the world.

9.2 The Contracting Parties agree that the responsibility for realizing Farmers' Rights, as they relate to plant genetic resources for food and agriculture, rests with national governments. In accordance with their needs and priorities, each Contracting Party should, as appropriate, and subject to its national legislation, take measures to protect and promote Farmers' Rights, including:

(a) protection of traditional knowledge relevant to plant genetic resources for food and agriculture;

(b) the right to equitably participate in sharing benefits arising from the utilization of plant genetic resources for food and agriculture; and

(c) the right to participate in making decisions, at the national level, on matters related to the conservation and sustainable use of plant genetic resources for food and agriculture.

9.3 Nothing in this Article shall be interpreted to limit any rights that farmers have to save, use, exchange and sell farm-saved seed/propagating material, subject to national law and as appropriate. 


\section{PART IV - THE MULTILATERAL SYSTEM OF ACCESS AND BENEFIT-SHARING}

\section{Article 10 - Multilateral System of Access and Benefit-sharing}

10.1 In their relationships with other States, the Contracting Parties recognize the sovereign rights of States over their own plant genetic resources for food and agriculture, including that the authority to determine access to those resources rests with national governments and is subject to national legislation.

10.2 In the exercise of their sovereign rights, the Contracting Parties agree to establish a multilateral system, which is efficient, effective, and transparent, both to facilitate access to plant genetic resources for food and agriculture, and to share, in a fair and equitable way, the benefits arising from the utilization of these resources, on a complementary and mutually reinforcing basis.

\section{Article 11 - Coverage of the Multilateral System}

11.1 In furtherance of the objectives of conservation and sustainable use of plant genetic resources for food and agriculture and the fair and equitable sharing of benefits arising out of their use, as stated in Article 1, the Multilateral System shall cover the plant genetic resources for food and agriculture listed in Annex I, established according to criteria of food security and interdependence.

11.2 The Multilateral System, as identified in Article 11.1, shall include all plant genetic resources for food and agriculture listed in Annex I that are under the management and control of the Contracting Parties and in the public domain. With a view to achieving the fullest possible coverage of the Multilateral System, the Contracting Parties invite all other holders of the plant genetic resources for food and agriculture listed in Annex I to include these plant genetic resources for food and agriculture in the Multilateral System.

11.3 Contracting Parties also agree to take appropriate measures to encourage natural and legal persons within their jurisdiction who hold plant genetic resources for food and agriculture listed in Annex I to include such plant genetic resources for food and agriculture in the Multilateral System.

11.4 Within two years of the entry into force of the Treaty, the Governing Body shall assess the progress in including the plant genetic resources for food and agriculture referred to in paragraph 11.3 in the Multilateral System. Following this assessment, the Governing Body shall decide whether access shall continue to be facilitated to those natural and legal persons referred to in paragraph 11.3 that have not included these plant genetic resources for food and agriculture in the Multilateral System, or take such other measures as it deems appropriate.

11.5 The Multilateral System shall also include the plant genetic resources for food and agriculture listed in Annex I and held in the ex situ collections of the International Agricultural Research Centres of the Consultative Group on International Agricultural Research (CGIAR), as provided in Article 15.1a, and in other international institutions, in accordance with Article 15.5.

\section{Article 12 - Facilitated access to plant genetic resources for food and agriculture within the Multilateral System}

12.1 The Contracting Parties agree that facilitated access to plant genetic resources for food and agriculture under the Multilateral System, as defined in Article 11, shall be in accordance with the provisions of this Treaty. 
12.2 The Contracting Parties agree to take the necessary legal or other appropriate measures to provide such access to other Contracting Parties through the Multilateral System. To this effect, such access shall also be provided to legal and natural persons under the jurisdiction of any Contracting Party, subject to the provisions of Article 11.4.

12.3 Such access shall be provided in accordance with the conditions below:

(a) Access shall be provided solely for the purpose of utilization and conservation for research, breeding and training for food and agriculture, provided that such purpose does not include chemical, pharmaceutical and/or other non-food/feed industrial uses. In the case of multiple-use crops (food and non-food), their importance for food security should be the determinant for their inclusion in the Multilateral System and availability for facilitated access.

(b) Access shall be accorded expeditiously, without the need to track individual accessions and free of charge, or, when a fee is charged, it shall not exceed the minimal cost involved;

(c) All available passport data and, subject to applicable law, any other associated available non-confidential descriptive information, shall be made available with the plant genetic resources for food and agriculture provided;

(d) Recipients shall not claim any intellectual property or other rights that limit the facilitated access to the plant genetic resources for food and agriculture, or their genetic parts or components, in the form received from the Multilateral System;

(e) Access to plant genetic resources for food and agriculture under development, including material being developed by farmers, shall be at the discretion of its developer, during the period of its development;

(f) Access to plant genetic resources for food and agriculture protected by intellectual and other property rights shall be consistent with relevant international agreements, and with relevant national laws;

(g) Plant genetic resources for food and agriculture accessed under the Multilateral System and conserved shall continue to be made available to the Multilateral System by the recipients of those plant genetic resources for food and agriculture, under the terms of this Treaty; and

(h) Without prejudice to the other provisions under this Article, the Contracting Parties agree that access to plant genetic resources for food and agriculture found in in situ conditions will be provided according to national legislation or, in the absence of such legislation, in accordance with such standards as may be set by the Governing Body.

12.4 To this effect, facilitated access, in accordance with Articles 12.2 and 12.3 above, shall be provided pursuant to a standard material transfer agreement (MTA), which shall be adopted by the Governing Body and contain the provisions of Articles 12.3a, $\mathrm{d}$ and g, as well as the benefit-sharing provisions set forth in Article 13.2d(ii) and other relevant provisions of this Treaty, and the provision that the recipient of the plant genetic resources for food and agriculture shall require that the conditions of the MTA shall apply to the transfer of plant genetic resources for food and agriculture to another person or entity, as well as to any subsequent transfers of those plant genetic resources for food and agriculture.

12.5 Contracting Parties shall ensure that an opportunity to seek recourse is available, consistent with applicable jurisdictional requirements, under their legal systems, in case of contractual disputes arising under such MTAs, recognizing that obligations arising under such MTAs rest exclusively with the parties to those MTAs.

12.6 In emergency disaster situations, the Contracting Parties agree to provide facilitated access to appropriate plant genetic resources for food and agriculture in the Multilateral System for the purpose of contributing to the re-establishment of agricultural systems, in cooperation with disaster relief co-ordinators. 


\section{Article 13 - Benefit-sharing in the Multilateral System}

13.1 The Contracting Parties recognize that facilitated access to plant genetic resources for food and agriculture which are included in the Multilateral System constitutes itself a major benefit of the Multilateral System and agree that benefits accruing therefrom shall be shared fairly and equitably in accordance with the provisions of this Article.

13.2 The Contracting Parties agree that benefits arising from the use, including commercial, of plant genetic resources for food and agriculture under the Multilateral System shall be shared fairly and equitably through the following mechanisms: the exchange of information, access to and transfer of technology, capacity-building, and the sharing of the benefits arising from commercialization, taking into account the priority activity areas in the rolling Global Plan of Action, under the guidance of the Governing Body:

(a) Exchange of information:

The Contracting Parties agree to make available information which shall, inter alia, encompass catalogues and inventories, information on technologies, results of technical, scientific and socio-economic research, including characterization, evaluation and utilization, regarding those plant genetic resources for food and agriculture under the Multilateral System. Such information shall be made available, where non-confidential, subject to applicable law and in accordance with national capabilities. Such information shall be made available to all Contracting Parties to this Treaty through the information system, provided for in Article 17.

(b) Access to and transfer of technology:

(i) The Contracting Parties undertake to provide and/or facilitate access to technologies for the conservation, characterization, evaluation and use of plant genetic resources for food and agriculture which are under the Multilateral System. Recognizing that some technologies can only be transferred through genetic material, the Contracting Parties shall provide and/or facilitate access to such technologies and genetic material which is under the Multilateral System and to improved varieties and genetic material developed through the use of plant genetic resources for food and agriculture under the Multilateral System, in conformity with the provisions of Article 12. Access to these technologies, improved varieties and genetic material shall be provided and/or facilitated, while respecting applicable property rights and access laws, and in accordance with national capabilities.

(ii) Access to and transfer of technology to countries, especially to developing countries and countries with economies in transition, shall be carried out through a set of measures, such as the establishment and maintenance of, and participation in, crop-based thematic groups on utilization of plant genetic resources for food and agriculture, all types of partnership in research and development and in commercial joint ventures relating to the material received, human resource development, and effective access to research facilities.

(iii) Access to and transfer of technology as referred to in (i) and (ii) above, including that protected by intellectual property rights, to developing countries that are Contracting Parties, in particular least developed countries, and countries with economies in transition, shall be provided and/or facilitated under fair and most favourable terms, in particular in the case of technologies for use in conservation as well as technologies for the benefit of farmers in developing countries, especially in least developed countries, and countries with economies in transition, including on concessional and preferential terms where mutually agreed, inter alia, through partnerships in research and development under the Multilateral System. Such access and transfer shall be provided on terms which recognize and are consistent with the adequate and effective protection of intellectual property rights. 
(c) Capacity-building:

Taking into account the needs of developing countries and countries with economies in transition, as expressed through the priority they accord to building capacity in plant genetic resources for food and agriculture in their plans and programmes, when in place, in respect of those plant genetic resources for food and agriculture covered by the Multilateral System, the Contracting Parties agree to give priority to (i) establishing and/or strengthening programmes for scientific and technical education and training in conservation and sustainable use of plant genetic resources for food and agriculture, (ii) developing and strengthening facilities for conservation and sustainable use of plant genetic resources for food and agriculture, in particular in developing countries, and countries with economies in transition, and (iii) carrying out scientific research preferably, and where possible, in developing countries and countries with economies in transition, in cooperation with institutions of such countries, and developing capacity for such research in fields where they are needed.

(d) Sharing of monetary and other benefits of commercialization

(i) The Contracting Parties agree, under the Multilateral System, to take measures in order to achieve commercial benefit-sharing, through the involvement of the private and public sectors in activities identified under this Article, through partnerships and collaboration, including with the private sector in developing countries and countries with economies in transition, in research and technology development;

(ii) The Contracting Parties agree that the standard Material Transfer Agreement referred to in Article 12.4 shall include a requirement that a recipient who commercializes a product that is a plant genetic resource for food and agriculture and that incorporates material accessed from the Multilateral System, shall pay to the mechanism referred to in Article 19.3f, an equitable share of the benefits arising from the commercialization of that product, except whenever such a product is available without restriction to others for further research and breeding, in which case the recipient who commercializes shall be encouraged to make such payment.

The Governing Body shall, at its first meeting, determine the level, form and manner of the payment, in line with commercial practice. The Governing Body may decide to establish different levels of payment for various categories of recipients who commercialize such products; it may also decide on the need to exempt from such payments small farmers in developing countries and in countries with economies in transition. The Governing Body may, from time to time, review the levels of payment with a view to achieving fair and equitable sharing of benefits, and it may also assess, within a period of five years from the entry into force of this Treaty, whether the mandatory payment requirement in the MTA shall apply also in cases where such commercialized products are available without restriction to others for further research and breeding.

13.3 The Contracting Parties agree that benefits arising from the use of plant genetic resources for food and agriculture that are shared under the Multilateral System should flow primarily, directly and indirectly, to farmers in all countries, especially in developing countries, and countries with economies in transition, who conserve and sustainably utilize plant genetic resources for food and agriculture.

13.4 The Governing Body shall, at its first meeting, consider relevant policy and criteria for specific assistance under the agreed funding strategy established under Article 18 for the conservation of plant genetic resources for food and agriculture in developing countries, and countries with economies in transition whose contribution to the diversity of plant genetic resources for food and agriculture in the Multilateral System is significant and/or which have special needs. 
13.5 The Contracting Parties recognize that the ability to fully implement the Global Plan of Action, in particular of developing countries and countries with economies in transition, will depend largely upon the effective implementation of this Article and of the funding strategy as provided in Article 18.

13.6 The Contracting Parties shall consider modalities of a strategy of voluntary benefit-sharing contributions whereby Food Processing Industries that benefit from plant genetic resources for food and agriculture shall contribute to the Multilateral System.

\section{PART V - SUPPORTING COMPONENTS}

\section{Article 14 - Global Plan of Action}

Recognizing that the rolling Global Plan of Action for the Conservation and Sustainable Use of Plant Genetic Resources for Food and Agriculture is important to this Treaty, Contracting Parties should promote its effective implementation, including through national actions and, as appropriate, international cooperation to provide a coherent framework, inter alia, for capacity-building, technology transfer and exchange of information, taking into account the provisions of Article 13.

\section{Article 15 - Ex Situ Collections of Plant Genetic Resources for Food and Agriculture held by the International Agricultural Research Centres of the Consultative Group on International Agricultural Research and other International Institutions}

15.1 The Contracting Parties recognize the importance to this Treaty of the ex situ collections of plant genetic resources for food and agriculture held in trust by the International Agricultural Research Centres (IARCs) of the Consultative Group on International Agricultural Research (CGIAR). The Contracting Parties call upon the IARCs to sign agreements with the Governing Body with regard to such ex situ collections, in accordance with the following terms and conditions:

(a) Plant genetic resources for food and agriculture listed in Annex I of this Treaty and held by the IARCs shall be made available in accordance with the provisions set out in Part IV of this Treaty.

(b) Plant genetic resources for food and agriculture other than those listed in Annex I of this Treaty and collected before its entry into force that are held by IARCs shall be made available in accordance with the provisions of the MTA currently in use pursuant to agreements between the IARCs and the FAO. This MTA shall be amended by the Governing Body no later than its second regular session, in consultation with the IARCs, in accordance with the relevant provisions of this Treaty, especially Articles 12 and 13, and under the following conditions:

(i) The IARCs shall periodically inform the Governing Body about the MTAs entered into, according to a schedule to be established by the Governing Body;

(ii) The Contracting Parties in whose territory the plant genetic resources for food and agriculture were collected from in situ conditions shall be provided with samples of such plant genetic resources for food and agriculture on demand, without any MTA;

(iii) Benefits arising under the above MTA that accrue to the mechanism mentioned in Article 19.3f shall be applied, in particular, to the conservation and sustainable use of the plant genetic resources for food and agriculture in question, particularly in national and regional programmes in developing countries and countries with economies in transition, especially in centres of diversity and the least developed countries; and

(iv) The IARCs shall take appropriate measures, in accordance with their capacity, to maintain effective compliance with the conditions of the MTAs, and shall promptly inform the Governing Body of cases of non-compliance. 
(c) IARCs recognize the authority of the Governing Body to provide policy guidance relating to ex situ collections held by them and subject to the provisions of this Treaty.

(d) The scientific and technical facilities in which such ex situ collections are conserved shall remain under the authority of the IARCs, which undertake to manage and administer these ex situ collections in accordance with internationally accepted standards, in particular the Genebank Standards as endorsed by the FAO Commission on Genetic Resources for Food and Agriculture.

(e) Upon request by an IARC, the Secretary shall endeavour to provide appropriate technical support.

(f) The Secretary shall have, at any time, right of access to the facilities, as well as right to inspect all activities performed therein directly related to the conservation and exchange of the material covered by this Article.

(g) If the orderly maintenance of these ex situ collections held by IARCs is impeded or threatened by whatever event, including force majeure, the Secretary, with the approval of the host country, shall assist in its evacuation or transfer, to the extent possible.

15.2 The Contracting Parties agree to provide facilitated access to plant genetic resources for food and agriculture in Annex I under the Multilateral System to IARCs of the CGIAR that have signed agreements with the Governing Body in accordance with this Treaty. Such Centres shall be included in a list held by the Secretary to be made available to the Contracting Parties on request.

15.3 The material other than that listed in Annex I, which is received and conserved by IARCs after the coming into force of this Treaty, shall be available for access on terms consistent with those mutually agreed between the IARCs that receive the material and the country of origin of such resources or the country that has acquired those resources in accordance with the Convention on Biological Diversity or other applicable law.

15.4 The Contracting Parties are encouraged to provide IARCs that have signed agreements with the Governing Body with access, on mutually agreed terms, to plant genetic resources for food and agriculture not listed in Annex I that are important to the programmes and activities of the IARCs.

15.5 The Governing Body will also seek to establish agreements for the purposes stated in this Article with other relevant international institutions.

\section{Article 16 - International Plant Genetic Resources Networks}

16.1 Existing cooperation in international plant genetic resources for food and agriculture networks will be encouraged or developed on the basis of existing arrangements and consistent with the terms of this Treaty, so as to achieve as complete coverage as possible of plant genetic resources for food and agriculture.

16.2 The Contracting Parties will encourage, as appropriate, all relevant institutions, including governmental, private, non-governmental, research, breeding and other institutions, to participate in the international networks.

\section{Article 17 - The Global Information System on Plant Genetic Resources for Food and Agriculture}

17.1 The Contracting Parties shall cooperate to develop and strengthen a global information system to facilitate the exchange of information, based on existing information systems, on scientific, technical and environmental matters related to plant genetic resources for food and agriculture, with the expectation that such exchange of information will contribute to the sharing of benefits by making information on plant genetic resources for food and agriculture 
available to all Contracting Parties. In developing the Global Information System, cooperation will be sought with the Clearing House Mechanism of the Convention on Biological Diversity.

17.2 Based on notification by the Contracting Parties, early warning should be provided about hazards that threaten the efficient maintenance of plant genetic resources for food and agriculture, with a view to safeguarding the material.

17.3 The Contracting Parties shall cooperate with the Commission on Genetic Resources for Food and Agriculture of the FAO in its periodic reassessment of the state of the world's plant genetic resources for food and agriculture in order to facilitate the updating of the rolling Global Plan of Action referred to in Article 14.

\section{PART VI - FINANCIAL PROVISIONS}

\section{Article 18 - Financial Resources}

18.1 The Contracting Parties undertake to implement a funding strategy for the implementation of this Treaty in accordance with the provisions of this Article.

18.2 The objectives of the funding strategy shall be to enhance the availability, transparency, efficiency and effectiveness of the provision of financial resources to implement activities under this Treaty.

18.3 In order to mobilize funding for priority activities, plans and programmes, in particular in developing countries and countries with economies in transition, and taking the Global Plan of Action into account, the Governing Body shall periodically establish a target for such funding.

18.4 Pursuant to this funding strategy:

(a) The Contracting Parties shall take the necessary and appropriate measures within the Governing Bodies of relevant international mechanisms, funds and bodies to ensure due priority and attention to the effective allocation of predictable and agreed resources for the implementation of plans and programmes under this Treaty.

(b) The extent to which Contracting Parties that are developing countries and Contracting Parties with economies in transition will effectively implement their commitments under this Treaty will depend on the effective allocation, particularly by the developed country Parties, of the resources referred to in this Article. Contracting Parties that are developing countries and Contracting Parties with economies in transition will accord due priority in their own plans and programmes to building capacity in plant genetic resources for food and agriculture.

(c) The Contracting Parties that are developed countries also provide, and Contracting Parties that are developing countries and Contracting Parties with economies in transition avail themselves of, financial resources for the implementation of this Treaty through bilateral and regional and multilateral channels. Such channels shall include the mechanism referred to in Article 19.3f.

(d) Each Contracting Party agrees to undertake, and provide financial resources for national activities for the conservation and sustainable use of plant genetic resources for food and agriculture in accordance with its national capabilities and financial resources. The financial resources provided shall not be used to ends inconsistent with this Treaty, in particular in areas related to international trade in commodities. ;

(e) The Contracting Parties agree that the financial benefits arising from Article 13.2d are part of the funding strategy.

(f) Voluntary contributions may also be provided by Contracting Parties, the private sector, taking into account the provisions of Article 13, non-governmental organisa- 
tions and other sources. The Contracting Parties agree that the Governing Body shall consider modalities of a strategy to promote such contributions;

18.5 The Contracting Parties agree that priority will be given to the implementation of agreed plans and programmes for farmers in developing countries, especially in least developed countries, and in countries with economies in transition, who conserve and sustainably utilize plant genetic resources for food and agriculture.

\section{PART VII - INSTITUTIONAL PROVISIONS}

\section{Article 19 - Governing Body}

19.1 A Governing Body for this Treaty is hereby established, composed of all Contracting Parties.

19.2 All decisions of the Governing Body shall be taken by consensus unless by consensus another method of arriving at a decision on certain measures is reached, except that consensus shall always be required in relation to Articles 23 and 24.

19.3 The functions of the Governing Body shall be to promote the full implementation of this Treaty, keeping in view its objectives, and, in particular, to:

(a) provide policy direction and guidance to monitor, and adopt such recommendations as necessary for the implementation of this Treaty and, in particular, for the operation of the Multilateral System;

(b) adopt plans and programmes for the implementation of this Treaty;

(c) adopt, at its first session, and periodically review the funding strategy for the implementation of this Treaty, in accordance with the provisions of Article 18;

(d) adopt the budget of this Treaty;

(e) consider and establish subject to the availability of necessary funds such subsidiary bodies as may be necessary, and their respective mandates and composition;

(f) establish, as needed, an appropriate mechanism, such as a Trust Account, for receiving and utilizing financial resources that will accrue to it for purposes of implementing this Treaty;

(g) establish and maintain cooperation with other relevant international organizations and treaty bodies, including in particular the Conference of the Parties to the Convention on Biological Diversity, on matters covered by this Treaty, including their participation in the funding strategy;

(h) consider and adopt, as required, amendments to this Treaty, in accordance with the provisions of Article 23;

(i) consider and adopt, as required, amendments to annexes to this Treaty, in accordance with the provisions of Article 24;

(j) consider modalities of a strategy to encourage voluntary contributions, in particular, with reference to Articles 13 and 18;

(k) perform such other functions as may be necessary for the fulfilment of the objectives of this Treaty;

(1) take note of relevant decisions of the Conference of the Parties to the Convention on Biological Diversity and other relevant international organizations and treaty bodies;

(m) inform, as appropriate, the Conference of the Parties to the Convention on Biological Diversity and other relevant international organizations and treaty bodies of matters regarding the implementation of this Treaty; and

(n) approve the terms of agreements with the IARCs and other international institutions under Article 15, and review and amend the MTA in Article 15.

19.4 Subject to Article 19.6, each Contracting Party shall have one vote and may be represented at sessions of the Governing Body by a single delegate who may be accompanied by an alternate, and by experts and advisers. Alternates, experts and advisers may take part in the 
proceedings of the Governing Body but may not vote, except in the case of their being duly authorized to substitute for the delegate.

19.5 The United Nations, its specialized agencies and the International Atomic Energy Agency, as well as any State not a Contracting Party to this Treaty, may be represented as observers at sessions of the Governing Body. Any other body or agency, whether governmental or nongovernmental, qualified in fields relating to conservation and sustainable use of plant genetic resources for food and agriculture, which has informed the Secretary of its wish to be represented as an observer at a session of the Governing Body, may be admitted unless at least one third of the Contracting Parties present object. The admission and participation of observers shall be subject to the Rules of Procedure adopted by the Governing Body.

19.6 A Member Organization of FAO that is a Contracting Party and the member states of that Member Organization that are Contracting Parties shall exercise their membership rights and fulfil their membership obligations in accordance, mutatis mutandis, with the Constitution and General Rules of FAO.

19.7 The Governing Body shall adopt and amend, as required, its own Rules of Procedure and financial rules which shall not be inconsistent with this Treaty.

19.8 The presence of delegates representing a majority of the Contracting Parties shall be necessary to constitute a quorum at any session of the Governing Body.

19.9 The Governing Body shall hold regular sessions at least once every two years. These sessions should, as far as possible, be held back-to-back with the regular sessions of the Commission on Genetic Resources for Food and Agriculture.

19.10 Special Sessions of the Governing Body shall be held at such other times as may be deemed necessary by the Governing Body, or at the written request of any Contracting Party, provided that this request is supported by at least one third of the Contracting Parties.

19.11 The Governing Body shall elect its Chairperson and Vice-Chairpersons (collectively referred to as "the Bureau"), in conformity with its Rules of Procedure.

\section{Article 20 - Secretary}

20.1 The Secretary of the Governing Body shall be appointed by the Director-General of FAO, with the approval of the Governing Body. The Secretary shall be assisted by such staff as may be required.

20.2 The Secretary shall perform the following functions:

(a) arrange for and provide administrative support for sessions of the Governing Body and for any subsidiary bodies as may be established;

(b) assist the Governing Body in carrying out its functions, including the performance of specific tasks that the Governing Body may decide to assign to it;

(c) report on its activities to the Governing Body.

20.3 The Secretary shall communicate to all Contracting Parties and to the Director-General:

(a) decisions of the Governing Body within sixty days of adoption;

(b) information received from Contracting Parties in accordance with the provisions of this Treaty.

20.4 The Secretary shall provide documentation in the six languages of the United Nations for sessions of the Governing Body. 
20.5 The Secretary shall cooperate with other organizations and treaty bodies, including in particular the Secretariat of the Convention on Biological Diversity, in achieving the objectives of this Treaty.

\section{Article 21 - Compliance}

The Governing Body shall, at its first meeting, consider and approve cooperative and effective procedures and operational mechanisms to promote compliance with the provisions of this Treaty and to address issues of non-compliance. These procedures and mechanisms shall include monitoring, and offering advice or assistance, including legal advice or legal assistance, when needed, in particular to developing countries and countries with economies in transition.

\section{Article 22 - Settlement of Disputes}

22.1 In the event of a dispute between Contracting Parties concerning the interpretation or application of this Treaty, the parties concerned shall seek solutions by negotiation.

22.2 If the parties concerned cannot reach agreement by negotiation, they may jointly seek the good offices of, or request mediation by, a third party.

22.3 When ratifying, accepting, approving or acceding to this Treaty, or at any time thereafter, a Contracting Party may declare in writing to the Depositary that for a dispute not resolved in accordance with Article 22.1 or Article 22.2 above, it accepts one or both of the following means of dispute settlement as compulsory:

(a) Arbitration in accordance with the procedure laid down in Part 1 of Annex II to this Treaty;

(b) Submission of the dispute to the International Court of Justice.

22.4 If the parties to the dispute have not, in accordance with Article 22.3 above, accepted the same or any procedure, the dispute shall be submitted to conciliation in accordance with Part 2 of Annex II to this Treaty unless the parties otherwise agree.

\section{Article 23 - Amendments of the Treaty}

23.1 Amendments to this Treaty may be proposed by any Contracting Party.

23.2 Amendments to this Treaty shall be adopted at a session of the Governing Body. The text of any proposed amendment shall be communicated to Contracting Parties by the Secretary at least six months before the session at which it is proposed for adoption.

23.3 All amendments to this Treaty shall only be made by consensus of the Contracting Parties present at the session of the Governing Body.

23.4 Any amendment adopted by the Governing Body shall come into force among Contracting Parties having ratified, accepted or approved it on the ninetieth day after the deposit of instruments of ratification, acceptance or approval by two-thirds of the Contracting Parties. Thereafter the amendment shall enter into force for any other Contracting Party on the ninetieth day after that Contracting Party deposits its instrument of ratification, acceptance or approval of the amendment.

23.5 For the purpose of this Article, an instrument deposited by a Member Organization of FAO shall not be counted as additional to those deposited by member states of such an organization. 


\section{Article 24 - Annexes}

24.1 The annexes to this Treaty shall form an integral part of this Treaty and a reference to this Treaty shall constitute at the same time a reference to any annexes thereto.

24.2 The provisions of Article 23 regarding amendments to this Treaty shall apply to the amendment of annexes.

\section{Article 25 - Signature}

This Treaty shall be open for signature at the FAO from 3 November 2001 to 4 November 2002 by all Members of FAO and any States that are not Members of FAO but are Members of the United Nations, or any of its specialized agencies or of the International Atomic Energy Agency.

\section{Article 26 - Ratification, Acceptance or Approval}

This Treaty shall be subject to ratification, acceptance or approval by the Members and nonMembers of FAO referred to in Article 25. Instruments of ratification, acceptance, or approval shall be deposited with the Depositary.

\section{Article 27 - Accession}

This Treaty shall be open for accession by all Members of FAO and any States that are not Members of FAO but are Members of the United Nations, or any of its specialized agencies or of the International Atomic Energy Agency from the date on which the Treaty is closed for signature. Instruments of accession shall be deposited with the Depositary.

\section{Article 28 - Entry into force}

28.1 Subject to the provisions of Article 29.2, this Treaty shall enter into force on the ninetieth day after the deposit of the fortieth instrument of ratification, acceptance, approval or accession, provided that at least twenty instruments of ratification, acceptance, approval or accession have been deposited by Members of FAO.

28.2 For each Member of FAO and any State that is not a Member of FAO but is a Member of the United Nations, or any of its specialized agencies or of the International Atomic Energy Agency that ratifies, accepts, approves or accedes to this Treaty after the deposit, in accordance with Article 28.1, of the fortieth instrument of ratification, acceptance, approval or accession, the Treaty shall enter into force on the ninetieth day following the deposit of its instrument of ratification, acceptance, approval or accession.

\section{Article 29 - Member Organizations of FAO}

29.1 When a Member Organization of FAO deposits an instrument of ratification, acceptance, approval or accession for this Treaty, the Member Organization shall, in accordance with the provisions of Article II.7 of the FAO Constitution, notify any change regarding its distribution of competence to its declaration of competence submitted under Article II.5 of the FAO Constitution as may be necessary in light of its acceptance of this Treaty. Any Contracting Party to this Treaty may, at any time, request a Member Organization of FAO that is a Contracting Party to this Treaty to provide information as to which, as between the Member Organization and its member states, is responsible for the implementation of any particular matter covered by this Treaty. The Member Organization shall provide this information within a reasonable time. 
29.2 Instruments of ratification, acceptance, approval, accession or withdrawal, deposited by a Member Organization of FAO, shall not be counted as additional to those deposited by its Member States.

\section{Article 30 - Reservations}

No reservations may be made to this Treaty.

\section{Article 31 - Non-Parties}

The Contracting Parties shall encourage any Member of FAO or other State, not a Contracting Party to this Treaty, to accept this Treaty.

\section{Article 32 - Withdrawals}

32.1 Any Contracting Party may at any time after two years from the date on which this Treaty has entered into force for it, notify the Depositary in writing of its withdrawal from this Treaty. The Depositary shall at once inform all Contracting Parties.

32.2 Withdrawal shall take effect one year from the date of receipt of the notification.

\section{Article 33 - Termination}

33.1 This Treaty shall be automatically terminated if and when, as the result of withdrawals, the number of Contracting Parties drops below forty, unless the remaining Contracting Parties unanimously decide otherwise.

33.2 The Depositary shall inform all remaining Contracting Parties when the number of Contracting Parties has dropped to forty.

33.3 In the event of termination the disposition of assets shall be governed by the financial rules to be adopted by the Governing Body.

\section{Article 34 - Depositary}

The Director-General of FAO shall be the Depositary of this Treaty.

\section{Article 35 - Authentic Texts}

The Arabic, Chinese, English, French, Russian and Spanish texts of this Treaty are equally authentic. 


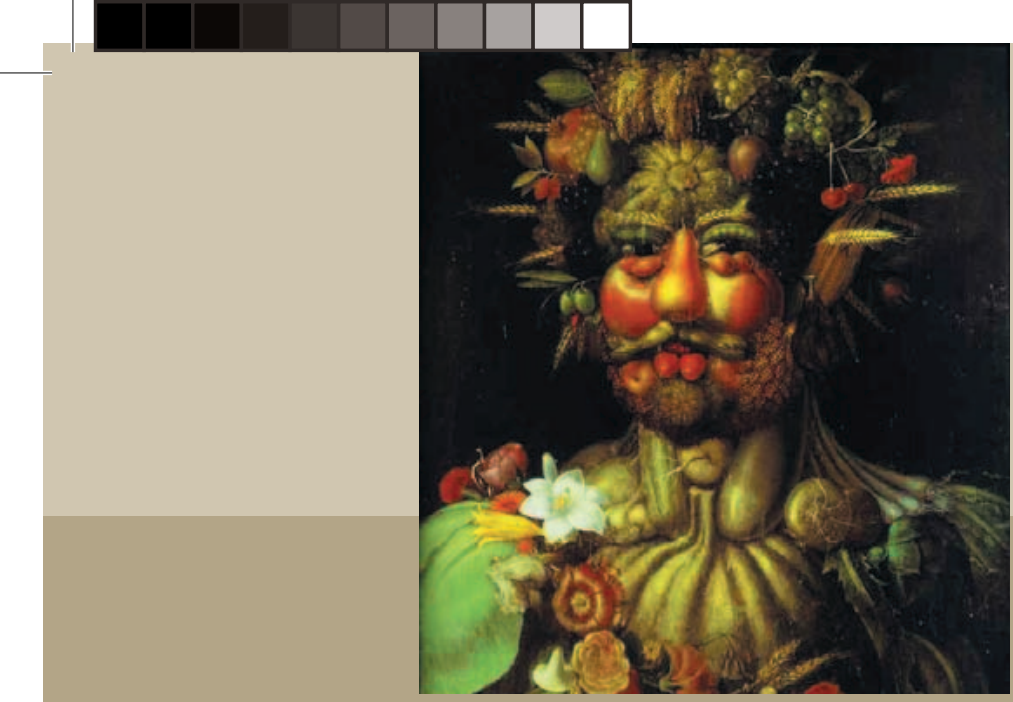

\title{
IUCN - The World Conservation Union
}

Founded in 1948, The World Conservation Union brings together States, government agencies and a diverse range of non-governmental organizations in a unique world partnership: over 1000 members in all, spread across some 140 countries.

As a Union, IUCN seeks to influence, encourage and assist societies throughout the world to conserve the integrity and diversity of nature and to ensure that any use of natural resources is equitable and ecologically sustainable. A central Secretariat coordinates the IUCN Programme and serves the Union membership, representing their views on the world stage and providing them with the strategies, services, scientific knowledge and technical support they need to achieve their goals. Through its six Commissions, IUCN draws together over 10,000 expert volunteers in project teams and action groups, focusing in particular on species and biodiversity conservation and the management of habitats and natural resources. The Union has helped many countries to prepare National Conservation Strategies, and demonstrates the application of its knowledge through the field projects it supervises. Operations are increasingly decentralized and are carried forward by an expanding network of regional and country offices, located principally in developing countries.

The World Conservation Union builds on the strengths of its members, networks and partners to enhance their capacity and to support global alliances to safeguard natural resources at local, regional and global levels.

\author{
IUCN Environmental Law Programme \\ Environmental Law Centre \\ Godesberger Allee 108-112 \\ 53175 Bonn, Germany \\ Tel: +49228 2692231 \\ Fax: +49228 2692250 \\ E-mail: elcsecretariat@iucn.org \\ www.iucn.org/themes/law
}

\section{IUCN Publications Services Unit}

219c Huntingdon Road

Cambridge CB3 ODL

United Kingdom

Tel: +441223277894

Fax: +44 1223277175

E-mail: info@books.iucn.org

www.iucn.org/bookstore 